\title{
From infant wheeze to childhood asthma : aetiological factors and early diagnostic techniques
}

Citation for published version (APA):

Klaassen, E. M. M. (2013). From infant wheeze to childhood asthma : aetiological factors and early diagnostic techniques. [Doctoral Thesis, Maastricht University]. Maastricht University. https://doi.org/10.26481/dis.20131205ek

Document status and date:

Published: 01/01/2013

DOI:

10.26481/dis.20131205ek

Document Version:

Publisher's PDF, also known as Version of record

\section{Please check the document version of this publication:}

- A submitted manuscript is the version of the article upon submission and before peer-review. There can be important differences between the submitted version and the official published version of record. People interested in the research are advised to contact the author for the final version of the publication, or visit the DOI to the publisher's website.

- The final author version and the galley proof are versions of the publication after peer review.

- The final published version features the final layout of the paper including the volume, issue and page numbers.

Link to publication

\footnotetext{
General rights rights.

- You may freely distribute the URL identifying the publication in the public portal. please follow below link for the End User Agreement:

www.umlib.nl/taverne-license

Take down policy

If you believe that this document breaches copyright please contact us at:

repository@maastrichtuniversity.nl

providing details and we will investigate your claim.
}

Copyright and moral rights for the publications made accessible in the public portal are retained by the authors and/or other copyright owners and it is a condition of accessing publications that users recognise and abide by the legal requirements associated with these

- Users may download and print one copy of any publication from the public portal for the purpose of private study or research.

- You may not further distribute the material or use it for any profit-making activity or commercial gain

If the publication is distributed under the terms of Article $25 \mathrm{fa}$ of the Dutch Copyright Act, indicated by the "Taverne" license above, 


\section{From infant wheeze to childhood asthma}

Aetiological factors and early diagnostic techniques 
(C) Copyright EMM Klaassen, Maastricht 2013

Cover Design: Tatiana Bruinshoofd-Vaessen (www.thump-art.nl)

Layout: $\quad$ Tiny Wouters

Printed by: $\quad$ Gildeprint Drukkerijen

ISBN/EAN: $\quad$ 978-94-6108-519-1

The research presented in this thesis was conducted at the School for Public Health and Primary Care: CAPHRI, Department Paediatrics, of Maastricht University. CAPHRI participates in the Netherlands School of Primary Care Research CaRe. CAPHRI was classified as 'excellent' by the external evaluation committee of leading international experts that reviewed CAPHRI in December 2010.

This PhD research was funded by grants from the Dutch Asthma Foundation (NAF 3.4.05.033), Stichting Astma Bestrijding (SAB 2006/018), and Maastricht University Medical Centre (PF 294). Financial support for the printing of this thesis was kindly provided by: TEVA Pharma NL, Stichting Bevordering Kindergeneeskunde, Stichting Astma Bestrijding, GlaxoSmithKline BV, Boehringer Ingelheim BV, Maastricht Instruments BV, Luminex BV and ABN AMRO Bank NV. 


\title{
From infant wheeze to childhood asthma
}

\section{Aetiological factors and early diagnostic techniques}

\author{
PROEFSCHRIFT
}

Ter verkrijging van de graad doctor aan de Universiteit Maastricht, op gezag van de Rector Manificus, Prof dr. L.L.G. Soete volgens het besluit van het College van Decanen, in het openbaar te verdedigen op donderdag 5 december 2013 om 12:00 uur

door

Ester Marlie Monique Klaassen

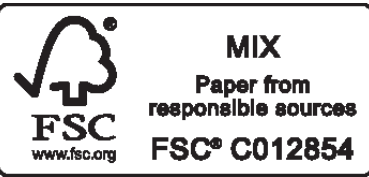




\section{Promotores:}

Prof. dr. E. Dompeling

Prof. dr. C.P. van Schayck

\section{Copromotor:}

Dr. Q. Jöbsis

\section{Beoordelingscommissie:}

Prof. dr. G. Wesseling (voorzitter)

Prof. dr. C.A. Bruggeman

Prof. dr. D.S. Postma (Universiteit Groningen)

Prof. dr. C.T.R.M. Stumpel

Prof. dr. L.J.I. Zimmermann 
En Ester, waar ben jij nu mee bezig?

Ik voer een studie uit aan de Universiteit Maastricht.

$\mathrm{O}$, dus je bent nog aan het studeren?

Ik studeer niet, maar ik ben bezig met een promotietraject.

Wat moet je dan promoten?

Niets, ik doe een onderzoek.

En wat ben je dan als je klaar bent?

Dan word ik doctor.

Maar je bent toch al dokter?

Nee, ik ben arts en doctorandus, maar nog geen doctor.

Maar doctorandus is toch meer dan doctor?

Eerst ben je doctorandus en daarna kun je pas doctor worden.

En bij welke afdeling werk je dan?

Bij de kindergeneeskunde.

Dus je wordt kinderarts?

Nee, ik wil graag huisarts worden.

Wanneer ben je dan klaar met je promotie?

Eind 2013.

O dat is fijn, dan kun je eindelijk echt gaan werken...

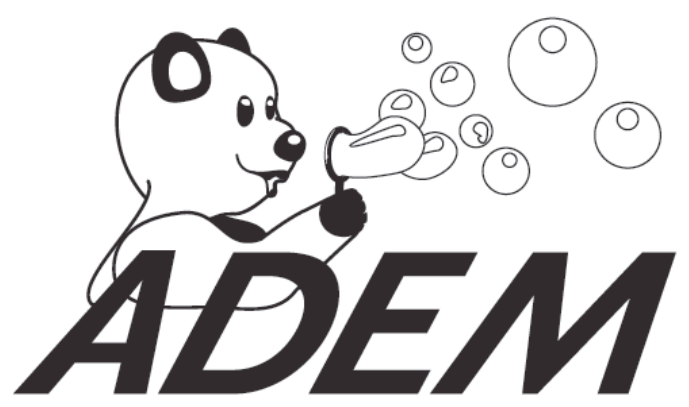





\section{Contents}

Chapter 1 General introduction

Chapter 2 Early diagnosis of asthma in young children by using non-invasive biomarkers of airway inflammation and early lung function measurements: study protocol of a case-control study

Chapter 3 A systematic review of CD14 and toll-like receptors in relation to asthma in Caucasian children

Chapter 4 CD14 and TLR polymorphisms interact with bacteria and regulatory T-cells in childhood asthma development

Chapter 5 Integrative genomic analysis identifies a role for ICAM1 in childhood asthma

Chapter 6 Genetic variants in ADAM33 are associated with asthma at six years of age

Chapter 7 Symptoms, but not a biomarker response to inhaled corticosteroids, predict asthma in preschool children with recurrent wheeze

Chapter 8 Profiling of volatile organic compounds in exhaled breath as a strategy to find early predictive signatures of asthma in children

Chapter 9 Predicting asthma at preschool age by family history and expression of inflammation genes

Chapter 10 Exhaled biomarkers and expression of inflammation genes at preschool age improve prediction of asthma at age six

Chapter 11 General discussion

Samenvatting

Dankwoord

Curriculum Vitae 


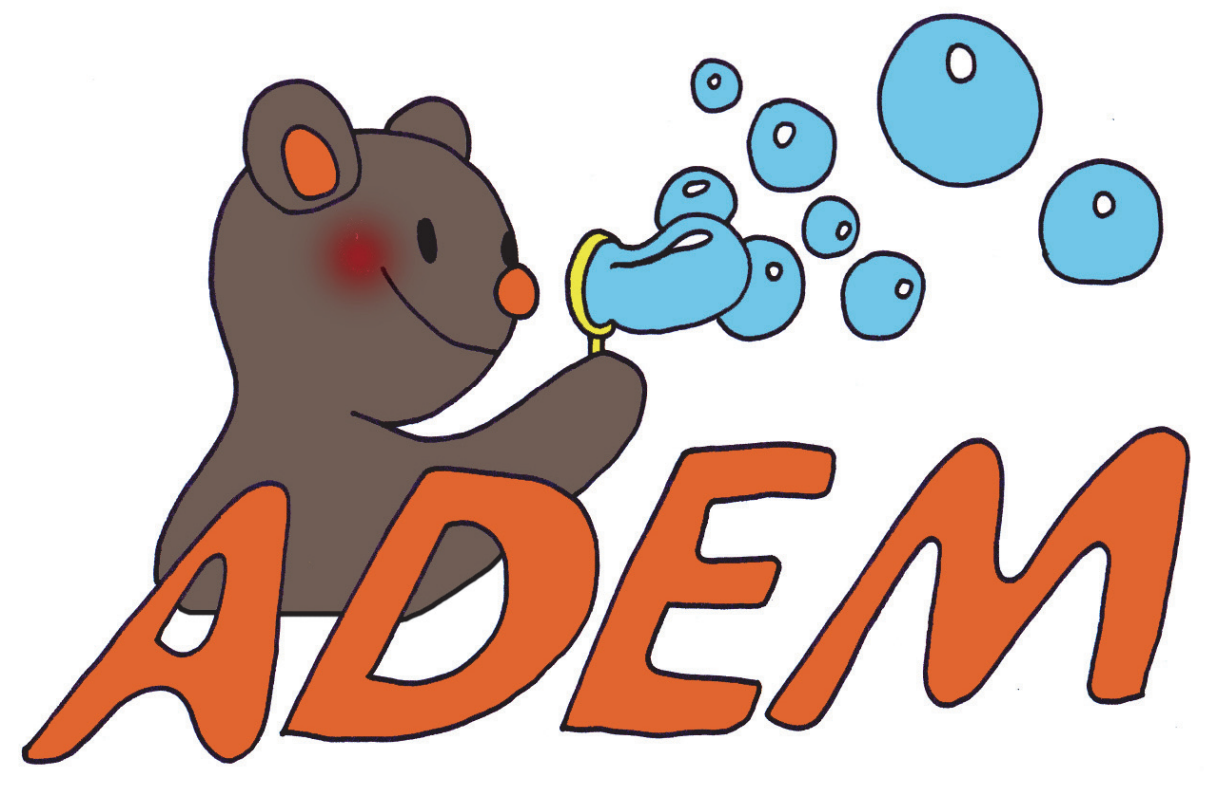




\section{Chapter 1}

General introduction 


\section{Childhood asthma}

Asthma is the most common chronic disease in childhood. Asthma is characterised by chronic airway inflammation with consequent airway obstruction and hyperresponsiveness leading to airway remodelling. ${ }^{1}$ Episodes of respiratory symptoms, such as wheeze, cough and dyspnoea are common in childhood asthma. However, not all children with these symptoms will develop asthma. Only $30 \%$ of symptomatic preschool children are diagnosed with asthma at the age of six years. The remaining children have transient symptoms and are symptom-free at the age of six years, the so-called 'transient' or 'viral' wheezers. ${ }^{2,3}$

Due to influences on quality of life and morbidity, the social burden of childhood asthma is extensive. ${ }^{4,5}$ As a result, asthma has a large impact on the health care system and on health care costs. ${ }^{6}$ An effective therapy of asthma by means of antiinflammatory treatment with inhaled corticosteroids (ICS) is available. ${ }^{3,7}$ This treatment has a beneficial influence on airway inflammation, respiratory symptoms, asthma exacerbations, quality of life, lung function and may prevent airway remodelling. It is also known that ICS are not very effective in young children with transient symptoms. ${ }^{3,7}$ A symptomatic therapy is available in the form of $\beta_{2}$-agonists which induce bronchodilatation. ${ }^{8}$

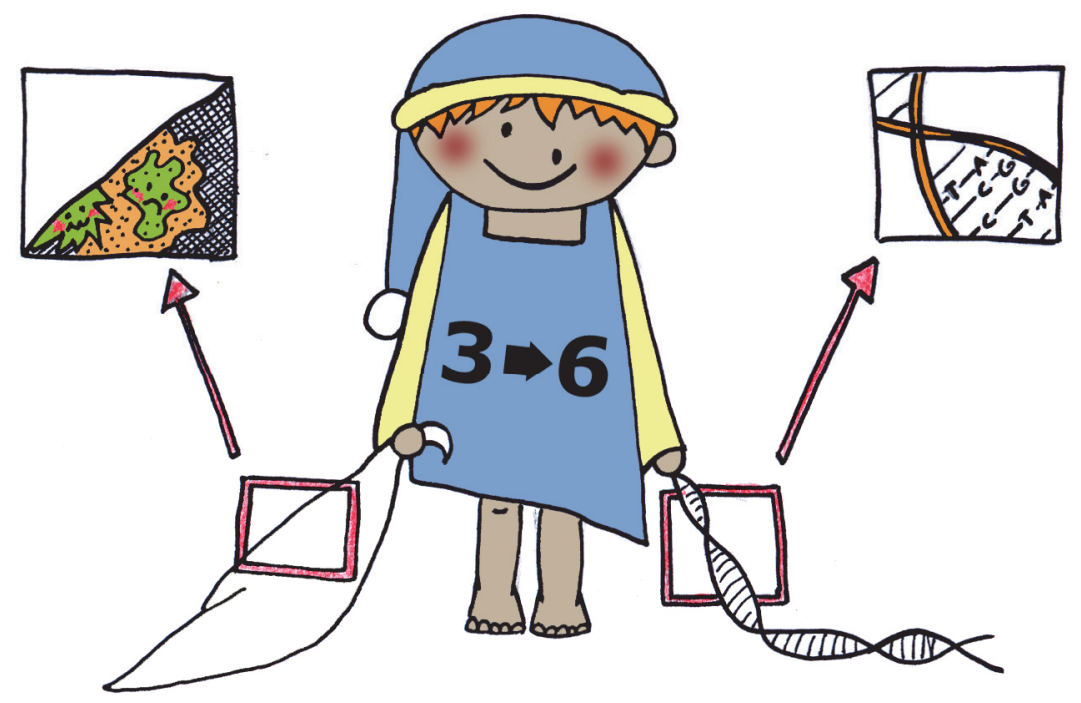




\section{Aetiology of childhood asthma}

It is generally accepted that the susceptibility for asthma development in childhood is influenced by genetic components, as well as environmental factors and the interaction between these factors. ${ }^{9,10}$ Twin studies have demonstrated a large contribution of genetics in the development of asthma. ${ }^{11,12}$ Genome-wide studies have identified several loci and genes involved in asthma, such as 17q21 harbouring the ORMDL3 gene. ${ }^{13,14}$ Although multiple studies have demonstrated associations between genetic variants and asthma, replication studies of these candidate genes in relation to asthma often have demonstrated contradictory results. These contradictions are probably attributable to unknown underlying environmental or additional genetic factors. Examples of environmental stimuli that have been implicated in asthma are viral infections, passive smoking and exposure to furry pets at home. ${ }^{15-17}$ Therefore, the importance in combining information of genetics and environment has become clear, like the demonstrated interaction between endotoxin exposure and a polymorphism in $\mathrm{CD} 14 .{ }^{18}$ However, the mechanisms behind the interactions mostly need to be elucidated. Consequently, the underlying pathophysiological mechanisms of asthma have not completely been understood.

The innate immune system reacts with pathogens such as bacteria. Regulatory T-cells are involved in the regulation of immune responses to pathogens and play an important role in the maturation of the immune system. ${ }^{19,20}$ As the immune system is not fully developed at birth, young children are highly vulnerable to external stimuli. ${ }^{9}$ Genetic variants in genes involved in the immune system in combination with external stimuli can lead to an altered immune response, further increasing the risk of these children to develop asthma. ${ }^{21}$ This altered immune response might be demonstrated by a decrease in number or function of regulatory T-cells. ${ }^{19,22}$ Therefore, studying genetic predisposition of genes involved in the immune system, bacterial exposure and the resulting immune response in relation to asthma development will further enhance our knowledge on the aetiology of asthma.

Genetic variants in the regulatory and promoter sequences of a gene can influence gene expression and consequently protein level. ${ }^{23}$ Alhough the genetic information of an individual is unchanged during life, gene expression is dynamic and reacts to changes in the body and influences protein levels. By studying relationships between genetic variants, gene expression and protein levels of markers known to be involved in the aetiology of childhood asthma and their effect on asthma development, more information on the aetiology of childhood asthma can be retrieved.

The population and the analysis in which the relationship between genes, environmental exposures and childhood asthma are studied has influence on the insight that can be gained in the origins of childhood asthma. The best possible way to study genetic and environmental factors that contribute to childhood asthma is by observational studies. In these studies, cohort studies are preferred as information on 
the outcome is not known at the start of the study and, consequently, cannot influence the results. The more information is gathered during the study, the more contributing factors can be identified in analysis. However, associations have to be confirmed by external validation in independent studies to limit possible false positive associations. Besides, systematic reviews possibly with meta-analyses can summarize the known literature and provide future directions.

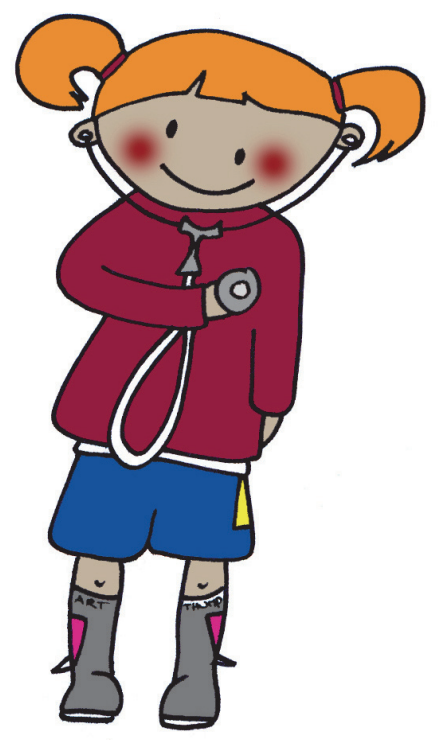

\section{Diagnosing childhood asthma}

From the age of six years and over, asthma can be diagnosed based on symptoms, use of medication and lung function. ${ }^{24,25}$ The diagnosis of asthma at an earlier age is hampered as asthma symptoms, like wheeze, are highly prevalent in this age group and often not based on true asthma. ${ }^{26}$ Moreover, young children are not able to perform lung function tests which require active cooperation. An early asthma diagnosis will enable proper treatment decisions, which might result in prevention of under-treatment of 'true asthmatics' and over-treatment of 'transient wheezers'. ${ }^{27}$ As stated, ICS are an effective therapy for asthma. ${ }^{3,7}$ Although the diagnosis of asthma at preschool age is insecure, international guidelines advocate a trial treatment with ICS for a likely diagnosis of asthma in young children. ${ }^{3}$ However, studies addressing the response to ICS as a diagnostic tool for asthma in children have been limited. Investigating, for example, the response of biomarkers or clinical parameters to ICS 
treatment might add to reliable diagnose childhood asthma before the age of six years.

Chronic airway inflammation is the most characteristic feature in childhood asthma. However, current diagnostics are based on indirect measurements of inflammation in the airways. Direct measurement of inflammation in the lungs is possible by analysis of induced sputum, broncho-alveolar lavage or biopsy. ${ }^{28}$ These measurements are not suitable for routine use due to their invasive nature, especially in young children. Consequently, there has been an urgent need to further develop non-invasive technologies that reflect the inflammatory process in the lungs which may help to diagnose asthma at an early age.

\section{Non-invasive techniques to study airway inflammation}

\section{Exhaled Nitric Oxide}

Fractional exhaled Nitric Oxide (FeNO) is the most extensive studied inflammation marker in exhaled breath. ${ }^{29}$ Nitric oxide (NO) is synthesised from L-arginine by nitric oxide synthetase and is involved in the regulation of pulmonary function and circulation. ${ }^{30}$ FeNO has been identified as a marker of allergic status. ${ }^{31}$ As FeNO in not specific for one disease such as asthma, its diagnostic value is limited. However, due to increasing levels of FeNO during exacerbations, FeNO may have additional value for the monitoring of asthma. ${ }^{29,30}$ Due to the incapability of young children to perform lung function tests, FeNO can be collected and analysed off-line. ${ }^{32}$

\section{Exhaled breath condensate}

A potential valuable and non-invasive technique to measure inflammation is assessment of inflammation markers in exhaled breath condensate (EBC). ${ }^{33,34}$ As a result of a turbulent airflow in the lungs, respiratory droplets of the lung epithelium lining fluid become airborne. ${ }^{35}$ Inside these droplets small quantities of inflammation markers are stored. When collected and analysed, these inflammation markers can give an indication of the inflammation status in the lungs. 36,37

An efficient double-jacketed glass condenser with recirculation unit has been developed by our department (patent 07102586, Maastricht University Medical Centre). This technique is especially suitable for young children. ${ }^{38}$ Children exhale through a mask connected to a two-way non-rebreathing valve and a nasal septum to avoid nasal contamination. The exhaled air is guided through a condenser cooled by ice water. Not directly condensed air is deposited in a heated compartment. After ten minutes, when the child has finished the test, recirculation of stored air provides optimal condensation. The condensate is collected and stored at -80 degrees until 
analysis. Several cytokines, chemokines and adhesion molecules can be measured in a reproducible way. ${ }^{39}$

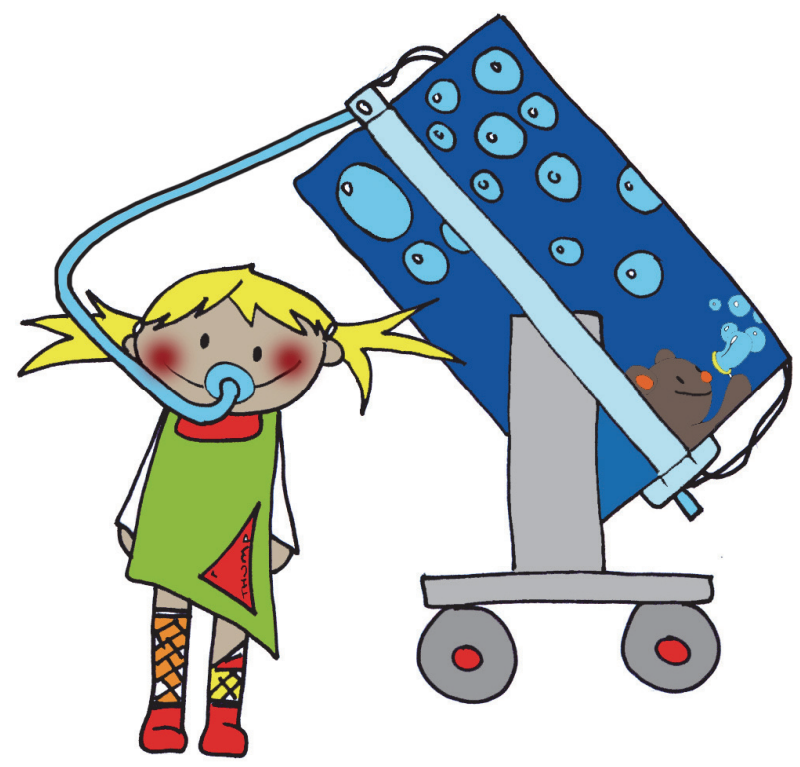

\section{Exhaled volatile organic compounds}

Volatile organic compounds (VOCs) are carbon-based chemicals, which are formed during several (patho)physiological processes. ${ }^{40,41}$ Inflammatory cells produce reactive oxygen species that react with lipid membrane structures causing lipid peroxidation and degradation of the membrane. Thus, several breakdown products such as hydrocarbons are formed. ${ }^{40,41}$ After formation, VOCs enter the bloodstream and are excreted in the lungs. Consequently, thousands of VOCs can be detected in exhaled breath. These VOCs can be measured by gas-chromatography, the electronic nose ) and some less common techniques. ${ }^{40,42,43}$

Exhaled VOCs differ between healthy and asthmatic people. ${ }^{44-47}$ Clinically, VOCs are not needed to identify healthy people from those with asthma. However, VOCs with discriminative power between 'transient wheezers' and 'true asthmatics' in preschool children at risk for asthma have potential additional clinical value.

\section{Lung function indices}

As previously stated, preschool aged children are not able to perform standardised forced breathing manoeuvres. Therefore, spirometry is not appropriate to assess lung 
function at this age. To gain information on the status of lung function in these young children, alternative techniques have been developed like the interrupter resistance technique. ${ }^{48-50}$ During tidal breathing in an upright position the airway is briefly interrupted and resistance is assessed. However, although non-invasive, it is a functional test of total airway resistance and, therefore, does not directly reflect airway inflammation.

Researchers are interested to assess whether differentiation between children with transient symptoms and asthma is possible based on the previously discussed noninvasive techniques. However, in practice doctors have information on clinical features as well. These features are readily available and easily obtained. Therefore, the real question is whether these non-invasive techniques have incremental diagnostic value to the clinical characteristics for an early asthma diagnosis.

\section{Objectives and outline of this dissertation}

This dissertation has two main objectives. The first objective is to assess underlying pathophysiological mechanisms of asthma. The second objective is to assess whether exhaled inflammation markers and early lung function measurements in children at risk for asthma can diagnose asthma at preschool age.

The chapters in this dissertation are based on data of the ADEM study (Asthma Detection and Monitoring study), which is a prospective case-control study that started in 2006 in the province of Limburg, the Netherlands. The primary objective of the ADEM study was to develop a non-invasive instrument for an early and reliable asthma diagnosis by using exhaled inflammatory biomarkers and early lung function measurements in preschool children. In chapter $\mathbf{2}$ the study protocol of the ADEM study is described.

A systematic review on clinical studies about CD14 and toll-like receptors in relation to asthma in Caucasian children is presented in chapter 3. Potential applications, limitations and considerations as well as future objectives regarding these mediators in the field of childhood asthma are discussed.

Chapter 4 evaluates the relationship between genetic variants in CD14 and toll-like receptors, presence of bacteria and proportion of regulatory T-cells at preschool age in healthy children, children with transient wheeze and children with asthma at six years of age. 
In chapter 5 an integrative genomic analysis assessing inflammation markers on DNA, mRNA and protein level is used to determine significant markers in the development of asthma.

Association between genetic variants in genes involved in asthma development is assessed in chapter 6. Furthermore, associations found in the ADEM study are replicated in the KOALA (Kind, Ouders en gezondheid: Aandacht voor Leefstijl en Aanleg) study.

The potential clinical use of the response to ICS at preschool age to identify children prone to develop asthma at six years of age is discussed in chapter 7. This response is based on changes in inflammation markers in EBC, feNO, airway resistance and symptoms during an ICS trial for the duration of eight weeks.

In chapter 8 the predictive power of VOCs at preschool age for a diagnosis of asthma at six years of age is analyzed.

Chapter 9 regards the added value of expression of inflammation genes to a family history of asthma in the diagnosis of asthma at preschool age.

The incremental diagnostic value of inflammation markers in exhaled breath (condensate), expression of inflammation genes and of lung function in diagnosing asthma at preschool age are addressed in chapter 10.

Finally, in chapter $\mathbf{1 1}$ a general discussion on the main findings of this dissertation and recommendations for future studies are provided. 


\section{References}

1. Masoli M, Fabian D, Holt S, Beasley R. The global burden of asthma: executive summary of the GINA Dissemination Committee report. Allergy 2004;59:469-78.

2. Savenije OE, Granell R, Caudri D, Koppelman GH, Smit HA, Wijga A, et al. Comparison of childhood wheezing phenotypes in 2 birth cohorts: ALSPAC and PIAMA. J Allergy Clin Immunol 2011;127:150512.

3. Pedersen SE, Hurd SS, Lemanske RF, Jr., Becker A, Zar HJ, Sly PD, et al. Global strategy for the diagnosis and management of asthma in children 5 years and younger. Pediatr Pulmonol 2011;46: 1-17.

4. von Mutius E. The burden of childhood asthma. Arch Dis Child 2000;82 Suppl 2:II2-5.

5. Oostenbrink R, Jansingh-Piepers EM, Raat H, Nuijsink M, Landgraf JM, Essink-Bot ML, et al. Healthrelated quality of life of pre-school children with wheezing illness. Pediatr Pulmonol 2006;41: 993-1000.

6. Stevens CA, Turner D, Kuehni CE, Couriel JM, Silverman M. The economic impact of preschool asthma and wheeze. Eur Respir J 2003;21:1000-6.

7. Schokker S, Kooi EM, de Vries TW, Brand PL, Mulder PG, Duiverman EJ, et al. Inhaled corticosteroids for recurrent respiratory symptoms in preschool children in general practice: randomized controlled trial. Pulm Pharmacol Ther 2008;21:88-97.

8. de Jongste JC, Vrijlandt EJLE. Richtlijn astma bij kinderen. Nederlandse Vereninging voor Kindergeneeskunde 2007.

9. Holt PG, Rowe J, Kusel M, Parsons F, Hollams EM, Bosco A, et al. Toward improved prediction of risk for atopy and asthma among preschoolers: a prospective cohort study. J Allergy Clin Immunol 2010; 125:653-9.

10. Sly PD, Holt PG. Role of innate immunity in the development of allergy and asthma. Curr Opin Allergy Clin Immunol 2011;11:127-31.

11. Thomsen SF, van der Sluis S, Kyvik KO, Skytthe A, Skadhauge LR, Backer V. Increase in the heritability of asthma from 1994 to 2003 among adolescent twins. Respir Med 2011;105:1147-52.

12. Pinto LA, Stein RT, Kabesch M. Impact of genetics in childhood asthma. J Pediatr (Rio J) 2008;84: S68-75.

13. Moffatt MF, Kabesch M, Liang L, Dixon AL, Strachan D, Heath S, et al. Genetic variants regulating ORMDL3 expression contribute to the risk of childhood asthma. Nature 2007;448:470-3.

14. Halapi E, Gudbjartsson DF, Jonsdottir GM, Bjornsdottir US, Thorleifsson G, Helgadottir H, et al. A sequence variant on $17 q 21$ is associated with age at onset and severity of asthma. Eur J Hum Genet 2010;18:902-8.

15. Visser CA, Garcia-Marcos L, Eggink J, Brand PL. Prevalence and risk factors of wheeze in Dutch infants in their first year of life. Pediatr Pulmonol 2010;45:149-56.

16. Kerkhof M, Wijga AH, Brunekreef B, Smit HA, de Jongste JC, Aalberse RC, et al. Effects of pets on asthma development up to 8 years of age: the PIAMA study. Allergy 2009;64:1202-8.

17. Holt PG, Strickland DH, Sly PD. Virus infection and allergy in the development of asthma: what is the connection? Curr Opin Allergy Clin Immunol 2012;12:151-7.

18. Simpson A, John SL, Jury F, Niven R, Woodcock A, Ollier WE, et al. Endotoxin exposure, CD14, and allergic disease: an interaction between genes and the environment. Am J Respir Crit Care Med 2006; 174:386-92.

19. Damoiseaux J. Regulatory T cells: back to the future. Neth J Med 2006;64:4-9.

20. Lloyd CM, Hawrylowicz CM. Regulatory T cells in asthma. Immunity 2009;31:438-49.

21. Halfhide C, Smyth RL. Innate immune response and bronchiolitis and preschool recurrent wheeze. Paediatr Respir Rev 2008;9:251-62.

22. Xystrakis $\mathrm{E}$, Boswell $\mathrm{SE}$, Hawrylowicz $\mathrm{CM}$. T regulatory cells and the control of allergic disease. Expert Opin Biol Ther 2006;6:121-33.

23. Rosenwasser LJ, Borish L. Genetics of atopy and asthma: the rationale behind promoter-based candidate gene studies (IL-4 and IL-10). Am J Respir Crit Care Med 1997;156:S152-5. 
24. Bateman ED, Hurd SS, Barnes PJ, Bousquet J, Drazen JM, FitzGerald M, et al. Global strategy for asthma management and prevention: GINA executive summary. Eur Respir J 2008;31:143-78.

25. Lougheed MD, Lemiere C, Ducharme FM, Licskai C, Dell SD, Rowe BH, et al. Canadian Thoracic Society 2012 guideline update: diagnosis and management of asthma in preschoolers, children and adults. Can Respir J 2012;19:127-64.

26. Bisgaard H, Szefler S. Prevalence of asthma-like symptoms in young children. Pediatr Pulmonol 2007; 42:723-8.

27. Caudri D, Wijga AH, Smit HA, Koppelman GH, Kerkhof M, Hoekstra MO, et al. Asthma symptoms and medication in the PIAMA birth cohort: evidence for under and overtreatment. Pediatr Allergy Immunol 2011;22:652-9.

28. van de Kant KD, van der Sande LJ, Jöbsis Q, van Schayck OC, Dompeling E. Clinical use of exhaled volatile organic compounds in pulmonary diseases: a systematic review. Respir Res 2012; 13:117.

29. Pijnenburg MW, De Jongste JC. Exhaled nitric oxide in childhood asthma: a review. Clin Exp Allergy 2008;38:246-59.

30. Barnes PJ, Dweik RA, Gelb AF, Gibson PG, George SC, Grasemann H, et al. Exhaled nitric oxide in pulmonary diseases: a comprehensive review. Chest 2010;138:682-92.

31. Scott M, Raza A, Karmaus W, Mitchell F, Grundy J, Kurukulaaratchy RJ, et al. Influence of atopy and asthma on exhaled nitric oxide in an unselected birth cohort study. Thorax 2010;65:258-62.

32. Gabriele C, Asgarali R, Jaddoe VW, Hofman A, Moll HA, de Jongste JC. Smoke exposure, airway symptoms and exhaled nitric oxide in infants: the Generation R study. Eur Respir J 2008;32:307-13.

33. Rosias PP, Robroeks CM, Kester A, den Hartog GJ, Wodzig WK, Rijkers GT, et al. Biomarker reproducibility in exhaled breath condensate collected with different condensers. Eur Respir J 2008; 31:934-42.

34. Hunt J. Exhaled breath condensate: an evolving tool for noninvasive evaluation of lung disease. J Allergy Clin Immunol 2002;110:28-34.

35. Effros RM, Hoagland KW, Bosbous M, Castillo D, Foss B, Dunning $M$, et al. Dilution of respiratory solutes in exhaled condensates. Am J Respir Crit Care Med 2002;165:663-9.

36. Robroeks CM, Rijkers GT, Jöbsis Q, Hendriks HJ, Damoiseaux JG, Zimmermann LJ, et al. Increased cytokines, chemokines and soluble adhesion molecules in exhaled breath condensate of asthmatic children. Clin Exp Allergy 2010;40:77-84.

37. Brunetti L, Francavilla R, Tesse R, Fiermonte P, Fiore FP, Lore M, et al. Exhaled breath condensate cytokines and $\mathrm{pH}$ in pediatric asthma and atopic dermatitis. Allergy Asthma Proc 2008;29:461-7.

38. Rosias PP, Robroeks CM, van de Kant KD, Rijkers GT, Zimmermann LJ, van Schayck CP, et al. Feasibility of a new method to collect exhaled breath condensate in pre-school children. Pediatr Allergy Immunol 2010;21:e235-44.

39. de Jager W, te Velthuis H, Prakken BJ, Kuis W, Rijkers GT. Simultaneous detection of 15 human cytokines in a single sample of stimulated peripheral blood mononuclear cells. Clin Diagn Lab Immunol 2003;10:133-9.

40. Buszewski B, Kesy M, Ligor T, Amann A. Human exhaled air analytics: biomarkers of diseases. Biomed Chromatogr 2007;21:553-66.

41. Miekisch W, Schubert JK, Noeldge-Schomburg GF. Diagnostic potential of breath analysis--focus on volatile organic compounds. Clin Chim Acta 2004;347:25-39.

42. Pavlou AK, Turner AP. Sniffing out the truth: clinical diagnosis using the electronic nose. Clin Chem Lab Med 2000;38:99-112.

43. Ras MR, Borrull F, Marce SM. Sampling and preconcentration techniques for determination of volatile organic compounds in air samples. TrAC 2009;28:347-61.

44. Olopade CO, Zakkar M, Swedler WI, Rubinstein I. Exhaled pentane levels in acute asthma. Chest 1997; 111:862-5.

45. Paredi P, Kharitonov SA, Barnes PJ. Elevation of exhaled ethane concentration in asthma. Am J Respir Crit Care Med 2000;162:1450-4.

46. Ibrahim B, Basanta M, Cadden P, Singh D, Douce D, Woodcock A, et al. Non-invasive phenotyping using exhaled volatile organic compounds in asthma. Thorax 2011;66:804-9. 
47. Dallinga JW, Robroeks CM, van Berkel JJ, Moonen EJ, Godschalk RW, Jöbsis Q, et al. Volatile organic compounds in exhaled breath as a diagnostic tool for asthma in children. Clin Exp Allergy 2010; 40: 68-76.

48. Merkus PJ, Stocks J, Beydon N, Lombardi E, Jones M, McKenzie SA, et al. Reference ranges for interrupter resistance technique: the Asthma UK Initiative. Eur Respir J 2010;36:157-63.

49. Brussee JE, Smit HA, Koopman LP, Wijga AH, Kerkhof M, Corver K, et al. Interrupter resistance and wheezing phenotypes at 4 years of age. Am J Respir Crit Care Med 2004;169:209-13.

50. Kooi EM, Schokker S, van der Molen T, Duiverman EJ. Airway resistance measurements in pre-school children with asthmatic symptoms: the interrupter technique. Respir Med 2006;100:955-64. 


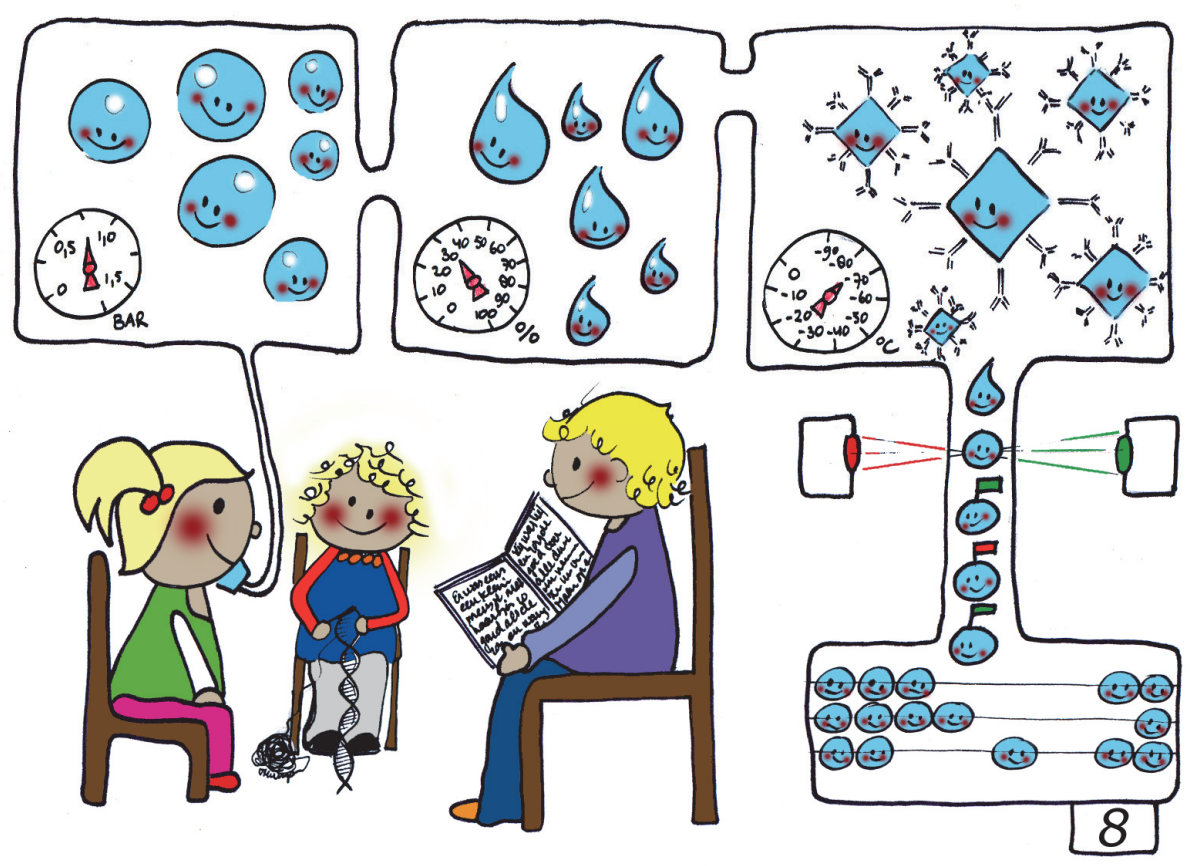




\section{Chapter 2}

Early diagnosis of asthma in young children by using non-invasive biomarkers of airway inflammation and early lung function measurements: study protocol of a case-control study

van de Kant KDG, Klaassen EMM, Jöbsis Q, Nijhuis AJ, van Schayck CP, Dompeling E BMC Public Health 2009;9:210 


\section{Abstract}

\section{Background}

Asthma is the most common chronic disease in childhood, characterised by chronic airway inflammation. There are problems with the diagnosis of asthma in young children since the majority of the children with recurrent asthma-like symptoms is symptom-free at six years and does not have asthma. With the conventional diagnostic tools it is not possible to differentiate between preschool children with transient symptoms and children with asthma. The analysis of biomarkers of airway inflammation in exhaled breath is a non-invasive and promising technique to diagnose asthma and monitor inflammation in young children. Moreover, relatively new lung function tests (airway resistance using the interrupter technique) have become available for young children. The primary objective of the ADEM study (Asthma DEtection and Monitoring study), is to develop a non-invasive instrument for an early asthma diagnosis in young children using exhaled inflammation markers and early lung function measurements. In addition, aetiological factors, including gene polymorphisms and gene expression, in relation to the development of asthma are studied.

\section{Methods / design}

A case-control study is started in 202 children with recurrent respiratory symptoms and 50 control subjects without respiratory symptoms. At six years, a definite diagnosis of asthma is made (primary outcome measure) on basis of lung function assessments and current respiratory symptoms ('gold standard'). From inclusion until the definite asthma diagnosis, repeated measurements of lung function tests and inflammation markers in exhaled breath (condensate), blood and faeces are performed. The study is registered and ethically approved.

\section{Discussion}

This manuscript describes the study protocol of the ADEM study. The new diagnostic techniques applied in this study could make an early diagnosis of asthma possible. An early and reliable asthma diagnosis at two and three years will have consequences for the management of the large group of young children with asthma-like symptoms. It will avoid both over-treatment of children with transient wheeze and undertreatment of children with asthma. This might have a beneficial influence on the prognosis of asthma in these young children. Besides, insight into the pathophysiology and aetiology of asthma will be obtained. 


\section{Background}

Asthma is one of the major chronic health problems in children. Worldwide, approximately $30 \%$ of all young children have at least one episode of asthmatic symptoms like wheezing, coughing and dyspnoea. ${ }^{1,2}$ Although asthmatic symptoms are common in preschool children, only $30 \%$ will have asthma the age of six years and over. The rest of the children with recurrent respiratory symptoms is symptomfree at six years and does not have asthma but transient, viral associated wheeze. ${ }^{1,3,4}$ A reliable diagnosis of asthma in young children is difficult. With the conventional diagnostic measures it is currently not possible to discriminate between 'true asthmatics' and children with 'transient wheezing' in association with frequent viral infections. An early asthma diagnosis is important for the proper treatment of young children with respiratory symptoms. An effective therapy of asthma by means of antiinflammatory treatment with inhaled corticosteroids (ICS) is available. This treatment has a beneficial influence on airway inflammation, respiratory symptoms, asthma exacerbations, quality of life and lung function. ${ }^{5}$ Probably, ICS are not very effective in children with transient wheezing, which may cause unnecessary treatment with preventable costs and side-effects. ${ }^{6,7}$ Therefore, an early diagnosis will prevent overtreatment of transient wheezers and under-treatment of true asthmatics and will improve asthma control.

\section{Measuring inflammation}

Although chronic airway inflammation is the most common feature in asthma, measurement of inflammation plays a small role in the diagnosis and monitoring of asthma. Currently, the 'gold standard' to measure airway inflammation is bronchoscopy with biopsy and/or bronchoalveolar lavage. However, this is far too invasive for routine use in (young) children. Since a non-invasive method to measure inflammation is lacking, diagnosis and management of asthma in young children are currently based on subjective clinical features and medical examination. Therefore, there is an increasing interest in non-invasive techniques to assess inflammation, especially in children.

\section{Inflammation biomarkers in exhaled breath (condensate)}

The last decade, non-invasive techniques are developed to assess inflammation in the airways. One of these new techniques is assessment of inflammation biomarkers in exhaled breath. This technique is currently possible in children and is promising for an early asthma diagnosis and monitoring of the disease. ${ }^{8-10}$ The most studied marker in exhaled breath is nitric oxide. Elevated levels of fractional exhaled nitric oxide (FeNO) are found in both adults and children with asthma as a consequence of up-regulation 
of the enzyme iNOS. ${ }^{9}$ In addition to FeNO, other gases can be measured in exhaled breath including volatile organic compounds (VOCs). Inflammation in the airways gives rise to reactive oxygen species (ROS) that can degradate cell membranes through peroxidation of lipids. ${ }^{11,12}$ Due to degradation of cell membranes, VOCs, such as alkanes, alkane derivates and aldehydes are formed. Increased levels of alkanes (such as ethane and pentane) and aldehydes are described in exhaled breath during (exacerbations of) asthma. ${ }^{13-15}$ Besides gases in exhaled breath, non-volatile compounds in exhaled breath condensate (EBC) can be measured in children. ${ }^{10,16-19}$ EBC is collected by cooling exhaled breath in a condenser. During this non-invasive procedure, small droplets of breath condensate are formed. Besides water vapour, droplets consist of aerosol particles that are released from the epithelial lining fluid of the airways. They contain non-volatile inflammation markers and there is evidence that abnormalities in condensate composition reflect biochemical changes of the epithelial lining fluid. ${ }^{20}$ In EBC, inflammation markers such as cytokines, chemokines and adhesion molecules, can be measured. Increased concentrations of various markers in EBC were found in patients with asthma. ${ }^{10,16-18,21}$

\section{Early lung function measurements}

In the past ten years, new lung function techniques became available in young children. Techniques to evaluate airway resistance such as the interrupter technique (MicroRint), impulse oscillation and forced oscillation technique are increasingly applied in young children. ${ }^{22-24}$ In contrast to the forced expiration manoeuvres, these measurements are performed during tidal breathing. The measurements are possible in children of one year and over. However, feasibility increases with age. ${ }^{22}$ These techniques are used in children with asthma to assess baseline airway resistance, reversibility on bronchodilators, bronchial hyper-responsiveness and responses to ICS.

\section{Response to inhaled corticosteroid treatment}

A good responsiveness to ICS is a hallmark of asthma. ${ }^{25}$ This response might discriminate between asthmatic and non-asthmatic children. Several international guidelines advocate a trial of ICS in preschool children with recurrent wheeze. However, the diagnostic value of the response to ICS for asthma is not clear in these children.

\section{Regulatory T-cells}

The inflammatory response in asthma is highly complex in which many inflammatory cells are involved. T-helper (Th) cells play a central role in the inflammatory response in asthma and can be roughly divided in the pro-inflammatory Th2 cells and antiinflammatory Th1 cells. ${ }^{26-29}$ Regulatory T-cells ( $T_{\text {reg }}$ cells) inhibit both Th1 and Th2 cells 
resulting in a balance of the immune system. An imbalance between Th2 and Th1 cells occurs in asthma with an increase of Th2 and a decrease of Th1 cells. ${ }^{26,27}$ This imbalance might be due to a decrease in number or function of $\mathrm{T}_{\text {reg }}$ cells. ${ }^{28,29}$

\section{Genetic background}

Asthma has a multifactorial aetiology in which genetic factors, environmental influences and their interaction play an important role. Over the last two decades the genetic background of asthma has become increasingly clear through twin studies and studies in subjects with a family history of atopy and asthma. Around 30 to 100 genes are involved in asthma. ${ }^{30,31}$ Although a lot of progress has been made in the field of asthma genetics, the influence of many candidate genes in relation to asthma susceptibility in young children needs to be further defined. Gene polymorphism in the coding sequences of genes may affect the function of a protein. Polymorphisms in the regulatory and promoter sequences of genes may influence the expression characteristics of a gene, making gene expression an important area in asthma research. Linking specific genetic polymorphisms and gene expression to wheezing phenotypes in children and to inflammatory levels in EBC and lung function indices can lead to a better understanding of the early pathogenesis of asthma in young children (Figure 1). Subsequently, this will identify children with an enhanced risk.

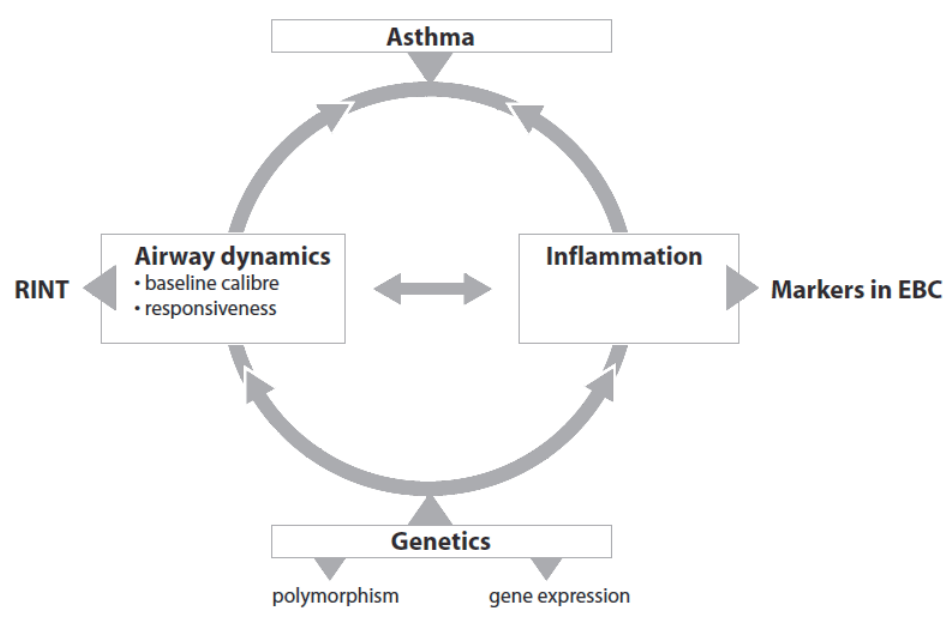

Figure 1 Relation between genetic background and pathophysiology in asthma.

Central features in the pathophysiology of asthma are chronic airway inflammation and airway (hyper-) responsiveness. These features can be measured by markers in exhaled breath condensate (EBC) and MicroRint, respectively and are influenced by genetic factors. 


\section{Environmental factors in relation to asthma}

The hygiene hypothesis suggests a relationship between exposure to microbes in early childhood and the development of allergies and asthma. According to this hypothesis, infections protect against asthma. ${ }^{32,33}$ However, this is not in line with increasing evidence that certain infections might also promote asthma development. ${ }^{33} \mathrm{~A}$ unifying concept is still lacking and the precise relationship between infections and the development of asthma is not clear.

\section{Hypothesis}

The primary hypothesis of the ADEM study (Asthma DEtection and Monitoring study), is that an early asthma diagnosis is possible by using non-invasive measurements of biomarkers of airway inflammation and oxidative stress in exhaled breath (condensate) and early lung function measurements (airway resistance). Besides, this study tests the hypothesis that certain gene polymorphisms and gene expressions, early infections and $\mathrm{T}_{\text {reg }}$ cells in blood are related to the development of asthma.

\section{Aim and research questions}

The primary aim of the study is to develop a non-invasive instrument for an early asthma diagnosis in young children. Besides, aetiological factors (such as $T_{\text {reg }}$ cells, gene polymorphisms, gene expression and infections at early age) are studied in relation to the early development of asthma.

\section{The primary research question is:}

Which non-invasive inflammation biomarkers in exhaled breath (condensate) or early lung function indices (pre- and post-bronchodilator airway resistance) can reliably predict asthma at an early age?

\section{The secondary research questions are:}

1. What are the differences in inflammation biomarkers and lung function indices between asthmatic and non-asthmatic children?

2. Which of the selected gene polymorphism and/or gene expressions are related to asthma susceptibility in young children?

3. Is early colonisation of the airways and intestines related to the development of asthma?

4. What are the differences in number of $T_{\text {reg }}$ cells between asthmatic and nonasthmatic children?

5. What is the relation between gene coding and gene expression of inflammation markers (e.g. genes coding for Interleukin (IL)-4, IL-13 and Tumour-Necrosis- 
Factor alpha (TNF- $\alpha)$ ), levels of inflammation markers in EBC and lung function indices during the development of asthma in young children?

To answer these research questions, markers in different media are measured (Table 1).

Table 1 Overview of measurements per visit.

\begin{tabular}{|c|c|c|c|c|c|c|}
\hline Media/Method & Marker & ED I & ED II & ED III & $\begin{array}{l}\text { Follow- } \\
\text { up }\end{array}$ & $\begin{array}{l}\text { Definite } \\
\text { diagnosis }\end{array}$ \\
\hline \multirow[t]{2}{*}{ Exhaled breath } & Fractional exhaled Nitric Oxide & - & $\bullet$ & $\bullet$ & $\bullet$ & $\bullet$ \\
\hline & Volatile Organic Compounds & - & $\bullet$ & - & $\bullet$ & $\bullet$ \\
\hline \multirow[t]{4}{*}{$\begin{array}{l}\text { Exhaled breath } \\
\text { condensate }\end{array}$} & $\begin{array}{l}\text { Cytokines: IL-1a,-2,-4,-5,-10,-13, } \\
\text { IFN- } \gamma \text {, TNF- } \alpha\end{array}$ & $\bullet$ & $\bullet$ & $\bullet$ & $\bullet$ & $\bullet$ \\
\hline & Chemokines: Eotaxin, Rantes, IL-8 & - & - & $\bullet$ & $\bullet$ & $\bullet$ \\
\hline & Adhesion molecules: sICAM1 & - & $\bullet$ & $\bullet$ & $\bullet$ & $\bullet$ \\
\hline & Acidity (pH) & $\bullet$ & - & $\bullet$ & $\bullet$ & $\bullet$ \\
\hline \multirow[t]{3}{*}{ Blood } & $\begin{array}{l}\text { Total Immunoglobulin E (IgE) and } \\
\text { specific IgE }\end{array}$ & $\bullet$ & & & & $\bullet$ \\
\hline & Regulatory T-cells & $\bullet$ & & & & \\
\hline & $\begin{array}{l}\text { Antibodies against: Mycoplasma } \\
\text { and Chlamydia pneumoniae }\end{array}$ & - & & & & \\
\hline \multirow[t]{2}{*}{ Saliva } & $\begin{array}{l}\text { Gene polymorphism: e.g. in IL4, } \\
\text { IL13, TNF } \alpha, A D A M 33\end{array}$ & $\bullet$ & & & & \\
\hline & $\begin{array}{l}\text { Gene expression: e.g. in IL4, IL13, } \\
\text { TNF } \alpha\end{array}$ & $\bullet$ & & & & \\
\hline $\begin{array}{l}\text { Nasal and troat } \\
\text { swaps }\end{array}$ & $\begin{array}{l}\text { Colonisation: Streptococcus } \\
\text { pneumoniae, Haemophilus } \\
\text { (para)influenzae, Staphylococcus } \\
\text { aureus }\end{array}$ & - & & & & $\bullet$ \\
\hline Faeces & $\begin{array}{l}\text { Colonisation: E.Coli, Clostridium } \\
\text { difficile }\end{array}$ & $\bullet$ & & & & \\
\hline \multirow[t]{3}{*}{ Lung function test } & $\begin{array}{l}\text { Airway resistance before and after } \\
\text { bronchodilator: MicroRint }\end{array}$ & $\bullet$ & $\bullet$ & - & $\bullet$ & \\
\hline & $\begin{array}{l}\text { Dynamic spirometry before and } \\
\text { after bronchodilator: MEFV, } \mathrm{FEV}_{1} \text {, } \\
\text { FVC, } \mathrm{MEF}_{50}\end{array}$ & & & & & - \\
\hline & Histamine provocation test & & & & & - \\
\hline \multirow[t]{3}{*}{ Questionnaire } & $\begin{array}{l}\text { Parental administrated respiratory } \\
\text { symptoms (ISAAC) }\end{array}$ & $\bullet$ & $\bullet$ & - & $\bullet$ & $\bullet$ \\
\hline & $\begin{array}{l}\text { Demographic factors: e.g. } \\
\text { smoking, pets }\end{array}$ & - & $\bullet$ & $\bullet$ & $\bullet$ & $\bullet$ \\
\hline & $\begin{array}{l}\text { Parental administrated Quality of } \\
\text { life (FSII) }\end{array}$ & $\bullet$ & $\bullet$ & $\bullet$ & $\bullet$ & $\bullet$ \\
\hline
\end{tabular}

ED I / II / III = Consecutive measurements in Early Diagnosis phase 


\section{Methods / Design}

\section{Study design}

The study design is a long-term case-control study during four years. The study consists of four phases: 1) the selection phase; 2) the early diagnosis phase; 3) the follow-up phase; and 4) the definite diagnosis at six years (Figure 2).

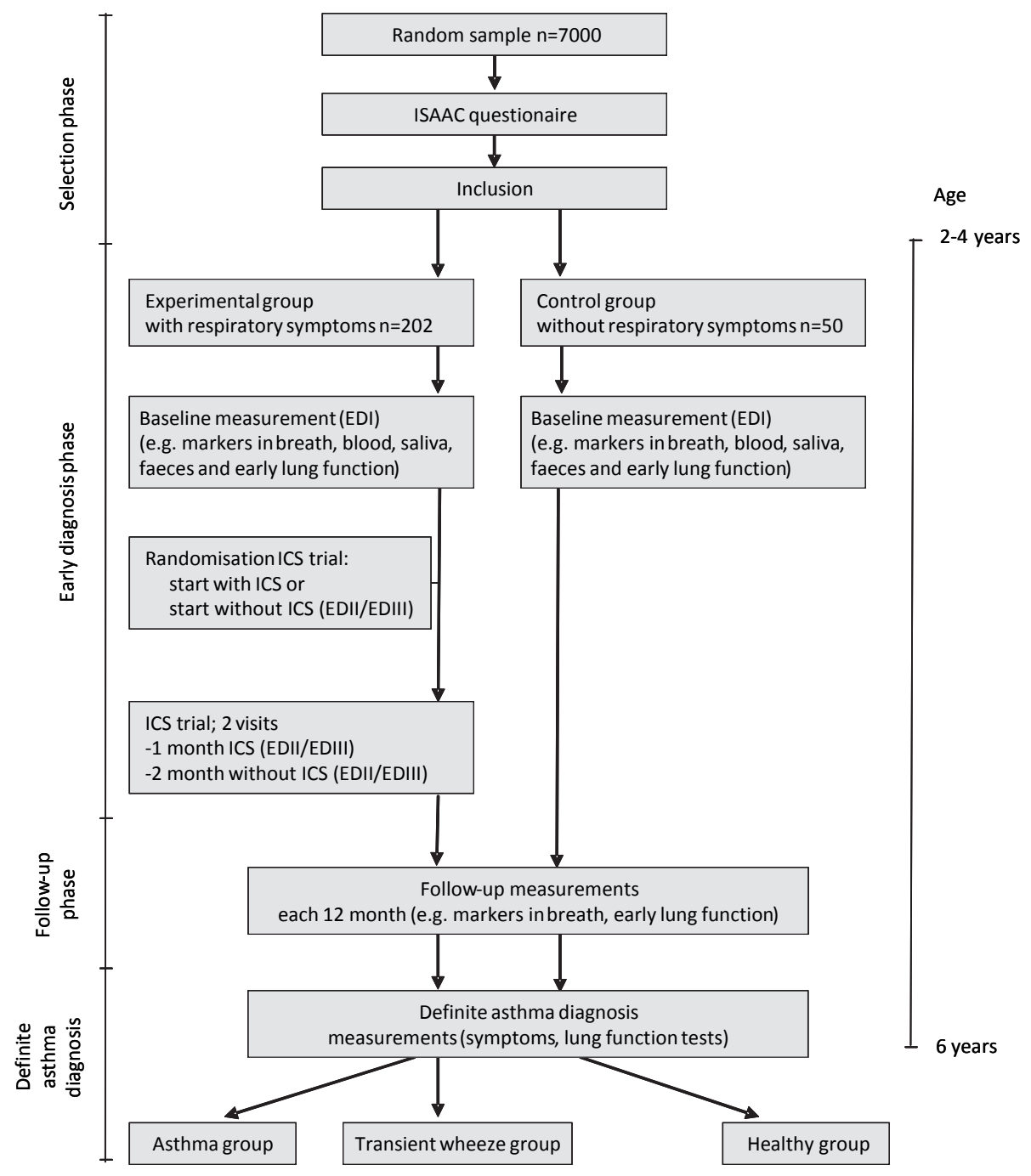

Figure 2 Study design

ED I/II/III=Consecutive measurements in Early Diagnosis phase; ICS=Inhaled corticosteroids. 
In the selection phase, a random sample of children aged two to four years of primary care practice and of two cities in Limburg, the Netherlands, receives a standardised questionnaire on respiratory symptoms (ISAAC). ${ }^{34}$ From the results of this questionnaire, a group of 202 children with recurrent asthma-like symptoms (experimental group) and 50 children with no respiratory symptoms (control group) are selected. In the early diagnosis phase, a two-month trial with ICS is performed. In addition, repeated measurements of early predictors, like exhaled biomarkers of inflammation/oxidative stress and lung function tests are assessed. During the followup phase, the development of respiratory symptoms, lung function indices and inflammation biomarkers are studied. At six years of age, a definite diagnosis of asthma is made, based on various lung function measurements and current respiratory symptoms ('gold standard'). At this stage, early measurements of (noninvasive) inflammation biomarkers and lung function measurements are related to the definitive diagnosis of asthma in order to select the combination of biomarkers which can reliable assess asthma. The study design is described in more detail below.

\section{Selection phase}

Subjects are recruited from two sources. The first source consists of general practices from the Registration Network of Family Practices of the University of Maastricht. This department is used for other studies and has extensive research logistics, including 55 general practitioners and 110,000 patients. ${ }^{36}$ In addition, a community-based random sample of children aged two to four years is selected of two cities in Limburg (Maastricht and Heerlen).

Parents receive information about the study, along with the informed consent form. When parents are willing to participate with their child in the study, they are asked to fill in an internationally standardised questionnaire on respiratory symptoms (ISAAC). ${ }^{34}$ From the results of the ISAAC questionnaire, 202 children with recurrent respiratory symptoms (experimental group) and 50 with no respiratory symptoms (control group) are selected.

\section{Experimental group}

In total, 202 children aged two to four years with recurrent respiratory symptoms participate in the experimental group. The inclusion criterion for this group is that children experienced at least two episodes of wheeze during life, based on the parents-completed questionnaire. ${ }^{34}$ Exclusion criteria are mental retardation, cardiac anomalies, congenital malformations, other diseases of the lungs/airways, Crohn's disease or rheumatic arthritis and the inability to perform lung function measurements or exhaled breath collection. The use of ICS is not an exclusion criterion. However, ICS are stopped at least four weeks before the start of the measurements. 


\section{Control group}

In addition, 50 children aged two to four years without wheeze and other recurrent respiratory symptoms are selected, based on the parents-completed questionnaire. ${ }^{34}$ Exclusion criteria are similar as for the experimental group. After written informed consent, children and parents are invited for a visit to the lung function laboratory. The lung function assistant and/or research physician further evaluates suitability for participation. A questionnaire on demographic data, medical history of the child, family history, day-care attendance, housing, prescribed drug therapy, exposure to pets and passive smoking is completed.

\section{Early diagnosis phase}

In the early diagnosis phase, repeated measurements of early predictors, including lung function tests and markers of inflammation/oxidative stress in exhaled breath (condensate), blood and faeces are performed in both the experimental and control group (Table 1).

Besides, a trial with ICS is part of the diagnosis phase for the children in the experimental group. This trial consists of a treatment period of two months with ICS therapy (Beclometasone extra-fine two times 100 microgram a day via the Aerochamber ) and a two-month period without ICS. Based on randomisation, half the children start with ICS, the other half starts the period without ICS. All other antiinflammatory medication is stopped. Clinical visits and measurements for the ICS trial occur at $\mathrm{t}=0,2$ and 4 months.

\section{Follow-up phase}

The purpose of the third phase is to monitor the development of respiratory symptoms, inflammation biomarkers and lung function in both the experimental and control group. At twelve-month intervals, each child visits the lung function laboratory for measurements of inflammation biomarkers and lung function tests. Relevant therapy (e.g. dose and period) is registered. If possible, ICS are stopped four weeks before the measurements.

In practices of the participating general practitioners, a computer program for the study is installed. With this program, general practitioners register standardised diagnoses of asthma, atopic dermatitis and allergic rhino conjunctivitis on-line. Diagnoses are based on international Classification of Health Problems in Primary Care (ICHPPC) definitions.

Children are treated according to the guidelines for treatment of asthma of the Dutch Society of General Practice. ${ }^{37}$ These national guidelines approach the international GINA guidelines of asthma diagnosis and treatment. ${ }^{25}$ 


\section{Definite asthma diagnosis phase}

At six years, a definite diagnosis of asthma is made (primary outcome measure and 'gold standard') upon the presence of current asthma symptoms in combination with characteristic lung function abnormalities (reversibility on a $\beta_{2}$-agonist and/or bronchial hyper-responsiveness). Airway reversibility is defined as an increase in forced expiratory volume in one second $\left(\mathrm{FEV}_{1}\right)$ of at least nine percent after 400 microgram of extra-fine salbutamol. Bronchial hyper-responsiveness is present when a $20 \%$ fall in $\mathrm{FEV}_{1}$ is obtained with a provocative concentration of histamine $\left(\mathrm{PC}_{20}\right)$ of 8 $\mathrm{mg} / \mathrm{ml}$ or less. Early measurements of (non-invasive) inflammation biomarkers and lung function measurements are related to the definitive diagnosis of asthma. The definite diagnosis of asthma divides the children in the experimental group into an 'asthma group' and a 'transient wheeze group'.

\section{Study parameters}

As described before, repeated measurements are performed from inclusion until the asthma diagnosis. One hour before each experiment, eating and exercise are not allowed. The parameters that are measured are listed in Table 1.

\section{Fractional exhaled Nitric Oxide}

FeNO is off-line collected in a $500 \mathrm{ml}$ inert balloon during tidal breathing. Exhaled breath is collected via a face mask that is connected to a two-way non-rebreathing valve. ${ }^{38}$ The valve is connected to a filter that allows inspiration of NO-free ambient air to avoid contamination by ambient NO. To avoid nasal contamination a septum between nose and mouth is placed in the mask. After a washout period of five tidal breaths, an NO-inert bag is connected on the expiratory port of the valve to collect exhaled breath. FeNO levels in the bag are determined by off-line sampling using the NIOX (Aerocrine, Solna, Sweden).

\section{Chromatogram of exhaled breath}

During tidal breathing, expired air is collected in a one-litre inert bag by means of the two-way valve system described above. After collection, the bag is immediately emptied across a small tube with active carbon, with rapid adsorption and stabilisation of volatile markers. A profile of inflammation biomarkers in exhaled breath is assessed by means of gas-chromatography time-of-flight mass spectrometer. $^{39}$ 


\section{Inflammation markers in exhaled breath condensate}

To collect EBC in young children, a special system is designed in close collaboration with the Department of Instrument Development Engineering \& Evaluation of the MUMC. ${ }^{19}$ Figure 3 shows a schematic representation of this closed glass condenser. Children breathe tidally for ten minutes through a mask connected to the two-way non-rebreathing valve. EBC is collected using a cooled double-jacketed glass condenser that is connected to the valve via a tube. The two-way valve and tubing serve as a trap to minimise salivary contamination. Circulating ice water cools the condenser to $0^{\circ} \mathrm{C}$. During this procedure small droplets of breath condensate are formed and are collected in a tube. During the procedure, children can watch cartoons. Exhaled breath that does not directly condense is collected in an inert bag that is connected to the condenser. To avoid that the exhaled air condenses in the bag, the bag is placed in a heated box $\left(37^{\circ} \mathrm{C}\right)$. When the child finishes the procedure, the exhaled breath that is temporarily collected in the inert bag is conducted through the condenser (recirculation) to increase the amount of condensate. After collection, $\mathrm{EBC}$ is rapidly frozen using dry ice and is stored at $-80^{\circ} \mathrm{C}$ until analysis. Inflammation markers (e.g. Interferon- $\gamma$ (IFN- - ), TNF- $\alpha$, Interleukins (IL), soluble Intercellular Adhesion Molecule 1 (sICAM1)) are assayed using multiplex immunoassay (Luminex technology ${ }^{\bullet}$, Luminex Corporation, Austin, TX, USA). ${ }^{40}$

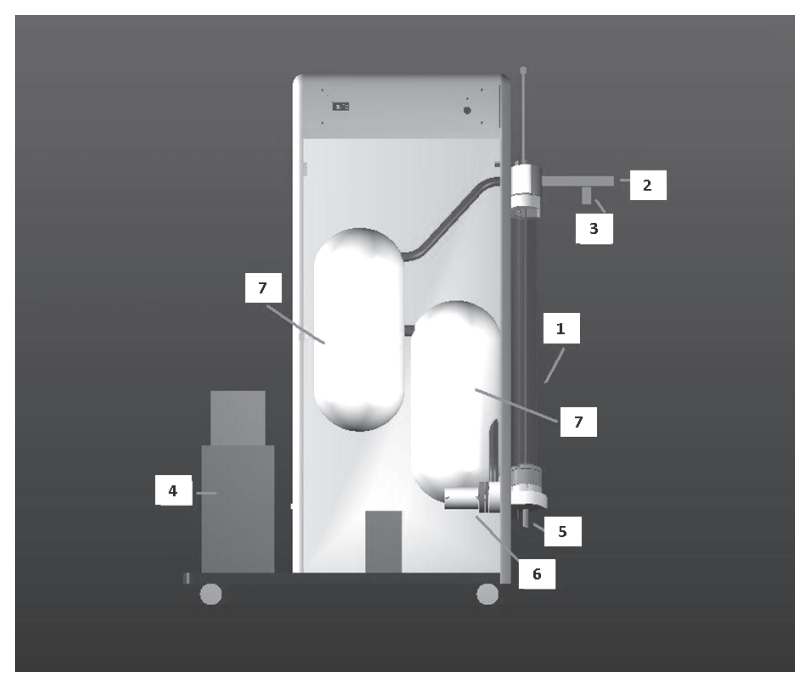

Figure 3 Schematic representation of the glass closed condenser

1. Inclined glass condenser with a moveable plunger; 2 . Swan-neck tubing (saliva trap) and two-way nonrebreathing valve, connected to a face mask with separated nose and mouth cavity; 3 . Entrance of inspired room air; 4. Cooling unit; 5. Sample vial to collect EBC; 6. Ventilator system for recirculation of noncondensed exhaled breath; 7 . Heated (at $37^{\circ} \mathrm{C}$ ) inert Tedlar ${ }^{\mathrm{TM}}$ gas sample bag to collect the residual noncondensed exhaled breath. 


\section{Polymorphism in inflammation genes}

Saliva is used for DNA collection. DNA is isolated according to the protocol of Oragene (Oragene, Ottowa, Canada). For genotyping matrix-assisted laser desorption/ ionization time-of-flight (MALDI-TOF) mass spectrometry is used (Sequenom Inc., San Diego, USA). Sequences are evaluated in the ProxSNP and PreXTEND software (www.realsnp.com). The reactions are designed using Sequenom Assay Designer 3.1 software. Genotyping is executed according to the iPLEX method. In short, multiplexed polymerase chain reaction (PCR) is performed in five $\mu$ l volume using the Sequenom PCR kit. Deactivation of unincorporated deoxyribonucleotide triphosphates (dNTPs) is achieved using shrimp alkaline phosphatase. The iPLEX reagent kit carries out primer extension. To remove residual salt from the reactions a cation exchange resin is added. Approximately $15 \mathrm{nl}$ of the primer extension reaction is loaded onto a matrix pad of a SpectroCHIP (Sequenom). MassARRAY Compact Analyzer is used to analyse the SpectroCHIPs (Sequenom). The PCR primer and extension primer sequences are available on request. The genotyping calls are made using Typer Analyzer 4.0 software. The Single Nucleotide Polymorphisms (SNPs) that are studied are selected from PubMed in combination with the HapMap database (www.hapmap.org). Inclusion of genes for SNP analysis is based on the following criteria: association with asthma based on biomedical literature and a minor allele frequency of at least five percent in the (asthmatic) population. Genes selected for analysis are: Filaggrin, $T N F \alpha$, Interleukin 4 receptor alpha $(I L 4 R \alpha), I L 4, I L 5, I L 8, I L 10$, IL13, IL33, ICAM1, A Disintegrin And Metallopeptidase domain 33 (ADAM33), Orosomucoid 1-like 3 (ORMDL3), toll-like receptor (TLR) 2, TLR4, TLR9, Cluster of Differentiation 14 (CD14), Secretoglobin family $1 \mathrm{~A}$ member 1 (SCGB1A1/CC16), Cysteinyl Leukotriene Receptor 1 (CYSLTR1), Leukotriene C4 (LTC4), Protocadherin-1 $(P C D H 1)$, Interleukin 1 receptor-like 1 (IL1RL1) and Plasminogen Activator Urokinase Receptor (PLAUR).

\section{Venous blood sampling}

At the first visit of the study, venous blood is sampled for:

1. Total Immunoglobulin E (IgE) and specific IgE for pollen, cats, dogs, house dust mite and Aspergillus Fumigatus (Pharmacia, Uppsala, Sweden);

2. Presence of $\mathrm{T}_{\text {reg }}$ cells (described below);

3. Gene expression of relevant markers (described below);

4. Infection serology (Mycoplasma and Chlamydia pneumoniae).

In addition, total and specific IgE are also determined at the last visit. 


\section{Regulatory T-cells}

$T_{\text {reg }}$ cells were quantified in the circulation by flow cytometry. The phenotype of the $\mathrm{T}_{\text {reg }}$ was defined as being positive for CD3, CD4 and CD25 (IL-2R $\alpha$ ), while being negative for CD127 (IL-7R $\alpha$ ). Cells with this phenotype have been shown to be positive for FoxP $3,^{41}$ a transcription factor which is closely related to the suppressive function of $\mathrm{T}_{\text {reg }}$ cells.

\section{Gene expression of markers of inflammation}

In addition to gene polymorphisms, expression of inflammation genes are determined in the early diagnosis phase of the study. Total RNA from venous blood is isolated that is used to generate cDNAs by poly-A and random priming reverse transcription. The CDNAs are stored and used for the production of copy RNA pools. Real-Time Quantitative PCR was used to assess up- or down-regulated expression of genes (AROS, Aarhus, Denmark). Inclusion of genes for gene expression is based on the same criteria as the inclusion of genes for SNP analysis and on an altered gene expression in asthma suggested in the literature. Genes studied are: IL4, IL5, IL8, IL10, IL12, IL13, IL17A, TNFa, ICAM1, TLR4, TLR5, TLR9, TRL2, Eotaxin (CCL11), RANTES (CCL5), Macrophage migration Inhibitory Factor (MIF), Macrophage Inflammatory Protein $1 \alpha$ (MIP1 $\alpha$ ), Gluthathiontransferase (GST), Catalase (CAT), Superoxide Dismutase (SOD3), Nitric Oxide Synthase 1 (NOS1), Signal Transducer and Activator of Transcription 6 (STAT6), NF-K-B inhibitor alpha (IKB $\alpha$ ), Chitinase (CHIA), Forkhead box P3 (FoxP3), Monocyte chemotactic protein-1 (MCP1), chemokine (C-C motif) ligand 23 (CCL23), Cyclooxygenase (COX2), Transforming Growth Factor-Beta1 (TGF $\beta 1$ ).

\section{Infection serology}

At the start and at the end of the study, a nose and throat swab is collected to analyse possible colonisations of Streptococcus pneumoniae, Haemophilus (para)influenzae and/or Staphylococcus aureus. At the first visit, antibodies of Chlamydia and Mycoplasma pneumoniae are analysed in venous blood, using ELISA. In addition, faeces samples are tested for E. coli and Clostridium difficile.

\section{Lung function tests of airway resistance}

Measurements of airway resistance are performed by means of the MicroRint (Micro Medical Ltd, Rochester, UK). ${ }^{22}$ While children are sitting in an upright position, they are asked to breathe tidally through a facemask. Seven airflow interruptions are made on the peak flow of expiration. The median MicroRint value and the flow- and pressure curves are displayed. The median MicroRint value of at least five successful interruptions is used for analysis. Thereafter, 300 microgram of extra-fine salbutamol 
is inhaled via the Aerochamber. After 15 minutes, MicroRint measurements are repeated to assess the reversibility to a $\beta_{2}$-agonist.

\section{Dynamic spirometry, bronchial hyper-responsiveness and reversibility}

At the end of the study, additional lung function tests are performed as described before. ${ }^{36}$ Maximal expiratory flow volume (MEFV) curves are assessed in each child by means of the Flowscreen (Jaeger, Wuerzburg, Germany). The highest FEV ${ }_{1}$, forced vital capacity (FVC) and maximal expiratory flow at 50\% FVC (MEF 50 ) of three technically satisfactory MEFV curves are used for analysis. After three baseline MEFV curves, an aerosol of buffered saline is inhaled, followed by aerosols of histamine acid phosphate in doubling concentrations from 0.03 to $16 \mathrm{mg} / \mathrm{ml}$ at five minute intervals. Dynamic spirometry is repeated once after 30 and after 90 seconds following each inhalation. The inhalation of histamine is discontinued in case of a $20 \%$ fall in $\mathrm{FEV}_{1}$ $\left(P C_{20}\right)$ or when $16 \mathrm{mg} / \mathrm{ml}$ histamine has been administered. Thereafter, 400 microgram of extra-fine salbutamol is inhaled. After 15 minutes, three MEFV curves are assessed in a comparable way. The change in $\mathrm{FEV}_{1}$ is expressed as a percentage of the predicted value.

\section{Questionnaires on respiratory symptoms and quality of life}

Presence of cough, breathlessness and wheeze are registered according to the internationally standardised ISAAC questionnaire. ${ }^{34}$ Besides, a questionnaire designed for preschool children to record patterns of wheeze and other respiratory symptoms is completed by parents. ${ }^{42}$ In addition, medical history in relation to respiratory symptoms is assessed by a physician. ${ }^{43}$ The quality of life in children is measured by parent-administered general health related quality of life (FSII) questionnaires. ${ }^{35}$

\section{Samples size calculations}

In a population of infants with recurrent asthma-like symptoms, the prevalence of asthma at six years is known to be $30 \% .{ }^{1}$ In this study, this will result in at least 50 asthmatic children given the 202 children with recurrent respiratory symptoms aged two and three years at the start and a 10\% drop-out rate. The standard error of the sensitivity given a chance on a positive test result of 0.8 will be $4.0 \%$. The standard error of the specificity with 150 children without disease will be $3.0 \%$ given a chance on a positive test result of 0.8 . If the positive predictive value of the test is 0.7 and the negative predictive value 0.2 in a population of $\mathrm{N}=200$, the statistical power for the relation between the test and the definite diagnosis of asthma is $94 \%$. 


\section{Data collection}

The collected data are checked and cleaned by the centre for data and information management of Maastricht University (MEMIC). All data are stored in a database at MEMIC.

\section{Data analysis}

The data are analysed using quantitative statistics. Normally distributed data are expressed as mean and standard error. Not normally distributed data are expressed as median with inter quartile ranges.

\section{Statistics of the primary research question}

The primary research question is whether non-invasive inflammation biomarkers in exhaled breath and lung function indices can reliably predict asthma at an early age. For this purpose, biomarkers collected in the experimental group during the early diagnosis phase are used. These parameters are related to the definite diagnosis of asthma by means of multiple logistic regression analysis and discriminant analysis.

\section{Statistics of the secondary research questions}

To answer the second research questions, data from both experimental group and control group are used. Differences in parameters between the three groups (asthma, 'transient wheezers' and controls) are tested with analysis of variance (one-way ANOVA or Kruskal-Wallis test in case of parametric and non-parametric data, respectively). For normally distributed data, Student's t-tests are used for further analysis. Mann-Whitney $U$ tests are used to test for differences among nonparametric data. Differences are defined as significant when $p<0.05$.

\section{Ethics}

Ethical approval is obtained from the Dutch National Medical Ethical Committee (CCMO). All parents gave written informed consent. At the end of the study all parents are informed about the personal primary outcome measure (asthma diagnosis) of their child and general results of the study. The study protocol is extensively studied by the funding organizations: the Dutch Asthma Foundation, Stichting Astma Bestrijding and Maastricht University Medical Centre. This study is registered at clinicaltrial.gov (NCT 00422747). 


\section{Discussion}

We presented the protocol of the ADEM study that aims at an early asthma diagnosis in young children by using non-invasive biomarkers of airway inflammation and early lung function measurements. The design of the study is a case-control study in 202 children with recurrent respiratory symptoms and 50 control subjects with no respiratory symptoms. Our primary hypothesis is that an early asthma diagnosis is possible using non-invasive measurements of inflammation biomarkers in exhaled breath (condensate) and lung function tests. Besides, aetiological factors including gene polymorphisms, gene expression, $T_{\text {reg }}$ cells and microbial colonisation of airways and intestines are studied in relation to the development of asthma.

The development of a new diagnostic tool for asthma at an early age, based on noninvasive inflammation biomarkers in exhaled breath and lung function can lead to an early asthma diagnosis. This will result in better treatment and probable a better prognosis of asthma in children. Moreover, exclusion of asthma at an early age prevents over-treatment in the children with transient wheezing, which will reduce possible side-effects and economic costs.

The design and setting of the ADEM study is ideally suited to study the relationship between different parameters that are measured in early life and the susceptibility for asthma. This will increase insight in, for example, the relationship between the genetic background and the pathophysiology of asthma in young children.

There are several critical success factors to be mentioned. The study performs measurements in children aged two to six years. Although the measurements are not invasive, the question arises whether the measurements are feasible in these young children. In a previous study in 70 preschool children, we established a success rate of EBC measurements of $83 \%$ using the same condenser. ${ }^{19}$ With respect to early lung functions measurements, Merkus et al. found a feasibility of $88 \%$ of MicroRint measurements in children aged two years and over. ${ }^{22}$ We hope to achieve success rates of the measurements of at least $90 \%$ taken into account the non-invasive character of the measurements and our experience and learning curve in the field of measurements of exhaled breath (condensate) and lung function tests in children. ${ }^{19,36}$

A trial with ICS is part of the diagnosis phase for the children in the experimental group. A trial period with ICS is often advocated but the precise diagnostic value is not clear from earlier studies. ${ }^{25}$ The children in the experimental group consist of children who experienced at least two episodes of wheeze during life. This can imply that some children are symptom-free at the start of the ICS trial. Therefore, we expect a lower compliance in the group children without current respiratory symptoms. Compliance will be measured by weighting the ICS inhalators before and after the trial. 
Children in this study are followed-up for three to four years. This long-term study can induce lost to follow-up, which is dependent on compliance and the involvement of the parents with the study. In our power analysis we calculated a lost to follow-up of ten percent. Other studies of our research group with a comparable design had a similar drop-out rate. ${ }^{44}$

In this study various parameters are measured. Because of the large number of parameters that are measured, it is important to distinguish the primary outcome measure from the aetiological factors that are studied. The results of the aetiological part of this study have a more exploring character and should be tested more extensively in future research.

\section{Conclusion}

As an early diagnosis of asthma is currently difficult, both under-diagnosis and undertreatment of asthmatic children as well as over-treatment of transient wheezers occur frequently. So far, assessment of inflammation biomarkers play a minor role in the diagnosis of asthma. The development of a new diagnostic tool for asthma at an early age, based on non-invasive inflammation biomarkers in exhaled breath and early lung function measurements is a promising technique. These new diagnostic techniques are applied in this study and might make an early diagnosis of asthma possible. This will result in earlier and better treatment of childhood asthma. 


\section{References}

1. Martinez FD, Wright AL, Taussig LM, Holberg CJ, Halonen M, Morgan WJ. Asthma and wheezing in the first six years of life. The Group Health Medical Associates. N Engl J Med 1995;332:133-8.

2. Bisgaard H, Szefler S. Prevalence of asthma-like symptoms in young children. Pediatr Pulmonol 2007; 42:723-8.

3. Kurukulaaratchy RJ, Fenn MH, Waterhouse LM, Matthews SM, Holgate ST, Arshad SH. Characterization of wheezing phenotypes in the first 10 years of life. Clin Exp Allergy 2003;33:573-8.

4. Taussig LM, Wright AL, Holberg CJ, Halonen M, Morgan WJ, Martinez FD. Tucson Children's Respiratory Study: 1980 to present. J Allergy Clin Immunol 2003;111:661-75.

5. Castro-Rodriguez JA, Rodrigo GJ. Efficacy of inhaled corticosteroids in infants and preschoolers with recurrent wheezing and asthma: a systematic review with meta-analysis. Pediatrics 2009;123: e519-25.

6. Kaditis AG, Winnie G, Syrogiannopoulos GA. Anti-inflammatory pharmacotherapy for wheezing in preschool children. Pediatr Pulmonol 2007;42:407-20.

7. McKean M, Ducharme F. Inhaled steroids for episodic viral wheeze of childhood. Cochrane Database Syst Rev 2000CD001107.

8. Baraldi E, Ghiro L, Piovan V, Carraro S, Zacchello F, Zanconato S. Safety and success of exhaled breath condensate collection in asthma. Arch Dis Child 2003;88:358-60.

9. Pijnenburg MW, De Jongste JC. Exhaled nitric oxide in childhood asthma: a review. Clin Exp Allergy 2008;38:246-59.

10. Robroeks CM, van de Kant KD, Jöbsis $Q$, Hendriks HJ, van Gent R, Wouters EF, Damoiseaux JG, Bast A, Wodzig WK, Dompeling E. Exhaled nitric oxide and biomarkers in exhaled breath condensate indicate the presence, severity and control of childhood asthma. Clin Exp Allergy 2007;37:1303-11.

11. Doelman CJ, Bast A. Oxygen radicals in lung pathology. Free Radic Biol Med 1990;9:381-400.

12. Phillips M, Gleeson K, Hughes JM, Greenberg J, Cataneo RN, Baker L, McVay WP. Volatile organic compounds in breath as markers of lung cancer: a cross-sectional study. Lancet 1999;353:1930-3.

13. Paredi P, Kharitonov SA, Barnes PJ. Elevation of exhaled ethane concentration in asthma. Am J Respir Crit Care Med 2000;162:1450-4.

14. Olopade CO, Zakkar M, Swedler WI, Rubinstein I. Exhaled pentane levels in acute asthma. Chest 1997;111:862-5.

15. Corradi M, Folesani G, Andreoli R, Manini P, Bodini A, Piacentini G, Carraro S, Zanconato S, Baraldi E. Aldehydes and glutathione in exhaled breath condensate of children with asthma exacerbation. Am J Respir Crit Care Med 2003;167:395-9.

16. Baraldi E, Ghiro L, Piovan V, Carraro S, Ciabattoni G, Barnes PJ, Montuschi P. Increased exhaled 8isoprostane in childhood asthma. Chest 2003;124:25-31.

17. Csoma Z, Kharitonov SA, Balint B, Bush A, Wilson NM, Barnes PJ. Increased leukotrienes in exhaled breath condensate in childhood asthma. Am J Respir Crit Care Med 2002;166:1345-9.

18. Formanek W, Inci D, Lauener RP, Wildhaber JH, Frey U, Hall GL. Elevated nitrite in breath condensates of children with respiratory disease. Eur Respir J 2002;19:487-91.

19. Rosias PP, Robroeks CM, van de Kant KD, Rijkers GT, Zimmermann LJ, van Schayck CP, Heynens JW, Jöbsis Q, Dompeling E. Feasibility of a new method to collect exhaled breath condensate in pre-school children. Pediatr Allergy Immunol 2010;21:e235-44.

20. Effros RM, Hoagland KW, Bosbous M, Castillo D, Foss B, Dunning M, Gare M, Lin W, Sun F. Dilution of respiratory solutes in exhaled condensates. Am J Respir Crit Care Med 2002;165:663-9.

21. Kostikas K, Koutsokera A, Papiris S, Gourgoulianis KI, Loukides S. Exhaled breath condensate in patients with asthma: implications for application in clinical practice. Clin Exp Allergy 2008: 38;557-65.

22. Merkus PJ, Arets HG, Joosten T, Siero A, Brouha M, Mijnsbergen JY, de Jongste JC, van der Ent CK. Measurements of interrupter resistance: reference values for children 3-13 yrs of age. Eur Respir J 2002;20:907-11.

23. Bridge PD, Ranganathan S, McKenzie SA. Measurement of airway resistance using the interrupter technique in preschool children in the ambulatory setting. Eur Respir J 1999;13:792-6. 
24. Nielsen KG, Bisgaard H. Discriminative capacity of bronchodilator response measured with three different lung function techniques in asthmatic and healthy children aged 2 to 5 years. Am J Respir Crit Care Med 2001;164:554-9.

25. Global Initiative for asthma (GINA). Global strategy for asthma management and prevention. National Institute of Health, National Heart, Lung, and Blood Institute 2008.

26. Robinson DS, Hamid Q, Ying S, Tsicopoulos A, Barkans J, Bentley AM, Corrigan C, Durham SR, Kay AB. Predominant TH2-like bronchoalveolar T-lymphocyte population in atopic asthma. N Engl J Med 1992; 326:298-304.

27. Busse WW, Lemanske RF, Jr. Asthma. N Engl J Med 2001;344:350-62.

28. Damoiseaux J. Regulatory T cells: back to the future. Neth J Med 2006;64:4-9.

29. Xystrakis E, Boswell SE, Hawrylowicz CM. T regulatory cells and the control of allergic disease. Expert Opin Biol Ther 2006;6:121-33.

30. Ober C, Hoffjan S. Asthma genetics 2006: the long and winding road to gene discovery. Genes Immun 2006;7:95-100.

31. Koppelman GH, te Meerman GJ, Postma DS. Genetic testing for asthma. Eur Respir J 2008;32:775-82.

32. Strachan DP. Hay fever, hygiene, and household size. BMJ 1989;299:1259-60.

33. Schaub B, Lauener R, von Mutius E. The many faces of the hygiene hypothesis. J Allergy Clin Immunol 2006;117:969-77.

34. Worldwide variation in prevalence of symptoms of asthma, allergic rhinoconjunctivitis, and atopic eczema: ISAAC. The International Study of Asthma and Allergies in Childhood (ISAAC) Steering Committee. Lancet 1998;351:1225-32.

35. Stein RE, Jessop DJ. Functional status II(R). A measure of child health status. Med Care. 1990;28: 1041-55.

36. Kuiper S, Maas T, van Schayck CP, Muris JW, Schonberger HJ, Dompeling E, Gijsbers B, van Weel C, Knottnerus JA. The primary prevention of asthma in children study: design of a multifaceted prevention program. Pediatr Allergy Immunol 2005;16:321-31.

37. Bindels PJ, Grol MH, Ponsioen BP, Salome PL, Wiersma T, Goudswaard AN. [Summary of the practice guideline 'Asthma in children' (second revision) from the Dutch College of General Practitioners]. Ned Tijdschr Geneeskd 2008;152:550-5.

38. Gabriele C, Asgarali R, Jaddoe VW, Hofman A, Moll HA, de Jongste JC. Smoke exposure, airway symptoms and exhaled nitric oxide in infants: the Generation R study. Eur Respir J 2008;32:307-13.

39. Van Berkel JJ, Dallinga JW, Moller GM, Godschalk RW, Moonen E, Wouters EF, Van Schooten FJ. Development of accurate classification method based on the analysis of volatile organic compounds from human exhaled air. J Chromatogr B Analyt Technol Biomed Life Sci 2008;861:101-7.

40. Rosias PP, Robroeks CM, Kester A, den Hartog GJ, Wodzig WK, Rijkers GT, Zimmermann L, van Schayck CP, Jöbsis Q, Dompeling E. Biomarker reproducibility in exhaled breath condensate collected with different condensers. Eur Respir J 2008;31:934-42.

41. Liu W, Putnam AL, Xu-Yu Z, Szot GL, Lee MR, Zhu S, Gottlieb PA, Kapranov P, Gingeras TR, Fazekas de St Groth B, Clayberger C, Soper DM, Ziegler SF, Bluestone JA. CD127 expression inversely correlates with FoxP3 and suppressive function of human CD4+ T reg cells. J Exp Med 2006;203:1701-11.

42. Powell CV, McNamara P, Solis A, Shaw NJ. A parent completed questionnaire to describe the patterns of wheezing and other respiratory symptoms in infants and preschool children. Arch Dis Child 2002; 87:376-9.

43. Hammer SC, Robroeks CM, van Rij C, Heynens J, Droog R, Jöbsis Q, Hendriks HJ, Dompeling E. Actual asthma control in a paediatric outpatient clinic population: Do patients perceive their actual level of control? Pediatr Allergy Immunol. 2008;19:626-33.

44. Schonberger HJ, Dompeling E, Knottnerus JA, Maas T, Muris JW, van Weel C, van Schayck CP. The PREVASC study: the clinical effect of a multifaceted educational intervention to prevent childhood asthma. Eur Respir J 2005;25:660-70. 


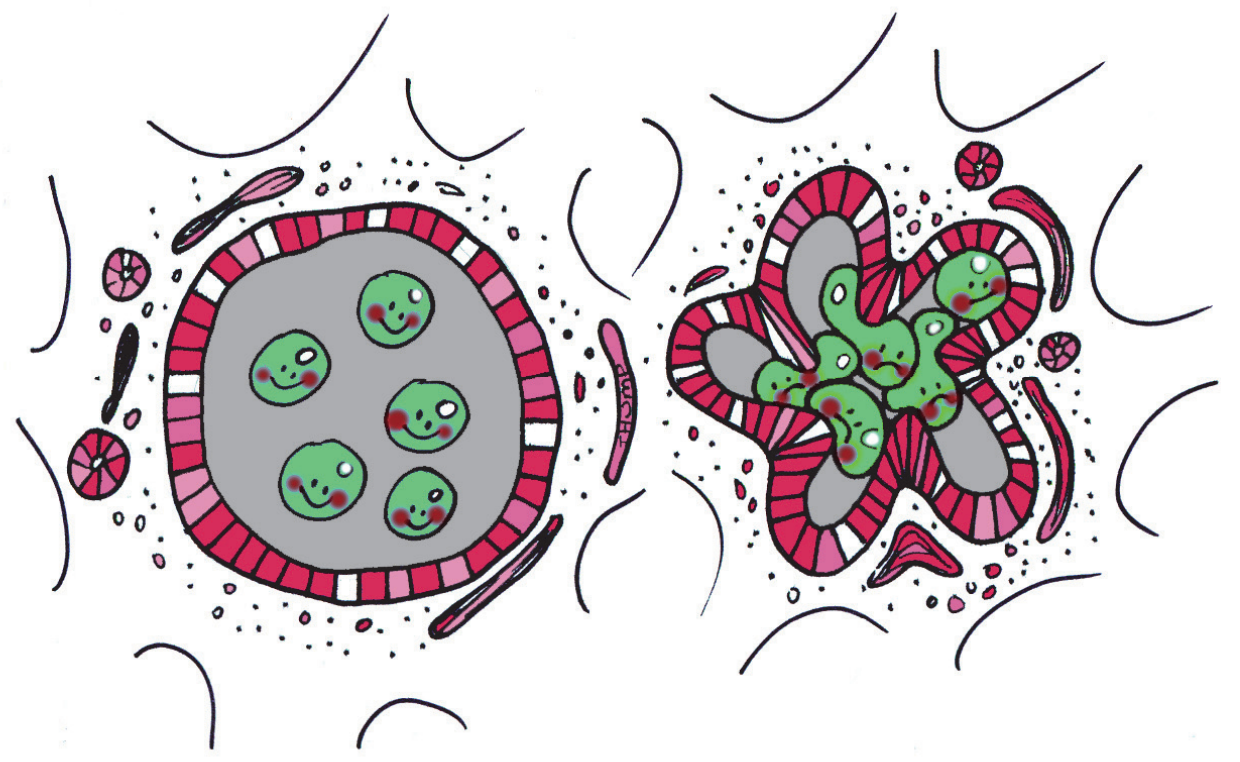




\section{Chapter 3}

\section{A systematic review of CD14 and toll-like receptors in relation to asthma in Caucasian children}

Klaassen EMM, Thönissen BEJT, van Eys G, Dompeling E, Jöbsis Q Allergy, Asthma \& Clinical Immunology 2013;9:10 


\section{Abstract}

The aetiology of childhood asthma is complex. An early dysfunction in the immunological development of the innate immune system in combination with environmental factors possibly triggers asthma. CD14 and toll-like receptors are important components of the innate immune system. The aim of this systematic review was to obtain a better insight into the relation between CD14 and toll-like receptors and childhood asthma in Caucasians. We searched PubMed and EMBASE for relevant articles and 44 articles were included. The quality of the selected studies was independently assessed by the first two authors using the Newcastle-Ottawa quality assessment scale. Toll-like receptor 2, toll-like receptor 6 , toll-like receptor 9 and tolllike receptor 10 appear to have some association with childhood asthma in Caucasians. The evidence for a relation of CD14 with childhood asthma is limited. In conclusion, there is no convincing evidence yet for a role of CD14 and toll-like receptors in relationship to childhood asthma. Future studies should include haplotype analysis and take environmental factors into account to further clarify the role of CD14 and toll-like receptors on childhood asthma. 


\section{Background}

Asthma is a common disease in childhood, which is characterised by chronic eosinophilic airway inflammation and airway (hyper-)responsiveness. ${ }^{1}$ Both, genetic and environmental factors have been associated with asthma. The cumulative effect of these factors is large, though the individual contribution of each factor may be limited. ${ }^{2-6}$ Also, genetic and environmental factors can modulate each other. As this modulation can differ with age, it can be time dependent. ${ }^{3}$ Hence, the aetiology of asthma is complex.

It is expected that an early dysfunction in the immunological development of the innate immune system, in combination with environmental factors may trigger asthma. ${ }^{7}$ The innate immune system makes the first contact with pathogens. Genetic variations in components of the innate immune system can alter the capability to deal with pathogens. The direction of the innate immune system response can depend on presented environmental signals, like endotoxin exposure. ${ }^{8}$ The difference in genetic make-up combined with differences in environmental factors leads to variations in the immune response. Important components of the innate immune system are CD14, an adaptor molecule, and a system of pathogen receptors named toll-like receptors (TLRs). ${ }^{9}$

CD14 is a multifunctional high-affinity receptor for endotoxins, lipopolysaccharides and other bacterial wall components. It has been implicated in the development and maturation of the innate immune system. ${ }^{10-13}$ Several studies have associated CD14 with determination of the balance between Th1 versus Th2 cytokines. ${ }^{14-16}$ It is expressed on the surface of monocytes, macrophages and neutrophils and occurs as a membrane-bound form and a soluble form. ${ }^{17,18}$ Polymorphisms in CD14 and levels of soluble CD14 (sCD14) have been implicated in childhood asthma. ${ }^{10,19-23}$

TLRs are evolutionarily conserved receptor complexes in the pathogen-recognition process. ${ }^{24}$ Each of the 10 TLRs described in humans recognizes a different spectrum of pathogen-associated molecular conformations. After interaction with pathogens, TLRs induce the innate immune response. They are involved in balancing Th1 versus Th2 immune responses, shifting the balance towards a Th1 response. ${ }^{9}$ TLRs are expressed in immune cells such as antigen-presenting cells and in epithelial cells. ${ }^{24}$ Polymorphisms in TLRs have been linked to childhood asthma. ${ }^{25-28}$

In this systematic review we summarise research on CD14 and TLRs in relation to asthma in Caucasian children. By selecting this specific group we expect more clarity in study outcome as conclusions can differ between ethnicities. ${ }^{29}$ Consequently, a better insight into the relationship between CD14 and TLRs and the pathology of childhood asthma in Caucasians would be achieved. Further, we analyse the effect of environmental factors on the relationship between the innate immune system and asthma in Caucasian children. 


\section{Methods}

\section{Search strategy}

PubMed and EMBASE were searched for relevant articles up to October 2012 by two independent investigators. Primary search terms (CD14, toll-like, TLR) were combined with secondary search terms (asthma*, wheez*) and limitation 'child' to find as many relevant publications as possible. Articles were included if they concerned asthma in Caucasian children and investigated the relationship with CD14 or TLRs. Articles were excluded if the study population was non-Caucasian (based on area where the study was conducted and stated by the authors) or if the full-text was not available in English. Also, conference abstracts and reviews were excluded. The articles were screened by the authors for suitability first by title, later by abstract and finally by fulltext. In case of disagreement, the senior author was asked to screen the article as well. Additionally, a number of studies were identified by a manual search of references of included studies. A PRISMA flow diagram of the search is included in Figure $1^{30}$

\section{Quality assessment}

The first two authors independently assessed the quality of the selected studies. Quality assessment was carried out using the Newcastle-Ottawa quality assessment scale (www.ohri.ca/programs/clinical_epidemiology/oxford.htm) which has especially been developed for assessment of observational studies in systematic reviews. ${ }^{31}$ In case criteria were met, a "*" was assigned. In case criteria were not met, a "-" was assigned. The overall quality of each article was assessed as better than average (+), average (+/-) or less than average (-). In case of disagreement, the senior author was asked to score the article as well. We did not attempt to pool the data.

The categories for cohort studies were as follows: S1: Representativeness of the exposed cohort, S2: Selection of non-exposed cohort, S3: Ascertainment of exposure, S4: Outcome of interest not present at start of study, C1a/C1b: Comparability of cohorts on the basis of the design or analysis, 01: Assessment of outcome, 02: Duration of follow-up and 03: Adequacy of follow-up. The categories for case-control studies were as follows: S1: Case definition, S2: Representativeness of the cases, S3: Selection of controls, S4: Definition of controls, C1a/C1b Comparability of cases and controls on the basis of the design or analysis, E1: Ascertainment of exposure, E2: Same method of ascertainment for cases and controls and E3: Non-response rate. As no cross-sectional assessment tool was available in the Newcastle-Ottowa quality assessment scale, cross-sectional studies (as identified in the method section of the respective article) were assessed in both the cohort scale and the case-control scale. Nested case-control studies were scored as case-control studies. Polymorphisms, gene 
expression and/or levels were analysed by a standard method in all studies. Therefore ascertainment of exposure (S3 for cohorts, E1 and E2 for case-control studies) was only scored in case of exposure to environmental factors. Also, we assigned a "*" for E3 in case-control studies if the non-response rate was mentioned. Five articles could not be scored as they had neither cohort nor case-control or cross-sectional design. $^{19,32-34}$
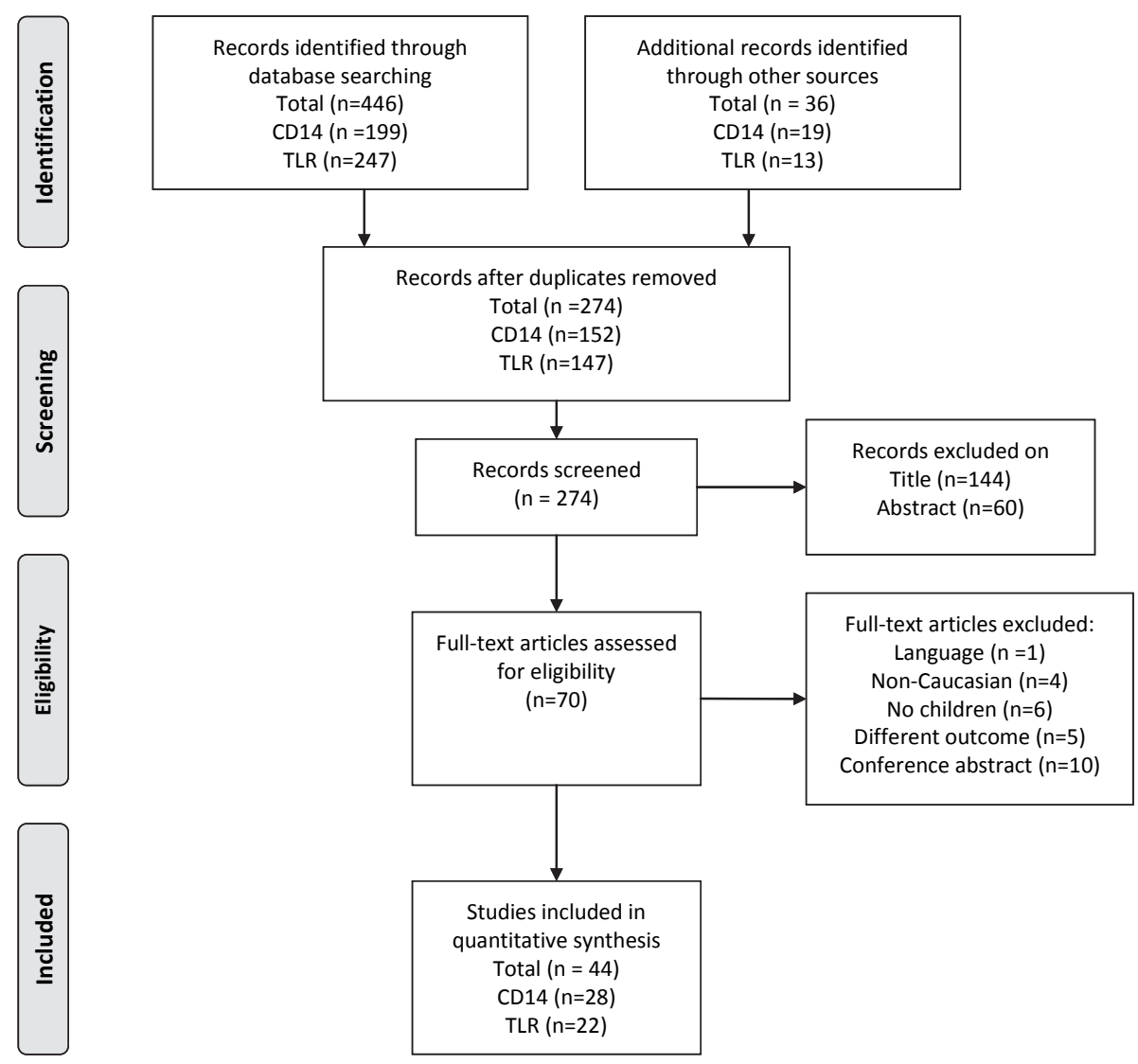

Figure 1 PRISMA flow diagram of search.

The flow diagram depicts the flow of information through the different phases of the systematic review. It maps out the number of records identified, included and excluded and the reasons for exclusions. 


\section{Results}

Of the 274 collected records, a total of 44 articles were included in this study (Figure 1). Only one article was excluded based on language. ${ }^{35}$ Characteristics of included studies are provided in additional Table A1. The results of the quality scoring can be viewed in Table 1 for cohort studies and in Table 2 for case-control studies.

Table 1 Quality scoring based on the Newcastle-Ottawa Quality Assessment Scale: Cohort studies.

\begin{tabular}{lccccccccccc}
\hline First author & Year & S1 & S2 & S3 & S4 & C1a & C1b & O1 & O2 & O3 & OQ \\
\hline Bieli $^{10}$ & 2007 & $*$ & $*$ & $*$ & - & $*$ & $*$ & - & $*$ & - & $+/-$ \\
Bottema $^{26}$ & 2010 & $*$ & $*$ & NA & $*$ & - & - & - & $*$ & - & $+/-$ \\
Custovic $^{62}$ & 2011 & $*$ & $*$ & - & $*$ & $*$ & $*$ & - & $*$ & $*$ & + \\
Edert $^{25}$ & 2004 & $*$ & $*$ & $*$ & - & $*$ & $*$ & - & $*$ & - & $+/-$ \\
Eget $^{22}$ & 2007 & $*$ & $*$ & $*$ & - & $*$ & $*$ & - & $*$ & - & $+/-$ \\
Fageras Bottchert $^{39}$ & 2004 & - & $*$ & $*$ & - & $*$ & $*$ & $*$ & $*$ & - & $+/-$ \\
Guerra $^{11}$ & 2004 & $*$ & $*$ & - & $*$ & $*$ & $*$ & - & - & - & $+/-$ \\
Jones $^{48}$ & 2002 & - & $*$ & NA & $*$ & - & - & - & - & - & - \\
Kabesch $^{13}$ & 2004 & $*$ & $*$ & NA & $*$ & - & - & - & $*$ & - & $+/-$ \\
Kerkhof $^{56}$ & 2010 & $*$ & $*$ & $*$ & $*$ & $*$ & $*$ & - & $*$ & - & + \\
Lange $^{63}$ & 2011 & $*$ & $*$ & NA & - & $*$ & $*$ & $*$ & $*$ & - & + \\
Lodrup Carlsen $^{51}$ & 2010 & $*$ & $*$ & NA & $*$ & $*$ & $*$ & - & $*$ & $*$ & + \\
O’Donnell $^{36}$ & 2004 & $*$ & $*$ & NA & - & $*$ & $*$ & - & $*$ & $*$ & + \\
Reijmerink $^{41}$ & 2010 & $*$ & $*$ & NA & $*$ & - & - & - & $*$ & - & $+/-$ \\
Rothenbacher $^{53}$ & 2005 & $*$ & $*$ & $*$ & $*$ & $*$ & $*$ & - & - & $*$ & + \\
Simpson $^{8}$ & 2006 & $*$ & $*$ & $*$ & $*$ & $*$ & $*$ & - & $*$ & $*$ & + \\
Snijders $^{52}$ & 2006 & $*$ & $*$ & $*$ & $*$ & $*$ & $*$ & - & - & $*$ & + \\
Soferman $^{54}$ & 2004 & - & $*$ & NA & $*$ & $*$ & $*$ & $*$ & $*$ & $*$ & + \\
\hline
\end{tabular}

S1: Representativeness of the exposed cohort, S2: Selection of non-exposed cohort, S3: Ascertainment of exposure, S4: Outcome of interest not present at start of study, C1a/C1b: Comparability of cohorts on the basis of the design or analysis, 01: Assessment of outcome, 02: Duration of follow-up, 03: Adequacy of follow-up (*: criteria were met; -: criteria were not met); OQ: Overall quality (+ better than average quality, + - average quality, - less than average quality); NA=not applicable; + cross-sectional design.

\section{Limited evidence for a relationship between polymorphisms of CD14 and childhood asthma}

The relationship between childhood asthma and polymorphisms in CD14 was studied in 17 studies. ${ }^{10,12,13,19-21,34,36-45}$ In most studies, asthma was taken as outcome. In two studies asthma severity was taken as outcome. ${ }^{19,34}$ Age ranged from 0 up to 19 years of age. Cases varied from 10 to 644 and controls from 115 to 1858 subjects. CD14 rs2569190 polymorphism, also known as C-260T or C-159T, was studied in 15 studies. ${ }^{10,12,13,19,20,34,36-40,42-45}$ Only one study found an association of this polymorphism with childhood asthma, showing an association of the T-allele with decreased asthma severity (Table 3). ${ }^{19}$ For rs4914 an association was indicated for decreased asthma incidence in one of the two children cohorts (Study of Asthma Genetics and 
Environment Cohort) included in one study (Table 3). ${ }^{20}$ However, another study investigating rs4914 found no association. ${ }^{38}$ All other polymorphisms studied did not show any association with asthma. ${ }^{10,12,20,21,38,40,41,43-45}$ Partial duplication in studied population and studied single nucleotide polymorphisms (SNPs) was present between two studies. $^{20,21}$

In three studies the association between rs2569190 in CD14 and wheeze was addressed..$^{8,46,47}$ The age of the population studied varied from 18 months up to 13 years. One study investigated two additional polymorphisms (rs5744441 and rs5744455). ${ }^{46}$ None of these studies found a relationship between CD14 polymorphisms and childhood wheeze.

Table 2 Quality scoring based on the Newcastle-Ottawa Quality Assessment Scale: Case-control studies.

\begin{tabular}{|c|c|c|c|c|c|c|c|c|c|c|c|}
\hline First author & Year & S1 & $\mathrm{S} 2$ & S3 & S4 & C1a & $\mathrm{C} 1 \mathrm{~b}$ & E1 & E2 & E3 & $\mathrm{OQ}$ \\
\hline Bielit $^{10}$ & 2007 & - & $*$ & $*$ & - & $*$ & $*$ & $*$ & $*$ & $*$ & + \\
\hline Bjornvold $^{38}$ & 2009 & $* /-$ & $*$ & $*$ & $*$ & - & - & NA & NA & - & $+/-$ \\
\hline Choudhry $^{40}$ & 2005 & - & - & $*$ & - & $*$ & $*$ & - & $*$ & - & $+/-$ \\
\hline Daley $^{21}$ & 2009 & - & $* /-$ & $*$ & - & - & - & NA & NA & - & $+/-$ \\
\hline Edert ${ }^{25}$ & 2004 & - & $*$ & $*$ & - & $*$ & $*$ & $*$ & $*$ & - & $+/-$ \\
\hline $\mathrm{Ege}^{22}$ & 2007 & - & $*$ & $*$ & - & $*$ & $*$ & $*$ & $*$ & $*$ & + \\
\hline Fageras Bottchert ${ }^{39}$ & 2004 & $*$ & - & - & - & $*$ & $*$ & $*$ & $*$ & - & $+/-$ \\
\hline Genuneit $^{46}$ & 2009 & - & $*$ & $*$ & $* /-$ & $*$ & - & NA & NA & - & $+/-$ \\
\hline Heinzmann ${ }^{12}$ & 2003 & $*$ & $*$ & $*$ & - & - & - & NA & NA & - & $+/-$ \\
\hline Heinzmann ${ }^{58}$ & 2010 & $*$ & - & $*$ & - & - & - & NA & NA & - & $+1-$ \\
\hline Hoffjan $^{61}$ & 2005 & - & - & - & $*$ & - & - & NA & NA & - & - \\
\hline Hussein $^{59}$ & 2012 & $*$ & $*$ & - & $*$ & - & - & NA & NA & - & $+/-$ \\
\hline Jackola ${ }^{23}$ & 2006 & $*$ & - & $*$ & $*$ & $*$ & - & NA & NA & - & $+/-$ \\
\hline Kabesch ${ }^{13}$ & 2004 & - & $*$ & $*$ & - & - & - & NA & NA & - & $+/-$ \\
\hline Kormann§ ${ }^{27}$ & 2008 & $*$ & $*$ & $*$ & $*$ & $*$ & - & NA & NA & - & + \\
\hline Kurowski ${ }^{44}$ & 2011 & - & - & $*$ & - & - & - & $*$ & $*$ & - & - \\
\hline $\operatorname{Marcos}^{50}$ & 2010 & $*$ & - & - & $*$ & - & - & $*$ & - & - & - \\
\hline Miedema§ ${ }^{45}$ & 2012 & - & - & $*$ & $*$ & - & - & NA & NA & - & $+/-$ \\
\hline Moller-Larsen ${ }^{28}$ & 2008 & $*$ & - & $*$ & $*$ & $*$ & - & NA & NA & - & $+/-$ \\
\hline Perin $^{42}$ & 2011 & $*$ & - & - & $*$ & - & - & NA & NA & - & $+/-$ \\
\hline Puthothu ${ }^{57}$ & 2006 & $*$ & - & $*$ & - & - & - & NA & NA & - & $+/-$ \\
\hline Schubert $^{60}$ & 2006 & $*$ & - & $*$ & - & - & - & NA & NA & - & $+/-$ \\
\hline Sengler $\S^{37}$ & 2003 & - & $*$ & $*$ & $*$ & $*$ & - & NA & NA & - & $+/-$ \\
\hline Snijders ${ }^{52}$ & 2006 & - & $*$ & $*$ & $*$ & $*$ & $*$ & $*$ & $*$ & - & + \\
\hline Sorensen§ ${ }^{47}$ & 2009 & - & $*$ & $*$ & $*$ & $*$ & $*$ & $*$ & $*$ & $*$ & + \\
\hline Tremblay $^{20}$ & 2008 & - & $* /-$ & $*$ & - & - & - & NA & NA & - & $+/-$ \\
\hline Yang $^{55}$ & 2004 & - & - & $*$ & $*$ & $*$ & $*$ & NA & NA & - & $+/-$ \\
\hline Zhang $^{43}$ & 2011 & $*$ & $*$ & $*$ & $*$ & $*$ & $*$ & $*$ & $*$ & - & + \\
\hline
\end{tabular}

S1: Case definition; S2: Representativeness of the cases; S3: Selection of controls; S4: Definition of controls; $\mathrm{C} 1 \mathrm{a} / \mathrm{C} 1 \mathrm{~b}$ Comparability of cases and controls on the basis of the design or analysis; E1: Ascertainment of exposure; E2: Same method of ascertainment for cases and controls; E3: Non-response rate (*: criteria were met; -: criteria were not met); OQ: Overall quality (+: better than average quality, +/- average quality, - less than average quality); + cross-sectional design; $\S$ nested; NA=not applicable. 


\section{The relationship between polymorphisms of $C D 14$ and childhood asthma can be influenced by environmental exposures}

The protective effect of farm milk consumption was increased in carriers of one or, even more so, two major alleles of $\mathrm{rs} 2915863 .^{10}$ Also, in individuals exposed to tobacco smoke, a significant association was found between rs 2569190 and rs3776138 polymorphisms and asthma severity. ${ }^{40}$ Eastern (Russian) or Western (Finnish) environment/lifestyle did not influence the relationship of rs2569190 and rs5744455 on asthma ever in childhood. ${ }^{43}$ Neither did age, breastfeeding, allergies to mold, house dust mites or pollens and exposure to cats and dogs or other large animals in combination with rs5744454, rs2569190 and rs3776138 and asthmarelated traits ${ }_{10}^{40}$ nor dust or living area (rural or urban) with rs2569190 or rs3138078 and asthma. ${ }^{44}$ Finally, a dose-dependent relationship of endotoxin with non-atopic wheeze for individuals with homozygosity of the major allele of rs2569190 was shown. ${ }^{8}$ The association between smoking or pet keeping and the risk of recurrent wheeze was not affected by the rs 2569190 polymorphism. ${ }^{47}$

\section{Polymorphisms in CD14 lead to increased levels of SCD14}

Several studies have shown that SCD14 levels are higher in the presence of one or two minor allele of rs 2569190 in chronic and also acute asthma in children., ${ }^{8,13,19,33}$ In addition, during asthma attacks an inverse correlation was shown between asthma severity scores and the log value of SCD14 for the major allele of rs $2569190 .{ }^{19}$ No significant association was found between rs574441, rs2569193 and rs2569190 and gene expression of $\mathrm{CD} 14 .^{10}$

\section{Higher levels of sCD14 are related to childhood asthma depending on disease status and time of measurement}

Levels of SCD14 in cord blood were significantly higher in children with transient-atopy (positive skin prick test at two years of age but not at five years of age and without asthma), compared with never-atopic or persistent-atopic children. However, no changes between transient-atopy, never-atopic or persistent-atopic children could be shown in plasma SCD14 at six months, one year and five years of age. ${ }^{48}$ Also, levels of SCD14 were significantly higher during acute asthma attacks than at recovery in children with status asthmaticus. ${ }^{32}$ However, these results might be biased by the administration of corticosteroids during the acute stage which might have caused suppression of cell activation, thereby reducing $\mathrm{SCD} 14$ levels in serum. ${ }^{49}$ Multiple studies showed no association of SCD14 levels with asthma as measured in cord blood, serum or bronchoalveolar lavage fluid. ${ }^{23,50,51}$ In one study no association of SCD14 levels in breast milk with wheeze was found. ${ }^{52}$ 


\section{(Expression) levels of (s)CD14 can be related to environmental exposures leading to a different disease risk}

One study showed that of the protective farm related factors that were associated with asthma (pig farming, farm milk consumption, frequent stay in animal sheds and child's involvement in haying), only being a farm child in general was associated with higher expression levels of CD14. ${ }^{22}$ Breastfed children who received breast milk with high sCD14 levels had less chance to develop asthma, reaching statistical significance in children of mothers with no history of atopic disease. ${ }^{53}$ Another study showed that age or gender did not influence SCD14 production in asthmatic families. ${ }^{23}$ CD14 serum levels in infants without recurrent wheezing was significantly higher than in wheezing infants twelve months after hospitalisation due to RSV-induced bronchiolitis. Also, in hospitalised patients SCD14 levels increased with age of admission. ${ }^{54}$ Overall, results suggest that some environmental exposures like a farm child or breast milk with high sCD14 levels protect against development of asthma, however, the number of studies is limited.

\section{Some evidence for a relationship between polymorphisms of TLRS $(2,6,9,10)$ and childhood asthma}

Childhood asthma in relation to polymorphisms in TLRs was addressed in 19 studies. $^{21,25-28,34,38,39,41,43-45,55-61}$ The age of the population in these studies ranged from 0 to 18 years with 31 to 644 cases and 184 to 2927 controls. The outcome was defined as atopic/allergic asthma, non-atopic asthma, bronchial asthma, current asthma symptoms or asthma in general.

TLR4 is by far the most studied of all TLRs in relation to asthma in children, but only some studies showed an association (Table 3). Rs2737195 was statistically more frequent in mild atopic asthmatics, whereas rs 2737190 showed an association with asthma in general and also non-atopic asthma. ${ }^{27}$ Rs4986790 showed no association with asthma in seven studies, ${ }^{43-45,55,56,60}$ but was associated with symptoms of (atopic) asthma in two other studies. ${ }^{34,39}$ Also, rs4986790 was associated with increased asthma severity in atopic children. ${ }^{59}$ However, in most studies polymorphisms of TLR4 did not show any association with asthma. ${ }^{21,25,27,38,41,44,45,55,56,59,60}$ Some duplication between the studies of Reijmerink et al. and Kerkhof et al. was present as the same population was used for SNP analysis. ${ }^{41,56}$ Studied polymorphisms in the study of Reijmerink at al. were not specified. ${ }^{41}$

TLR2, TLR6, TLR9 and TLR10 have been associated with asthma in several studies. For $T L R 2$, rs4696480, rs3804099, rs3804100 and rs1898830 showed an association with childhood asthma in a number of studies, but not in others (Table 3). ${ }^{21,25-27,38,43,56,62}$ Moreover, rs5743708 was associated with increased asthma severity in atopic children (Table 3). ${ }^{59}$ Finally, rs13150331, rs4696483, rs5743704, rs7656411, rs1339, rs2289318 and rs5743708 showed no association with childhood asthma. ${ }^{21,43,59}$ Two 
studies had an overlap in data. ${ }^{26,56}$ For TLR6, rs6531666, rs5743789, rs5743798 and rs5743810 significant associations with asthma and atopic asthma were found, but not with asthma in other studies (Table 3)..$^{21,27,45,57,61}$ Haplotype spanning of polymorphisms in TLR6 and TLR10 (see TLR10) revealed an association with childhood asthma indicating no individual but a combined influence of these polymorphisms on asthma in children. ${ }^{21,57}$ Other TLR6 polymorphisms were not associated with asthma in children. $^{21,27,45}$ For TLR9, rs 187084 showed a positive association with childhood asthma (Table 3), ${ }^{27}$ but not in all studies. ${ }^{21,45}$ Other polymorphisms revealed no association with childhood asthma. ${ }^{21,27,44,45,60,63}$ For TLR10, out of eight studied polymorphisms, rs4129009 and rs11096957 showed association with (atopic) asthma in some studies (Table 3). ${ }^{21,27,45,58}$ The rs11096957 polymorphism only demonstrated association in one of the two children cohorts (Study of Asthma Genetics and Environment Cohort) studied by Daley et al. ${ }^{21}$ Several polymorphisms (rs4274855, rs10856839, rs11096957, rs11096956, rs11096955, rs11466657 and rs4219009) showed no individual association with bronchial asthma, however, haplotype spanning together with polymorphisms in TLR6 (rs5743794 and rs5743810) did. ${ }^{57}$ Also rs4274855, rs10856839, rs11096957 and rs4129009 demonstrated a haplotype-based association. ${ }^{58}$

TLR7 and TLR8 were only studied in two studies and TLR1, TLR3 and TLR5 in one study: For TLR7, associations with asthma phenotypes for rs179008, rs5743781 and rs864058 haplotypes were observed in one study, however, rs179008 showed no association in another study (Table 3). ${ }^{27,28}$ For TLR8, association with asthma phenotype in childhood was shown for rs5741883, rs3764879, rs3764880, rs5744077, rs2159377 and rs2407992 haplotypes, but not rs3761624 (Table 3). ${ }^{27,28}$ For TLR1, rs5743595, rs4833095 and not rs5743594 showed significant inverse effects with atopic asthma in childhood (Table 3). ${ }^{27}$ For TLR3, rs3775291 showed no association with childhood asthma. ${ }^{27}$ Also, rs5744168, rs2072493 and rs5744174 of TLR5 showed no significant association with childhood asthma. ${ }^{27}$

One study with 1105 cases and 3137 controls aged 8 to 12 years used wheeze in the past 12 months as outcome variable. ${ }^{46}$ For TLR4, rs11536896 showed an association, but three other polymorphisms did not. In TLR2, rs1898830 showed an association with more frequent wheeze. For TLR9, out of the three studied polymorphisms, rs187084 showed a positive association with wheeze.

\section{The relationship between polymorphisms of TLRs and childhood asthma is dependent on environmental influences}

Four studies addressed the relationship between TLR polymorphisms and environmental exposure on childhood asthma. ${ }^{25,43,44,56}$ The polymorphisms rs4696480 and rs1898830 in TLR2 and polymorphisms rs2770150, rs10759931, rs6478317, rs10759932 and rs1927911 in TLR4 increased the effect of fine particulate matter 
exposure on the prevalence of doctor-diagnosed asthma from birth up to eight years of age. Polymorphism rs10759931 in TLR4 showed an interaction between childhood asthma symptoms and air pollutant levels. ${ }^{56}$ High or low endotoxin exposure revealed no interaction with rs4696480, rs3804099 and rs3804100 for asthma diagnosis or current asthma symptoms in children. ${ }^{25}$ There was no relationship between TLR2 rs5743708 or TLR4 rs4986790 on asthma ever when Eastern or Western environment was taken into account. ${ }^{43}$ A relationship neither existed for TLR4 rs4986790 or TLR9 rs352140 with asthma when dust or area (rural/urban) was taken into account. ${ }^{44}$ Also, for polymorphism rs4696480 in TLR2, a significant interaction was shown with day care attendance on the development of atopic wheeze in a longitudinal analysis from birth until the age of five years. ${ }^{62}$

Table 3 Single nucleotide polymorphisms in association with asthma.

\begin{tabular}{|c|c|c|c|c|c|c|}
\hline Gene & rs-number & alleles & $\begin{array}{l}\text { Number of } \\
\text { associations }\end{array}$ & $\begin{array}{l}\text { Minor allele related } \\
\text { to }\end{array}$ & $\begin{array}{l}\text { Association } \\
\text { ref. }\end{array}$ & $\begin{array}{l}\text { No association } \\
\text { ref. }\end{array}$ \\
\hline$C D 14$ & rs2569190 & $\mathrm{C}>\mathrm{T}$ & $\begin{array}{l}1 \text { out of } 16 \\
\text { (duplication }^{20,21} \text { ) }\end{array}$ & $\begin{array}{l}\text { decreased asthma } \\
\text { severity }\end{array}$ & 19 & $10,12,13,20,21,34,36-45$ \\
\hline$C D 14$ & rs4914 & $\mathrm{G}>\mathrm{C}$ & $\begin{array}{l}1 \text { out of } 2 \\
\text { (duplication }^{20,21} \text { ) }\end{array}$ & $\begin{array}{l}\text { decreased asthma } \\
\text { incidence }\end{array}$ & 20,21 & 38 \\
\hline TLR1 & rs5743595 & $\mathrm{T}>\mathrm{C}$ & 1 out of 1 & atopic asthma & 27 & NA \\
\hline TLR1 & rs4833095 & $A>G$ & 1 out of 1 & atopic asthma & 27 & NA \\
\hline TLR2 & rs4696480 & $A>T$ & $\begin{array}{l}3 \text { out of } 5 \text { (partial } \\
\text { duplication }{ }^{26,56} \text { ) }\end{array}$ & $\begin{array}{l}\text { asthma/current } \\
\text { asthma symptoms }\end{array}$ & $25,26,56$ & 27,45 \\
\hline TLR2 & rs3804099 & $\mathrm{T}>\mathrm{C}$ & $\begin{array}{l}1 \text { out of } 5 \text { (partial } \\
\text { duplication }{ }^{26,56} \text { ) }\end{array}$ & $\begin{array}{l}\text { non-atopic asthma } \\
\text { (inverse) }\end{array}$ & 27 & $25,26,38,45,56$ \\
\hline TLR2 & rs3804100 & $\mathrm{T}>\mathrm{C}$ & $\begin{array}{l}1 \text { out of } 6 \text { (partial } \\
\text { duplication }{ }^{26,56} \text { ) }\end{array}$ & $\begin{array}{l}\text { allergic asthma } \\
\text { (inverse) }\end{array}$ & 38 & $21,25,26,45,56$ \\
\hline TLR2 & rs1898830 & $A>G$ & 1 out of 4 & asthma & 26 & $21,27,56$ \\
\hline TLR2 & rs5743708 & $G>A$ & 1 out of 2 & $\begin{array}{l}\text { asthma severity in } \\
\text { atopic children }\end{array}$ & 59 & 43 \\
\hline TLR4 & rs2737190 & $A>G$ & 1 out of 1 & (non-atopic) asthma & 27 & NA \\
\hline TLR4 & rs4986790 & $A>G$ & 3 out of 10 & $\begin{array}{l}\text { asthma, atopic } \\
\text { asthma and asthma } \\
\text { severity in atopic } \\
\text { children }\end{array}$ & $34,39,59$ & $43-45,55$ \\
\hline TLR4 & rs4986791 & $\mathrm{C}>\mathrm{T}$ & 1 out of 4 & mild atopic asthma & 34 & $27,56,60$ \\
\hline TLR6 & rs6531666 & $\mathrm{T}>\mathrm{C}$ & 1 out of 1 & asthma & 45 & NA \\
\hline TLR6 & rs5743789 & $\mathrm{T}>\mathrm{A}$ & 1 out of 1 & atopic asthma & 27 & NA \\
\hline TLR6 & rs5743798 & $C>T$ & 1 out of 1 & asthma & 45 & NA \\
\hline TLR6 & rs5743810 & $C>T$ & 2 out of 5 & (atopic) asthma & 27,61 & $21,45,57$ \\
\hline TLR7 & rs179008 & $A>T$ & 1 out of 2 & asthma & 28 & 27 \\
\hline TLR8 & rs2407992 & $\mathrm{G}>\mathrm{C}$ & 1 out of 1 & asthma & 28 & NA \\
\hline TLR9 & rs187084 & $\mathrm{T}>\mathrm{C}$ & 1 out of 3 & asthma & 27 & 21,45 \\
\hline TLR10 & rs4129009 & $A>G$ & 1 out of 2 & atopic asthma inverse & 27 & 45 \\
\hline TLR10 & rs11096957 & $A>C$ & 1 out of 3 & asthma & 21 & 45,57 \\
\hline
\end{tabular}

Ref: reference, TLR: toll-Like Receptor, NA: not applicable 


\section{Polymorphisms in TLRs relate to an increased gene expression of TLRS}

Minor alleles of TLR1 rs5743595, TLR6 rs5743789 and TLR10 rs4129009 polymorphisms were associated with increased mRNA expression of the respective TLRs in children. ${ }^{27}$ In asthmatic children, farm related factors in combination with TLR polymorphisms were related to higher expression levels of respective TLRs in children. $^{22}$

\section{Discussion}

We reviewed the literature on the relationship between CD14 and TLRs (polymorphisms) and asthma in Caucasian children. Although a number of studies suggest such a relationship, the reviewed literature does not provide convincing evidence for a significant direct role of CD14. TLR2, TLR6, TLR9 and TLR10 did show moderate association with asthma in childhood, but TLR4 did not.

CD14 rs2569190 may be exemplary for the relevance of polymorphisms in relation to asthma. This polymorphism has been analysed in two meta-analysis. ${ }^{64,65}$ No significant overall association was detected between rs2569190 and asthma. However, when analysis was stratified by atopy, there was an association indicating a protective effect of the T-allele of rs2569190 in relationship to atopic asthma. ${ }^{65}$ This was also the case when the analysis was stratified by atopy and restricted to children. ${ }^{64}$ However, these results should be interpreted with caution because of the exclusion of studies and the small sample sizes. Also, as the current review was restricted to Caucasian children, comparison is difficult. The lack of similarity in the set-up and populations of these studies makes deduction of conclusions difficult, even more so if the complexity of the disease is taken in account.

Although some TLRs showed associations with asthma in childhood, the most investigated TLR4 did not. A possible explanation is that TLR4, contrary to TLR2, TLR6, TLR9 and TLR10, mainly plays a role in immune response to gram-negative bacteria. ${ }^{25,61}$ As the other TLRs are involved in the immune response to multiple microbial products, it can be expected that their role in heterogeneous symptoms and/or diseases is easier to establish than TLR4. ${ }^{25,27,56,61}$

Since CD14 and TLRs are the first mediators in the response of the innate immune system, it is plausible that their contribution to asthma development is influenced by environmental conditions. An increasing number of association studies have included such conditions. However, up to now, the evidence for an interplay between environment and polymorphisms of the mentioned genes is scanty and based on few observations only. If important environmental factors are not included, associations might be overlooked or misinterpreted. For example, it has been demonstrated that the direction of the relationship between a CD14 polymorphism and asthma was 
dependent on endotoxin exposure. ${ }^{8}$ Also interesting is the fact that SCD14 in serum seems to be increased at specific time points, which might indicate a time window at which children are more vulnerable for exposure. ${ }^{54}$ Consequently, increasing the number of populations studied, without inclusion of environmental influences, will not guarantee more valid results. Indeed, one may argue that studies not taking environmental influences into account underestimate the complexity of the disease.

Another important development in recent years is the focus on haplotype analysis instead of individual polymorphisms. ${ }^{66-68}$ It has been shown that the combined analysis of several polymorphisms by haplotypes increases the power to detect associations. In this review, two studies clearly show the strength of this approach, since in these studies individual polymorphisms did not provide an association, whereas haplotype spanning did. ${ }^{57,58}$ Consequently, our insight into the role of CD14 and TLRs in relationship to asthma would benefit from haplotype analysis. Application of this method will not demand a major investment since previous collected study populations can be reused.

Our review has several strengths. Firstly, by systematic evaluation of the available literature, our review provides an efficient and comprehensive summary of CD14 and $T L R$ polymorphisms in relation to childhood asthma. Secondly, to increase the number of articles included, we choose to include studies with various outcome measures of asthma. Thirdly, independent searching and scoring of articles was performed to come to a balanced opinion. Also, no articles were rejected based on assigned score, as there is no general agreement on evaluation of observational studies. ${ }^{69}$ Fourthly, we decided to focus on asthma as outcome measure as it is a more established entity than for example wheeze. While some studies only used parent reported diagnosis, other studies used more objective methods like doctor-diagnosis and lung function. ${ }^{10,12,23,36,38,56}$ However, as wheeze is a good predictor in older age for presence of asthma we included studies with outcome wheeze in our review as well. Though, we did separate the used definitions as the underlying mechanisms can differ. Finally, contrary to most reviews, the population included is restricted to Caucasian children.

Some limitations need to be mentioned. Firstly, the number of articles on this subject is limited. Secondly, the wide scatter in age within and between studies may lead to difficulties in interpretation of results due to such factors as behaviour and environment. Thirdly, as is the case for most reviews, the comparability between the studies was diminished by methodological differences between the studies. 


\section{Conclusions}

All studies taken together, no clear role for CD14 and TLRs on childhood asthma can be determined based on this review. This is probably due to unknown underlying confounding or mediating environmental factors. Another reason can be the fact that analysis has mostly been performed on individual polymorphisms instead of haplotype spanning. Therefore, planning future studies should include haplotype analysis and take environmental factors into account. Also, to be able to identify and confirm associations and gene-gene and gene-environmental interactions with sufficient power, large populations will be necessary. If the above mentioned suggestions are taken into consideration, future studies on the role of CD14 and TLRs in childhood asthma may be more successful. 


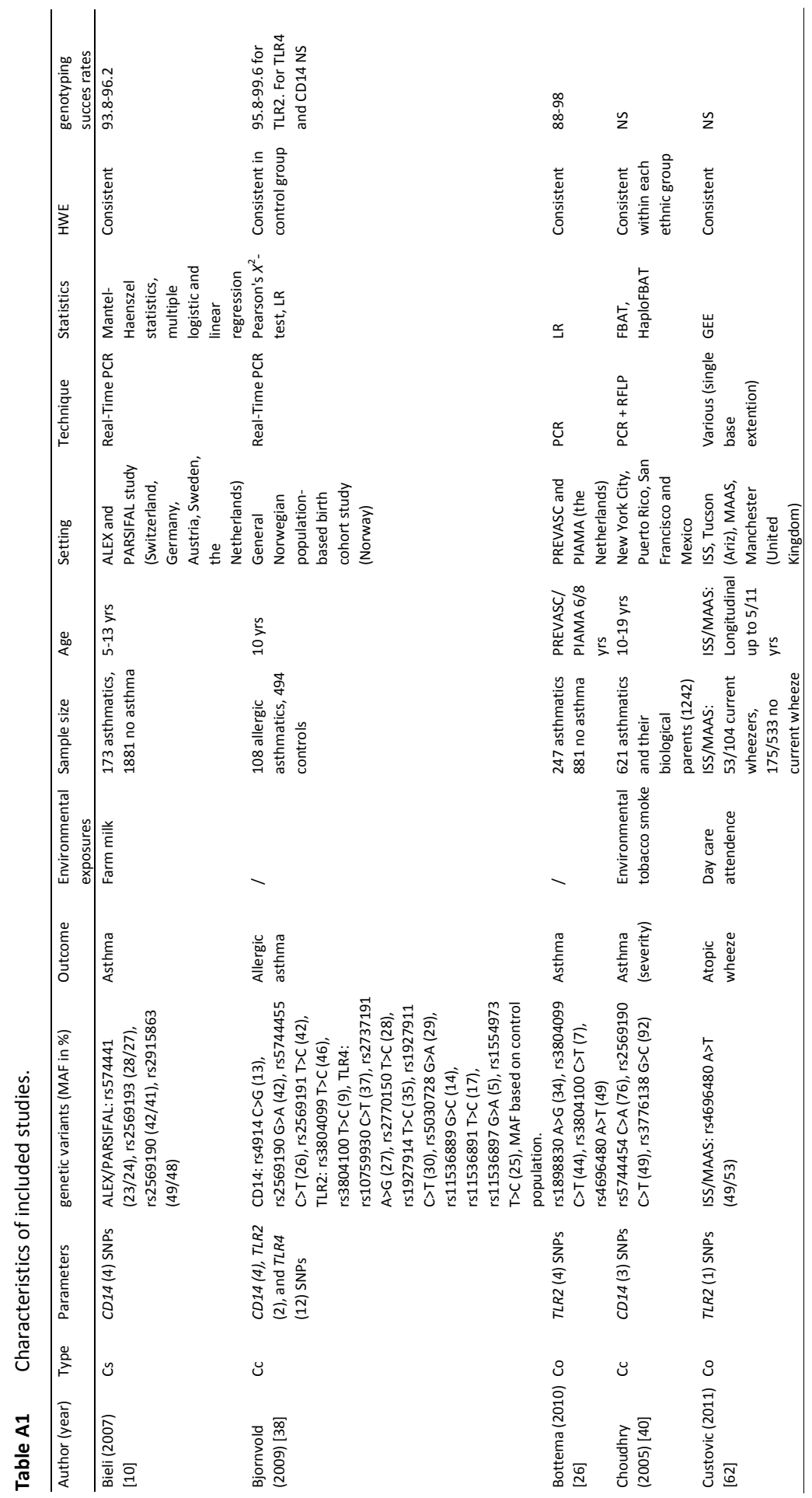




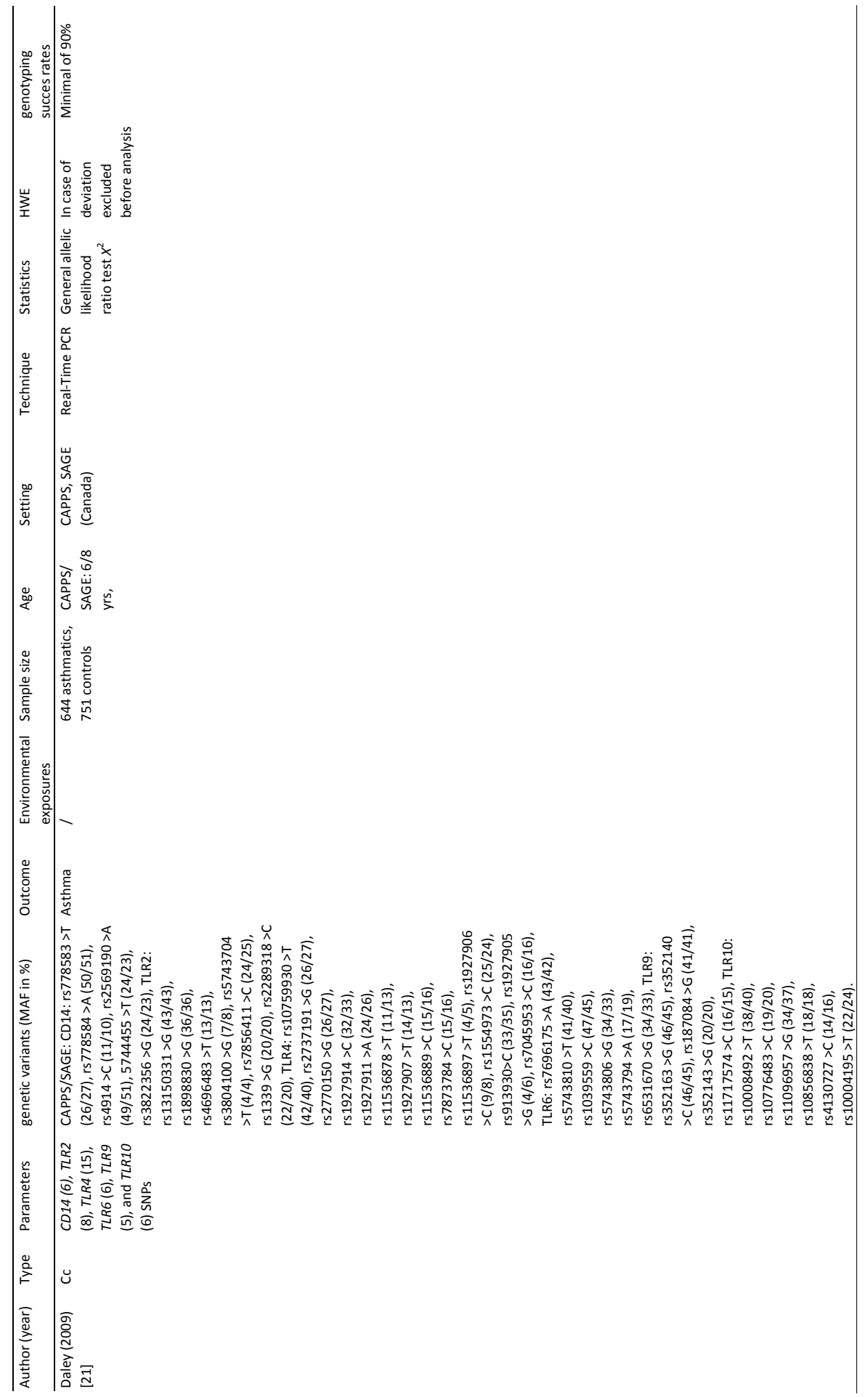




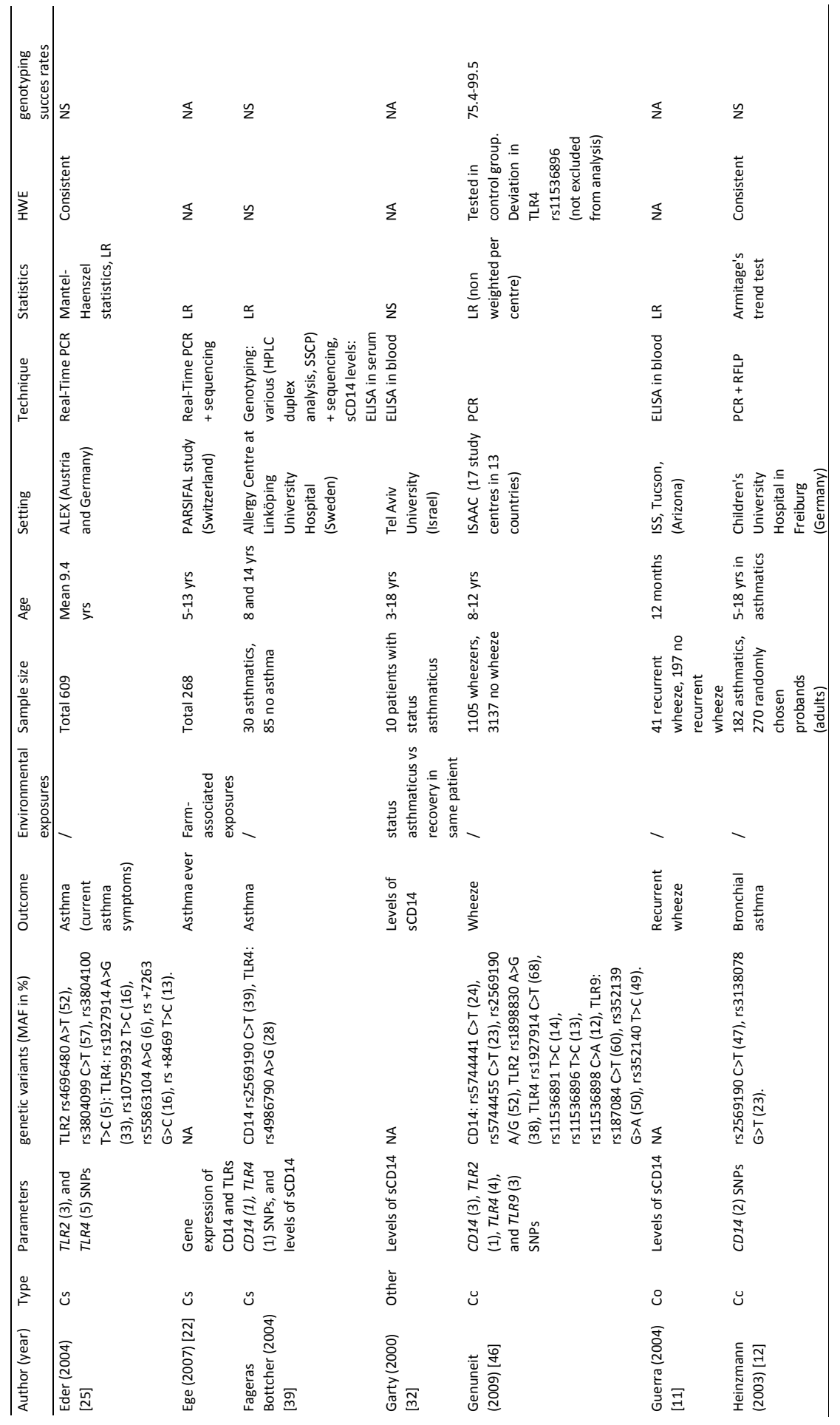




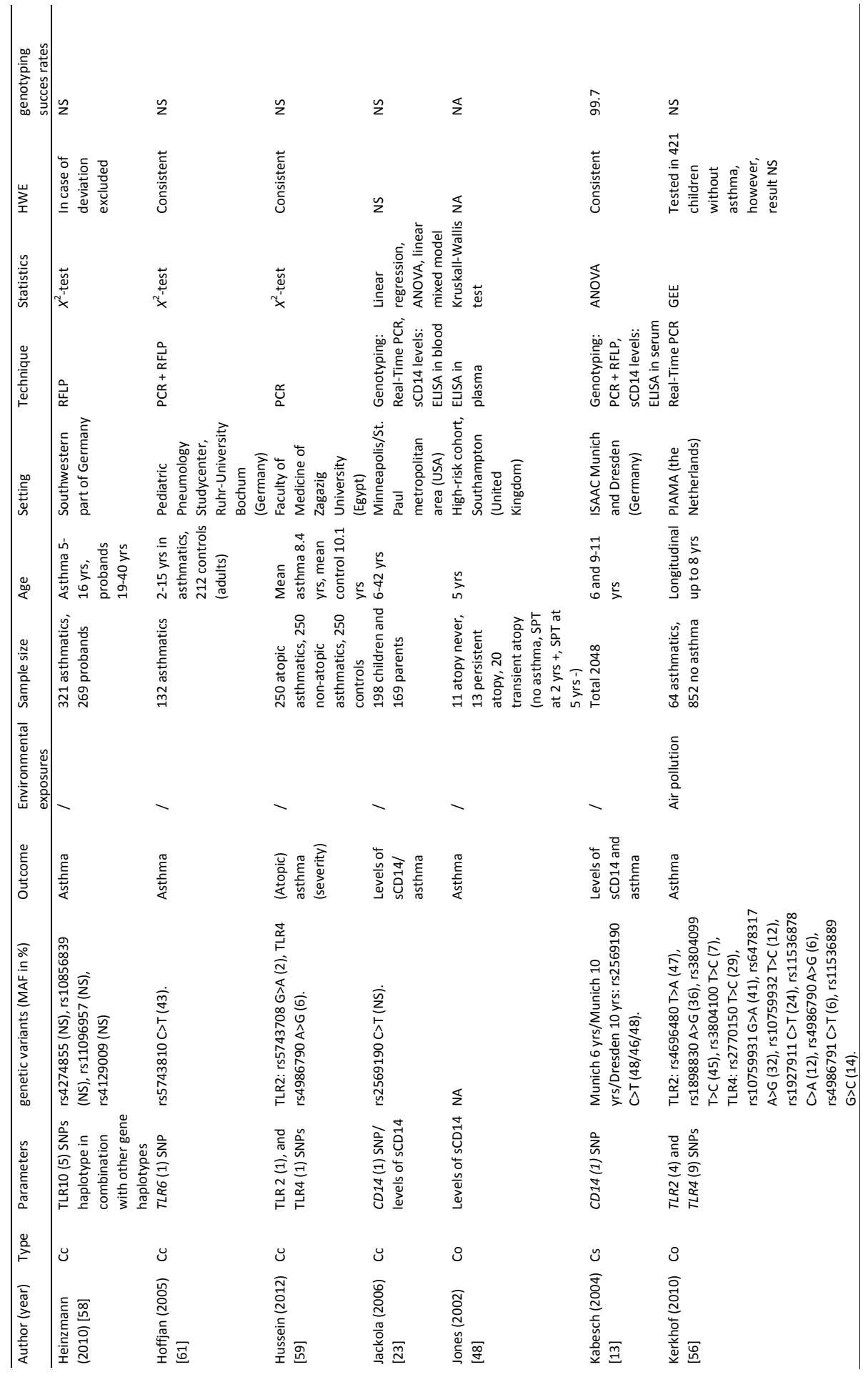




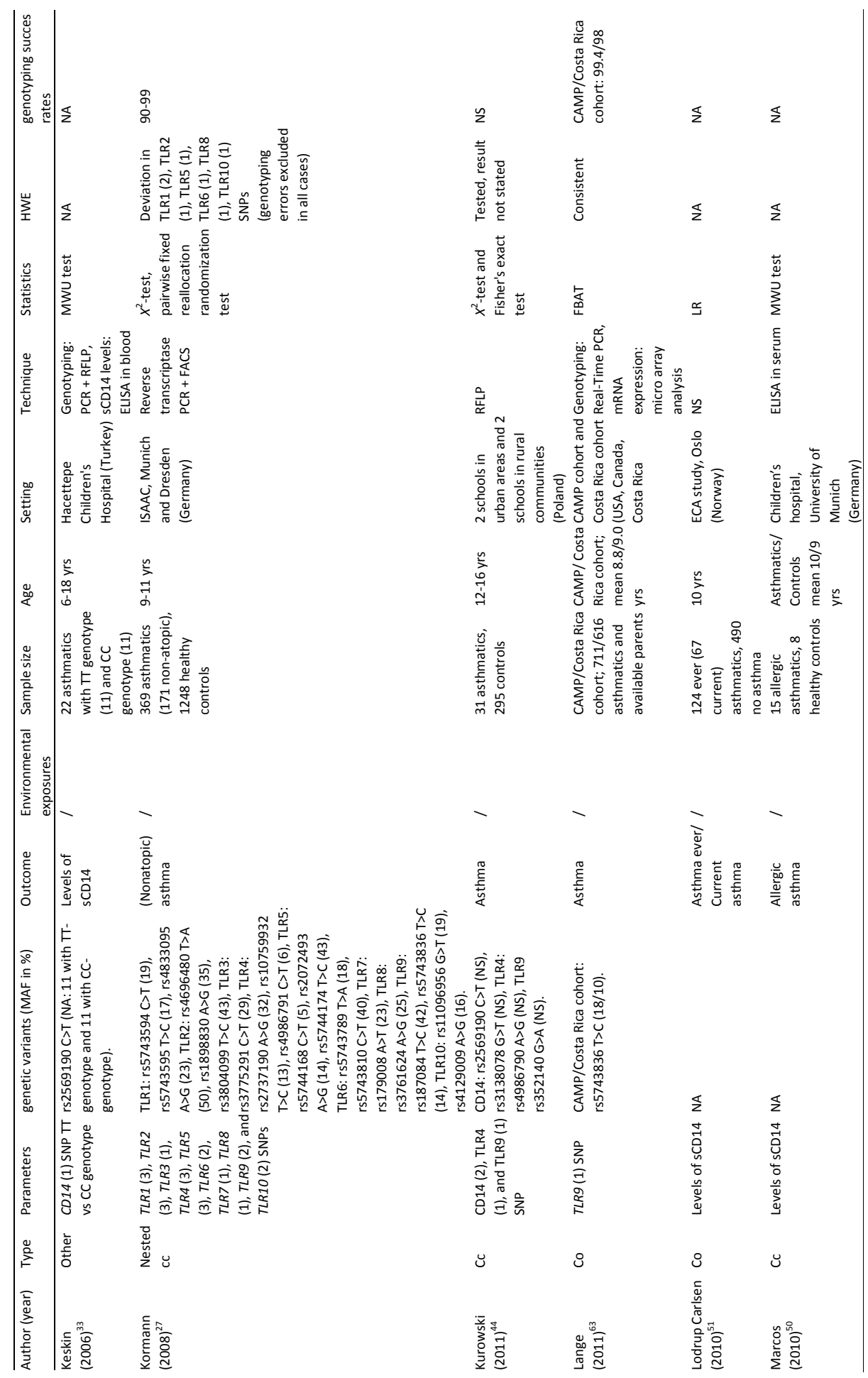




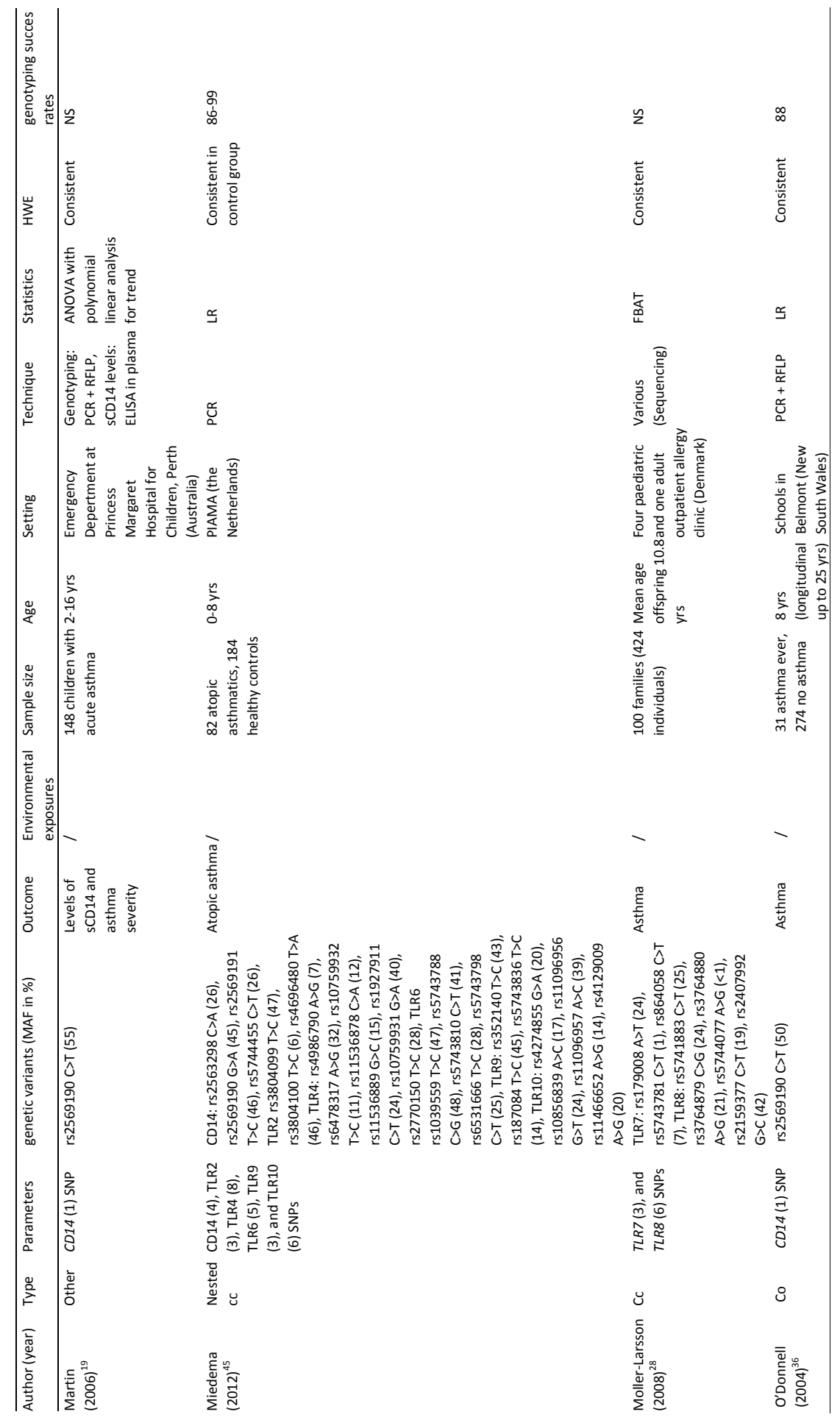




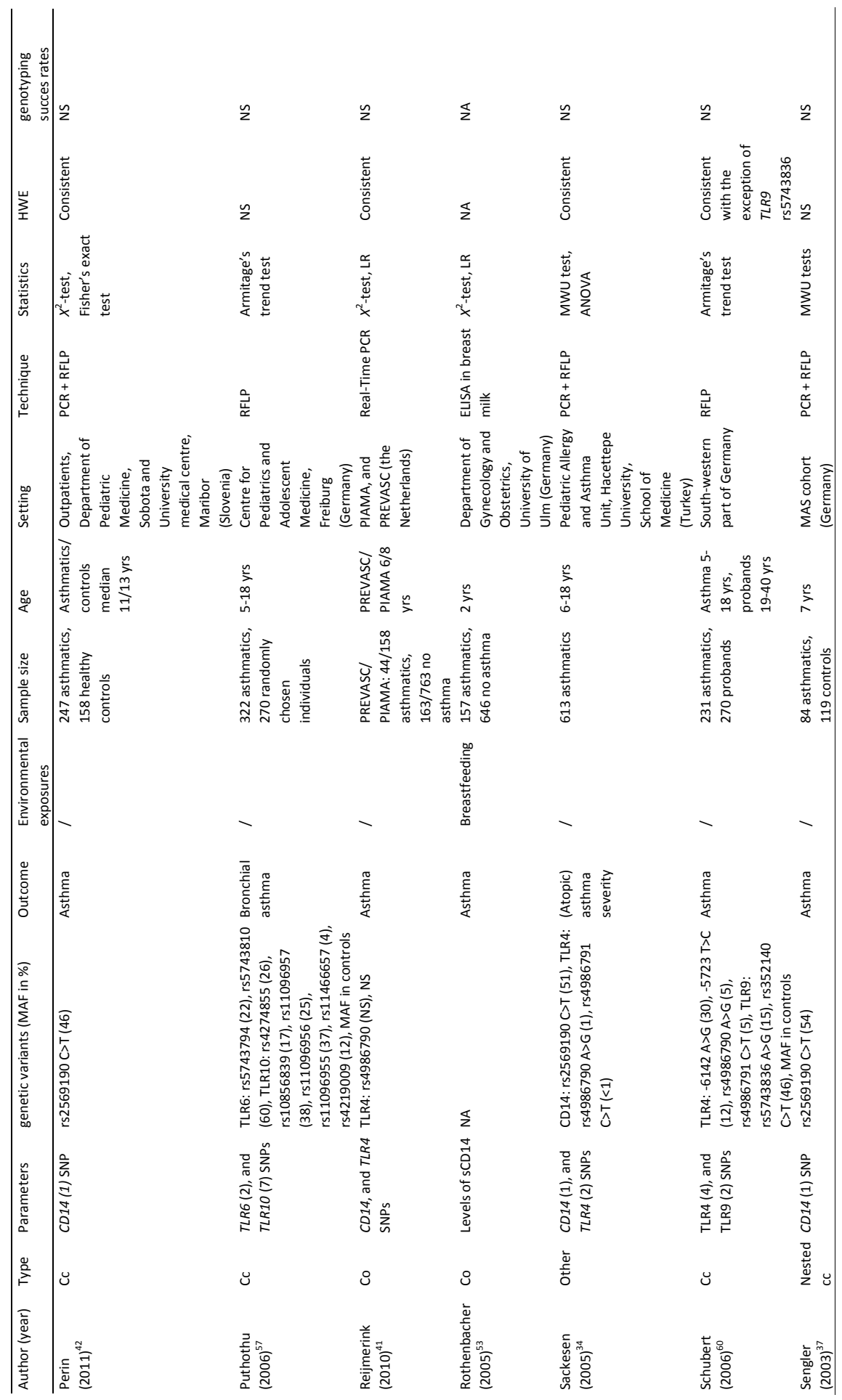




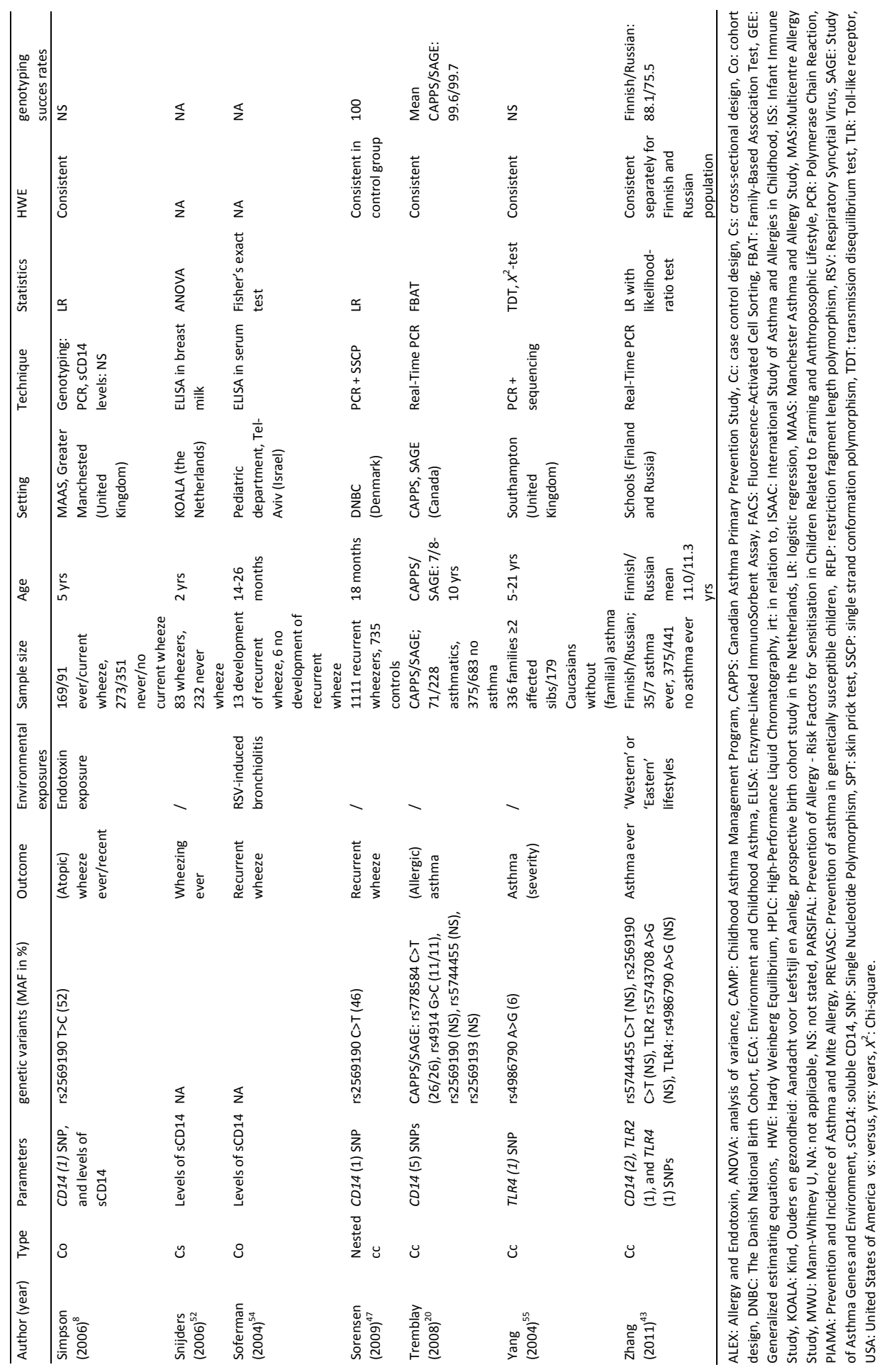




\section{References}

1. Masoli M, Fabian D, Holt S, Beasley R: The global burden of asthma: executive summary of the GINA Dissemination Committee report. Allergy 2004:59:469-78.

2. Le Souef PN: Gene-environmental interaction in the development of atopic asthma: new developments. Curr Opin Allergy Clin Immunol 2009;9:123-7.

3. Bartlett NW, McLean GR, Chang YS, Johnston SL: Genetics and epidemiology: asthma and infection. Curr Opin Allergy Clin Immunol 2009;9:395-400.

4. Prescott SL: Effects of early cigarette smoke exposure on early immune development and respiratory disease. Paediatr Respir Rev 2008;9:3-9.

5. Pinto LA, Stein RT, Kabesch M: Impact of genetics in childhood asthma. J Pediatr (Rio J) 2008;84: S68-75.

6. Thomsen SF, van der Sluis S, Kyvik KO, Skytthe A, Skadhauge LR, Backer V: Increase in the heritability of asthma from 1994 to 2003 among adolescent twins. Respir Med 2011;105:1147-52.

7. Halfhide C, Smyth RL: Innate immune response and bronchiolitis and preschool recurrent wheeze. Paediatr Respir Rev 2008;9:251-62.

8. Simpson A, John SL, Jury F, Niven R, Woodcock A, Ollier WE, Custovic A: Endotoxin exposure, CD14, and allergic disease: an interaction between genes and the environment. Am J Respir Crit Care Med 2006;174:386-92.

9. Cook DN, Pisetsky DS, Schwartz DA: Toll-like receptors in the pathogenesis of human disease. Nat Immunol 2004;5:975-9.

10. Bieli C, Eder W, Frei R, Braun-Fahrlander C, Klimecki W, Waser M, Riedler J, von Mutius E, Scheynius A, Pershagen $G$, et al: A polymorphism in CD14 modifies the effect of farm milk consumption on allergic diseases and CD14 gene expression. J Allergy Clin Immunol 2007;120:1308-15.

11. Guerra S, Lohman IC, Halonen M, Martinez FD, Wright AL: Reduced interferon gamma production and soluble CD14 levels in early life predict recurrent wheezing by 1 year of age. Am J Respir Crit Care Med 2004;169:70-6.

12. Heinzmann A, Dietrich H, Jerkic SP, Kurz T, Deichmann KA: Promoter polymorphisms of the CD14 gene are not associated with bronchial asthma in Caucasian children. Eur J Immunogenet 2003;30:345-8.

13. Kabesch M, Hasemann K, Schickinger V, Tzotcheva I, Bohnert A, Carr D, Baldini M, Hackstein H, Leupold W, Weiland SK, et al: A promoter polymorphism in the CD14 gene is associated with elevated levels of soluble CD14 but not with IgE or atopic diseases. Allergy 2004;59:520-5.

14. Holt PG, Sly PD, Bjorksten B: Atopic versus infectious diseases in childhood: a question of balance? Pediatr Allergy Immunol 1997;8:53-8.

15. Baldini M, Lohman IC, Halonen M, Erickson RP, Holt PG, Martinez FD: A Polymorphism* in the 5' flanking region of the CD14 gene is associated with circulating soluble CD14 levels and with total serum immunoglobulin E. Am J Respir Cell Mol Biol 1999;20:976-83.

16. Vercelli D, Baldini M, Stern D, Lohman IC, Halonen M, Martinez F: CD14: a bridge between innate immunity and adaptive IgE responses. J Endotoxin Res 2001;7:45-8.

17. Haziot A, Chen S, Ferrero E, Low MG, Silber R, Goyert SM: The monocyte differentiation antigen, CD14, is anchored to the cell membrane by a phosphatidylinositol linkage. J Immunol 1988;141: 547-52.

18. Ulevitch RJ, Tobias PS: Receptor-dependent mechanisms of cell stimulation by bacterial endotoxin. Annu Rev Immunol 1995;13:437-57.

19. Martin AC, Laing IA, Khoo SK, Zhang G, Rueter K, Teoh L, Taheri S, Hayden CM, Geelhoed GC, Goldblatt J, LeSouef PN: Acute asthma in children: Relationships among CD14 and CC16 genotypes, plasma levels, and severity. Am J Respir Crit Care Med 2006;173:617-22.

20. Tremblay K, Daley D, Chamberland A, Lemire M, Montpetit A, Laviolette M, Musk AW, James AL, Chan-Yeung $M$, Becker $A$, et al: Genetic variation in immune signaling genes differentially expressed in asthmatic lung tissues. J Allergy Clin Immunol 2008;122:529-36 e17. 
21. Daley D, Lemire M, Akhabir L, Chan-Yeung M, Qing He J, McDonald T, Sandford AJ, Stefanowicz D, Tripp B, Zamar D, et al: Analyses of associations with asthma in four asthma population samples from Canada and Austrialia. Hum Genet 2009;125:445-59.

22. Ege MJ, Frei R, Bieli C, Schram-Bijkerk D, Waser M, Benz MR, Weiss G, Nyberg F, van Hage M, Pershagen $G$, et al: Not all farming environments protect against the development of asthma and wheeze in children. J Allergy Clin Immunol 2007;119:1140-7.

23. Jackola DR, Basu S, Liebeler CL, Willaert R, Luah SS, Oetting W, King RA, Blumenthal MN: CD14 promoter polymorphisms in atopic families: implications for modulated allergen-specific immunoglobulin E and G1 responses. Int Arch Allergy Immunol 2006;139:217-24.

24. Imler JL, Hoffmann JA: Toll receptors in innate immunity. Trends Cell Biol 2001;11:304-11.

25. Eder W, Klimecki W, Yu L, von Mutius E, Riedler J, Braun-Fahrlander C, Nowak D, Martinez FD: Toll-like receptor 2 as a major gene for asthma in children of European farmers. J Allergy Clin Immunol 2004; 113:482-8.

26. Bottema RW, Kerkhof M, Reijmerink NE, Thijs C, Smit HA, van Schayck CP, Brunekreef B, van Oosterhout AJ, Postma DS, Koppelman GH: Gene-gene interaction in regulatory T-cell function in atopy and asthma development in childhood. J Allergy Clin Immunol 2010;126:338-46,346 e331-310.

27. Kormann MS, Depner M, Hartl D, Klopp N, Illig T, Adamski J, Vogelberg C, Weiland SK, von Mutius E, Kabesch M: Toll-like receptor heterodimer variants protect from childhood asthma. J Allergy Clin Immunol 2008;122:86-92, 92 e81-8.

28. Moller-Larsen S, Nyegaard M, Haagerup A, Vestbo J, Kruse TA, Borglum AD: Association analysis identifies TLR7 and TLR8 as novel risk genes in asthma and related disorders. Thorax 2008;63:1064-9.

29. Zhang G, Goldblatt J, LeSouef PN: Does the relationship between IgE and the CD14 gene depend on ethnicity? Allergy 2008;63:1411-7.

30. Moher D, Liberati A, Tetzlaff J, Altman DG: Preferred reporting items for systematic reviews and meta-analyses: the PRISMA statement. J Clin Epidemiol 2009;62:1006-12.

31. Wells GA, Shea B, O'Connell D, Peterson J, Welch V, Losos M, Tugwell P: Quality assessment scales for observational studies. Ottowa Health Research Institute 2004.

32. Garty BZ, Monselise Y, Nitzan M: Soluble CD14 in children with status asthmaticus. Isr Med Assoc J 2000;2:104-7.

33. Keskin O, Birben E, Sackesen C, Soyer OU, Alyamac E, Karaaslan C, Tokol N, Ercan H, Kalayci O: The effect of CD14-c159T genotypes on the cytokine response to endotoxin by peripheral blood mononuclear cells from asthmatic children. Ann Allergy Asthma Immunol 2006;97:321-8.

34. Sackesen C, Karaaslan C, Keskin O, Tokol N, Tahan F, Civelek E, Soyer OU, Adalioglu G, Tuncer A, Birben $E$, et al: The effect of polymorphisms at the CD14 promoter and the TLR4 gene on asthma phenotypes in Turkish children with asthma. Allergy 2005;60:1485-92.

35. Lis G, Kostyk E, Sanak M, Pietrzyk JJ: [Molecular studies in a population of children with bronchial asthma. I. Polymorphism in the promotor region of gene CD14]. Pneumonol Alergol Pol 2001;69: 265-72.

36. O'Donnell AR, Toelle BG, Marks GB, Hayden CM, Laing IA, Peat JK, Goldblatt J, Le Souef PN: Agespecific relationship between CD14 and atopy in a cohort assessed from age 8 to 25 years. Am J Respir Crit Care Med 2004;169:615-22.

37. Sengler C, Haider A, Sommerfeld C, Lau S, Baldini M, Martinez F, Wahn U, Nickel R: Evaluation of the CD14 C-159 T polymorphism in the German Multicenter Allergy Study cohort. Clin Exp Allergy 2003; 33:166-9.

38. Bjornvold M, Munthe-Kaas MC, Egeland T, Joner G, Dahl-Jorgensen K, Njolstad PR, Akselsen HE, Gervin K, Carlsen KC, Carlsen KH, Undlien DE: A TLR2 polymorphism is associated with type 1 diabetes and allergic asthma. Genes Immun 2009;10:181-7.

39. Fageras Bottcher $M$, Hmani-Aifa $M$, Lindstrom A, Jenmalm MC, Mai XM, Nilsson L, Zdolsek HA, Bjorksten B, Soderkvist P, Vaarala O: A TLR4 polymorphism is associated with asthma and reduced lipopolysaccharide-induced interleukin-12(p70) responses in Swedish children. J Allergy Clin Immunol 2004;114:561-7. 
40. Choudhry S, Avila PC, Nazario S, Ung N, Kho J, Rodriguez-Santana JR, Casal J, Tsai HJ, Torres A, Ziv E, et al: CD14 tobacco gene-environment interaction modifies asthma severity and immunoglobulin $E$ levels in Latinos with asthma. Am J Respir Crit Care Med 2005;172:173-82.

41. Reijmerink NE, Bottema RW, Kerkhof M, Gerritsen J, Stelma FF, Thijs C, van Schayck CP, Smit HA, Brunekreef B, Koppelman GH, Postma DS: TLR-related pathway analysis: novel gene-gene interactions in the development of asthma and atopy. Allergy 2009;65:199-207.

42. Perin P, Berce V, Potocnik U: CD14 gene polymorphism is not associated with asthma but rather with bronchial obstruction and hyperreactivity in Slovenian children with non-atopic asthma. Respir Med 2011;105 Suppl 1:S54-9.

43. Zhang G, Candelaria P, Makela JM, Khoo SK, Hayden MC, von Hertzen L, Laatikainen T, Vartiainen E, Goldblatt J, Haahtela T, LeSouef NP: Disparity of innate immunity-related gene effects on asthma and allergy on Karelia. Pediatr Allergy Immunol 2011;22:621-30.

44. Kurowski M, Majkowska-Wojciechowska B, Wardzynska A, Kowalski ML: Associations of allergic sensitization and clinical phenotypes with innate immune response genes polymorphisms are modified by house dust mite allergen exposure. Arch Med Sci 2011;7:1029-36.

45. Miedema KG, Tissing WJ, Te Poele EM, Kamps WA, Alizadeh BZ, Kerkhof M, de Jongste JC, Smit HA, de Pagter AP, Bierings $M$, et al: Polymorphisms in the TLR6 gene associated with the inverse association between childhood acute lymphoblastic leukemia and atopic disease. Leukemia 2012;26:1203-10.

46. Genuneit J, Cantelmo JL, Weinmayr G, Wong GW, Cooper PJ, Riikjarv MA, Gotua M, Kabesch M, von Mutius $E$, Forastiere $F$, et al: A multi-centre study of candidate genes for wheeze and allergy: the International Study of Asthma and Allergies in Childhood Phase 2. Clin Exp Allergy 2009;39:1875-88.

47. Sorensen M, Allermann L, Vogel U, Andersen PS, Jespersgaard C, Loft S, Raaschou-Nielsen O: Polymorphisms in inflammation genes, tobacco smoke and furred pets and wheeze in children. Pediatr Allergy Immunol 2009;20:614-23.

48. Jones CA, Holloway JA, Popplewell EJ, Diaper ND, Holloway JW, Vance GH, Warner JA, Warner JO: Reduced soluble CD14 levels in amniotic fluid and breast milk are associated with the subsequent development of atopy, eczema, or both. J Allergy Clin Immunol 2002;109:858-66.

49. Djukanovic R, Roche WR, Wilson JW, Beasley CR, Twentyman OP, Howarth RH, Holgate ST: Mucosal inflammation in asthma. Am Rev Respir Dis 1990;142:434-57.

50. Marcos V, Latzin P, Hector A, Sonanini S, Hoffmann F, Lacher M, Koller B, Bufler P, Nicolai T, Hartl D, Griese $M$ : Expression, regulation and clinical significance of soluble and membrane CD14 receptors in pediatric inflammatory lung diseases. Respir Res 2010;11:32.

51. Lødrup Carlsen KC, Mowinckel K, Granum B, Carlsen KH: Can childhood asthma be predicted at birth? Clin Exp Allergy 2010;40:1767-75.

52. Snijders BE, Damoiseaux JG, Penders J, Kummeling I, Stelma FF, van Ree R, van den Brandt PA, Thijs C: Cytokines and soluble CD14 in breast milk in relation with atopic manifestations in mother and infant (KOALA Study). Clin Exp Allergy 2006;36:1609-15.

53. Rothenbacher D, Weyermann M, Beermann C, Brenner H: Breastfeeding, soluble CD14 concentration in breast milk and risk of atopic dermatitis and asthma in early childhood: birth cohort study. Clin Exp Allergy 2005;35:1014-21.

54. Soferman R, Bar-Zohar D, Jurgenson U, Fireman E: Soluble CD14 as a predictor of subsequent development of recurrent wheezing in hospitalized young children with respiratory syncytial virusinduced bronchiolitis. Ann Allergy Asthma Immunol 2004;92:545-8.

55. Yang IA, Barton SJ, Rorke S, Cakebread JA, Keith TP, Clough JB, Holgate ST, Holloway JW: Toll-like receptor 4 polymorphism and severity of atopy in asthmatics. Genes Immun 2004;5:41-5.

56. Kerkhof M, Postma DS, Brunekreef B, Reijmerink NE, Wijga AH, de Jongste JC, Gehring U, Koppelman $\mathrm{GH}$ : Toll-like receptor 2 and 4 genes influence susceptibility to adverse effects of traffic-related air pollution on childhood asthma. Thorax 2010;65:690-7.

57. Puthothu B, Heinzmann A: Is toll-like receptor 6 or toll-like receptor 10 involved in asthma genetics-or both? Allergy 2006;61:649-50.

58. Heinzmann A, Brugger M, Bierbaum S, Mailaparambil B, Kopp MV, Strauch K: Joint influences of Acidic-Mammalian-Chitinase with Interleukin-4 and Toll-like receptor-10 with Interleukin-13 in the genetics of asthma. Pediatr Allergy Immunol 2010;21:e679-86. 
59. Hussein YM, Awad HA, Shalaby SM, Ali AS, Alzahrani SS: Toll-like receptor 2 and Toll-like receptor 4 polymorphisms and susceptibility to asthma and allergic rhinitis: a case-control analysis. Cell Immunol 2012;274:34-8.

60. Schubert K, von Bonnsdorf H, Burke M, Ahlert I, Braun S, Berner R, Deichmann KA, Heinzmann A: A comprehensive candidate gene study on bronchial asthma and juvenile idiopathic arthritis. Dis Markers 2006;22:127-32.

61. Hoffjan S, Stemmler S, Parwez Q, Petrasch-Parwez E, Arinir U, Rohde G, Reinitz-Rademacher K, Schultze-Werninghaus G, Bufe A, Epplen JT: Evaluation of the toll-like receptor 6 Ser249Pro polymorphism in patients with asthma, atopic dermatitis and chronic obstructive pulmonary disease. BMC Med Genet 2005;6:34.

62. Custovic A, Rothers J, Stern D, Simpson A, Woodcock A, Wright AL, Nicolaou NC, Hankinson J, Halonen $M$, Martinez FD: Effect of day care attendance on sensitization and atopic wheezing differs by Toll-like receptor 2 genotype in 2 population-based birth cohort studies. J Allergy Clin Immunol 2011;127:390397 e391-9.

63. Lange NE, Zhou X, Lasky-Su J, Himes BE, Lazarus R, Soto-Quiros M, Avila L, Celedon JC, Hawrylowicz CM, Raby BA, Litonjua AA: Comprehensive genetic assessment of a functional TLR9 promoter polymorphism: no replicable association with asthma or asthma-related phenotypes. BMC Med Genet 2011;12:26.

64. Zhang Y, Tian C, Zhang J, Li X, Wan H, He C, Guo L, Meilang Q, Peng C, Duo L, et al: The $-159 C / T$ polymorphism in the CD14 gene and the risk of asthma: a meta-analysis. Immunogenetics, 63:23-32.

65. Zhao L, Bracken MB: Association of CD14 -260 (-159) C>T and asthma: a systematic review and metaanalysis. BMC Med Genet 2011;12:93.

66. Browning SR, Browning BL: Haplotype phasing: existing methods and new developments. Nat Rev Genet 2011;12:703-14.

67. Steele EJ, Williamson JF, Lester S, Stewart BJ, Millman JA, Carnegie P, Lindley RA, Pain GN, Dawkins $\mathrm{RL}$ : Genesis of ancestral haplotypes: RNA modifications and reverse transcription-mediated polymorphisms. Hum Immunol 2011;72:283-93.

68. Stauffer D, Cebrat S: Haplotype complementarity under mutational pressure. Front Biosci (Schol Ed) 2011;3:408-15.

69. Sanderson S, Tatt ID, Higgins JP: Tools for assessing quality and susceptibility to bias in observational studies in epidemiology: a systematic review and annotated bibliography. Int J Epidemiol 2007; 36:666-76. 


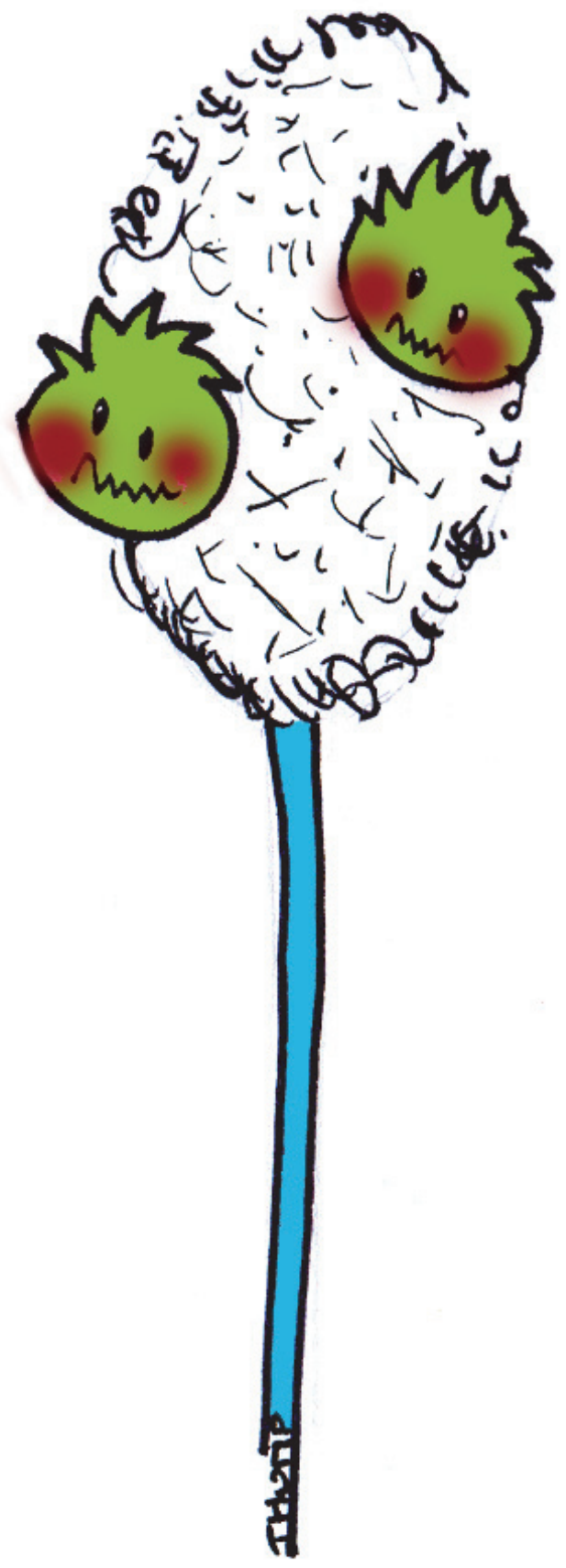




\section{Chapter 4}

\section{CD14 and TLR polymorphisms interact with bacteria}

and regulatory T-cells in childhood asthma development

Klaassen EMM, van de Kant KDG, Soeteman M, Damoiseaux J, van Eys G, Stobberingh EE, Stelma FF, van Schayck CP, Jöbsis Q, Dompeling E Submitted for publication 


\section{Abstract}

\section{Background}

Susceptibility for childhood asthma is determined by genetic predisposition and environmental factors such as bacteria, which influence the immune response. However, exact mechanisms in the development of childhood asthma remain largely unclear.

\section{Objective}

To investigate whether specific genetic variants in components of the innate immune system determine the response to bacteria and the recruitment of regulatory T-cells in preschool children leading to an increased likelihood of asthma at six years of age

\section{Methods}

In a prospective longitudinal study in preschool children with $(n=202)$ and without $(n=50)$ recurrent wheeze, genetic variants in toll-like receptors (TLRs) and CD14, colonisation with typical bacteria, antibodies (IgG) against atypical bacteria (Chlamydia, Mycoplasma) and proportions of regulatory T-cells (CD4 $4^{+} \mathrm{CD} 25^{\text {high }} \mathrm{CD} 127^{-}$) were assessed. At age six, a classification (asthma, transient wheeze or healthy) was based on symptoms, lung function and use of asthma medication.

\section{Results}

Significant interactions were found between genetic variants in CD14 and bacterial colonisation in relation to asthma development. Moreover, genetic variants in toll-like receptors interacted with bacterial colonisation and regulatory T-cells in asthma development. For example, the risk to develop asthma was increased with $H$. parainfluenzae colonisation in children with a TLR4 rs2737190 AA- or GG-genotype and with $H$. influenzae colonisation in CD14 rs2569190 GG-genotype children. Moreover, a higher proportion of regulatory T-cells in TLR2 rs4696480 in AA- or TLR9 rs187084 GG-genotype children increased the risk to develop asthma. No significant independent associations between genetic variants, bacteria and regulatory T-cells in relation to an asthma diagnosis were found.

\section{Conclusions \& Clinical Relevance}

Bacteria and regulatory T-cells are affected by genetic variants in toll-like receptors and CD14 and have an effect on asthma development in young children. 


\section{Introduction}

It is generally accepted that the susceptibility for asthma development in childhood is influenced by genetic components as well as environmental factors and interactions between these factors. ${ }^{1-4}$ The innate immune system reacts to environmental influences such as micro-organisms. Important regulators of the innate immune system are a group of pathogen-recognition receptors named toll-like receptors (TLRs) and the multifunctional high-affinity receptor for bacterial components called CD14., It is suggested that bacteria are important in the pathogenesis and clinical course of asthma by provoking airway inflammation. ${ }^{6-11}$ Genetic variation in elements of the innate immune system may lead to differential adaptive immune responses to bacteria and therefore may contribute to the development of asthma., ${ }^{3,12-15}$ Regulatory T-cells ( $T_{\text {reg }}$ cells) are part of the adaptive immune response as regulators of inflammatory responses in the respiratory tract. ${ }^{16,17}$

Although considerable research on the pathogenesis of asthma has been performed, the role of genetic predisposition, bacteria and $\mathrm{T}_{\text {reg }}$ cells in the early development of childhood asthma remains largely unclear. We performed a prospective longitudinal study in preschool children, in which we studied polymorphisms previously associated with childhood asthma in TLRs and CD14, the presence of bacteria and proportion of $\mathrm{T}_{\text {reg }}$ cells in relation to an asthma diagnosis at six years of age. We hypothesise that specific genetic variants in components of the innate immune system determine the response to bacteria and the recruitment of $T_{\text {reg }}$ cells in preschool children leading to an increased likelihood of asthma at six years of age (Figure 1).

\section{Methods}

\section{Study population and design}

The ADEM study (Asthma DEtection and Monitoring study: registered at clinicaltrial.gov: NCT 00422747) is a long-term prospective case-control study in which 252 children participated. The study protocol has been published previously. ${ }^{18}$ A total of 202 children who experienced at least two wheezing episodes (ISAAC questionnaire $)^{19}$ and 50 children without wheezing episodes were included at two to four years of age. These children were followed until a definite classification (healthy, transient wheeze, or asthma) was made at the age of six years.

During the initial visit, at two to four years of age, saliva or buccal cells (DNA), nasal and throat swabs (bacterial cultures) and blood (serology and $\mathrm{T}_{\text {reg }}$ cells) were collected. Moreover, questionnaires were completed by parents. Prior to the visit, asthma medication was temporary stopped (including inhaled corticosteroids (ICS) for four weeks and short-acting $\beta_{2}$-agonists eight hours before the visit). In case of clear 
symptoms of an airway infection, such as a runny nose, sneezing, a sore throat, cough, malaise or fever, the visit was postponed. Ethical approval was obtained from the Dutch National Medical Ethical Committee. All parents gave written informed consent.

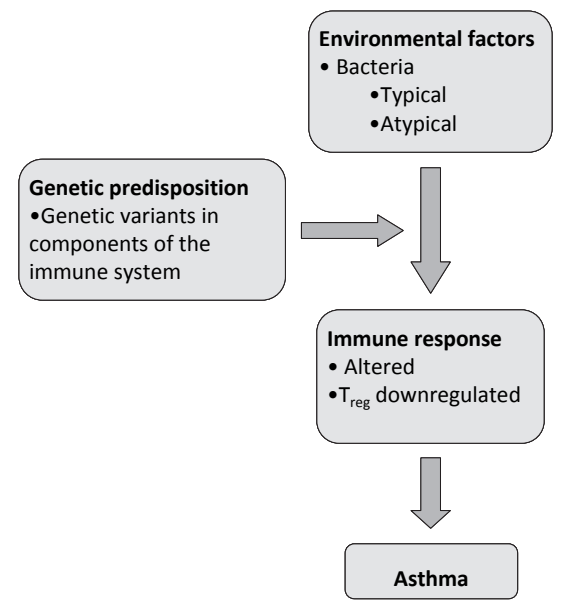

Figure 1 Hypothetical model of factors contributing to the development of asthma.

Schematic representation of hypothesis: Environmental factors, such as bacteria, initiate a reaction of the immune response. Genetic variations in components of the immune system may alter the response to pathogens. Regulatory T-cells ( $\mathrm{T}_{\text {reg }}$ cells) are important regulators of the immune response. The altered immune response could promote a micro-environment that facilitates airway inflammation and bronchial hyper-reactivity and consequently contributes to the development of asthma.

\section{Asthma diagnosis}

At six years of age, a classification (healthy, transient wheezer or true asthmatic) was made based on recurrent wheeze at inclusion, current respiratory symptoms, lung function (reversibility to a $\beta_{2}$-agonist and/or bronchial hyper-responsiveness) and the use of asthma medication by an experienced paediatrician in the field of respiratory medicine. Additionally, this classification was compared with a computer-algorithm as described previously. ${ }^{20}$ Mismatching cases between the clinical and the computer classification were re-evaluated by the paediatrician, who was blinded to the previous assessment. Measurements of bronchial hyper-responsiveness and reversibility on bronchodilators were performed according to the European Respiratory Society (ERS) guideline. $^{21}$ 


\section{DNA isolation and genotyping}

Saliva was collected by Oragene DNA self-collection kits (Oragene ${ }^{\circledR}$, Ottowa, Canada). If children were unable to produce sufficient saliva, buccal cells were obtained. DNA was isolated according to the manufacturer's protocol. Participants were genotyped for six single nucleotide polymorphisms (SNPs) in TLR2, TLR4, TLR9 and CD14 (see Table 1). All candidate markers were selected based on a significant association with childhood asthma in previous literature and a minor allele frequency of at least $10 \%$ (www.hapmap.org or the available literature). ${ }^{22}$ All SNPs were determined using the mass-spectroscopy based high-throughput MassARRAY ${ }^{\oplus}$ iPLEX $^{\bullet}$ platform (Sequenom ${ }^{\bullet}$ Inc., Hamburg, Germany) by using one multiplex genotyping reaction created by Sequenom Assay Designer 3.1 software. Sequences were evaluated by ProxSNP and PreXTEND software (http:www.realsnp.com). Primer and probe information is provided in Table 2.

Table 1 Genetic markers included in the current study.

\begin{tabular}{lcllccccc}
\hline Gene & Chr. & rs-number & Location & $\begin{array}{c}\text { Major/minor } \\
\text { allele }\end{array}$ & $\begin{array}{c}\text { MAF } \\
\%\end{array}$ & $\begin{array}{c}\text { Call- } \\
\text { rate }\end{array}$ & $\begin{array}{c}\text { HWE } \\
\text { p-value }\end{array}$ & $\begin{array}{c}\text { Reference } \\
\text { association }\end{array}$ \\
\hline TLR2 & 4 & rs3804099 & Coding exon & T/C & 45 & 98.8 & 0.30 & $5,19,27$ \\
& & rs4696480 & Intron & T/A & $50 *$ & 98.8 & 0.20 & $5,19,27$ \\
TLR4 & 9 & rs2737190 & Promoter & A/G & 32 & 99.2 & 0.55 & 19 \\
TLR9 & 3 & rs187084 & Promoter & A/G & 34 & 99.2 & 0.56 & 19,27 \\
& & rs5743836 & Promoter & A/G & $14 *$ & 99.2 & 0.05 & 46 \\
CD14 & 5 & rs2569190 & Promoter & A/G & 52 & 99.2 & 0.70 & 47 \\
\hline
\end{tabular}

Chr.: Chromosome; MAF: Minor Allele Frequency in Hapmap.org; HWE: Hardy-Weinberg Equilibrium (assessed in control group). *Allele frequencies are based on the literature as no information on Hapmap.org was provided. ${ }^{19}$

Table 2 Primer sequences used for genotyping.

\begin{tabular}{llll}
\hline rs-number & Extension primer & Forward primer & Reverse primer \\
\hline rs3804099 & TGAAGGATCAGATGACTTAC & ACGTTGGATGTATGCTGCTTCA & ACGTTGGATGGATCTACAGAG \\
& & TATGAAGG & CTATGAGCC \\
rs4696480 & AGCCAGATGACCCTC & ACGTTGGATGTCTCACCATGTG & ACGTTGGATGAGTCCAAGATT \\
& & ATGCTTTC & GAAGGGCTG \\
rs2737190 & TTTACACCCAAGTAGACAC & ACGTTGGATGCTCTGAACCACC & ACGTTGGATGACCTGTGATGA \\
& & TCCTCTAC & TTAGGGCTG \\
rs187084 & \multirow{2}{*}{ ATAAAAGATCACTGCCCT } & ACGTTGGATGTGCTGGGCACTG & ACGTTGGATGTATTCCCCTGCT \\
& & TACTGGAT & GGAATGTC \\
rs5743836 & CCCATGTTCCCTCTGCCTG & ACGTTGGATGTTGGGATGTGCT & ACGTTGGATGAGCAGAGACAT \\
& & GTTCCCTC & AATGGAGGC \\
rs2569190 & cCtAATCCTTCCTGTTACGG & ACGTTGGATGAGACACAGAAC & ACGTTGGATGGCAATGAAGGA \\
& & CCTAGATGC & TGTTTCAGG \\
\hline
\end{tabular}

Forward primer: complementary in direction to the extension primer; Reverse primer: in the same direction as the extension primer. The PCR primers contain a 10mer tag that helps to get a balanced amplification in the multiplex PCR and also gets them out of the mass window. The lower case letters in the extension primers are non-template bases that do not affect the annealing temperature but change the mass to allow more efficient multiplexing. 


\section{Bacterial cultures and serology}

Nasal and throat swabs were analysed for colonisation with typical bacteria Haemophilus (para)influenzae, Streptococcus pneumoniae and Staphylococcus aureus, by using standard microbiological methods. ${ }^{23}$ Antibodies (IgG) against atypical bacteria Mycoplasma pneumoniae and Chlamydia pneumoniae were analysed in venous blood using enzyme-linked immunosorbent assays (ELISAs) (Ani labsystems Ltd, Vantaa, Finland; Virion/Serion GmbH, Würzburg, Germany). Serum IgG titres of $>30 \mathrm{IU} / \mathrm{ml}$ were considered positive and were considered as evidence of a past infection. $^{24}$

\section{Regulatory T-cells}

$\mathrm{T}_{\text {reg }}$ cells were determined by means of flow cytometry as described previously. ${ }^{25}$ In short, heparin blood was incubated with monoclonal antibodies for CD3-PerCP (BD Biosciences, Breda, the Netherlands), CD4-APC (BD Biosciences), CD25-FITC (EBioscience, San Diego, USA) and CD127-PE (E-Bioscience). The phenotype of $\mathrm{T}_{\text {reg }}$ cells was defined as $\mathrm{CD} 4^{+} \mathrm{CD} 25^{\text {high }} \mathrm{CD} 127^{-}$, as described before. ${ }^{26}$ This phenotype has been shown to be positively related to FoxP3, a transcription factor closely related to the suppressive function of $T_{\text {reg }}$ cells. ${ }^{25,27,28}$ In order to test the assumption that the $\mathrm{CD} 4^{+} \mathrm{CD} 25^{\text {high }} \mathrm{CD} 127^{-}$phenotype is a valid marker for FoxP3 in a paediatric population, at preschool age we assessed FoxP3 in the first 24 included participants of our study (four asthmatics, thirteen transient wheezers and seven healthy children at age six years). FoxP3 and $\mathrm{CD} 4^{+} \mathrm{CD} 25^{\text {high }} \mathrm{CD} 127^{-}$phenotypes were highly correlated $(\mathrm{R}=0.86$, $\mathrm{p}<0.01$ ). Consequently, we conclude that the $C D 4^{+} \mathrm{CD} 25^{\text {high }} \mathrm{CD} 127^{-}$phenotype is a valid surrogate for FoxP3 in our study population. Cells were analysed on a FacsCalibur $^{\mathrm{TM}}$ flowcytometer (BD Biosciences, Figure 2). Results are presented as percentage of total CD4 T-cells.
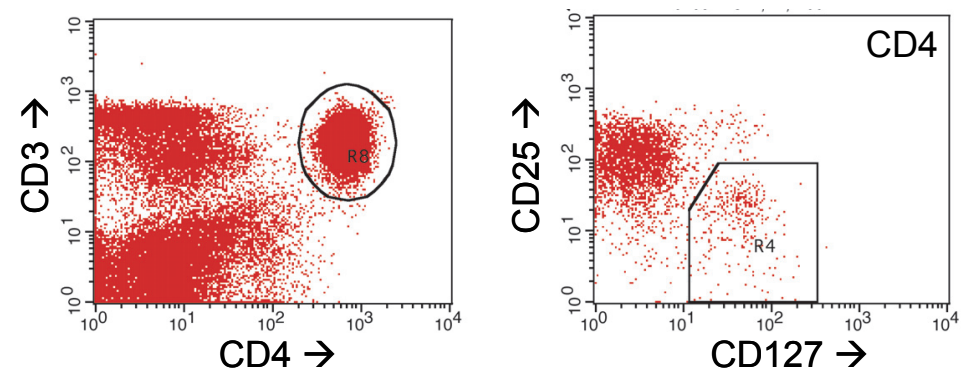

Figure 2 T-cell subset analysis by flow cytometry Representative plots are shown to demonstrate the gating strategy for the analysis of T-cell subsets within the lymphocyte gate (not shown). (A) CD3 vs. CD4 staining was used for gating CD4 T-cells, (B) within the CD4 T-cell subset CD25 and CD127 were used for identifying regulatory T-cells (CD4 ${ }^{+}$DD2 $5^{\text {high }}$ CD127). 


\section{Statistical analysis}

Data were analysed using SPSS/PASW 18 (SPSS inc., Chicago, IL). Differences in baseline characteristics were analysed by means of Chi-Square tests for categorical data and analysis of variance (ANOVA) for continuous parametrical data. Nominal regression analysis with reference category asthma was performed per predictor to test for associations of SNPs, presence of bacteria and $T_{\text {reg }}$ cells with asthma classification. SNPs were tested according to a co-dominant model. In case the minor homozygote genotype was present in less than $10 \%$ of the population, a dominant model was applied. Analysis of main effects was also performed corrected for possible confounders (type of child care (no child care, day-care centre, child care in a family setting), number of siblings, sex, smoking exposure, furry pets exposure, age at inclusion and ICS usage).

Based on biological conceivability, the effect of the following interactions between SNPs and bacterial colonisation on the classification were tested: TLR2 (rs3804099 and rs4696480) with gram positive bacteria (S. pneumonaie and S. aureus); TLR4 (rs2737190) and CD14 (rs2569190) with gram negative bacteria ( $H$. (para)influenzae). ${ }^{29,30}$ Besides, interaction between all SNPs and $\mathrm{T}_{\text {reg }}$ cells in relationship to asthma development were tested. The percentage of $T_{\text {reg }}$ cells was included in the analysis as a continuous variable. Interactions were analysed by using multivariable nominal regression analysis. In the presence of an interaction, separate nominal regression analysis per genotype was performed with asthma as a reference category to assess associations of either presence of bacteria or $\mathrm{T}_{\text {reg }}$ cells and asthma development. Results were expressed in odds ratios (ORs) and 95\% confidence intervals $(95 \% \mathrm{Cl})$. Differences were defined as significant in case of a $p<0.05$.

\section{Sample size calculation}

The calculation of sample size was performed using a power of 0.80 and an alpha of 0.05 for the main outcomes. Based on an expected development of asthma in $30 \%$ of children with recurrent wheeze, approximately 70 children will develop asthma in a population of 202 children. $^{31,32}$

The minor allele frequency of rs 2737190 in $T L R 4$, which is associated with asthma, is approximately $30 \% .{ }^{22}$ If we assume a minor allele frequency of $30 \%$ in the transient wheezers, a study group of 64 asthmatics and 128 transient wheezers is sufficient to detect associations with an OR of 2.4. S. pneumoniae and $H$. influenzae have been shown to be present in about $20 \%$ of healthy children. ${ }^{7}$ If we suppose comparable percentages in the transient wheeze group, 67 asthmatics and 134 transient wheezers are needed to detect associations with an OR of 2.5. In a recent study which compared asthmatic children to healthy controls, $\mathrm{T}_{\text {reg }}$ cells among total CD4+ T-cells of $2.4 \%$ in asthmatics and $2.6 \%$ in controls were found. ${ }^{33}$ If we presume comparable values in the current study 70 asthmatics and 140 transient wheezers are needed. 


\section{Results}

\section{Clinical characteristics}

In total, 252 children were included at preschool age (two to four years of age). At age six, four children were lost to follow-up due to personal constraints including lack of interest or time. Within the 'healthy group' one child was excluded from further analysis as this child was diagnosed with asthma at six years of age. Of the 247 children that were analysed at six years of age, 76 were diagnosed with asthma, 122 with transient wheeze and 49 were characterised as healthy controls. There was a high level of agreement (91\%) between the computer-algorithm diagnosis and the clinical diagnosis of the paediatrician. Baseline characteristics are displayed in Table 3. Atopy, eczema and the use of short-acting $\beta_{2}$-agonists and ICS were significantly different between the groups, with the highest percentages in the asthmatic group. Temporary discontinuation of ICS was not permitted by the responsible physician in six children at preschool age and five children at six years of age due to concerns of exacerbation. In nine children the lung function measurement was not performed at six years of age because of lack of parental consent. Sensitivity analyses excluding these groups did not alter the results. Consequently, these children were kept in the analysis.

Table 3 The patient characteristics at baseline.

\begin{tabular}{|c|c|c|c|c|}
\hline Patient characteristics & $\begin{array}{l}\text { Healthy } \\
\text { controls } \\
(\mathrm{N}=49)\end{array}$ & $\begin{array}{c}\text { Transient } \\
\text { wheeze } \\
(\mathrm{N}=122)\end{array}$ & $\begin{array}{l}\text { Asthma } \\
(\mathrm{N}=76)\end{array}$ & $\begin{array}{c}\text { Total } \\
\text { group } \\
(\mathrm{N}=247)\end{array}$ \\
\hline Mean age (SD), in years & $3.3(0.5)$ & $3.2(0.6)$ & $3.3(0.6)$ & $3.3(0.6)$ \\
\hline Sex: male / female, in $\mathrm{N}$ & $24 / 25$ & $63 / 59$ & $46 / 30$ & $133 / 114$ \\
\hline Atopy $^{+-*}$ & 23 & 17 & 37 & 24 \\
\hline Atopy first degree $e^{\S}$ & 65 & 79 & 79 & 76 \\
\hline Eczema* & 22 & 34 & 47 & 36 \\
\hline Use of short-acting $\beta_{2}$-agonist* & 0 & 27 & 53 & 30 \\
\hline Use of ICS* & 0 & 11 & 30 & 15 \\
\hline \multicolumn{5}{|l|}{ Positive culture with: } \\
\hline Haemophilus influenzae & 32 & 31 & 33 & 32 \\
\hline Haemophilus parainfluenzae & 49 & 48 & 57 & 51 \\
\hline Streptococcus pneumoniae & 28 & 24 & 26 & 25 \\
\hline Staphylococcus aureus & 17 & 17 & 17 & 17 \\
\hline \multicolumn{5}{|l|}{ Positive serology for: } \\
\hline Chlamydia pneumoniae IgG & 13 & 7 & 11 & 9 \\
\hline Mycoplasma pneumoniae lgG & 58 & 58 & 58 & 58 \\
\hline $\mathrm{CD}^{+} \mathrm{CD} 25^{\text {high }} \mathrm{CD} 127^{-}$in mean (SD) & $7.0(1.9)$ & $7.4(1.5)$ & $7.6(1.8)$ & $7.4(1.7)$ \\
\hline Availability DNA & 100 & 100 & 100 & 100 \\
\hline
\end{tabular}

Results are displayed as \%, unless stated otherwise. SD: Standard Deviation; N: Number of children; ICS: Inhaled Corticosteroids. ${ }^{+}$Atopy was defined as specific IgE concentration against a mixture of inhalant and food allergens of $\geq 0.35 \mathrm{kU} / \mathrm{I}$ on the Phadiatop Infant test ${ }^{\circledR}$ (Pharmacia, Uppsala, Sweden). $\S$ First degree relative with eczema, asthma or allergic rhinitis. ${ }^{*} p<0.05$. 


\section{Main effects}

\section{Single nucleotide polymorphisms}

DNA could be extracted in all 247 children. All SNPs had a high call-rate (98.8-99.2\%, Table 1). None of the SNPs deviated from Hardy-Weinberg equilibrium ( $p>0.01$ assessed in the control group, Table 1). Furthermore, linkage disequilibrium was assessed for SNPs within the same gene $\left(R^{2}=0.08\right.$ for $T L R 2, R^{2}=0.12$ for $\left.T L R 9\right)$. No significant associations between SNPs and asthma diagnosis at six years of age were found (Table 4), neither after correction for possible confounders (data not shown).

Table 4 Gene polymorphisms related to asthma diagnosis at six years of age.

\begin{tabular}{llcccccccc}
\hline Gene & SNP & Genotype & Asthma $^{+}$ & \multicolumn{3}{c}{ Healthy control } & \multicolumn{3}{c}{ Transient wheezer } \\
& & & N & N & OR & $95 \% \mathrm{Cl}$ & $\mathrm{N}$ & OR & $95 \% \mathrm{Cl}$ \\
\hline TLR2 & rs3804099 & TT & 27 & 14 & 1.00 & - & 37 & 1.00 & - \\
& & TC & 32 & 27 & 1.63 & $0.71-3.71$ & 55 & 1.25 & $0.65-2.43$ \\
& & CC & 16 & 7 & 0.84 & $0.28-2.53$ & 29 & 1.32 & $0.60-2.90$ \\
& rs4696480 & TT & 16 & 10 & 1.00 & - & 28 & 1.00 & - \\
& & TA & 39 & 29 & 1.19 & $0.47-3.00$ & 63 & 0.92 & $0.44-1.92$ \\
& & AA & 20 & 10 & 0.80 & $0.27-2.39$ & 29 & 0.83 & $0.36-1.92$ \\
TLR4 & rs2737190 & AA & 27 & 18 & 1.00 & - & 54 & 1.00 & - \\
& & AG & 36 & 25 & 1.04 & $0.48-2.28$ & 48 & 0.67 & $0.35-1.26$ \\
& & GG & 12 & 6 & 0.75 & $0.24-2.36$ & 19 & 0.79 & $0.34-1.87$ \\
TLR9 & rs187084 & AA & 30 & 17 & 1.00 & - & 45 & 1.00 & - \\
& & AG & 34 & 22 & 1.14 & $0.51-2.54$ & 51 & 1.00 & $0.53-1.89$ \\
& & GG & 11 & 10 & 1.60 & $0.57-4.55$ & 25 & 1.52 & $0.65-3.53$ \\
& rs5743836 & AA & 50 & 40 & 1.00 & - & 91 & 1.00 & - \\
& & AG/GG & 25 & 9 & 0.45 & $0.19-1.07$ & 30 & 0.66 & $0.35-1.24$ \\
CD 14 & rs2569190 & AA & 18 & 11 & 1.00 & - & 30 & 1.00 & - \\
& & AG & 38 & 23 & 0.99 & $0.40-2.46$ & 60 & 0.95 & $0.47-1.93$ \\
& & GG & 19 & 15 & 1.29 & $0.47-3.55$ & 31 & 0.98 & $0.43-2.22$ \\
\hline
\end{tabular}

${ }^{+}$Reference category. The SNPs were tested according to a co-dominant model or a dominant model in case of a minor homozygote genotype in $<10 \%$ of the population. SNP: single nucleotide polymorphism; $\mathrm{N}$ : number of children; OR: Odds Ratio; $95 \% \mathrm{Cl}$ : 95\% Confidence Interval; TLR: toll-like receptor.

\section{Bacterial colonisation and serology}

Nasal swabs could be successfully obtained in all children, whereas throat swabs could be obtained in 244 children (99\%). Sufficient blood for IgG serum analysis of C. pneumoniae and M. pneumoniae was obtained in 224 children (91\%).

Colonisation of S. pneumoniae, S. aureus or $H$. (para)influenzae at preschool age did not differ between children with asthma, transient wheeze and healthy controls at age six years (asthmatics: $17-57 \%$, transient wheezers: $17-48 \%$, healthy controls: $17-$ $49 \%$ Table 3, Table 5). No relation was found between $M$. pneumoniae IgG and C. pneumoniae $\lg$ at preschool age and an asthma diagnosis at six years of age 
(Table 3, Table 5). Results for both typical and atypical bacteria were comparable when adjusted for possible confounders.

Table 5 The relationship between bacterial colonisation or positive serology at preschool age and the risk on an asthma diagnosis at six years of age.

\begin{tabular}{lcrccccc}
\hline Bacteria & Asthma $^{+}$ & \multicolumn{3}{c}{ Healthy control } & \multicolumn{3}{c}{ Transient wheezer } \\
& $\mathrm{N}$ & $\mathrm{N}$ & $\mathrm{OR}$ & $95 \% \mathrm{Cl}$ & $\mathrm{N}$ & $\mathrm{OR}$ & $95 \% \mathrm{Cl}$ \\
H. influenzae & 25 & 15 & 0.96 & $0.44-2.08$ & 37 & 0.90 & $0.49-1.66$ \\
H. parainfluenza & 43 & 23 & 0.74 & $0.35-1.53$ & 58 & 0.71 & $0.40-1.26$ \\
S. pneumoniae & 20 & 13 & 1.07 & $0.47-2.43$ & 29 & 0.88 & $0.46-1.71$ \\
S. aureus & 13 & 8 & 0.97 & $0.37-2.55$ & 20 & 0.96 & $0.45-2.06$ \\
C. pneumoniae & 8 & 5 & 1.14 & $0.35-3.76$ & 8 & 0.62 & $0.22-1.72$ \\
M. pneumoniae & 42 & 23 & 0.97 & $0.44-2.11$ & 64 & 0.99 & $0.54-1.82$ \\
\hline
\end{tabular}

${ }^{+}$Reference category. N: number of children; OR: Odds Ratio; $95 \% \mathrm{Cl}$ : $95 \%$ Confidence Interval; H. influenza: Haemophilus influenza; H. parainfluenza: Haemophilus parainfluenza; S. pneumoniae: Streptococcus pneumoniae; S. aureus: Staphylococcus aureus; C. pneumoniae: Chlamydia pneumoniae; M. pneumoniae: Mycoplasma pneumoniae.

\section{Regulatory T-cells}

In 217 children (88\%) collection of venous blood and analysis of $\mathrm{T}_{\text {reg }}$ cells was successful. No associations were found between the proportion of $T_{\text {reg }}$ cells at preschool age and an asthma diagnosis at six years of age (asthma reference category; healthy control: OR $(95 \% \mathrm{Cl}) 0.84(0.65-1.09)$, transient wheeze 0.95 (0.79-1.15, Table 3). Correction for possible confounders did not alter the results.

\section{Interactions}

\section{Interactions between single nucleotide polymorphisms and bacteria}

Several significant interactions between SNPs and bacteria at preschool age in relationship to the asthma diagnosis at six years of age were found. At first, an interaction was found between TLR2 rs4696480 and S. pneumoniae; TLR4 rs2737190 and $H$. parainfluenzae; CD14 rs2569190 and $H$. influenzae; and between CD14 rs2569190 and $H$. parainfluenza ( $\leq \leq 0.05$, Figure 3 and Figure 4). Accordingly, stratified analyses were conducted (Table 6).

Children with the AA-genotype of TLR4 rs2737190 had an increased risk to develop asthma when colonised with $H$. parainfluenzae at preschool age. Besides, the GGgenotype increased the risk of asthma when colonised with $H$. parainfluenzae compared to the control group. The CD14 rs2569190 GG-genotype showed a positive association between colonisation of $H$. influenzae at preschool age and asthma development compared to the transient wheeze group. No association in stratified analysis for TLR2 rs4696480 and S. pneumoniae or CD14 rs2569190 and $H$. parainfluenzae in relation to development of asthma was demonstrated. 
Table 6 Stratified analysis by genotype for bacterial colonisation on asthma diagnosis.

\begin{tabular}{|c|c|c|c|c|c|c|c|c|c|c|}
\hline \multirow[t]{2}{*}{ Gene } & \multirow[t]{2}{*}{ SNP } & \multirow[t]{2}{*}{ Bacteria } & \multirow[t]{2}{*}{ Genotype } & \multirow{2}{*}{$\begin{array}{c}\text { Asthma }^{+} \\
\mathrm{n} / \mathrm{N}\end{array}$} & \multicolumn{3}{|c|}{ Healthy control } & \multicolumn{3}{|c|}{ Transient wheezer } \\
\hline & & & & & $\mathrm{n} / \mathrm{N}$ & OR & $95 \% \mathrm{Cl}$ & $\mathrm{n} / \mathrm{N}$ & OR & $95 \% \mathrm{Cl}$ \\
\hline \multirow{3}{*}{$\overline{T L R 2}$} & rs4696480 & S. pneumoniae & $\pi T$ & $6 / 16$ & $1 / 9$ & 0.21 & $0.02-2.10$ & $8 / 28$ & 0.67 & $0.18-2.45$ \\
\hline & & & TA & $11 / 39$ & $8 / 29$ & 0.97 & $0.33-2.83$ & $13 / 62$ & 0.68 & $0.27-1.71$ \\
\hline & & & AA & $3 / 20$ & $4 / 9$ & 4.53 & $0.75-27.39$ & $6 / 29$ & 1.48 & $0.32-6.77$ \\
\hline \multirow[t]{3}{*}{ TLR4 } & rs2737190 & H. parainfluenzae & AA & $18 / 27$ & $6 / 18$ & 0.25 & $0.07-0.89 *$ & $21 / 54$ & 0.32 & $0.12-0.84 *$ \\
\hline & & & AG & $16 / 36$ & $16 / 23$ & 2.86 & $0.95-8.63$ & $25 / 47$ & 1.42 & $0.59-3.40$ \\
\hline & & & GG & $9 / 12$ & $1 / 6$ & 0.07 & $0.01-0.82 *$ & $11 / 19$ & 0.46 & $0.09-2.25$ \\
\hline \multirow[t]{3}{*}{ CD14 } & rs2569190 & H. influenzae & AA & $6 / 18$ & $4 / 10$ & 1.33 & $0.27-6.61$ & $6 / 30$ & 0.50 & $0.13-1.89$ \\
\hline & & & AG & $11 / 38$ & $7 / 23$ & 1.07 & $0.35-3.33$ & $27 / 59$ & 2.07 & $0.87-4.94$ \\
\hline & & & GG & $8 / 19$ & $4 / 14$ & 0.55 & $0.13-2.40$ & $4 / 31$ & 0.20 & $0.05-0.82 *$ \\
\hline \multirow[t]{3}{*}{ CD14 } & rs2569190 & H. parainfluenzae & AA & $5 / 18$ & $5 / 10$ & 2.60 & $0.52-13.04$ & $16 / 30$ & 2.97 & $0.85-10.44$ \\
\hline & & & AG & $23 / 38$ & $11 / 23$ & 0.60 & $0.21-1.70$ & $24 / 59$ & 0.45 & $0.20-1.03$ \\
\hline & & & GG & $15 / 19$ & $7 / 14$ & 0.27 & $0.06-1.22$ & $17 / 31$ & 0.32 & $0.09-1.20$ \\
\hline
\end{tabular}

${ }^{+}$Reference category. SNP: single nucleotide polymorphism; $\mathrm{n} / \mathrm{N}$ : number with positive colonisation against total number in the respective group; OR: Odds Ratio; $95 \% \mathrm{Cl}$ : $95 \%$ Confidence Interval; TLR: toll-like receptor; S. pneumoniae: Streptococcus pneumoniae; H. parainfluenza: Haemophilus parainfluenza; $H$. influenza: Haemophilus influenza. ${ }^{*} \mathrm{p}<0.05$.

\section{Interaction between single nucleotide polymorphisms and regulatory T-cells}

Interactions between SNPS TLR2 rs4696480 and TLR9 rs187084 and proportion of $\mathrm{T}_{\text {reg }}$ cells at preschool age in relation to asthma at six years of age were found $(p<0.05$, Figure 3 and Figure 4). In stratified analysis, compared to healthy children, a higher proportion of $T_{\text {reg }}$ cells at preschool age was associated with the risk to develop asthma in children with either the AA-genotype of rs4696480 or the GG-genotype of TLR9 rs187084 (Table 7). No association in stratified analysis for TLR2 rs4696480 and proportion of $\mathrm{T}_{\text {reg }}$ cells in relationship to development of asthma was demonstrated.

Table 7 Stratified analysis by genotype for regulatory T-cells on asthma diagnosis.

\begin{tabular}{|c|c|c|c|c|c|c|c|}
\hline \multirow[t]{2}{*}{ Gene } & \multirow[t]{2}{*}{ SNP } & \multirow[t]{2}{*}{$\mathrm{T}_{\text {reg }}$ cells } & \multirow[t]{2}{*}{ Allele } & \multicolumn{2}{|c|}{ Healthy control } & \multicolumn{2}{|c|}{ Transient wheezer } \\
\hline & & & & OR & $95 \% \mathrm{Cl}$ & OR & $95 \% \mathrm{Cl}$ \\
\hline \multirow[t]{3}{*}{$\overline{T L R 2}$} & rs4696480 & $\mathrm{CD}^{+}{ }^{+} \mathrm{CD} 25^{\text {high }} \mathrm{CD} 127^{-}$ & TT & 1.12 & $0.61-2.05$ & 1.03 & $0.65-1.64$ \\
\hline & & & TA & 0.90 & $0.66-1.24$ & 0.93 & $0.73-1.18$ \\
\hline & & & $A A$ & 0.38 & $0.17-0.86^{*}$ & 0.95 & $0.61-1.47$ \\
\hline \multirow[t]{3}{*}{ TLR9 } & rs187084 & $\mathrm{CD} 4^{+} \mathrm{CD} 25^{\text {high }} \mathrm{CD} 127^{-}$ & $A A$ & 0.55 & $0.34-0.92 *$ & 0.76 & $0.56-1.05$ \\
\hline & & & $A G$ & 0.93 & $0.61-1.42$ & 1.00 & $0.73-1.38$ \\
\hline & & & GG & 1.29 & $0.76-2.22$ & 1.35 & $0.86-2.12$ \\
\hline
\end{tabular}

Reference category: asthma. SNP: Single Nucleotide Polymorphism; $\mathrm{T}_{\text {reg }}$ cells: Regulatory T-cells; OR: Odds Ratio; 95\% Cl: 95\% Confidence Interval; TLR: toll-like receptor. ${ }^{*} \mathrm{p}<0.05$ 

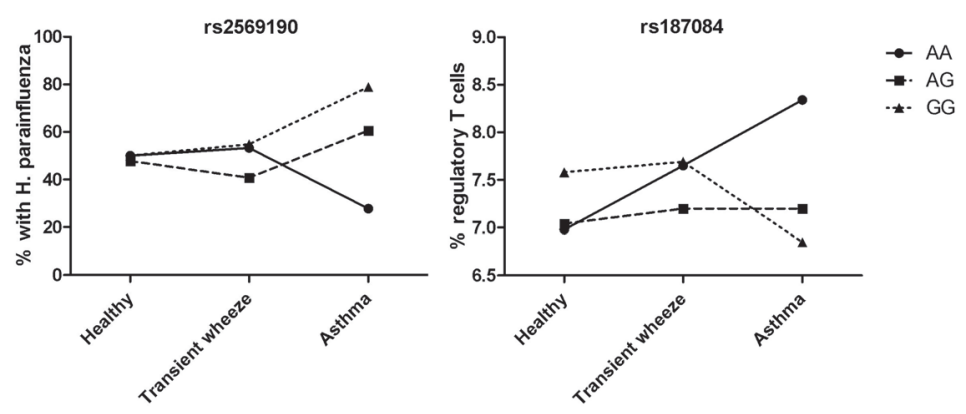

Figure 3 Interaction between CD14 rs2569190 and H. parainfluenzae and between TLR9 rs187084 and regulatory T-cells in relation to asthma development.

The percentage of colonisation with $H$. parainfluenzae per CD14 rs2569190 genotype and proportion of regulatory T-cells per TLR9 rs187084 genotype in the different groups (healthy, transient wheeze, asthma) is displayed. The graph demonstrates an interaction between these genetic variants and the bacterial colonisation respectively proportion of regulatory T-cells in relationship to asthma development at six years of age.
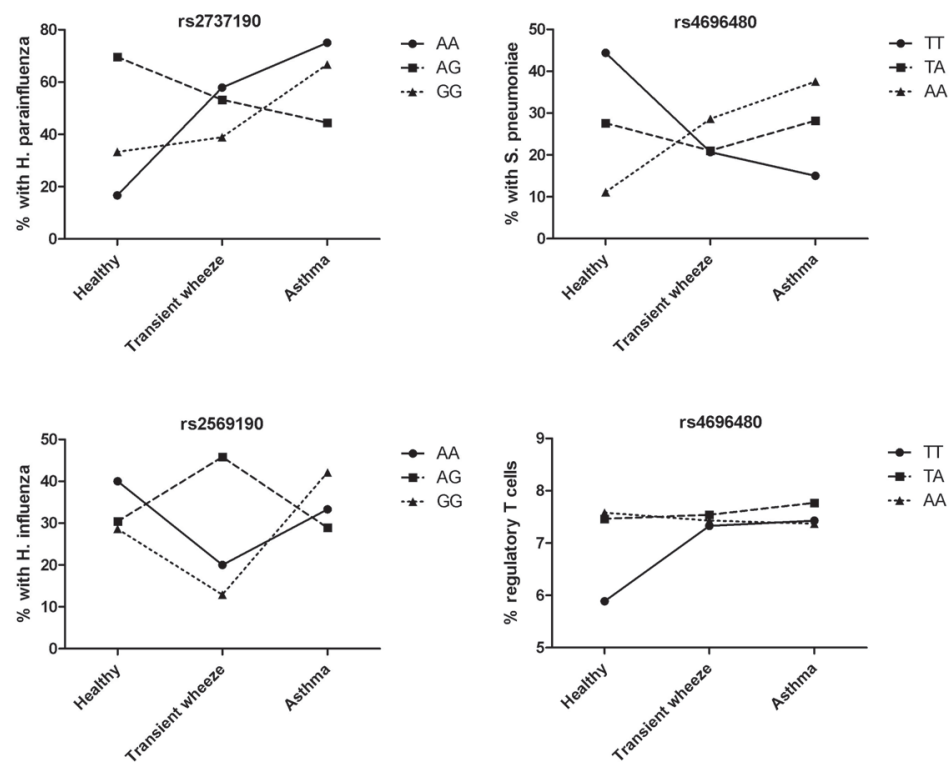

Figure 4 Interaction between genetic variants in CD14 and TLRs and both bacterial colonisation and regulatory T-cells in relation to asthma development.

The percentage of bacterial colonisation respectively proportion to regulatory T-cells in the different groups (healthy, transient wheeze, asthma) is displayed per genotype. The graph demonstrates interaction between the particular genetic variants and the bacterial colonisation respectively proportion of regulatory T-cells in relationship to asthma development at six years of age. 


\section{Discussion}

In this prospective, longitudinal study over four years we demonstrated that in preschool children the effect of genetic variants in receptors of the innate immune system (CD14 and TLRs) on early asthma development is affected by bacterial colonisation and by proportion of $\mathrm{T}_{\text {reg }}$ cells.

Despite an increasing interest in the role of genetic variants in TLRs and CD14 in the aetiology of childhood asthma, so far their exact role is still largely undetermined. Although some studies found an association, in most studies genetic variants in TLRs and CD14 have not been linked to the development of asthma. ${ }^{13,22,30,34-40}$ Our study demonstrated that genetic variants in TLRS and CD14 interact with bacteria in the airways and with $\mathrm{T}_{\text {reg }}$ cells with respect to the risk on asthma development. This interaction might explain the discrepancies between studies on this topic.,

Disruption of the barrier function of the respiratory epithelium by bacteria triggers the immune system. This can predispose the airways to the development of asthma., ${ }^{7,9-11}$ The seriousness and nature of the influence of bacteria on the immune system can be determined by genetic variants in immune receptors. ${ }^{2,3}$ Indeed, we demonstrated several interactions between genetic variants and typical bacteria, suggesting an increased risk to develop asthma in the presence of some genotypes in case of colonisation of the upper airways with certain typical bacteria. A direct influence of the bacteria studied at preschool age and the development of asthma was not established (even in a multivariable approach including all typical bacteria, data not shown).

Previous studies have shown that the nature and the magnitude of the effects of bacterial exposure on asthma development are influenced by timing as well as persistence of the exposure. ${ }^{7,41-43}$ The immune system is not fully developed at birth. ${ }^{1,4}$ Postnatal maturational defects have been linked to early life respiratory infections and asthma in children with a family history of atopy. ${ }^{30,39} \mathrm{~T}_{\text {reg }}$ cells are important endogenous regulators of inflammatory responses in the respiratory tract. ${ }^{16}$ Quantitative and functional impairment of $\mathrm{T}_{\text {reg }}$ cells have been demonstrated in children with asthma compared to healthy controls. ${ }^{17,44}$ Therefore, we expected a down-regulation in proportion of $\mathrm{T}_{\text {reg }}$ cells at preschool age among children with asthma at six years of age. Though, no direct association between proportion and the development of childhood asthma was demonstrated, as was the case for absolute number of $\mathrm{T}_{\text {reg }}$ cells (data not shown). However, contrary to our expectation, a higher proportion of $\mathrm{T}_{\text {reg }}$ cells at preschool age, in combination with the AA-genotype of TLR2 rs4696480 or the AA-genotype of TLR9 rs187084, was associated with an increased asthma risk at six years of age. Although not significant, this effect was less evident in the heterozygote genotypes and even absent in the alternative homozygous genotypes. Thus, a higher proportion of $\mathrm{T}_{\text {reg }}$ cells at preschool age seems to be associated with the development of asthma at six years of age in the presence of 
certain genotypes in immune response genes. It would be interesting to observe whether also functionally differences are present. In the future new technological developments may provide in techniques to look at the functionality of $T_{\text {reg }}$ cells obtained from small quantities of blood.

Contrary to most studies, this study has a longitudinal design, which enabled us to investigate the effect of parameters on the development of childhood asthma in early life. We tried to obtain a better insight into the multifactorial background of asthma by investigating genetic markers as well as presence of bacteria and proportion of $T_{\text {reg }}$ cells at preschool age in relation to asthma development. We achieved a high followup success rate (98\%). In addition, less false positive and false negative diagnoses are expected as the diagnosis was based on both expert opinion and a computeralgorithm with re-assessment of inconclusive cases. This will result in a more accurate diagnosis as compared to studies that use 'doctor-diagnosed asthma' in a questionnaire as outcome measure. To reduce influences by viral exposures, children were clinically stable at the time of assessments. Additionally, to control for other factors, we included confounders in our analysis. A limitation of our study is that the parameters were collected in different body compartments. Bronchoalveolar lavage fluid is the gold standard to assess presence of bacteria and number of $T_{\text {reg }}$ cells in the airways. However, due to the invasive nature and ethical constraints, these measurements are not feasible for repeated use in children. ${ }^{9,17}$

In conclusion, we demonstrated that at preschool age the effect of bacterial colonisation of the upper airways and serum $T_{\text {reg }}$ cells on asthma development at six years of age is influenced by genetic variants in TLRs and CD14. We reasoned that the combination of genetic predisposition and bacterial exposure at preschool age leads to an altered immune response, as demonstrated by $\mathrm{T}_{\text {reg }}$ cell response, which in turn leads to the development of asthma at six years of age. 


\section{References}

1. Holt PG, Rowe J, Kusel M, Parsons F, Hollams EM, Bosco A, McKenna K, Subrata L, de Klerk N, Serralha M, Holt BJ, Zhang G, Loh R, Ahlstedt S, Sly PD, Toward improved prediction of risk for atopy and asthma among preschoolers: a prospective cohort study. J Allergy Clin immunol 2010;125: 653-9, 59 e1-59 e7.

2. Sly PD, Holt PG, Role of innate immunity in the development of allergy and asthma. Cur Opin Allergy Clin Immunol 2011;11: 127-31.

3. Chang JC, Wang L, Chen RF, Liu CA, Perinatal gene-gene and gene-environment interactions on IgE production and asthma development. Clin Dev Immunol 2012;2012: 270869.

4. Rigoli L, Briuglia S, Caimmi S, Ferrau V, Gallizzi R, Leonardi S, La Rosa M, Salpietro C, Geneenvironment interaction in childhood asthma. Int J Immunopathol Pharmacol 2011;24: 41-7.

5. Cook DN, Pisetsky DS, Schwartz DA, Toll-like receptors in the pathogenesis of human disease. Nat Immunol 2004;5: 975-9.

6. Korppi M, Management of bacterial infections in children with asthma. Expert Rev Ant Infect Ther 2009;7: 869-77.

7. Bisgaard H, Hermansen MN, Buchvald F, Loland L, Halkjaer LB, Bonnelykke K, Brasholt M, Heltberg A, Vissing $\mathrm{NH}$, Thorsen SV, Stage M, Pipper $\mathrm{CB}$, Childhood asthma after bacterial colonization of the airway in neonates. N Engl J Med 2007;357: 1487-95.

8. Webley WC, Salva PS, Andrzejewski C, Cirino F, West CA, Tilahun Y, Stuart ES, The bronchial lavage of pediatric patients with asthma contains infectious Chlamydia. Am J Respir Crit Care Med 2005;171: 1083-8.

9. Korppi M, Paldanius M, Hyvarinen A, Nevalainen A, Husman T, Chlamydia pneumoniae and newly diagnosed asthma: a case-control study in 1 to 6-year-old children. Respirology 2004;9: 255-9.

10. Hauk PJ, Krawiec M, Murphy J, Boguniewicz J, Schiltz A, Goleva E, Liu AH, Leung DY, Neutrophilic airway inflammation and association with bacterial lipopolysaccharide in children with asthma and wheezing. Pediatr Pulmonol 2008;43: 916-23.

11. Holgate ST, Has the time come to rethink the pathogenesis of asthma? Cur Opin Allergy Clin Immunol 2010;10: 48-53.

12. Martin AC, Laing IA, Khoo SK, Zhang G, Rueter K, Teoh L, Taheri S, Hayden CM, Geelhoed GC, Goldblatt J, LeSouef PN, Acute asthma in children: Relationships among CD14 and CC16 genotypes, plasma levelsand severity. Am J Respir Crit Care Med 2006;173: 617-22.

13. Eder W, Klimecki W, Yu L, von Mutius E, Riedler J, Braun-Fahrlander C, Nowak D, Martinez FD, Toll-like receptor 2 as a major gene for asthma in children of European farmers. J Allergy Clin immunol 2004;113: 482-8.

14. Bottema RW, Kerkhof M, Reijmerink NE, Thijs C, Smit HA, van Schayck CP, Brunekreef B, van Oosterhout AJ, Postma DS, Koppelman GH, Gene-gene interaction in regulatory T-cell function in atopy and asthma development in childhood. J Allergy Clin immunol 2010;126: 338-46, 46 e1-10.

15. Tesse R, Pandey RC, Kabesch M, Genetic variations in toll-like receptor pathway genes influence asthma and atopy. Allergy 2011;66: 307-16.

16. Strickland DH, Holt PG, T regulatory cells in childhood asthma. Trends Immunol 2011;32: 420-7.

17. Hartl D, Koller B, Mehlhorn AT, Reinhardt D, Nicolai T, Schendel DJ, Griese M, Krauss-Etschmann S, Quantitative and functional impairment of pulmonary $C D 4+C D 25$ hi regulatory $T$ cells in pediatric asthma. J Allergy Clin immunol 2007;119: 1258-66.

18. van de Kant KD, Klaassen EM, Jöbsis Q, Nijhuis AJ, van Schayck OC, Dompeling E, Early diagnosis of asthma in young children by using non-invasive biomarkers of airway inflammation and early lung function measurements: study protocol of a case-control study. BMC public health 2009;9: 210.

19. Worldwide variation in prevalence of symptoms of asthma, allergic rhinoconjunctivitisand atopic eczema: ISAAC. The International Study of Asthma and Allergies in Childhood (ISAAC) Steering Committee. Lancet 1998;351: 1225-32. 
20. Klaassen EM, van Kant KD, Jöbsis Q, Hovig ST, van Schayck CP, Rijkers GT, Dompeling E, Symptoms, but not a biomarker response to inhaled corticosteroids, predict asthma in preschool children with recurrent wheeze. Mediators Inflamm 2012;2012: 162571.

21. Miller MR, Hankinson J, Brusasco V, Burgos F, Casaburi R, Coates A, Crapo R, Enright P, van der Grinten CP, Gustafsson P, Jensen R, Johnson DC, Maclntyre N, McKay R, Navajas D, Pedersen OF, Pellegrino R, Viegi G, Wanger J, Standardisation of spirometry. Eur Respir J 2005;26: 319-38.

22. Kormann MS, Depner M, Hartl D, Klopp N, Illig T, Adamski J, Vogelberg C, Weiland SK, von Mutius E, Kabesch $\mathrm{M}$, Toll-like receptor heterodimer variants protect from childhood asthma. J Allergy Clin immunol 2008;122: 86-92, 92 e1-8.

23. Isenberg H, Clinical microbiology procedures handbook, 2nd edn. Washington: ASM Press, 2004.

24. Persson K, Boman J, Comparison of five serologic tests for diagnosis of acute infections by Chlamydia pneumoniae. Clin Diagn Lab Immunol 2000;7: 739-44.

25. Smolders J, Thewissen M, Peelen E, Menheere P, Tervaert JW, Damoiseaux J, Hupperts R, Vitamin D status is positively correlated with regulatory $T$ cell function in patients with multiple sclerosis. PloS one 2009;4: e6635.

26. van de Kant KD, Klaassen EM, van Aerde KJ, Damoiseaux J, Bruggeman CA, Stelma FF, Stobberingh EE, Muris JW, Jöbsis Q, van Schayck OC, Dompeling E, Impact of bacterial colonization on exhaled inflammatory markers in wheezing preschool children. J Breath Res 2012;6: 046001.

27. Liu W, Putnam AL, Xu-Yu Z, Szot GL, Lee MR, Zhu S, Gottlieb PA, Kapranov P, Gingeras TR, Fazekas de St Groth B, Clayberger C, Soper DM, Ziegler SF, Bluestone JA, CD127 expression inversely correlates with FoxP3 and suppressive function of human CD4+ T reg cells. J Exp Med 2006;203: 1701-11.

28. Seddiki N, Santner-Nanan B, Martinson J, Zaunders J, Sasson S, Landay A, Solomon M, Selby W, Alexander SI, Nanan R, Kelleher A, Fazekas de St Groth B, Expression of interleukin (IL)-2 and IL-7 receptors discriminates between human regulatory and activated T cells. J Exp Med 2006;203: 1693700.

29. Hussein YM, Awad HA, Shalaby SM, Ali AS, Alzahrani SS, Toll-like receptor 2 and Toll-like receptor 4 polymorphisms and susceptibility to asthma and allergic rhinitis: a case-control analysis. Cell Immunol 2012;274: 34-8.

30. Kabesch M, Hasemann K, Schickinger V, Tzotcheva I, Bohnert A, Carr D, Baldini M, Hackstein H, Leupold W, Weiland SK, Martinez FD, Mutius E, Bein G, A promoter polymorphism in the CD14 gene is associated with elevated levels of soluble CD14 but not with IgE or atopic diseases. Allergy 2004;59: 520-5.

31. Pedersen SE, Hurd SS, Lemanske RF, Jr., Becker A, Zar HJ, Sly PD, Soto-Quiroz M, Wong G, Bateman ED, Global strategy for the diagnosis and management of asthma in children 5 years and younger. Pediatr Pulmonol 2011;46: 1-17.

32. Savenije OE, Granell R, Caudri D, Koppelman GH, Smit HA, Wijga A, de Jongste JC, Brunekreef B, Sterne JA, Postma DS, Henderson J, Kerkhof M, Comparison of childhood wheezing phenotypes in 2 birth cohorts: ALSPAC and PIAMA. J Allergy Clin immunol 2011;127: 1505-12 e14.

33. Pumputiene I, Emuzyte R, Siaurys A, Tamosiunas V, Valiulis A, CD4+CD25(high) Treg cells in peripheral blood during remission and exacerbation of allergic asthma in children. Acta Paediatr 2011;100: 100610.

34. Reijmerink NE, Bottema RW, Kerkhof M, Gerritsen J, Stelma FF, Thijs C, van Schayck CP, Smit HA, Brunekreef B, Koppelman GH, Postma DS, TLR-related pathway analysis: novel gene-gene interactions in the development of asthma and atopy. Allergy 2009;65: 199-207.

35. Daley D, Lemire M, Akhabir L, Chan-Yeung M, Qing He J, McDonald T, Sandford AJ, Stefanowicz D, Tripp B, Zamar D, Bosse Y, Ferretti V, Montpetit A, Tessier MC, Becker A, Kozyrskyj AL, Beilby J, McCaskie PA, Musk B, Warrington N, James AL, Laprise C, Palmer LJ, Pare PD, Hudson TJ, Analyses of associations with asthma in four asthma population samples from Canada and Austrialia. Hum Genet 2009;125: 445-59.

36. Tremblay K, Daley D, Chamberland A, Lemire M, Montpetit A, Laviolette M, Musk AW, James AL, Chan-Yeung M, Becker A, Kozyrskyj AL, Sandford AJ, Hudson TJ, Pare PD, Laprise C, Genetic variation in immune signaling genes differentially expressed in asthmatic lung tissues. J Allergy Clin immunol 2008;122: 529-36. 
37. Bieli C, Eder W, Frei R, Braun-Fahrlander C, Klimecki W, Waser M, Riedler J, von Mutius E, Scheynius A, Pershagen G, Doekes G, Lauener R, Martinez FD, A polymorphism in CD14 modifies the effect of farm milk consumption on allergic diseases and CD14 gene expression. J Allergy Clin immunol 2007;120: 1308-15.

38. Sackesen C, Karaaslan C, Keskin O, Tokol N, Tahan F, Civelek E, Soyer OU, Adalioglu G, Tuncer A, Birben E, Oner C, Kalayci O, The effect of polymorphisms at the CD14 promoter and the TLR4 gene on asthma phenotypes in Turkish children with asthma. Allergy 2005;60: 1485-92.

39. Zhang G, Candelaria P, Makela JM, Khoo SK, Hayden MC, von Hertzen L, Laatikainen T, Vartiainen E, Goldblatt J, Haahtela T, LeSouef NP, Disparity of innate immunity-related gene effects on asthma and allergy on Karelia. Pediatr Allergy Immunol 2011;22: 621-30.

40. Kerkhof M, Postma DS, Brunekreef B, Reijmerink NE, Wijga AH, de Jongste JC, Gehring U, Koppelman $\mathrm{GH}$, Toll-like receptor 2 and 4 genes influence susceptibility to adverse effects of traffic-related air pollution on childhood asthma. Thorax 2010;65: 690-7.

41. Von Mutius E, Of attraction and rejection - asthma and the microbial world. N Engl J Med 2007;357: 1545-7.

42. Sordillo JE, Hoffman EB, Celedon JC, Litonjua AA, Milton DK, Gold DR, Multiple microbial exposures in the home may protect against asthma or allergy in childhood. Clin Exp Allergy 2010;40: 902-10.

43. Schroder NW, Crother TR, Naiki Y, Chen S, Wong MH, Yilmaz A, Slepenkin A, Schulte D, Alsabeh R, Doherty $\mathrm{TM}$, Peterson $\mathrm{E}, \mathrm{Nel} \mathrm{AE}$, Arditi $\mathrm{M}$, Innate immune responses during respiratory tract infection with a bacterial pathogen induce allergic airway sensitization. J Allergy Clin immunol 2008;122: 595602.

44. Yamamoto $Y$, Negoro $T$, Hoshi A, Wakagi A, Shimizu S, Banham AH, Ishii M, Akiyama H, Kiuchi $Y$, Sunaga $\mathrm{S}$, Tobe $\mathrm{T}$, Roncador $\mathrm{G}$, Itabashi $\mathrm{K}$, Nakano $\mathrm{Y}$, Impaired $\mathrm{Ca}(2)$ regulation of $\mathrm{CD} 4 \mathrm{CD} 25$ regulatory T cells from pediatric asthma. Int Arch Allergy Immunol 2011;156: 148-58. 


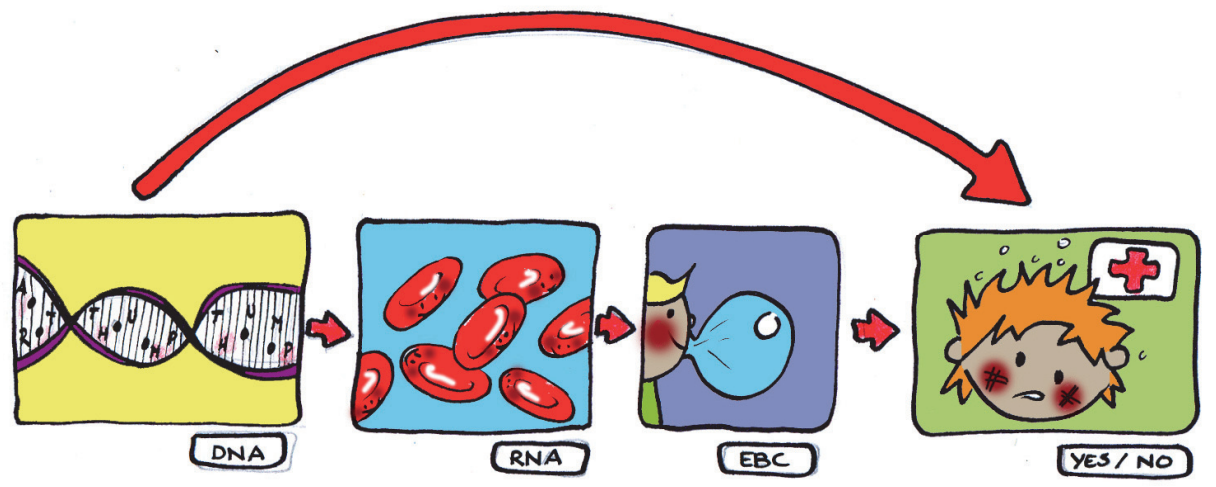




\title{
Chapter 5
}

\section{Integrative genomic analysis identifies a role for}

\author{
ICAM1 in childhood asthma
}

Klaassen EMM, van de Kant KDG, Jöbsis Q, Penders J, van Schooten FJ, Quaak M, den Hartog GJM, Koppelman GH, van Schayck CP, van Eys G, Dompeling E

Submitted for publication 


\section{Abstract}

\section{Background}

Childhood asthma is characterised by chronic airway inflammation. Integrative genomic analysis of airway inflammation on genetic and protein level may help to unravel mechanisms of childhood asthma.

\section{Objective}

To employ an integrative genomic approach investigating inflammation markers on DNA, mRNA and protein level at preschool age in relationship to asthma development.

\section{Methods}

In a prospective study, 252 preschool children (202 recurrent wheezers, 50 controls) from the ADEM (Asthma DEtection and Monitoring) study were followed until the age of six. Genetic variants, mRNA expression in peripheral blood mononuclear cells and protein levels in exhaled breath condensate for Intercellular Adhesion Molecule 1 (ICAM1), interleukin (IL)4, IL8, IL10, IL13 and Tumour-Necrosis-Factor alpha were analysed at preschool age. At six years of age a classification (healthy, transient wheeze or asthma) was based on symptoms, lung function and medication use.

\section{Results}

The ICAM1 rs5498 A-allele was positively associated with asthma development $(p=0.02)$ and ICAM1 gene expression $(p=0.01)$. ICAM1 gene expression was positively associated with exhaled levels of soluble ICAM1 $(p=0.04)$ which in turn was positively associated with asthma development $(p=0.01)$. Furthermore, rs1800872 and rs1800896 in IL10 ( $p<0.01)$ were associated with altered IL10 mRNA expression. Exhaled levels of IL4, IL10, IL13, $(p<0.01)$ and IL8 $(p=0.05)$ were positively associated with asthma development.

\section{Conclusions \& Clinical Relevance}

In this unique prospective study we demonstrated that ICAM1 is associated with asthma development on DNA, mRNA and protein level. Thus, ICAM1 is likely to be involved in the development of childhood asthma. 


\section{Introduction}

Asthma is characterised by chronic airway inflammation and airway hyperresponsiveness which lead to symptoms like wheeze. ${ }^{1,2}$ However, wheezing symptoms at preschool age are mostly transient and caused by viral infections. Only around $30 \%$ of wheezing children at preschool age will have persistent symptoms and will ultimately develop asthma. ${ }^{2,3}$ The exact mechanisms of childhood asthma are largely unclear and, therefore, it is not possible to distinguish true asthmatics from transient wheezers at preschool age. ${ }^{3}$

We previously demonstrated that various levels of exhaled cytokines, chemokines and adhesion molecules were elevated in children with preschool wheeze. ${ }^{4}$ However, in that cross-sectional analysis we could not determine the role of these markers in relationship to asthma development. With an integrative genomic approach the role of these markers can be further elucidated. ${ }^{5}$ This approach is employed in the present study to investigate airway inflammation on DNA, mRNA and protein level. Protein levels can be measured in exhaled breath condensate (EBC) with adequate sensitivity and reproducibility. ${ }^{6-8}$ Pro-inflammatory cytokines (T-helper 1 cytokine TumourNecrosis-Factor alpha (TNF $\alpha$ ) and T-helper 2 cytokines interleukin (IL)4 and IL13), an anti-inflammatory cytokine (IL10), a chemokine (IL8) and an adhesion molecule (Intercellular Adhesion Molecule 1 (ICAM1)) were selected for analysis. All these markers have previously been associated with childhood asthma and are involved in airway inflammation. ${ }^{6,9-25}$

We hypothesise that when an inflammation marker is found to be associated with the development of asthma at the age of six, causal pathways can be inferred when the data are combined with DNA and RNA analysis (Figure 1). The aim of our unique prospective study is to study inflammation markers in childhood asthma at gene coding, gene expression and protein level.

\section{Methods}

\section{Study population}

The current study is conducted within the context of the Asthma DEtection and Monitoring (ADEM) study which is a long-term, case-control study that aims to develop a non-invasive instrument for an early asthma diagnosis in children and to study aetiological factors in relation to early development of asthma. ${ }^{26}$ A total of 202 children with recurrent wheeze ( $\geq 2$ episodes during life according to the International Study of Asthma and Allergies in Childhood (ISAAC) questionnaire) and 50 healthy controls (random selection of children without wheezing episodes during life) at two to four years of age were included. ${ }^{27}$ At preschool age, saliva or buccal cells (DNA), 
blood (RNA) and EBC were collected. If possible, according to the doctor consultation, the use of asthma medication was temporarily stopped prior to the measurement (such as inhaled corticosteroids for four weeks and $\beta_{2}$-agonists for eight hours). In case of symptoms of an airway infection one week prior to the measurement, the measurement was postponed for four weeks.

\section{Asthma diagnosis}

At the age of six a classification (healthy, transient wheezer or true asthmatic) was assessed by an experienced paediatrician in the field of respiratory medicine based on recurrent wheeze at inclusion, current respiratory symptoms, lung function (reversibility to a $\beta_{2}$-agonist, bronchial hyper-responsiveness) and the use of asthma medication. Additionally, this classification was compared with a computer-algorithm as described previously. ${ }^{28}$ Mismatching cases were re-assessed by a blinded paediatrician in the field of respiratory medicine who decided on the final classification. Measurements of bronchial hyper-responsiveness and reversibility on bronchodilators were performed according to the European Respiratory Society guideline. ${ }^{29}$ Forced expiratory volume in one second $\left(\mathrm{FEV}_{1}\right)$ and the forced vital capacity (FVC) were assessed by means of spirometry (Master screen Pneumo ${ }^{\varpi}$, Jaeger, Würzburg, Germany). The curve with the highest $\mathrm{FEV}_{1}$ and FVC of three technically satisfactory curves was used for analysis. The bronchial hyperresponsiveness was assessed with a histamine provocation test using histamine dissolved in physiologic saline in doubling concentrations from 0.032 to $16 \mathrm{mg} / \mathrm{ml}$. Concentrations were increased until a fall of $\geq 20 \%$ in $\mathrm{FEV}_{1}\left(\mathrm{PC}_{20}\right)$ was measured or the final dilution was reached. All children inhaled $400 \mu \mathrm{g}$ of salbutamol (Airomir, Teva Pharma NL, Haarlem, the Netherlands) directly after the provocation test and FEV was re-evaluated after fifteen minutes. The change in $\mathrm{FEV}_{1}$ was expressed as a percentage of the predicted value and an increase in $\mathrm{FEV}_{1}$ of $\geq 9 \%$ was defined as reversibility to a $\beta_{2}$-agonist. ${ }^{30}$

\section{DNA isolation and genotyping}

Saliva was collected by Oragene DNA self-collection kits (Oragene ${ }^{\circledR}$ Ottowa, Canada). If children were unable to produce sufficient saliva, buccal cells were obtained. DNA was isolated according to the manufacturers' protocol. Participants were genotyped for seven SNPs (single nucleotide polymorphisms) in six genes (see Table 1). Candidate markers were selected based on previous association with childhood asthma, the ability to measure their product in EBC and a minor allele frequency of at least $10 \%$ (www.hapmap.org or literature for IL13 rs1800925). ${ }^{31}$ Six of the SNPs were determined using the mass-spectroscopy based, high-throughput Mass ARRAY iPLEX platform (Sequenom Inc., Hamburg, Germany) using two multiplex genotyping 
reactions. Sequences were evaluated by ProxSNP and PreXTEND software (http:www.realsnp.com). Sequenom Assay Designer 3.1 software was used to create the different multiplexes. Genotyping was performed according to the iPLEX method. Primer and probe information is provided in Table 2 and was designed based on the absence of SNPs, to avoid the 'SNP under the probe' problem. Rs 2243250 could not be fitted into the multiplex reactions and was therefore determined using the Taqman genotyping assay ID C_16176216_10 (Applied Biosystems, California, USA).

Table 1 Markers included in the current study.

\begin{tabular}{llllllllll}
\hline Gene & Chr. & rs-number & Location & $\begin{array}{c}\text { Major/ } \\
\text { minor } \\
\text { allele }\end{array}$ & $\begin{array}{c}\text { MAF } \\
\text { Call-rate } \\
(\%)\end{array}$ & $\begin{array}{c}\text { HWE } \\
\text { p-value }\end{array}$ & NM-number & $\begin{array}{c}\text { Association } \\
\text { asthma }\end{array}$ \\
\hline IL4 & 5 & rs2243250 & Promoter & C/T & 13.7 & 96.8 & 0.32 & NM_000589.2 & $6,17,18$ \\
IL8 & 4 & rs2227306 & Intron 1 & C/T & 39.2 & 98.4 & 0.46 & NM_000584.2 & $6,19,26$ \\
IL10 & 1 & rs1800872 & Promoter & G/T & 21.2 & 99.6 & 0.05 & NM_000572.2 & $10,11,20$ \\
& & rs1800896 & Promoter & T/C & 53.1 & 99.2 & 0.61 & & \\
IL13 & 1 & rs1800925 & Promoter & C/T & $20 *$ & 98.4 & 0.94 & NM_002188.2 & $6,12,17,21,22$ \\
TNF 2 & 6 & rs1800629 & Promoter & G/A & 17.3 & 99.6 & 0.05 & NM_000594.2 & $13,14,23,24$ \\
ICAM1 & 19 & rs5498 & Exon 6 & A/G & 39.3 & 99.2 & 0.06 & NM_000201.2 & $6,15,16,25$ \\
\hline
\end{tabular}

Chr.: Chromosome; ICAM1: Intercellular Adhesion Molecule 1; HWE: Hardy-Weinberg Equilibrium (assessed in control group); IL: Interleukin; MAF: Minor Allele Frequency based on Hapmap.org; TNF $\alpha$ : TumourNecrosis-Factor alpha; .*Allele frequencies are based on the literature when no information on Hapmap.org was provided.

Table 2 Primer sequences used for genotyping by Sequenom.

\begin{tabular}{llll}
\hline Rs-number & Extension primer & PCR-1 & PCR-2 \\
\hline rs2227306 & ggGTCATAACTGACAACATTGAAC & ACGTTGGATGACAGTCATAAC & ACGTTGGATGCCATGAAGAT \\
& & TGACAACA & GTTGATATTG \\
rs1800872 & GACTGGCTTCCTACAG & ACGTTGGATGAAGCAGCCCTT & ACGTTGGATGCCTGGAACAC \\
& & CCATTTTAC & ATCCTGTGAC \\
rs1800896 & tcCCTATCCCTACTTCCCC & ACGTTGGATGCTGGATAGGA & ACGTTGGATGGACAACACTAC \\
& & GGTCCCTTAC & TAAGGCTTC \\
rs1800925 & TCCTGCTCTTCCCTC & ACGTTGGATGTGCAGCCATGT & ACGTTGGATGGGGTTTCTGG \\
& & CGCCTTTTC & AGGACTTCTA \\
rs1800629 & GGAGGCTGAACCCCGTCC & ACGTTGGATGGATTTGTGTGT & ACGTTGGATGGGTCCCAAA \\
& & AGGACCCTG & AGAAATGGAG \\
rs5498 & gagcGCACATTCACGGTCACCT & ACGTTGGATGCTCACAGAGC & ACGTTGGATGTTGAGGGCAC \\
& & ACATTCACGG & CTACCTCTGT \\
\hline
\end{tabular}

PCR-1: complementary in direction to the extension primer; PCR-2: in the same direction as the extension primer. The PCR primers contain a $10 \mathrm{mer}$ tag that helps to get a balanced amplification in the multiplex PCR and also takes them out of the mass window. The lower case letters in the extension primers are nontemplate bases that do not affect the annealing temperature but change the mass to allow more efficient multiplexing. 


\section{RNA isolation and mRNA expression}

Total RNA was extracted from peripheral blood mononuclear cells (PBMCs) obtained by blood sampling. PBMCs were isolated with the Qiagen PaxGene Blood RNA kit (Qiagen " Hilden, Germany). cDNAs were generated by poly-A and random primed reverse transcription with the accompanying Qiagen kit and used for the productions of cRNA pools. Quantitative real-time PCR was performed by using the Fluidigm BioMark system (AROS Applied Biotechnology, Aarhus, Denmark) to assess expression of the six selected genes (Table 1). A quality control was conducted based on slope and appearance of the amplification curve (AROS Applied Biotechnology, Aarhus, Denmark). An internal standard was obtained by computing the geometric mean of three housekeeping genes (GAPDH, Beta-actin, Cyclophilin A) in each participant. For each selected gene the Cycle threshold $(\mathrm{Ct})$ value was adjusted by subtraction of the geometric mean (Delta $\mathrm{Ct}$ ) according to this internal standard. In eleven samples two out of the three two housekeeping genes passed the quality control and the Ct value of the missing housekeeping gene was replaced by the mean $\mathrm{Ct}$ value of this gene within the study population. In two samples less than two housekeeping genes passed the quality control and, therefore, these samples were excluded for analysis.

\section{Inflammation markers in Exhaled Breath Condensate}

EBC was collected using a closed glass condenser system with a breath recirculation unit developed at our institute. ${ }^{7,26}$ Six inflammation markers in EBC (Table 1 ) were assayed using the multiplex immunoassay (Luminex Corporation, Austin, TX, USA). ${ }^{32}$ In case of values under the detection limit a randomly generated value was added using the uniform distribution between zero and the detection limit. ${ }^{33}$

\section{Statistical analysis}

SPSS version 17.0 was used for data analysis (SPSS inc., Chicago IL, USA). Due to the skewed distributions, EBC markers were log-transformed which successfully imparted a normal distribution. For the relationship between individual SNPS and childhood asthma and the relationship between individual protein levels in EBC and childhood asthma, ordinal regression modeling adjusted for confounders was used. Confounders were selected based on previous literature (gender, age, passive smoking and exposure to furry pets at home) and remained in the model irrespective of their statistical significance. ${ }^{34-37}$ All SNPs were tested according to a co-dominant model . In case the minor allele genotype was present in less than $10 \%$ of the participants, a dominant model was used. Linear regression was used to assess associations between SNPs and gene expression and associations between gene expression and inflammation markers in EBC. The condition at preschool age (recurrent wheeze or control) and confounders were included in the linear regression models. Results were 
expressed in adjusted odds ratio (OR) with $95 \%$ confidence interval $(95 \% \mathrm{Cl})$ in case of logistic regression and adjusted B with standard error (S.E.) in case of linear regression. Differences were defined as significant when $p<0.05$.

\section{Power analysis}

Differences between transient wheezers and true asthmatics were analysed with a power of 0.80 and an alpha of 0.05 . A group of 134 transient wheezers and 67 asthmatics is sufficient to detect associations with an OR of 2.5 or 0.4 in allele frequency, when assuming the presence of one or more variant alleles of at least $20 \%$ in transient wheezers. In an earlier study in children with asthma and healthy controls aged 6-16 years, differences in concentrations of IL4, IL8, IL10, IL13 and TNF $\alpha$ ranging from 1.5 to $5.1 \mathrm{pg} / \mathrm{ml}$ and soluble (s)ICAM1 of $79.5 \mathrm{pg} / \mathrm{ml}$ were found. ${ }^{6}$ If we assume comparable differences in the present population, a study group of 148 transient wheezers and 74 asthmatics is sufficient to detect differences for all analysed inflammation markers.

\section{Ethical consideration}

The study protocol was approved by the Dutch Central Committee on Research Involving Human Subjects (CCMO: NL17407.000.07/2007-001817-40, The Hague, the Netherlands). All parents provided written informed consent.

\section{Results}

\section{Baseline characteristics}

At preschool age 252 children were included. Due to personal constraints of parents (e.g. lack of time or interest) four children were lost in the follow-up at six years of age. One child from the control group was excluded from analysis as this child was diagnosed with asthma at the age of six years. In total, 247 children were included in the analysis (76 asthmatics, 122 transient wheezers and 49 healthy controls). The agreement between the computer-algorithm classification and the clinical classification was high (91\%). Baseline characteristics are displayed in Table 3. Atopy, eczema and the use of asthma medication were significantly different between the groups, with the highest frequencies in asthmatic children. After consultation of the responsible doctor, treatment of inhaled corticosteroids could not be stopped prior to measurement in six children. A sensitivity analysis by excluding these children did not alter the results. An additional sensitivity analysis excluding non-white children $(n=10)$ did not alter the results either. Consequently, these children were kept in the analysis. 
Table 3 Baseline characteristics of the study population at preschool age.

\begin{tabular}{|c|c|c|c|}
\hline Patient characteristics & $\begin{array}{c}\text { Healthy } \\
\text { controls } \\
(\mathrm{N}=49)\end{array}$ & $\begin{array}{c}\text { Transient } \\
\text { wheeze } \\
(\mathrm{N}=122)\end{array}$ & $\begin{array}{l}\text { Asthma } \\
(\mathrm{N}=76)\end{array}$ \\
\hline Mean age (SD), in years & $3.3(0.5)$ & $3.2(0.6)$ & $3.3(0.6)$ \\
\hline Gender: male / female, in $\mathrm{N}$ & $24 / 25$ & $63 / 59$ & $46 / 30$ \\
\hline Atopy $^{+} * *$ & 23 & 17 & 37 \\
\hline Atopy first degree $^{\ddagger}$ & 65 & 79 & 79 \\
\hline Eczema* & 22 & 34 & 47 \\
\hline Allergic rhinitis & 2 & 2 & 8 \\
\hline White European descent ${ }^{\S}$ & 98 & 95 & 97 \\
\hline Use of short-acting $\beta_{2}$-agonist* & 0 & 27 & 53 \\
\hline Use of ICS* & 0 & 11 & 30 \\
\hline Day-care attendance & 63 & 73 & 71 \\
\hline Exposure to furry pets & 55 & 46 & 46 \\
\hline Passive smoking & 35 & 30 & 30 \\
\hline Availability DNA & 100 & 100 & 100 \\
\hline Availability RNA & 84 & 92 & 88 \\
\hline Availability of EBC & 98 & 98 & 100 \\
\hline
\end{tabular}

Results are displayed in \%, unless stated otherwise. EBC: Exhaled Breath Condensate; ICS: Inhaled Corticosteroids N: Number of children;SD: Standard Deviation. ${ }^{*} p<0.05$. †Atopy was defined as specific IgE concentration against a mixture of inhalant and food allergens of $\geq 0.35 \mathrm{kU} / \mathrm{l}$ on the Phadiatop Infant test ${ }^{\circledR}$ (Pharmacia, Uppsala, Sweden). ¥ First degree relative with eczema, asthma or allergic rhinitis. $\S$ White European descent was defined as at least two grandparents from white European descent.

\section{Single nucleotide polymorphisms in relationship to classification at age six and mRNA expression}

DNA extraction was successful in all children (100\%). All SNPs had a high call-rate (96.8-99.6\%, Table 1). No deviation from Hardy-Weinberg equilibrium was observed in the control group $(p \geq 0.05$, Table 1$)$. Furthermore, linkage disequilibrium was calculated $\left(R^{2}=0.27\right.$ for IL10 rs1800872 and rs1800896).

Regarding the relationship between SNPs and the classification at age six, the ICAM1 rs5498 AA-genotype was associated with an increased likelihood of childhood asthma compared to the GG-genotype $(p=0.02$, Table 4, Figure 1). For the relationship between SNPs and their respective gene expression we found that the AG-genotype of ICAM1 rs5498 ( $p=0.01)$ and the minor allele of IL10 rs1800896 ( $p<0.01)$ were negatively associated with their mRNA expression levels, whereas the minor allele of IL10 rs1800872 ( $p<0.01)$ was positively associated with IL10 mRNA expression levels (Table 5, Figure 1). The relationship between IL4 and IL13 polymorphisms and their gene expression was not assessed as expression was only detected in a small number of samples ( $n=23$ and $n=44$, respectively). Alternatively, the direct effect of IL4 and IL13 polymorphisms on levels of IL4 and IL13 in EBC was analysed, but did not show any significant association ( $p>0.05$, data not shown). 


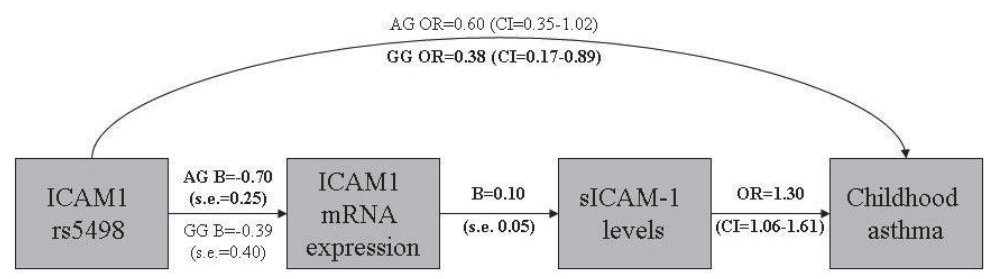

Figure 1 Summary of findings for ICAM1.

The effect of genotype on gene expression and in turn on soluble ICAM1 levels in exhaled breath condensate with as outcome the development of asthma. Besides the direct effect of genotype on asthma development is shown. Abbreviations: B: regression coefficient; ICAM1: Cl: 95\% Confidence Interval; Intercellular Adhesion Molecule 1; OR: Odds Ratio; s.e: standard error; AG: rs5498 AG-genotype, GG: rs5498 GG-genotype. Significant results $(p<0.05)$ are bold.

Table 4 Association between SNPs and the development of childhood asthma.

\begin{tabular}{|c|c|c|c|c|c|c|}
\hline Gene & rs-number & Genotype & $\mathrm{N}$ & $\mathrm{OR}^{\mathrm{a}}$ & $95 \% \mathrm{Cl}$ & $\mathrm{p}$-value \\
\hline \multirow[t]{2}{*}{ IL4 } & rs2243250 & $\mathrm{CC}$ & 175 & ref & & \\
\hline & & $\mathrm{CT} / \mathrm{TT}$ & 64 & 1.70 & $0.98-2.93$ & 0.06 \\
\hline \multirow[t]{3}{*}{ IL8 } & rs2227306 & $\mathrm{CC}$ & 89 & ref & & \\
\hline & & CT & 119 & 1.11 & $0.66-1.86$ & 0.70 \\
\hline & & TT & 35 & 0.53 & $0.25-1.13$ & 0.10 \\
\hline \multirow[t]{5}{*}{ IL10 } & rs1800872 & GG & 131 & ref & & \\
\hline & & $\mathrm{GT} / \mathrm{TT}$ & 115 & 0.80 & $0.50-1.28$ & 0.35 \\
\hline & rs1800896 & TT & 75 & ref & & \\
\hline & & TC & 122 & 0.89 & $0.52-1.53$ & 0.67 \\
\hline & & $\mathrm{CC}$ & 48 & 0.91 & $0.46-1.81$ & 0.79 \\
\hline \multirow[t]{2}{*}{ IL13 } & rs1800925 & $\mathrm{CC}$ & 144 & ref & & \\
\hline & & $\mathrm{CT} / \mathrm{TT}$ & 99 & 1.44 & $0.89-2.35$ & 0.14 \\
\hline \multirow[t]{2}{*}{$T N F \alpha$} & rs1800629 & GG & 174 & ref & & \\
\hline & & GA/AA & 72 & 1.13 & $0.67-1.90$ & 0.66 \\
\hline \multirow[t]{3}{*}{ ICAM1 } & rs5498 & AA & 81 & ref & & \\
\hline & & $A G$ & 137 & 0.60 & $0.35-1.02$ & 0.06 \\
\hline & & GG & 27 & 0.38 & $0.17-0.89$ & 0.02 \\
\hline
\end{tabular}

${ }^{\text {a }}$ Adjusted for gender, age, passive smoking and exposure to furry pets. Abbreviations: $95 \% \mathrm{Cl}$ : $95 \%$ Confidence Interval; ICAM1: Intercellular Adhesion Molecule 1; IL: Interleukin; N: Number of children; OR: Odds Ratio; ref: reference category; TNF $\alpha$ : Tumour-Necrosis-Factor alpha.

\section{mRNA expression in relationship to exhaled breath condensate levels}

In 25 children no RNA samples were obtained as these children refused venous puncture. The mRNA expression markers could be determined in $91-95 \%$ of the samples. A significant positive association was seen for ICAM1 mRNA expression level with the concentration of sICAM1 in EBC ( $p=0.04$, Table 6, Figure 1$)$. 
Table 5 Association between SNPs and mRNA expression at preschool age.

\begin{tabular}{|c|c|c|c|c|c|c|}
\hline Gene & rs-number & Genotype & $\mathrm{N}$ & $B^{a}$ & S.E. & $\mathrm{p}$-value \\
\hline \multirow[t]{3}{*}{ IL8 } & rs2227306 & $\mathrm{CC}$ & 79 & ref & & \\
\hline & & $\mathrm{CT}$ & 106 & 0.04 & 0.20 & 0.86 \\
\hline & & TT & 34 & -0.45 & 0.28 & 0.11 \\
\hline \multirow[t]{5}{*}{ IL10 } & rs1800872 & TT & 117 & ref & & \\
\hline & & TG/GG & 105 & 0.83 & 0.16 & $<0.01$ \\
\hline & rs1800896 & TT & 67 & ref & & \\
\hline & & TC & 111 & -0.58 & 0.19 & $<0.01$ \\
\hline & & $\mathrm{CC}$ & 43 & -1.06 & 0.23 & $<0.01$ \\
\hline \multirow[t]{2}{*}{$T N F \alpha$} & rs1800629 & GG & 159 & ref & & \\
\hline & & GA/AA & 63 & -0.18 & 0.22 & 0.41 \\
\hline \multirow[t]{3}{*}{ ICAM1 } & rs5498 & AA & 74 & ref & & \\
\hline & & $A G$ & 122 & -0.70 & 0.25 & 0.01 \\
\hline & & GG & 25 & -0.39 & 0.40 & 0.34 \\
\hline
\end{tabular}

a Adjusted for group at preschool age, gender, age, passive smoking and exposure to furry pets. Abbreviations: B: regression coefficient; ICAM1: Intercellular Adhesion Molecule 1; IL: Interleukin; N: Number of children; ref: reference category; S.E.: Standard Error; TNF $\alpha$ : Tumour-Necrosis-Factor alpha.

Table 6 Association between mRNA expression and inflammation markers in EBC at preschool age.

\begin{tabular}{lllll}
\hline Gene & N & $B^{\text {a }}$ & S.E. & p-value \\
\hline IL8 & 210 & 0.05 & 0.06 & 0.33 \\
IL10 & 204 & 0.02 & 0.07 & 0.77 \\
TNF $\alpha$ & 201 & 0.02 & 0.05 & 0.72 \\
ICAM1 & 210 & 0.10 & 0.05 & 0.04 \\
\hline
\end{tabular}

a Adjusted for group at preschool age, gender, age, passive smoking and exposure to furry pets. Abbreviations: B: regression coefficient; ICAM1: Intercellular Adhesion Molecule 1; IL: Interleukin; N: Number of children; S.E.: Standard Error; TNF $\alpha$ : Tumour-Necrosis-Factor alpha.

\section{Levels in exhaled breath condensate in relationship to classification at age six}

Inflammation markers in EBC were successfully analysed in all but three children due to technical problems. EBC markers were above the detection limit in more than $98 \%$ of the samples. sICAM1 (Figure 1), IL4, IL8, IL10 and IL13 were significantly positively associated with the risk to develop asthma $(p=0.01, p<0.01, p=0.05, p<0.01, p<0.01$ respectively, Table 7). 
Table 7 Association between inflammation markers in EBC at preschool age and the development of childhood asthma.

\begin{tabular}{lcccr}
\hline Marker & $\mathrm{N}$ & $\mathrm{OR}^{\mathrm{a}}$ & $95 \% \mathrm{Cl}$ & \multicolumn{1}{c}{$\mathrm{p}$-value } \\
\hline IL4 & 244 & 1.42 & $1.11-1.83$ & $<0.01$ \\
IL8 & 244 & 1.26 & $1.00-1.57$ & 0.05 \\
IL10 & 244 & 1.43 & $1.15-1.78$ & $<0.01$ \\
IL13 & 244 & 1.42 & $1.12-1.81$ & $<0.01$ \\
TNF $\alpha$ & 244 & 1.02 & $0.81-1.29$ & 0.85 \\
sICAM1 & 244 & 1.30 & $1.06-1.61$ & 0.01 \\
\hline
\end{tabular}

a Adjusted for gender, age, passive smoking and exposure to furry pets. Abbreviations: N: number of children; OR: Odds Ratio; 95\% Cl: 95\% Confidence Interval; IL: Interleukin; TNF $\alpha$ : Tumour-Necrosis-Factor alpha; sICAM1: soluble Intercellular Adhesion Molecule 1.

\section{Discussion}

In this prospective study, we examined associations between SNPs, gene expression levels in white blood cells and protein levels in EBC for various inflammation markers at preschool age in relationship to the risk of developing asthma at the age of six. ICAM1 has previously been shown to play a central role in the recruitment and migration of leukocytes to sites of inflammation and has been linked to childhood asthma. ${ }^{6,14,38-40}$ In this study, the ICAM1 rs5498 A-allele was found to be associated with increased mRNA expression of this gene and an increased likelihood of developing asthma. Similar results have been reported in an Afro-American population were the A-allele was also found to be associated with asthma. ${ }^{14}$ However, the G-allele has also been associated with asthma. ${ }^{41}$ Moreover, we demonstrated that increased ICAM1 mRNA levels were associated with increased levels of sICAM1 in EBC and higher levels of SICAM1 were in turn associated with an increased risk for asthma at the age of six. Furthermore, levels of IL4, IL8, IL10 and IL13 in EBC, were positively associated with the risk to develop asthma. A potential mechanism is that increased expression and levels of sICAM1 might lead to an increased binding of leukocytes and thereby increased production of inflammation. Taken together, our study indicates that ICAM1 is a significant marker of and may be involved in childhood asthma development.

The ICAM1 polymorphism rs5498 G-allele results in an amino acid change in exon 6 (K469E). The domain in the protein to which this amino acid belongs, is subject to debate. According to Bella and co-workers the rs5498 polymorphism is located in the membrane-spanning region, causing a shift in electrical charge, which may influence anchorage in the membrane, thereby affecting the ability to bind inflammatory cells. ${ }^{42}$ This disagrees with other studies stating that rs5498 is located outside the membrane. $^{43-45}$ It has been hypothesised that this polymorphism can influence 
protein-protein dimerization and, in this way alter the ability to bind inflammatory cells. ${ }^{46,47}$ Moreover, Robledo et al, suggested that the rs5498 polymorphism makes ICAM1 more prone to enzymatic cleavage. ${ }^{44}$ This may result in an increased generation of SICAM1, which could decrease the binding ability of leukocytes. On the other hand, the presence of the A-allele has been shown to lead to alternative splicing, also resulting in an increased formation of sICAM1. ${ }^{46}$ Overall, these data suggest that the rs5498 polymorphism in ICAM1 may play a role in the development of airway inflammation by decreasing the binding capacity of leukocytes. This is in line with data obtained in animal models, in which the absence of ICAM1 caused reduced leukocyte influx and consequently decreased airway hyper-reactivity. ${ }^{48}$

We demonstrated that the ICAM1 mRNA concentration was increased among subjects with the ICAM1 rs5498 AA-genotype. This increased concentration may be due to either linkage of rs5498 with a SNP in the promoter region, a decreased degradation of the mRNA or a reduced feedback mechanism due to alternative splicing and/or generation of sICAM1. Remarkable in this respect is the positive relationship we found between ICAM1 mRNA concentration and levels of sICAM1 in EBC. It is conceivable that increased mRNA concentrations lead to a higher expression of ICAM1 on the leukocyte cell membrane. This increased expression is, in turn, expected to enhance the binding of leucocytes to the affected lung epithelium, thereby increasing the number of local leucocytes. Consequently, the total production of inflammation markers might be increased due to the increased number of leucocytes. This can explain the higher levels of interleukins and SICAM1 detected in EBC of asthmatics. Increased levels of interleukins and SICAM1 in EBC have also been reported previously in asthmatic children. 6,24

We found no association between the studied IL10 polymorphisms and asthma development. This is in contrast with previous studies that demonstrated that IL10 polymorphisms rs 1800896 and rs1800872 were associated with asthma in children. ${ }^{9,19}$ However, we did provide evidence that gene expression of IL10 is decreased in the presence of at least one rs $1800896 \mathrm{C}$-allele and increased in the presence of at least one rs1800872 G-allele. However, gene expression of IL10 was not related to levels of IL10 in EBC. Nevertheless, in our study the levels of IL10 in EBC were positively associated with asthma development. Previous research has demonstrated low levels of IL10 in plasma of asthmatic children, but IL10 in EBC did not differ between healthy controls and asthmatics in other studies. ${ }^{6,7,10}$ As stated before, the relationship between increased IL10 levels and asthma development might be a consequence of the presence of more leucocytes and consequently increased inflammation in the lung tissue and as such is related to sICAM1 levels.

We found no associations for rs2243250 in IL4 and rs1800925 in IL13 and the development of asthma, although these SNPs have repeatedly been reported to be associated with childhood asthma. ${ }^{16,20,21}$ Neither were these SNPs related to levels in EBC. Expression data on IL4 and IL13 could not be analysed. These markers probably 
have a low expression in PBMCs and might only be detected in activated cells. However, levels of IL4 and IL13 in EBC were positively associated with asthma development. This is possibly due to the suggested increase in the number of leukocytes and enhanced inflammation in the lung tissue. Our findings are in line with previous research, demonstrating increased levels of IL4 and IL13 in EBC in asthmatic children and healthy children, but no difference in EBC levels between wheezing phenotypes and healthy children was found in another study. ${ }^{6,7}$

A major strength of the present study is that we have prospectively studied inflammation markers in childhood asthma at gene coding, gene expression and protein level with a unique approach. Furthermore, we used a non-invasive and feasible method to measure airway inflammation by using markers in EBC. Although this technique seems to be sensitive and reproducible, more research is required before implementation in daily practice is possible. ${ }^{6-8}$ The high follow-up rate (98\%) and our diagnostic approach (expert opinion and computer-algorithm with reassessment in case of inconclusive findings) provided us with a well-defined study population. Moreover, the use of ordinal regression permitted us to observe the relationship of inflammation markers with childhood asthma in three different groups with increasing severity of symptoms. However, a limitation of the current study is that, due to ethical considerations, it was not possible to measure expression of ICAM1 on the cell membrane of local leucocytes in the lungs. Consequently, the mRNA samples are at best a reference for the overall status of the immune system and, therefore, also of the lungs.

In summary, in this study we have investigated the role of genetic variants, gene expression and protein levels in EBC of inflammation markers at preschool age in relationship to asthma development at six years of age. Our results suggest a significant role of ICAM1 in the development of childhood asthma. We demonstrated an adverse effect for the ICAM1 rs5498 A-allele which is associated with an increased expression of ICAM1 mRNA and in turn increased sICAM1 levels in EBC. This might lead to an increased binding of leukocytes and thereby an increased production of inflammation markers, ultimately leading to the development of asthma. 


\section{References}

1. Bisgaard H, Szefler S, Prevalence of asthma-like symptoms in young children. Pediatr Pulmonol 2007;42: 723-8.

2. Pedersen SE, Hurd SS, Lemanske RF, Jr., Becker A, Zar HJ, Sly PD, Soto-Quiroz M, Wong G, Bateman $E D$, Global strategy for the diagnosis and management of asthma in children 5 years and younger. Pediatr Pulmonol 2011;46: 1-17.

3. Savenije OE, Granell R, Caudri D, Koppelman GH, Smit HA, Wijga A, de Jongste JC, Brunekreef B, Sterne JA, Postma DS, Henderson J, Kerkhof M, Comparison of childhood wheezing phenotypes in 2 birth cohorts: ALSPAC and PIAMA. J Allergy Clin Immunol 2011;127: 1505-12 e14.

4. van de Kant KD, Klaassen EM, Jöbsis $Q$, Koers $K$, Rijkers GT, van der Grinten $C P$, van Schayck OC, Passos VL, Dompeling E, Wheezing in preschool children is associated with increased levels of cytokines/chemokines in exhaled breath condensate. J Allergy Clin Immunol 2010;126: 669-71.

5. Koppelman GH, Nawijn MC, Recent advances in the epigenetics and genomics of asthma. Curr Opin Allergy Clin Immunol 2011;11: 414-9.

6. Robroeks CM, Rijkers GT, Jöbsis Q, Hendriks HJ, Damoiseaux JG, Zimmermann LJ, van Schayck OP, Dompeling $\mathrm{E}$, Increased cytokines, chemokines and soluble adhesion molecules in exhaled breath condensate of asthmatic children. Clin Exp Allergy 2010;40: 77-84.

7. Rosias PP, Robroeks CM, van de Kant KD, Rijkers GT, Zimmermann LJ, van Schayck CP, Heynens JW, Jöbsis Q, Dompeling E, Feasibility of a new method to collect exhaled breath condensate in pre-school children. Pediatr Allergy Immunol 2009.

8. Hunt J, Exhaled breath condensate: an evolving tool for noninvasive evaluation of lung disease. J Allergy Clin Immunol 2002;110: 28-34.

9. Hunninghake GM, Soto-Quiros ME, Lasky-Su J, Avila L, Ly NP, Liang C, Klanderman BJ, Raby BA, Gold DR, Weiss ST, Celedon JC, Dust mite exposure modifies the effect of functional IL10 polymorphisms on allergy and asthma exacerbations. J Allergy Clin Immunol 2008;122: 93-8, 98 e1-5.

10. Zheng XQ, Li CC, Xu DP, Lin A, Bao WG, Yang GS, Yan WH, Analysis of the plasma soluble human leukocyte antigen-G and interleukin-10 levels in childhood atopic asthma. Hum Immunol 2010;71: 982-7.

11. Hunninghake GM, Soto-Quiros ME, Avila L, Su J, Murphy A, Demeo DL, Ly NP, Liang C, Sylvia JS, Klanderman BJ, Lange C, Raby BA, Silverman EK, Celedon JC, Polymorphisms in IL13, total IgE, eosinophiliaand asthma exacerbations in childhood. J Allergy Clin Immunol 2007;120: 84-90.

12. Munthe-Kaas MC, Carlsen KL, Carlsen KH, Egeland T, Haland G, Devulapalli CS, Akselsen H, Undlien D, HLA Dr-Dq haplotypes and the TNFA-308 polymorphism: associations with asthma and allergy. Allergy 2007;62: 991-8.

13. Castro-Giner F, Kogevinas M, Machler M, de Cid R, Van Steen K, Imboden M, Schindler C, Berger W, Gonzalez JR, Franklin KA, Janson C, Jarvis D, Omenaas E, Burney P, Rochat T, Estivill X, Anto JM, Wjst $\mathrm{M}$, Probst-Hensch NM, TNFA -308G>A in two international population-based cohorts and risk of asthma. Eur Respir J 2008;32: 350-61.

14. Li YF, Tsao YH, Gauderman WJ, Conti DV, Avol E, Dubeau L, Gilliland FD, Intercellular adhesion molecule-1 and childhood asthma. Hum Genet 2005;117: 476-84.

15. El-Sawy IH, Badr-El-Din OM, El-Azzouni OE, Motawae HA, Soluble intercellular adhesion molecule-1 in sera of children with bronchial asthma exacerbation. Int Arch Allergy Immunol 1999;119: 126-32.

16. Kabesch M, Schedel M, Carr D, Woitsch B, Fritzsch C, Weiland SK, von Mutius E, IL-4/IL-13 pathway genetics strongly influence serum IgE levels and childhood asthma. J Allergy Clin Immunol 2006;117: 269-74.

17. Beghe B, Barton S, Rorke S, Peng Q, Sayers I, Gaunt T, Keith TP, Clough JB, Holgate ST, Holloway JW, Polymorphisms in the interleukin-4 and interleukin-4 receptor alpha chain genes confer susceptibility to asthma and atopy in a Caucasian population. Clin Exp Allergy 2003;33: 1111-7.

18. Heinzmann A, Ahlert I, Kurz T, Berner R, Deichmann KA, Association study suggests opposite effects of polymorphisms within IL8 on bronchial asthma and respiratory syncytial virus bronchiolitis. J Allergy Clin Immunol 2004;114: 671-6. 
19. Lyon H, Lange C, Lake S, Silverman EK, Randolph AG, Kwiatkowski D, Raby BA, Lazarus R, Weiland KM, Laird N, Weiss ST, IL10 gene polymorphisms are associated with asthma phenotypes in children. Genet Epidemiol 2004;26: 155-65.

20. Heinzmann A, Jerkic SP, Ganter K, Kurz T, Blattmann S, Schuchmann L, Gerhold K, Berner R, Deichmann KA, Association study of the IL13 variant Arg110Gln in atopic diseases and juvenile idiopathic arthritis. J Allergy Clin Immunol 2003;112: 735-9.

21. Hoffjan S, Ostrovnaja I, Nicolae D, Newman DL, Nicolae R, Gangnon R, Steiner L, Walker K, Reynolds R, Greene D, Mirel D, Gern JE, Lemanske RF, Jr., Ober C, Genetic variation in immunoregulatory pathways and atopic phenotypes in infancy. J Allergy Clin Immunol 2004;113: 511-8.

22. Albuquerque RV, Hayden CM, Palmer LJ, Laing IA, Rye PJ, Gibson NA, Burton PR, Goldblatt J, Lesouef $\mathrm{PN}$, Association of polymorphisms within the tumour necrosis factor (TNF) genes and childhood asthma. Clin Exp Allergy 1998;28: 578-84.

23. Li YF, Gauderman WJ, Avol E, Dubeau L, Gilliland FD, Associations of tumor necrosis factor G-308A with childhood asthma and wheezing. Am J Respir Crit Care Med 2006;173: 970-6.

24. Tang RB, Chen SJ, Soong WJ, Chung RL, Circulating adhesion molecules in sera of asthmatic children. Pediatr Pulmonol 2002;33: 249-54.

25. Puthothu B, Krueger M, Heinze J, Forster J, Heinzmann A, Impact of IL8 and IL8-receptor alpha polymorphisms on the genetics of bronchial asthma and severe RSV infections. Clin Mol Allergy 2006;4: 2.

26. van de Kant KD, Klaassen EM, Jöbsis Q, Nijhuis AJ, van Schayck OC, Dompeling E, Early diagnosis of asthma in young children by using non-invasive biomarkers of airway inflammation and early lung function measurements: study protocol of a case-control study. BMC Public Health 2009;9: 210.

27. Worldwide variation in prevalence of symptoms of asthma, allergic rhinoconjunctivitisand atopic eczema: ISAAC. The International Study of Asthma and Allergies in Childhood (ISAAC) Steering Committee. Lancet 1998;351: 1225-32.

28. Klaassen EM, van Kant KD, Jöbsis $Q, H \varnothing v i g ~ S T$, van Schayck CP, Rijkers GT, Dompeling E, Symptoms, but not a biomarker response to inhaled corticosteroids, predict asthma in preschool children with recurrent wheeze. Mediators Inflamm 2012;2012: 162571.

29. Miller MR, Hankinson J, Brusasco V, Burgos F, Casaburi R, Coates A, Crapo R, Enright P, van der Grinten CP, Gustafsson P, Jensen R, Johnson DC, Maclntyre N, McKay R, Navajas D, Pedersen OF, Pellegrino R, Viegi G, Wanger J, Standardisation of spirometry. Eur Respir J 2005;26: 319-38.

30. Pellegrino R, Viegi G, Brusasco V, Crapo RO, Burgos F, Casaburi R, Coates A, van der Grinten CP, Gustafsson P, Hankinson J, Jensen R, Johnson DC, Maclntyre N, McKay R, Miller MR, Navajas D, Pedersen OF, Wanger J, Interpretative strategies for lung function tests. Eur Respir J 2005;26: 948-68.

31. Bottema RW, Reijmerink NE, Kerkhof M, Koppelman GH, Stelma FF, Gerritsen J, Thijs C, Brunekreef B, van Schayck CP, Postma DS, Interleukin 13, CD14, pet and tobacco smoke influence atopy in three Dutch cohorts: the allergenic study. Eur Respir J 2008;32: 593-602.

32. de Jager W, te Velthuis H, Prakken BJ, Kuis W, Rijkers GT, Simultaneous detection of 15 human cytokines in a single sample of stimulated peripheral blood mononuclear cells. Clin Diagn Lab Immunol 2003;10: 133-9.

33. van de Kant KD, Koers K, Rijkers GT, Lima Passos V, Klaassen EM, Mommers M, Dagnelie PC, van Schayck CP, Dompeling E, Jöbsis Q, Can exhaled inflammatory markers predict a steroid response in wheezing preschool children? Clin Exp Allergy 2011;41: 1076-83.

34. Visser CA, Garcia-Marcos L, Eggink J, Brand PL, Prevalence and risk factors of wheeze in Dutch infants in their first year of life. Pediatr Pulmonol 2010;45: 149-56.

35. Kerkhof M, Wijga AH, Brunekreef B, Smit HA, de Jongste JC, Aalberse RC, Hoekstra MO, Gerritsen J, Postma DS, Effects of pets on asthma development up to 8 years of age: the PIAMA study. Allergy 2009;64: 1202-8.

36. Kuiper S, Muris JW, Dompeling E, Kester AD, Wesseling G, Knottnerus JA, van Schayck CP, Interactive effect of family history and environmental factors on respiratory tract-related morbidity in infancy. J Allergy Clin Immunol 2007;120: 388-95. 
37. Schultz A, Devadason SG, Savenije OE, Sly PD, Le Souef PN, Brand PL, The transient value of classifying preschool wheeze into episodic viral wheeze and multiple trigger wheeze. Acta Paediatr 2010;99: 56-60.

38. Vogel SM, Orrington-Myers J, Broman M, Malik AB, De novo ICAM-1 synthesis in the mouse lung: model of assessment of protein expression in lungs. Am J Physiol Lung Cell Mol Physiol 2006;291: L496-501.

39. Keramidaris E, Merson TD, Steeber DA, Tedder TF, Tang ML, L-selectin and intercellular adhesion molecule 1 mediate lymphocyte migration to the inflamed airway/lung during an allergic inflammatory response in an animal model of asthma. J Allergy Clin Immunol 2001;107: 734-8.

40. Montefort S, Holgate ST, Adhesion molecules and their role in inflammation. Respir Med 1991;85: 91-9.

41. Puthothu B, Krueger M, Bernhardt M, Heinzmann A, ICAM1 amino-acid variant K469E is associated with paediatric bronchial asthma and elevated sICAM1 levels. Genes Immun 2006;7: 322-6.

42. Bella J, Kolatkar PR, Marlor CW, Greve JM, Rossmann MG, The structure of the two amino-terminal domains of human ICAM-1 suggests how it functions as a rhinovirus receptor and as an LFA-1 integrin ligand. Proc Natl Acad Sci U S A 1998;95: 4140-5.

43. Staunton DE, Marlin SD, Stratowa C, Dustin ML, Springer TA, Primary structure of ICAM-1 demonstrates interaction between members of the immunoglobulin and integrin supergene families. Cell 1988;52: 925-33.

44. Robledo O, Papaioannou A, Ochietti B, Beauchemin C, Legault D, Cantin A, King PD, Daniel C, Alakhov VY, Potworowski EF, St-Pierre Y, ICAM-1 isoforms: specific activity and sensitivity to cleavage by leukocyte elastase and cathepsin G. Eur J Immunol 2003;33: 1351-60.

45. Jun CD, Shimaoka M, Carman CV, Takagi J, Springer TA, Dimerization and the effectiveness of ICAM-1 in mediating LFA-1-dependent adhesion. Proc Natl Acad Sci U S A 2001;98: 6830-5.

46. Iwao M, Morisaki $H$, Morisaki $T$, Single-nucleotide polymorphism g.1548G > A (E469K) in human ICAM-1 gene affects mRNA splicing pattern and TPA-induced apoptosis. Biochem Biophys Res Commun 2004;317: 729-35.

47. Casasnovas JM, Stehle T, Liu JH, Wang JH, Springer TA, A dimeric crystal structure for the N-terminal two domains of intercellular adhesion molecule-1. Proc Natl Acad Sci U S A 1998;95: 4134-9.

48. Tang ML, Fiscus LC, Important roles for L-selectin and ICAM-1 in the development of allergic airway inflammation in asthma. Pulm Pharmacol Ther 2001;14: 203-10. 

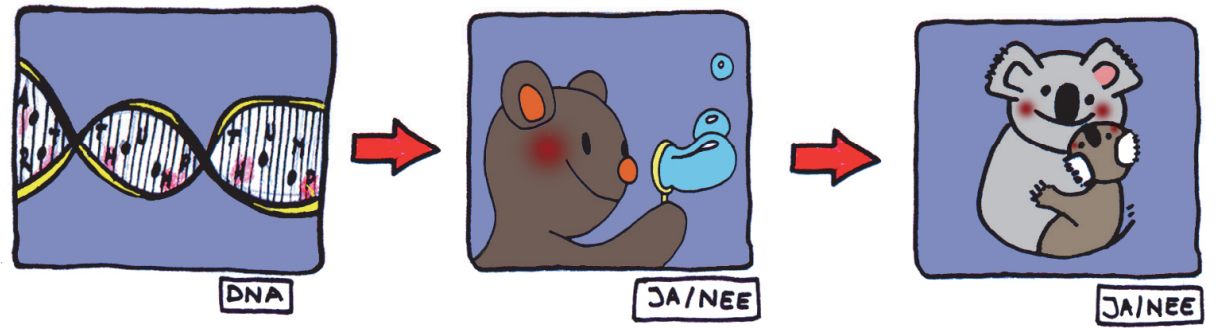


\title{
Chapter 6
}

\section{Genetic variants in ADAM33 are associated with}

\author{
asthma at six years of age
}

Klaassen EMM, Penders J, Jöbsis Q, van de Kant KDG, Thijs C, Mommers M, van Schayck CP, van Eys G, Koppelman GH, Dompeling E

Submitted for publication 


\section{Abstract}

\section{Background}

The influence of various candidate genes in relation to the development of asthma in young children still needs to be defined. We aimed to link genetic variants in various asthma candidate genes to children with transient wheeze and children with asthma in order to increase the insight into the pathophysiology of asthma.

\section{Methods}

In a prospective study, 202 children with recurrent wheeze from the ADEM (Asthma DEtection and Monitoring) study were followed until the age of six. At six years of age a classification (transient wheeze or asthma) was based on symptoms, lung function and medication use. The relationship between this classification and 30 polymorphisms in 16 asthma candidate genes was assessed by logistic regression. In case of an association based on a $\mathrm{p}<0.10$, replication analysis was performed in an independent birth cohort study (KOALA study) based on a $\mathrm{p}<0.05$.

\section{Results}

The ADAM33 rs511898 and rs528577 and the ORMDL3 rs7216389 polymorphisms were negatively associated and the IL4 rs2243250 and rs2070874 polymorphisms were positively associated with childhood asthma in the ADEM study. Replication in the KOALA study was successful for ADAM33 rs528577 with a negative association of the CG/GG-genotype with childhood asthma (OR $(95 \% \mathrm{Cl}): 0.42(0.21-0.82) \mathrm{p}=0.01)$.

\section{Conclusions}

Polymorphisms in ADAM33, ORML3 and IL4 were associated with childhood asthma in a group of children with recurrent wheeze. The replication of the negative association of the CG/GG-genotype of rs528577 ADAM33 with childhood asthma in an independent birth cohort study confirms the relationship of ADAM33 with childhood asthma. 


\section{Introduction}

Asthma is a common disease in childhood. Twin studies have demonstrated a large contribution of genetics in the development of asthma. ${ }^{1,2}$ While the cumulative effect of genetic factors is large, the individual contribution of each factor may be limited. Recently much progress has been made in the field of asthma genetics. However, the influence of many candidate genes in relation to the development of asthma in young children still needs to be defined.

Asthma is characterised by chronic airway inflammation and airway (hyper-) responsiveness. ${ }^{3,4}$ Although asthma starts with wheeze, not all wheezing children will develop asthma. ${ }^{4,5}$ It is assumed that a dysfunction of the maturating immune system at a young age caused by genetic predisposition in combination with an environmental trigger, such as a viral or bacterial infection can lead to asthma. ${ }^{6-8}$ Several asthma candidate genes can be functionally implicated in this hypothesis including pro-inflammatory genes ( $I L 4, I L 5, I L 8, I L 13, I L 33, T N F \alpha)$, anti-inflammatory genes (IL10, CC16), genes involved in airway remodelling (ADAM33, PLAUR and possibly ORMDL3), genes involved in the epithelial barrier function (PCDH1 and possibly ORMDL3), genes involved in leukocyte migration (ICAM1) and genes involved in immune modulation (IL4RA, LTC4, ILIRL1).

The linkage of genetic variants in asthma candidate genes to children with transient wheeze and children with asthma is expected to result into an increased insight into the pathophysiology of asthma. Therefore, in a cohort study of recurrent wheezers we assessed genetic variants in the 16 above mentioned asthma candidate genes with childhood asthma. In an independent birth cohort study we assessed whether we could replicate our findings.

\section{Materials and methods}

\section{The ADEM study}

\section{Study population of the ADEM study}

The Asthma DEtection and Monitoring (ADEM) study is a long-term case-control study executed in the Netherlands. The aim of this study is to develop a non-invasive instrument for an early asthma diagnosis in children and to study aetiological factors in relation to the early development of asthma. ${ }^{9}$ A total of 202 children with recurrent wheeze ( $\geq 2$ episodes during life according to the International Study of Asthma and Allergies in Childhood (ISAAC) questionnaire) ${ }^{10}$ and 50 healthy controls (random selection of children without wheezing episodes during life) at two to four years of age were included. For the current analysis, only the children with recurrent wheeze 
were included. The study protocol was approved by the Dutch Central Committee on Research Involving Human Subjects. All parents provided written informed consent.

\section{Asthma classification in the ADEM study}

At the age of six years a classification (transient wheezer or true asthmatic) was assessed by an experienced paediatrician in the field of respiratory medicine. This classification was based on symptoms, lung function (reversibility to a $\beta_{2}$-agonist and bronchial hyper-responsiveness) and medication use. Bronchial hyper-responsiveness and reversibility measurements were performed according to the European Respiratory Society guideline. ${ }^{12}$ In addition to this clinical classification, the classification was assessed by a computer-calculated algorithm as described previously. ${ }^{11}$ Mismatching cases between the clinical and the computer classification were re-evaluated by the paediatrician, who was blinded to the previous assessment.

\section{DNA isolation and genotyping in the ADEM study}

Saliva was collected by Oragene DNA self-collection kits (Oragene ${ }^{\circledR}$ Ottowa, Canada). If children were unable to produce sufficient saliva, buccal cells were obtained. DNA was isolated according to the manufacturers' protocol. Participants were genotyped for 30 single nucleotide polymorphisms (SNPs) in 16 genes (Table 1). Candidate markers were selected based on previous association with childhood asthma and a minor allele frequency of at least 10\% (www.hapmap.org or literature). In total, 27 of the SNPs were determined by using a mass-spectroscopy based, high-throughput Mass ARRAY ${ }^{\circ}$ iPLEX platform (Sequenom Inc., Hamburg, Germany) using three multiplex genotyping reactions. Sequences were evaluated by ProxSNP and PreXTEND software (http:www.realsnp.com). Sequenom Assay Designer 3.1 software was used to create the different multiplexes. Genotyping was performed according to the iPLEX method. Primer and probe information is provided in Table 2. Three of the selected SNPs could not be fitted into the multiplex reactions ( $r$ 1805010, rs2243250, rs3741240) and therefore these SNPs were determined by using Taqman ${ }^{\circledR}$ genotyping assays ID C_2769554_10, ID C_16176216_10 and ID C_25473445_10 (Applied Biosystems, California, USA).

\section{The KOALA birth cohort study}

\section{Study population of the KOALA birth cohort study}

The KOALA Birth Cohort Study (the Child, Parent and Health: Lifestyle and, Genetic Constitution study) is a prospective study in the Netherlands with the goal of investigating early life risk factors for atopy and asthma. ${ }^{13}$ Pregnant healthy women (2343 women with conventional lifestyle32we and 491 women with alternative 
lifestyles) were enrolled at 34 weeks of gestation. Ultimately, 2834 children were included in the study. The KOALA study was approved by the Ethical Committee of the University Hospital of Maastricht and all parents signed informed consent for the study. For the current analysis, only the children with recurrent wheeze were included ( $\geq 2$ episodes during life according to the ISAAC questionnaire ${ }^{10}$ at four years of age, $n=427$ ).

Table 1 Candidate genes and selected SNPs.

\begin{tabular}{|c|c|c|c|c|c|c|c|}
\hline Gene & Chr. & SNP & Location & $\begin{array}{l}\text { Major/mi } \\
\text { nor allele }\end{array}$ & MAF* & $\mathrm{HWE}^{*}(\mathrm{p})$ & $\begin{array}{c}\text { Call-rate* } \\
(\%)\end{array}$ \\
\hline \multirow[t]{5}{*}{ ADAM33 } & 20 & rs511898 & Intron & $\mathrm{C} / \mathrm{T}$ & 38 & 0.41 & 99 \\
\hline & & rs528557 & Exon & $C / G$ & 31 & 0.17 & 100 \\
\hline & & rs574174 & Intron & $\mathrm{C} / \mathrm{T}$ & 24 & 0.85 & 99 \\
\hline & & rs597980 & Intron & $A / G$ & 51 & 0.48 & 100 \\
\hline & & rs2280091 & Exon & $A / G$ & 13 & 0.24 & 100 \\
\hline CC16 & 11 & rs3741240 & 5'UTR & $\mathrm{G} / \mathrm{A}$ & 36 & 0.05 & 96 \\
\hline$C D 14$ & 5 & rs2569190 & Intron & $A / G$ & 51 & 1.00 & 99 \\
\hline ICAM1 & 19 & rs5498 & Exon & $A / G$ & 37 & 0.02 & 99 \\
\hline \multirow[t]{2}{*}{ ILIRL1 } & 2 & rs1420101 & Intron & $\mathrm{C} / \mathrm{T}$ & 39 & 0.24 & 99 \\
\hline & & rs1861245 & Intron & $\mathrm{C} / \mathrm{T}$ & 32 & $<0.01$ & 99 \\
\hline \multirow[t]{2}{*}{ IL4 } & 5 & rs2070874 & 5'UTR & $\mathrm{C} / \mathrm{T}$ & 14 & 0.93 & 99 \\
\hline & & rs2243250 & Promoter & $C / T$ & 15 & 0.37 & 97 \\
\hline \multirow[t]{4}{*}{ IL4RA } & 16 & rs1805010 & Exon & $A / G$ & 46 & 0.34 & 92 \\
\hline & & rs1805011 & Exon & $\mathrm{A} / \mathrm{C}$ & 10 & 0.12 & 100 \\
\hline & & rs1805015 & Exon & $\mathrm{T} / \mathrm{C}$ & 15 & 0.07 & 99 \\
\hline & & rs1801275 & Exon & $A / G$ & 20 & 0.48 & 99 \\
\hline IL5 & 5 & rs2069812 & Promoter & $\mathrm{G} / \mathrm{A}$ & 34 & 0.27 & 99 \\
\hline IL8 & 4 & rs2227306 & Intron & $C / T$ & 38 & 0.35 & 99 \\
\hline \multirow[t]{2}{*}{ IL10 } & 1 & rs1800872 & Promoter & $\mathrm{G} / \mathrm{T}$ & 25 & 0.37 & 100 \\
\hline & & rs1800896 & Promoter & $\mathrm{T} / \mathrm{C}$ & 44 & 0.91 & 99 \\
\hline IL13 & 1 & rs1800925 & Promoter & $\mathrm{C} / \mathrm{T}$ & 24 & 0.51 & 99 \\
\hline IL33 & 5 & rs3939286 & Promoter & $\mathrm{C} / \mathrm{T}$ & 28 & 0.29 & 100 \\
\hline LTC4 & 9 & rs730012 & Promoter & $\mathrm{A} / \mathrm{C}$ & 28 & 0.11 & 100 \\
\hline ORMDL3 & 5 & rs7216389 & Intron & $\mathrm{T} / \mathrm{C}$ & 40 & 0.06 & 100 \\
\hline \multirow[t]{2}{*}{ PCDH1 } & 5 & rs3797054 & Exon & $A / G$ & 35 & 0.26 & 99 \\
\hline & & rs3822357 & Exon & $\mathrm{C} / \mathrm{T}$ & 6 & 0.80 & 100 \\
\hline \multirow[t]{3}{*}{ PLAUR } & 19 & rs2239372 & Intron & $A / G$ & 46 & 0.14 & 100 \\
\hline & & rs4493171 & 5'UTR & $\mathrm{C} / \mathrm{T}$ & 19 & 0.40 & 99 \\
\hline & & rs4803648 & Downstream & $\mathrm{T} / \mathrm{A}$ & 16 & 0.27 & 99 \\
\hline \multirow[t]{2}{*}{ TLR2 } & 2 & rs3804099 & Intron & $\mathrm{T} / \mathrm{C}$ & 45 & 0.15 & 99 \\
\hline & & rs4696480 & Exon & $\mathrm{T} / \mathrm{A}$ & 51 & 0.51 & 99 \\
\hline TLR4 & 9 & rs2737190 & Promoter & $A / G$ & 37 & 0.24 & 99 \\
\hline \multirow[t]{2}{*}{ TLR9 } & 3 & rs187084 & Promoter & $A / G$ & 40 & 0.17 & 99 \\
\hline & & rs5743836 & Promoter & $A / G$ & 17 & 0.02 & 99 \\
\hline$T N F \alpha$ & 6 & rs1800629 & Promoter & $\mathrm{G} / \mathrm{A}$ & 16 & 0.86 & 100 \\
\hline
\end{tabular}

Chr.: chromosome; HWE: Harby-Weinberg equilibrium; MAF: Minor Allele Frequency in \%; p: p-value; SNP: Single Nucleotide Polymorphism. * based on the ADEM (Asthma DEtection and Monitoring) study. 
Table 2 Primer sequences used for genotyping by Sequenom.

\begin{tabular}{|c|c|c|c|c|}
\hline Gene & SNP & Extension primer & PCR-1 & PCR-2 \\
\hline \multirow[t]{5}{*}{ ADAM33 } & rs511898 & aAGGCCTGTGAATTCC & $\begin{array}{l}\text { ACGTTGGATGAAAATACTG } \\
\text { GGACTCGAGGC }\end{array}$ & $\begin{array}{l}\text { ACGTTGGATGATGGGAGT } \\
\text { GGGAATGCTGTA }\end{array}$ \\
\hline & rs528557 & ccGCTGCCTCTGCTCCCAGG & $\begin{array}{l}\text { ACGTTGGATGACCTTCCTG } \\
\text { CTGGCCATGCT }\end{array}$ & $\begin{array}{l}\text { ACGTTGGATGAGTCGGTA } \\
\text { GCAACACCAGG }\end{array}$ \\
\hline & rs597980 & ttACAGGGGCAGCCAGCACC & $\begin{array}{l}\text { ACGTTGGATGGGTCACAG } \\
\text { AGAACTGGGTTA }\end{array}$ & $\begin{array}{l}\text { ACGTTGGATGTTCACTCCA } \\
\text { TACCACTGG } \\
\end{array}$ \\
\hline & rs574174 & cctcGACTGTCCCCATCCCATC & $\begin{array}{l}\text { ACGTTGGATGTGCCCTTGA } \\
\text { TGATTCCAAGC } \\
\end{array}$ & $\begin{array}{l}\text { ACGTTGGATGGGAACATCA } \\
\text { CAGGAAATGAC }\end{array}$ \\
\hline & rs2280091 & $\begin{array}{l}\text { ACGTTGGATGCTGTCCAGTG } \\
\text { GCTGTGGG } \\
\end{array}$ & $\begin{array}{l}\text { ACGTTGGATGCCAAAGATG } \\
\text { GCCCACACAG } \\
\end{array}$ & $\begin{array}{l}\text { ACGTTGGATGCTGTCCAGT } \\
\text { GGCTGTGGG }\end{array}$ \\
\hline CD14 & rs2569190 & cctAATCCTTCCTGTTACGG & $\begin{array}{l}\text { ACGTTGGATGAGACACAG } \\
\text { AACCCTAGATGC }\end{array}$ & $\begin{array}{l}\text { ACGTTGGATGGCAATGAA } \\
\text { GGATGTTTCAGG }\end{array}$ \\
\hline ICAM1 & rs5498 & $\begin{array}{l}\text { gagcGCACATTCACGGTCACC } \\
\mathrm{T}\end{array}$ & $\begin{array}{l}\text { ACGTTGGATGCTCACAGAG } \\
\text { CACATTCACGG }\end{array}$ & $\begin{array}{l}\text { ACGTTGGATGTTGAGGGC } \\
\text { АCСTACСTCTGT }\end{array}$ \\
\hline \multirow[t]{2}{*}{ IL1RL1 } & rs1420101 & $\begin{array}{l}\text { tcCCATCACAAAGCCTCTCAT } \\
\text { TA } \\
\end{array}$ & $\begin{array}{l}\text { ACGTTGGATGCGACAACAT } \\
\text { TTATGTACACC }\end{array}$ & $\begin{array}{l}\text { ACGTTGGATGCTTTAGTAA } \\
\text { TACTCATTGG }\end{array}$ \\
\hline & rs1861245 & GGACATGCATTGACAGA & $\begin{array}{l}\text { ACGTTGGATGGGAAAGGT } \\
\text { CAGAGGACATGC } \\
\end{array}$ & $\begin{array}{l}\text { ACGTTGGATGTGCCTTCAA } \\
\text { TGTGTGACAAC } \\
\end{array}$ \\
\hline IL4 & rs2070874 & $\begin{array}{l}\text { TTAGCTTCTCCTGATAAACTA } \\
\text { ATTG } \\
\end{array}$ & \begin{tabular}{|l|} 
ACGTTGGATGTGCATCGTT \\
AGCTTCTCCTG \\
\end{tabular} & $\begin{array}{l}\text { ACGTTGGATGGAGGTGAG } \\
\text { ACCCATTAATAG } \\
\end{array}$ \\
\hline \multirow[t]{3}{*}{ IL4RA } & rs1801275 & \begin{tabular}{|l|} 
tctaGGCCCCCACCAGTGGCT \\
ATC \\
\end{tabular} & $\begin{array}{l}\text { ACGTTGGATGTCCAGCATG } \\
\text { GGGCAGCTGCA } \\
\end{array}$ & $\begin{array}{l}\text { ACGTTGGATGACCCTGCTC } \\
\text { CACCGCATGTA } \\
\end{array}$ \\
\hline & rs1805011 & TCCAGGAGGGAAGGG & $\begin{array}{l}\text { ACGTTGGATGAGAGCAGC } \\
\text { AGGGATGACTTC }\end{array}$ & $\begin{array}{l}\text { ACGTTGGATGAGGAACAG } \\
\text { GCTCTCTGTTAG }\end{array}$ \\
\hline & rs1805015 & $\begin{array}{l}\text { accgGCTTACCGCAGCTTCAG } \\
\text { CAAC }\end{array}$ & $\begin{array}{l}\text { ACGTTGGATGAGAGACGC } \\
\text { CCCTCGTCATC }\end{array}$ & $\begin{array}{l}\text { ACGTTGGATGTCTGGGACA } \\
\text { CGGTGACTGG }\end{array}$ \\
\hline IL5 & rs2069812 & $\begin{array}{l}\text { gggcgGCTCATGAACAGAATA } \\
\text { CATA }\end{array}$ & $\begin{array}{l}\text { ACGTTGGATGCCTGCTGCT } \\
\text { CATGAACAGAA }\end{array}$ & $\begin{array}{l}\text { ACGTTGGATGCTTGGGCAC } \\
\text { CTTTCCCATTG }\end{array}$ \\
\hline IL8 & rs2227306 & $\begin{array}{l}\text { ggGTCATAACTGACAACATT } \\
\text { GAAC } \\
\end{array}$ & $\begin{array}{l}\text { ACGTTGGATGACAGTCATA } \\
\text { ACTGACAACA } \\
\end{array}$ & $\begin{array}{l}\text { ACGTTGGATGCCATGAAGA } \\
\text { TGTTGATATTG } \\
\end{array}$ \\
\hline \multirow[t]{2}{*}{ IL10 } & rs1800872 & GACTGGCTTCCTACAG & $\begin{array}{l}\text { ACGTTGGATGAAGCAGCCC } \\
\text { TTCCATTTTAC }\end{array}$ & $\begin{array}{l}\text { ACGTTGGATGCCTGGAACA } \\
\text { CATCCTGTGAC }\end{array}$ \\
\hline & rs1800896 & tсCСТАТСССТАСТTСCCC & $\begin{array}{l}\text { ACGTTGGATGCTGGATAG } \\
\text { GAGGTCCCTTAC }\end{array}$ & $\begin{array}{l}\text { ACGTTGGATGGACAACACT } \\
\text { ACTAAGGCTTC }\end{array}$ \\
\hline IL13 & rs1800925 & TCCTGCTCTTCCCTC & $\begin{array}{l}\text { ACGTTGGATGTGCAGCCAT } \\
\text { GTCGCCTTTTC }\end{array}$ & $\begin{array}{l}\text { ACGTTGGATGGGGTTTCTG } \\
\text { GAGGACTTCTA }\end{array}$ \\
\hline IL33 & rs3939286 & ATCCCCATGGTTTGTTGTTG & $\begin{array}{l}\text { ACGTTGGATGCAGGAAATT } \\
\text { CAGTTCTCCAC }\end{array}$ & $\begin{array}{l}\text { ACGTTGGATGCAGACAGAT } \\
\text { AACAACAACCC }\end{array}$ \\
\hline LTC4 & rs730012 & ССАССТTАТСТGTTССС & $\begin{array}{l}\text { ACGTTGGATGACTCCTCCA } \\
\text { CCCACCTTATC } \\
\end{array}$ & $\begin{array}{l}\text { ACGTTGGATGTTCCGCAGA } \\
\text { GGAGGGTTTG }\end{array}$ \\
\hline ORMDL3 & rs7216389 & ctccGGGCCGAGTCCATGC & \begin{tabular}{|l|} 
ACGTTGGATGAAGGCCCTT \\
ATTAGTGCCTG \\
\end{tabular} & $\begin{array}{l}\text { ACGTTGGATGAGTATGAA } \\
\text { GTGAGGCAACCC } \\
\end{array}$ \\
\hline \multirow[t]{2}{*}{ PCDH1 } & rs3797054 & GCAATGCTGTAGATCAGCTC & $\begin{array}{l}\text { ACGTTGGATGTCTGGAAGA } \\
\text { GTCCATAAGGG }\end{array}$ & $\begin{array}{l}\text { ACGTTGGATGAGCCGAGG } \\
\text { ACTTTGACTCTG }\end{array}$ \\
\hline & rs3822357 & AGAGTGTCACTGAGGTC & $\begin{array}{l}\text { ACGTTGGATGATGACAACG } \\
\text { САCCTGTCTTC }\end{array}$ & $\begin{array}{l}\text { ACGTTGGATGACCAGGCTT } \\
\text { GTTGTTTTCCG }\end{array}$ \\
\hline
\end{tabular}


Table 2 (continued)

\begin{tabular}{|c|c|c|c|c|}
\hline PLAUR & rs2239372 & ATTTACATCCAAAGCCCA & $\begin{array}{l}\text { ACGTTGGATGGCTAGCTGT } \\
\text { AATTAGGCGAA }\end{array}$ & $\begin{array}{l}\text { ACGTTGGATGGTGGGTGG } \\
\text { CCTTGTAGTTAT }\end{array}$ \\
\hline & rs4493171 & $\begin{array}{l}\text { ggtAGCCTCTCTCCTCAAGAT } \\
\text { TT }\end{array}$ & $\begin{array}{l}\text { ACGTTGGATGCTCTCAACC } \\
\text { GTGATGTTTGG }\end{array}$ & $\begin{array}{l}\text { ACGTTGGATGAGCCCAGG } \\
\text { CTTACCTCTTG }\end{array}$ \\
\hline & rs4803648 & gCCTTTCTGACCTCAAAACCA & $\begin{array}{l}\text { ACGTTGGATGCTCCCAGTA } \\
\text { TCCTTTCTGAC }\end{array}$ & $\begin{array}{l}\text { ACGTTGGATGAGAAGACA } \\
\text { CTGGGAGCCAT }\end{array}$ \\
\hline \multirow[t]{2}{*}{ TLR2 } & rs3804099 & TGAAGGATCAGATGACTTAC & $\begin{array}{l}\text { ACGTTGGATGTATGCTGCT } \\
\text { TCATATGAAGG }\end{array}$ & $\begin{array}{l}\text { ACGTTGGATGGATCTACAG } \\
\text { AGCTATGAGCC }\end{array}$ \\
\hline & rs4696480 & AGCCAG & $\begin{array}{l}\text { ACGTTGGATGTCTCACCAT } \\
\text { GTGATGCTTTC }\end{array}$ & $\begin{array}{l}\text { ACGTTGGATGAGTCCAAGA } \\
\text { TTGAAGGGCTG }\end{array}$ \\
\hline TLR4 & rs2737190 & TTTACACCCAAGTAGACAC & $\begin{array}{l}\text { ACGTTGGATGCTCTGAACC } \\
\text { АССТССTCTAC }\end{array}$ & $\begin{array}{l}\text { ACGTTGGATGACCTGTGAT } \\
\text { GATTAGGGCTG }\end{array}$ \\
\hline \multirow[t]{2}{*}{ TLR9 } & rs187084 & ATAAAAGAT & $\begin{array}{l}\text { ACGTTGGATGTGCTGGGC } \\
\text { ACTGTACTGGAT }\end{array}$ & $\begin{array}{l}\text { ACGTTGGATGTATTCCCCT } \\
\text { GCTGGAATGTC }\end{array}$ \\
\hline & rs5743836 & СССАTGTTCССТСТGССТG & $\begin{array}{l}\text { ACGTTGGATGTTGGGATGT } \\
\text { GCTGTTCCCTC }\end{array}$ & $\begin{array}{l}\text { ACGTTGGATGAGCAGAGA } \\
\text { CATAATGGAGGC }\end{array}$ \\
\hline TNF $\alpha$ & rs1800629 & GGAGGCTGAACCCCGTCC & $\begin{array}{l}\text { ACGTTGGATGGATTTGTGT } \\
\text { GTAGGACCCTG }\end{array}$ & $\begin{array}{l}\text { ACGTTGGATGGGTCCCCAA } \\
\text { AAGAAATGGAG }\end{array}$ \\
\hline
\end{tabular}

PCR-1: complementary in direction to the extension primer; PCR-2: in the same direction as the extension primer. The PCR primers contain a $10 \mathrm{mer}$ tag that helps to get a balanced amplification in the multiplex PCR and also gets them out of the mass window. The lower case letters in the extension primers are nontemplate bases that do not affect the annealing temperature but change the mass to allow more efficient multiplexing.

\section{Asthma diagnosis in the KOALA birth cohort study}

Asthma at age six to seven years was defined as ever physician diagnosed asthma with clinical symptoms and/or the use of asthma medication in the last 12 months adapted from the ISAAC questionnaire. ${ }^{10}$ Clinical symptoms were defined as having had at least one episode of wheeze or dyspnoea in the last twelve months. The use of asthma medication was defined as regular use (everyday use during at least 2 months or use associated with physical activity) of short-acting $\beta_{2}$-agonists or the use of inhaled corticosteroids and medication use according to the Dutch guidelines of treatment of bronchial asthma in children. ${ }^{14}$

\section{DNA isolation and genotyping in the KOALA birth cohort study}

Parents were asked to collect buccal swabs from their children. Genomic DNA was extracted from these swabs by using standard methods. ${ }^{15}$ DNA was amplified by using REPLI-g UltraFast technology (Qiagen ${ }^{\circledR}$, Hilden, Germany). Participants were genotyped for five SNPs in three genes that demonstrated an association with an asthma classification at age six in the ADEM study. Genotyping was performed by Competitive Allele-Specific PCR by using KASPar genotyping chemistry, under contract 
by LGC Genomics (LGC, Teddington, UK) with extensive quality control as described previously. $^{16}$

\section{Statistical analysis}

IBM SPSS version 20 was used for data analysis (SPSS inc., Chicago IL, USA). Differences in baseline characteristics were evaluated by chi-square test for categorical variables and independent t-tests for continuous parametric variables. Logistic regression with outcome transient wheezer or true asthmatic adjusted for confounders was performed for each individual SNP. Confounders were selected based on the previous literature (sex and exposure to furry pets) and remained in the model irrespective of their statistical significance according to methodological recommendations. ${ }^{17,}{ }^{18} \mathrm{~A}$ sub-analysis in the ADEM study adjusted for smoking exposure in addition to sex and exposure to furry pets was performed. SNPs were tested according to a co-dominant model. In case the genotype of the two variant alleles was present in $<10 \%$ of the population, a dominant model was applied. SNPs that demonstrated an association of $p<0.10$ with the asthma classification in the ADEM study were replicated in the KOALA birth cohort study and differences were considered statistically significant when $p<0.05$.

\section{Power calculation}

A group of 134 transient wheezers and 67 asthmatics is sufficient to detect associations with an odds ratio of 2.5 or 0.4 in allele frequency, when assuming the presence of one or more variant alleles of at least $20 \%$ in transient wheezers with a power of 0.80 and an alpha of 0.05 .

\section{Results}

\section{The ADEM study}

\section{Baseline characteristics}

In four children a diagnosis at six years of age could not be assessed due to personal constraints of the parents, leaving 198 children in the current analysis. At age six, 122 children were classified as 'transient wheezer' and 76 as 'true asthmatic'. Baseline characteristics are displayed in Table 3. Atopy was more present in the asthmatic group compared to the transient wheeze group. 
Table 3 Characteristics of the study populations at classification.

\begin{tabular}{|c|c|c|c|c|}
\hline & \multicolumn{2}{|c|}{ ADEM study } & \multicolumn{2}{|c|}{ KOALA study } \\
\hline & $\begin{array}{c}\text { Transient } \\
\text { wheeze } \\
\mathrm{N}=122\end{array}$ & $\begin{array}{l}\text { True asthma } \\
\qquad N=76\end{array}$ & $\begin{array}{c}\text { Transient } \\
\text { wheeze } \\
\mathrm{N}=177\end{array}$ & $\begin{array}{l}\text { True asthma } \\
\qquad \mathrm{N}=56\end{array}$ \\
\hline Age (years), mean (SD) & $6.0(0.1)$ & $6.0(0.1)$ & $6.5(0.6)$ & $6.5(0.5)$ \\
\hline Sex: male / female, in $n$ & $63 / 59$ & $46 / 30$ & $100 / 77$ & $37 / 19$ \\
\hline White European descent, $\%^{\dagger}$ & 95 & 92 & 97 & 96 \\
\hline Atopy, $\%^{\ddagger, \S}$ & 31 & $47^{*}$ & 79 & 70 \\
\hline Eczema, \% & 38 & 47 & 40 & $70^{*}$ \\
\hline Exposure to furry pets, \% & 53 & 51 & 49 & $27^{*}$ \\
\hline Parental asthma ${ }^{\S}, \%$ & 28 & 43 & 28 & 37 \\
\hline
\end{tabular}

ADEM study: Asthma DEtection and Monitoring study; KOALA study: Kind, Ouders en gezondheid: Aandacht voor Leefstijl en Aanleg study. N: Number of children; SD: Standard Deviation; † White European descent was defined as at least 3 grandparents from white European descent. $¥$ Atopy was defined as specific IgE concentration against a mixture of inhalant and food allergens of $\geq 0.35 \mathrm{kU} / \mathrm{l}$ on the Phadiatop Infant test ${ }^{\circledR}$ (Pharmacia, Uppsala, Sweden). ${ }^{*} p<0.05$. ${ }^{\S}$ based on a limited number of individuals ( 52 transient wheezers and 27 asthmatics) in the KOALA study

\section{Association of genetic variants with childhood asthma}

DNA extraction was successful in all children (100\%). All SNPs had a high call-rate (92$100 \%$, Table 1). No deviation from Hardy-Weinberg equilibrium was observed $(p \geq 0.05)$ with the exception of IL1RL1 rs1861245 and TLR9 rs5743836 (Table 1). Linkage disequilibrium (LD) was calculated and three blocks were identified (block $1: R^{2}=0.65$ for ADAM33 rs528557 and rs511898; block $2 \mathrm{R}^{2}=0.56$ for IL4RA rs 1805011 and rs $1805015, \mathrm{R}^{2}=0.45$ for IL4RA rs1805011 and $\mathrm{rs} 1801275, \mathrm{R}^{2}=0.69$ for IL4RA rs 1805015 and rs1801275; block $3 \mathrm{R}^{2}=0.13$ for TLR9 rs187084 and rs5743836). The TT-genotype of ADAM33 rs511898 ( $p=0.03$ ), the CG/GG-genotype of ADAM33 rs528577 ( $p=0.06$ ) and the TT-genotype of ORMDL3 rs7216389 ( $\mathrm{p}=0.07$ ) were negatively associated with childhood asthma. The CT/TT-genotype of IL4 rs2243250 ( $p=0.04)$ and the CT/TTgenotype of rs2070874 ( $p=0.03$ ) were positively associated with childhood asthma (Table 4). None of the other tested genetic variants demonstrated an association with childhood asthma. As described before, results were corrected for sex and exposure to furry pets. Inclusion of smoking exposure as an additional confounder in the analysis did not change the interpretation of the results.

\section{The KOALA birth cohort study}

\section{Baseline characteristics}

At four years of age, 427 children were categorised as recurrent wheezers. Of these children, a definitive classification at the age of six to seven years was determined in 321 children. In the remaining 106 children, a definitive classification could not be 
assessed due to missing data. Based on the availability of DNA, 233 recurrent wheezing children with a definitive classification were included in the current analysis (177 children with transient wheeze and 56 children with asthma). Eczema was significantly more frequent and exposure to furry pets was significantly less frequent in asthmatics compared to transient wheezers (Table 3).

Table 4 Results for analysis of genetic variants in the ADEM study.

\begin{tabular}{|c|c|c|c|c|c|c|}
\hline Gene & SNP & allele & TW/A (n) & $O R^{a}$ & $95 \% \mathrm{Cl}$ & $p$ \\
\hline \multirow[t]{12}{*}{ ADAM33 } & rs511898 & $\mathrm{CC}$ & $40 / 32$ & ref & & \\
\hline & & $\mathrm{CT}$ & $60 / 38$ & 0.79 & $0.43-1.47$ & 0.46 \\
\hline & & TT & $21 / 5$ & 0.29 & $0.10-0.86$ & 0.03 \\
\hline & rs528557 & $\mathrm{CC}$ & $49 / 41$ & Ref & & \\
\hline & & CG/GG & $73 / 35$ & 0.57 & $0.32-1.03$ & 0.06 \\
\hline & rs574174 & $\mathrm{CC}$ & $67 / 46$ & Ref & & \\
\hline & & $\mathrm{CT} / \mathrm{TT}$ & $54 / 29$ & 0.78 & $0.43-1.41$ & 0.42 \\
\hline & rs597980 & $A A$ & $30 / 20$ & Ref & & \\
\hline & & $A G$ & $57 / 37$ & 0.98 & $0.48-1.98$ & 0.96 \\
\hline & & GG & $35 / 19$ & 0.77 & $0.35-1.72$ & 0.53 \\
\hline & rs2280091 & $A A$ & $90 / 62$ & Ref & & \\
\hline & & AG/GG & $31 / 14$ & 0.67 & $0.33-1.37$ & 0.27 \\
\hline \multirow[t]{2}{*}{ CC16 } & rs3741240 & GG & $48 / 24$ & Ref & & \\
\hline & & $\mathrm{GA} / \mathrm{AA}$ & $71 / 47$ & 1.35 & $0.73-2.50$ & 0.35 \\
\hline \multirow[t]{3}{*}{ CD14 } & rs2569190 & $\mathrm{AA}$ & $30 / 18$ & Ref & & \\
\hline & & GA & $60 / 38$ & 1.05 & $0.51-2.17$ & 0.90 \\
\hline & & GG & $31 / 19$ & 1.00 & $0.44-2.28$ & 0.99 \\
\hline \multirow[t]{2}{*}{ ICAM1 } & rs5498 & $A A$ & $40 / 31$ & Ref & & \\
\hline & & AG/GG & $81 / 44$ & 0.73 & $0.40-1.32$ & 0.30 \\
\hline \multirow[t]{5}{*}{ IL1RL1 } & rs1420101 & $\mathrm{CC}$ & $44 / 34$ & Ref & & \\
\hline & & $\mathrm{CT}$ & $56 / 29$ & 0.67 & $0.35-1.26$ & 0.22 \\
\hline & & $\mathrm{TT}$ & $21 / 12$ & 0.72 & $0.31-1.67$ & 0.44 \\
\hline & rs1861245 & $\mathrm{CC}$ & $43 / 31$ & Ref & & \\
\hline & & $\mathrm{CT} / \mathrm{TT}$ & $78 / 44$ & 0.80 & $0.44-1.46$ & 0.47 \\
\hline \multirow[t]{4}{*}{ IL4 } & rs2070874 & $\mathrm{CC}$ & $96 / 49$ & Ref & & \\
\hline & & $\mathrm{CT} / \mathrm{TT}$ & $25 / 26$ & 1.97 & $1.02-3.80$ & 0.04 \\
\hline & rs2243250 & $\mathrm{CC}$ & $93 / 46$ & Ref & & \\
\hline & & $\mathrm{CT} / \mathrm{TT}$ & $25 / 27$ & 2.07 & $1.07-4.00$ & 0.03 \\
\hline \multirow[t]{9}{*}{ IL4RA } & rs1805010 & $A A$ & $33 / 16$ & Ref & & \\
\hline & & $A G$ & $57 / 40$ & 1.49 & $0.72-3.08$ & 0.28 \\
\hline & & GG & $22 / 14$ & 1.26 & $0.51-3.10$ & 0.62 \\
\hline & rs1805011 & $A A$ & $97 / 62$ & Ref & & \\
\hline & & $\mathrm{AC} / \mathrm{CC}$ & $25 / 14$ & 0.88 & $0.42-1.82$ & 0.73 \\
\hline & rs1805015 & TT & $85 / 55$ & Ref & & \\
\hline & & $\mathrm{TC} / \mathrm{CC}$ & $36 / 20$ & 0.84 & $0.44-1.60$ & 0.59 \\
\hline & rs1801275 & $\mathrm{AA}$ & $76 / 49$ & Ref & & \\
\hline & & AG/GG & $45 / 26$ & 0.89 & $0.48-1.63$ & 0.70 \\
\hline \multirow[t]{3}{*}{ IL5 } & rs2069812 & GG & $57 / 32$ & Ref & & \\
\hline & & GA & $44 / 37$ & 1.56 & $0.84-2.91$ & 0.16 \\
\hline & & $A A$ & $20 / 6$ & 0.51 & $0.18-1.40$ & 0.19 \\
\hline \multirow[t]{3}{*}{ IL8 } & rs2227306 & $\mathrm{CC}$ & $44 / 28$ & Ref & & \\
\hline & & $\mathrm{CT}$ & $58 / 40$ & 1.14 & $0.61-2.14$ & 0.69 \\
\hline & & TT & $18 / 7$ & 0.62 & $0.23-1.69$ & 0.35 \\
\hline
\end{tabular}


Table 4 (continued)

\begin{tabular}{|c|c|c|c|c|c|c|}
\hline Gene & SNP & allele & TW/A (n) & $O R^{a}$ & $95 \% \mathrm{Cl}$ & $p$ \\
\hline \multirow[t]{5}{*}{ IL10 } & rs1800872 & GG & $67 / 42$ & Ref & & \\
\hline & & $\mathrm{GT} / \mathrm{TT}$ & $55 / 34$ & 1.00 & $0.56-1.80$ & 0.99 \\
\hline & rs1800896 & $\mathrm{TT}$ & $37 / 24$ & ref & & \\
\hline & & $\mathrm{TC}$ & $59 / 37$ & 0.98 & $0.51-1.90$ & 0.96 \\
\hline & & $\mathrm{CC}$ & $25 / 14$ & 0.88 & $0.38-2.02$ & 0.76 \\
\hline \multirow[t]{2}{*}{ IL13 } & rs1800925 & $\mathrm{CC}$ & $75 / 39$ & Ref & & \\
\hline & & $\mathrm{CT} / \mathrm{TT}$ & $45 / 36$ & 1.53 & $0.85-2.76$ & 0.16 \\
\hline \multirow[t]{2}{*}{ IL33 } & rs3939286 & $\mathrm{CC}$ & $65 / 42$ & Ref & & \\
\hline & & $\mathrm{CT} / \mathrm{TT}$ & $57 / 34$ & 0.95 & $0.53-1.70$ & 0.87 \\
\hline \multirow[t]{2}{*}{ LTC4 } & rs730012 & $A A$ & $62 / 36$ & Ref & & \\
\hline & & $\mathrm{AC} / \mathrm{CC}$ & $60 / 40$ & 1.12 & $0.63-2.00$ & 0.70 \\
\hline \multirow[t]{3}{*}{ ORMDL3 } & rs7216389 & $\mathrm{TT}$ & $35 / 29$ & Ref & & \\
\hline & & $\mathrm{TC}$ & $67 / 41$ & 0.76 & $0.41-1.44$ & 0.41 \\
\hline & & $\mathrm{CC}$ & $20 / 6$ & 0.39 & $0.14-1.09$ & 0.07 \\
\hline \multirow[t]{5}{*}{ PCDH1 } & rs3797054 & $A A$ & $52 / 28$ & Ref & & \\
\hline & & AG & $58 / 38$ & 1.20 & $0.65-2.23$ & 0.56 \\
\hline & & GG & $11 / 9$ & 1.65 & $0.60-4.54$ & 0.33 \\
\hline & rs3822357 & $\mathrm{CC}$ & $108 / 66$ & Ref & & \\
\hline & & $\mathrm{CT} / \mathrm{TT}$ & $14 / 10$ & 1.17 & $0.49-2.80$ & 0.73 \\
\hline \multirow[t]{7}{*}{ PLAUR } & rs2239372 & $A A$ & $38 / 25$ & Ref & & \\
\hline & & AG & $53 / 35$ & 1.00 & $0.51-1.94$ & 0.99 \\
\hline & & GG & $31 / 16$ & 0.77 & $0.35-1.70$ & 0.52 \\
\hline & rs4493171 & $\mathrm{CC}$ & $80 / 50$ & Ref & & \\
\hline & & $\mathrm{CT} / \mathrm{TT}$ & $41 / 25$ & 0.96 & $0.52-1.78$ & 0.91 \\
\hline & rs4803648 & TT & $81 / 55$ & Ref & & \\
\hline & & $\mathrm{TA} / \mathrm{AA}$ & $40 / 20$ & 0.73 & $0.38-1.38$ & 0.33 \\
\hline \multirow[t]{6}{*}{ TLR2 } & rs3804099 & $\mathrm{TT}$ & $37 / 27$ & Ref & & \\
\hline & & $\mathrm{TC}$ & $55 / 32$ & 0.78 & $0.40-1.52$ & 0.47 \\
\hline & & $\mathrm{CC}$ & $29 / 16$ & 0.74 & $0.34-1.65$ & 0.47 \\
\hline & rs4696480 & $\mathrm{TT}$ & $28 / 16$ & Ref & & \\
\hline & & TA & $63 / 39$ & 1.10 & $0.52-2.29$ & 0.81 \\
\hline & & AA & $29 / 20$ & 1.20 & $0.52-2.78$ & 0.67 \\
\hline \multirow[t]{3}{*}{ TLR4 } & rs2737190 & $A A$ & $54 / 27$ & Ref & & \\
\hline & & AG & $48 / 36$ & 1.64 & $0.86-3.13$ & 0.14 \\
\hline & & GG & $19 / 12$ & 1.27 & $0.54-3.01$ & 0.59 \\
\hline \multirow[t]{5}{*}{ TLR9 } & rs187084 & $A A$ & $45 / 30$ & Ref & & \\
\hline & & AG & $51 / 34$ & 1.01 & $0.53-1.92$ & 0.98 \\
\hline & & GG & $25 / 11$ & 0.65 & $0.28-1.53$ & 0.33 \\
\hline & rs5743836 & $A A$ & $91 / 50$ & Ref & & \\
\hline & & AG/GG & $30 / 25$ & 1.52 & $0.80-2.87$ & 0.20 \\
\hline \multirow[t]{2}{*}{ TNFa } & rs1800629 & GG & $85 / 53$ & Ref & & \\
\hline & & GA/AA & $37 / 23$ & 1.04 & 0.55-1.95 & 0.91 \\
\hline
\end{tabular}

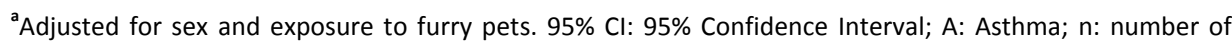
children; OR: Odds Ratio; p: p-value; Ref: Reference category; TW: Transient Wheeze. 


\section{Replication of associated genetic variants with childhood asthma}

All SNPs had a high call-rate (93-96\%). No deviation from Hardy-Weinberg equilibrium was observed $(p \geq 0.05)$. Furthermore, $L D$ was calculated $\left(R^{2}=0.63\right.$ for ADAM33 rs511898 and rs528577, $R^{2}=0.00$ for IL4 rs2070874 and rs2243250). The CG/GGgenotype of $A D A M 33$ rs528577 was significantly negatively associated with childhood asthma (Odds Ratio; OR (95\% confidence interval; 95\% Cl): 0.42 (0.21-0.82) $p=0.01$ adjusted for sex and exposure to furry pets, Table 5 ). When the analysis was restricted to participants with a conventional lifestyle $(n=199)$, the association remained (OR (95\% Cl): 0.42 (0.21-0.87), $\mathrm{p}=0.02$, adjusted for sex and exposure to furry pets). ADAM33 rs511898, ORMDL3 rs7216389, IL4 rs2070874 and IL4 rs2243250 polymorphisms were not associated with childhood asthma in the KOALA birth cohort study.

Table 5 Replication of associated genetic variants in the KOALA birth cohort study

\begin{tabular}{|c|c|c|c|c|c|c|}
\hline Gene & SNP & allele & TW/A (n) & $\mathrm{OR}^{\mathrm{a}}$ & $95 \% \mathrm{Cl}$ & $p$ \\
\hline \multirow[t]{4}{*}{ ADAM33 } & rs511898 & $\mathrm{CC}$ & $68 / 26$ & ref & & \\
\hline & & $\mathrm{CT} / \mathrm{TT}$ & $98 / 29$ & 0.69 & $0.36-1.30$ & 0.25 \\
\hline & rs528557 & $\mathrm{CC}$ & $84 / 35$ & ref & & \\
\hline & & $\mathrm{CG} / \mathrm{GG}$ & $80 / 19$ & 0.42 & $0.21-0.82$ & 0.01 \\
\hline \multirow[t]{4}{*}{ IL4 } & rs2070874 & $\mathrm{CC}$ & $115 / 41$ & ref & & \\
\hline & & $\mathrm{CT} / \mathrm{TT}$ & $53 / 13$ & 0.67 & $0.33-1.38$ & 0.28 \\
\hline & rs2243250 & $\mathrm{CC}$ & $112 / 40$ & ref & & \\
\hline & & $\mathrm{CT} / \mathrm{TT}$ & $51 / 13$ & 0.70 & $0.34-1.44$ & 0.33 \\
\hline \multirow[t]{3}{*}{ ORMDL3 } & rs7216389 & $\mathrm{CC}$ & $37 / 7$ & ref & & \\
\hline & & $\mathrm{CT}$ & $77 / 32$ & 2.29 & $0.90-5.86$ & 0.08 \\
\hline & & $\mathrm{TT}$ & $54 / 15$ & 1.39 & $0.50-3.84$ & 0.52 \\
\hline
\end{tabular}

${ }^{a}$ Adjusted for sex and exposure to furry pets. $95 \% \mathrm{Cl}$ : $95 \%$ Confidence Interval; A: Asthma; n: number of children; OR: Odds Ratio; p: p-value; Ref: Reference category; TW: Transient Wheeze.

\section{Discussion}

Multiple genetic variants in asthma candidate genes were assessed to study their relationship with the presence of asthma at six years of age in a group of 202 children with recurrent wheeze at preschool age. We demonstrated an association of ADAM33, IL4 and ORMDL3 polymorphisms with childhood asthma. In an independent birth cohort study we were able to replicate the significant negative association of the CG/GG-genotype of ADAM33 rs528577 with childhood asthma. The other associations could not be replicated.

ADAM33 was first reported as a susceptibility gene for asthma, bronchial hyperresponsiveness and variations in total and specific IgE levels through linkage analysis 
in a candidate region on chromosome $20 \mathrm{p} .{ }^{19}$ The gene is expected to be involved in airway remodelling. ${ }^{19}$ ADAM33 consists of 22 exons which can generate a protein with eight domains. ${ }^{20}$ The gene is highly polymorphic, containing more than 70 SNPs with extensive LD. ${ }^{21-23}$ Some of the disease-related SNPs encode amino acid changes and may therefore be functional. ${ }^{24}$ Other SNPs are located in the non-coding regions and may affect proliferation and/or inflammation of the airways by alternative splicing and splicing efficiency of messenger RNA turnover or their association is based on linkage with other SNPs. ${ }^{19,21,24-28}$ In previous studies, polymorphisms in ADAM33 have been related to childhood asthma and transient early wheeze. ${ }^{19,22,29,30}$ We found a negative association of the ADAM33 rs528577 and rs511898 polymorphism with childhood asthma in the present study. The replication of the association of the CG/GGgenotype of rs528577 with childhood asthma in an independent birth cohort study confirms the relationship of this gene with childhood asthma in children with recurrent wheeze. Contrary to our findings, the study by van Eerdewegh et al. revealed a positive association of this SNP with asthma. ${ }^{19}$ As the rs528557 polymorphism does not lead to an amino acid change, this conflicting observation might be based on variability of LD between the studied populations. ${ }^{31}$

ORMDL3 is mapped to a locus on chromosome 17q12-21, which was first identified in association with childhood asthma through genome-wide analysis. ${ }^{32}$ Since then, other studies have confirmed an association of ORMDL3 with childhood asthma. ${ }^{33-36}$ Its function is unknown, however, it is argued that it might be related to airway remodelling or the epithelial barrier function. ${ }^{37,38}$ In the present study, the CCgenotype of rs7216389 in ORMDL3 was demonstrated to be borderline associated with childhood asthma. However, replication failed in the independent birth cohort study. In contrast to our findings, previous studies identified the T-allele of rs7216389 in ORMDL3 as the childhood asthma risk allele. ${ }^{33,34,36}$ Environmental exposures such as tobacco smoke exposure and domestic furry pets have demonstrated to influence the relationship between polymorphisms in ORMDL3 and childhood asthma. ${ }^{39,40}$ In our analysis we corrected for exposure of sex and furry pets that did not influence our findings. Neither were our observations influenced by the additional confounder of passive smoking exposure in the ADEM study. However, it might be that other unknown environmental influences can affect the relationship of ORMDL3 with asthma, which may explain the opposite direction of our findings.

IL4 maps to a cytokine cluster on chromosome $5 q 31-q 33 .^{41-43}$ It is a pro-inflammatory cytokine that is involved in a number of immunoregulatory pathways such as the induction of IgE synthesis by B-cells and differentiation of T-helper-type-2 lymphocytes. ${ }^{41-44}$ IL4 has been linked to asthma phenotypes and atopy in several studies $^{41,42}$ including childhood populations. ${ }^{43,45}$ In accordance with these previous findings, we found associations of two SNPs in IL4 with childhood asthma. Our findings indicated an increased risk of asthma in children with CT/TT-genotypes for rs2070874 
and rs2243250 which is in concordance with previous studies. However, we were unable to replicate these findings in the independent birth cohort study.

We were able to replicate our findings concerning the association of ADAM33 rs528577 in an independent paediatric population. However, we could not replicate our other associations. Many asthma candidate gene studies are confronted with failure of replication or even opposite findings in independent studies. ${ }^{29}$ There are multiple causes for failure of replication. First of all, the gene effects are small and they may be important only in populations with unique (unidentified) characteristics ${ }^{27,46}$ Thus, ethnic diversity and variability in LD between populations can lead to population specific results. ${ }^{41,44}$ In addition, asthma is caused by different mutations that do not need to be universally, leading to genetic heterogeneity. ${ }^{22,27,29,31,45}$ Secondly, methodological differences between the studies can influence findings. For example, the used definition of asthma in studies varies, resulting in study populations with different phenotypes. ${ }^{27,31,46}$ As the asthma classification in the KOALA birth cohort study differed from the ADEM study, this might be a reason for replication failure in four of the five childhood asthma associated genetic variants. Thirdly, it is generally known that environmental influences can influence or even change the direction of underlying associations. ${ }^{47}$ Therefore, (unknown) environmental heterogeneity between studied populations can be responsible for failure of replication. ${ }^{27,29,31}$ Finally, observed associations can also be caused solely on LD. ${ }^{27,28,43}$ Naturally, a significant finding based on chance can also be a cause of replication failure.

Our study has several strengths. The design of the ADEM study enabled us to follow a large group of children with recurrent wheeze at preschool age until the asthma classification at six years of age. Furthermore, our definition of asthma was based on a clinical assessment and a computer-algorithm with re-assessment of inconclusive cases. This is expected to result in a more accurate classification. In addition, our analysis was corrected for confounders. Furthermore, replication of found associations were assessed in the independent KOALA birth cohort study. A limitation of our study might be that we did not correct of multiple testing. However, the use of an independent birth cohort for replication reduced the likelihood of finding associations based on chance.

In conclusion, we assessed 30 genetic variants in 16 asthma candidate genes in relationship to childhood asthma in a cohort of 202 children with recurrent wheeze. Polymorphisms in ADAM33 (rs511898 and rs528557) and ORMDL3 (rs7216389) were negatively associated and polymorphisms in IL4 (rs2070874 and rs2243250) were positively associated with childhood asthma. In an independent birth cohort we were able to confirm the negative association of ADAM33 rs528557 CG/GG-genotype with childhood asthma. 


\section{References}

1. Pinto LA, Stein RT, Kabesch M. Impact of genetics in childhood asthma. J Pediatr (Rio J) 2008;84: S68-75.

2. Thomsen SF, van der Sluis S, Kyvik KO, Skytthe A, Skadhauge LR, Backer V. Increase in the heritability of asthma from 1994 to 2003 among adolescent twins. Respir Med 2011;105:1147-52.

3. Bisgaard H, Szefler S. Prevalence of asthma-like symptoms in young children. Pediatr Pulmonol 2007; 42:723-8.

4. Pedersen SE, Hurd SS, Lemanske RF, Jr., Becker A, Zar HJ, Sly PD, et al. Global strategy for the diagnosis and management of asthma in children 5 years and younger. Pediatr Pulmonol 2011;46: 1-17.

5. Savenije OE, Granell R, Caudri D, Koppelman GH, Smit HA, Wijga A, et al. Comparison of childhood wheezing phenotypes in 2 birth cohorts: ALSPAC and PIAMA. J Allergy Clin Immunol 2011;127:150512 e14.

6. Chang JC, Wang L, Chen RF, Liu CA. Perinatal gene-gene and gene-environment interactions on IgE production and asthma development. Clin Dev Immunol 2012;2012:270869.

7. Bottema RW, Kerkhof M, Reijmerink NE, Thijs C, Smit HA, van Schayck CP, et al. Gene-gene interaction in regulatory T-cell function in atopy and asthma development in childhood. J Allergy Clin Immunol 2010;126:338-46,46 e1-10.

8. Rigoli L, Briuglia S, Caimmi S, Ferrau V, Gallizzi R, Leonardi S, et al. Gene-environment interaction in childhood asthma. Int J Immunopathol Pharmacol 2011;24:41-7.

9. van de Kant KD, Klaassen EM, Jöbsis Q, Nijhuis AJ, van Schayck OC, Dompeling E. Early diagnosis of asthma in young children by using non-invasive biomarkers of airway inflammation and early lung function measurements: study protocol of a case-control study. BMC Public Health 2009;9:210.

10. Worldwide variation in prevalence of symptoms of asthma, allergic rhinoconjunctivitis, and atopic eczema: ISAAC. The International Study of Asthma and Allergies in Childhood (ISAAC) Steering Committee. Lancet 1998;351:1225-32.

11. Klaassen EM, van Kant KD, Jöbsis Q, Hovig ST, van Schayck CP, Rijkers GT, et al. Symptoms, but not a biomarker response to inhaled corticosteroids, predict asthma in preschool children with recurrent wheeze. Mediators Inflamm 2012;2012:162571.

12. Miller MR, Hankinson J, Brusasco V, Burgos F, Casaburi R, Coates A, et al. Standardisation of spirometry. Eur Respir J 2005;26:319-38.

13. Kummeling I, Thijs C, Penders J, Snijders BE, Stelma F, Reimerink J, et al. Etiology of atopy in infancy: the KOALA Birth Cohort Study. Pediatr Allergy Immunol 2005;16:679-84.

14. Bindels PJ, Grol MH, Ponsioen BP, Salome PL, Wiersma T, Goudswaard AN, et al. [Summary of the practice guideline 'Asthma in children' (second revision) from the Dutch College of General Practitioners]. Ned Tijdschr Geneeskd 2008;152:550-5.

15. Sambrook J, Russell D. Molecular cloning, a laboratory manual. 3rd ed. New York: Cold Spring Harbor Laboratory Press 2001.

16. Bottema RW, Reijmerink NE, Kerkhof M, Koppelman GH, Stelma FF, Gerritsen J, et al. Interleukin 13, CD14, pet and tobacco smoke influence atopy in three Dutch cohorts: the allergenic study. Eur Respir J 2008;32:593-602.

17. Frank E, Harrell J. Regression Modeling Strategies. New York: Springer; 2001.

18. Steyerberg EW. Clinical Prediction Models. New York: Springer; 2009.

19. Van Eerdewegh P, Little RD, Dupuis J, Del Mastro RG, Falls K, Simon J, et al. Association of the ADAM33 gene with asthma and bronchial hyperresponsiveness. Nature 2002;418:426-30.

20. Holloway JW, Davies DE, Powell R, Haitchi HM, Keith TP, Holgate ST. The discovery and role of ADAM33, a new candidate gene for asthma. Expert Rev Mol Med 2004;6:1-12.

21. Ito I, Laporte JD, Fiset PO, Asai K, Yamauchi Y, Martin JG, et al. Downregulation of a disintegrin and metalloproteinase 33 by IFN-gamma in human airway smooth muscle cells. J Allergy Clin Immunol 2007;119:89-97. 
22. Noguchi E, Ohtsuki Y, Tokunaga K, Yamaoka-Sageshima M, Ichikawa K, Aoki T, et al. ADAM33 polymorphisms are associated with asthma susceptibility in a Japanese population. Clin Exp Allergy 2006;36:602-8.

23. Lee JH, Park HS, Park SW, Jang AS, Uh ST, Rhim T, et al. ADAM33 polymorphism: association with bronchial hyper-responsiveness in Korean asthmatics. Clin Exp Allergy 2004;34:860-5.

24. Haitchi HM, Powell RM, Shaw TJ, Howarth PH, Wilson SJ, Wilson DI, et al. ADAM33 expression in asthmatic airways and human embryonic lungs. Am J Respir Crit Care Med 2005;171:958-65.

25. Foley SC, Mogas AK, Olivenstein R, Fiset PO, Chakir J, Bourbeau J, et al. Increased expression of ADAM33 and ADAM8 with disease progression in asthma. J Allergy Clin Immunol 2007;119:863-71.

26. Kedda MA, Duffy DL, Bradley B, O'Hehir RE, Thompson PJ. ADAM33 haplotypes are associated with asthma in a large Australian population. Eur J Hum Genet 2006;14:1027-36.

27. Raby BA, Silverman EK, Kwiatkowski DJ, Lange C, Lazarus R, Weiss ST. ADAM33 polymorphisms and phenotype associations in childhood asthma. J Allergy Clin Immunol 2004;113:1071-8.

28. Howard TD, Postma DS, Jongepier H, Moore WC, Koppelman GH, Zheng SL, et al. Association of a disintegrin and metalloprotease 33 (ADAM33) gene with asthma in ethnically diverse populations. J Allergy Clin Immunol 2003;112:717-22.

29. Simpson A, Maniatis N, Jury F, Cakebread JA, Lowe LA, Holgate ST, et al. Polymorphisms in a disintegrin and metalloprotease 33 (ADAM33) predict impaired early-life lung function. Am J Respir Crit Care Med 2005;172:55-60.

30. Reijmerink NE, Kerkhof M, Koppelman GH, Gerritsen J, de Jongste JC, Smit HA, et al. Smoke exposure interacts with ADAM33 polymorphisms in the development of lung function and hyperresponsiveness. Allergy 2009;64:898-904.

31. Postma DS, Howard T. ADAM33 gene: confirming a gene without linkage. Clin Exp Allergy 2004;34: 1-3.

32. Moffatt MF, Kabesch M, Liang L, Dixon AL, Strachan D, Heath $S$, et al. Genetic variants regulating ORMDL3 expression contribute to the risk of childhood asthma. Nature 2007;448:470-3.

33. Sleiman PM, Annaiah K, Imielinski M, Bradfield JP, Kim CE, Frackelton EC, et al. ORMDL3 variants associated with asthma susceptibility in North Americans of European ancestry. J Allergy Clin Immunol 2008;122:1225-7.

34. Tavendale R, Macgregor DF, Mukhopadhyay S, Palmer CN. A polymorphism controlling ORMDL3 expression is associated with asthma that is poorly controlled by current medications. J Allergy Clin Immunol 2008;121:860-3.

35. Kavalar MS, Balantic M, Silar M, Kosnik M, Korosec P, Rijavec M. Association of ORMDL3, STAT6 and TBXA2R gene polymorphisms with asthma. Int J Immunogenet 2012;39:20-5.

36. Wu H, Romieu I, Sienra-Monge JJ, Li H, del Rio-Navarro BE, London SJ. Genetic variation in ORM1-like 3 (ORMDL3) and gasdermin-like (GSDML) and childhood asthma. Allergy 2009;64:629-35.

37. Miller M, Tam AB, Cho JY, Doherty TA, Pham A, Khorram N, et al. ORMDL3 is an inducible lung epithelial gene regulating metalloproteases, chemokines, OAS, and ATF6. Proc Natl Acad Sci U S A 2012;109:16648-53.

38. Holloway JW, Yang IA, Holgate ST. Genetics of allergic disease. J Allergy Clin Immunol 2010;125: S81-94.

39. Bouzigon E, Corda E, Aschard H, Dizier MH, Boland A, Bousquet J, et al. Effect of 17q21 variants and smoking exposure in early-onset asthma. N Engl J Med 2008;359:1985-94.

40. Blekic M, Kljaic Bukvic B, Aberle N, Marinho S, Hankinson J, Custovic A, et al. 17q12-21 and asthma: interactions with early-life environmental exposures. Ann Allergy Asthma Immunol 2013;110: 347-53 e2.

41. Basehore MJ, Howard TD, Lange LA, Moore WC, Hawkins GA, Marshik PL, et al. A comprehensive evaluation of IL4 variants in ethnically diverse populations: association of total serum IgE levels and asthma in white subjects. J Allergy Clin Immunol 2004;114:80-7.

42. Beghe B, Barton S, Rorke S, Peng Q, Sayers I, Gaunt T, et al. Polymorphisms in the interleukin-4 and interleukin-4 receptor alpha chain genes confer susceptibility to asthma and atopy in a Caucasian population. Clin Exp Allergy 2003;33:1111-7. 
43. Kabesch M, Tzotcheva I, Carr D, Hofler C, Weiland SK, Fritzsch C, et al. A complete screening of the IL4 gene: novel polymorphisms and their association with asthma and IgE in childhood. J Allergy Clin Immunol 2003;112:893-8.

44. de Faria IC, de Faria EJ, Toro AA, Ribeiro JD, Bertuzzo CS. Association of TGF-beta1, CD14, IL-4, IL-4R and ADAM33 gene polymorphisms with asthma severity in children and adolescents. J Pediatr (Rio J) 2008;84:203-10.

45. Schubert K, von Bonnsdorf H, Burke M, Ahlert I, Braun S, Berner R, et al. A comprehensive candidate gene study on bronchial asthma and juvenile idiopathic arthritis. Dis Markers 2006;22:127-32.

46. Murk W, Walsh K, Hsu LI, Zhao L, Bracken MB, Dewan AT. Attempted replication of 50 reported asthma risk genes identifies a SNP in RAD50 as associated with childhood atopic asthma. Hum Hered 2011;71:97-105.

47. Vercelli D. Gene-environment interactions: the road less traveled by in asthma genetics. J Allergy Clin Immunol 2009;123:26-7. 


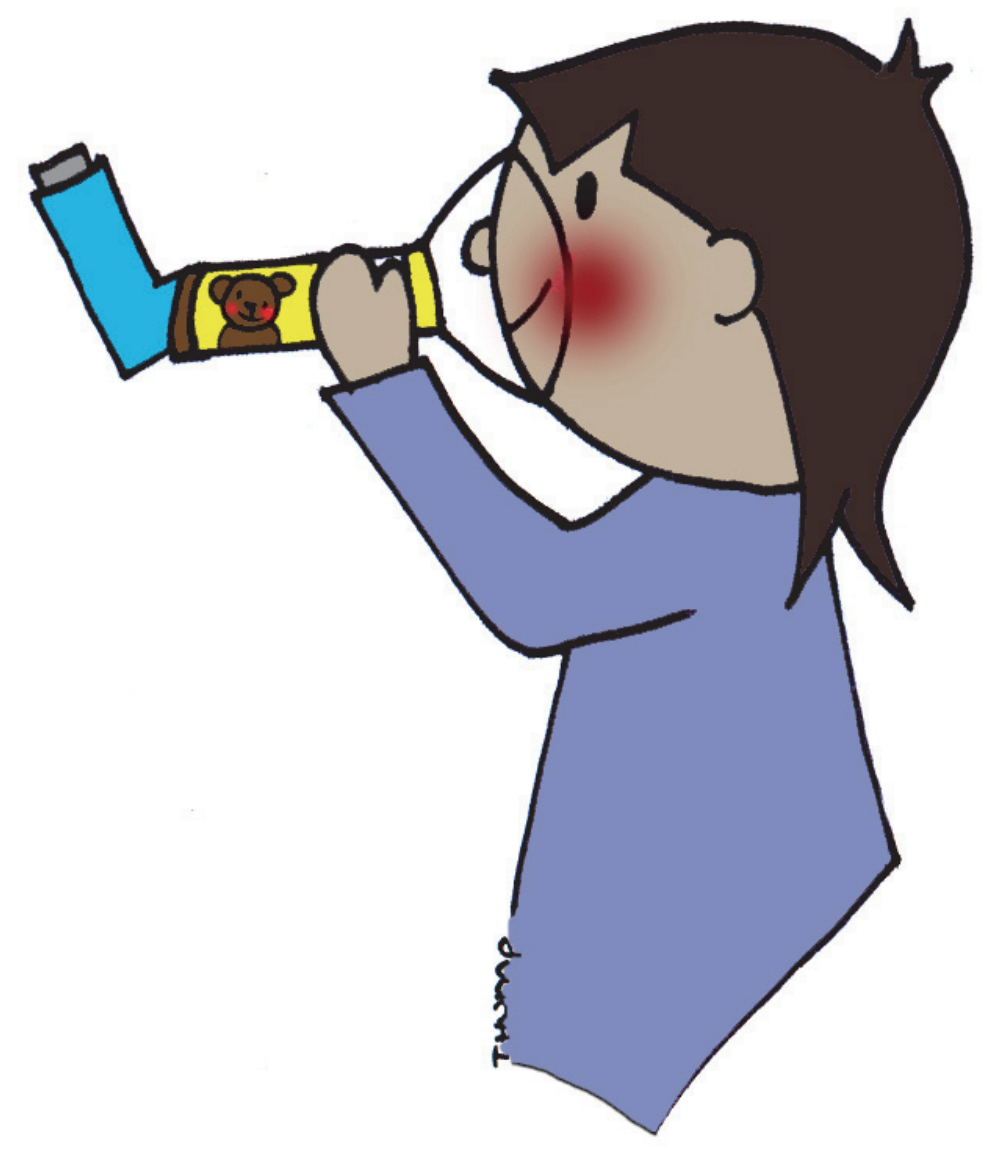




\section{Chapter 7}

Symptoms, but not a biomarker response to inhaled corticosteroids, predict asthma in preschool children with recurrent wheeze

Klaassen EMM, van de Kant KDG, Jöbsis Q, Høvig STP, van Schayck CP, Rijkers GT, Dompeling $\mathrm{E}$ Mediators of Inflammation 2012;2012:162571 


\section{Abstract}

\section{Background}

A reliable asthma diagnosis is challenging in preschool wheezing children. As inhaled corticosteroids (ICS) are more effective in asthmatics than in children with transient wheeze, an ICS response might be helpful in early asthma diagnosis.

\section{Methods}

In total, 175 children (aged two-four years) with recurrent wheeze received $200 \mu \mathrm{g}$ Beclomethasone extra-fine daily for eight weeks. Changes in Exhaled Breath Condensate (EBC) biomarkers ( $\mathrm{pH}$, interleukin (IL)-1 $\alpha$, IL-2, IL-4, IL-5, IL-10, IFN- $\gamma$, sICAM1 and CCL-11), Fractional exhaled Nitric Oxide (FeNO), airway resistance and symptoms were assessed. At six years of age, a child was diagnosed as transient wheezer or asthmatic. Adjusted logistic regression analysis was performed with multiple testing correction.

\section{Results}

In total, 106 transient wheezers and 64 asthmatics were analysed at six years of age. Neither changes in EBC biomarkers, nor FeNO, airway resistance or symptoms during the ICS trial at preschool age were related to an asthma diagnosis at six years of age. However, asthmatics had more airway symptoms before the start of the ICS trial than transient wheezers $(p<0.01)$.

\section{Discussion}

Although symptom score in preschool wheezing children at baseline was associated with asthma at six years of age, EBC biomarkers, FeNO, airway resistance or symptom response to ICS at preschool age could not predict asthma diagnosis at six years of age. 


\section{Introduction}

Asthma is one of the most commonly occurring chronic diseases in children. It mostly develops in early childhood and is characterised by recurrent episodes of wheezing, breathlessness and coughing due to airway inflammation and airway hyperresponsiveness. ${ }^{1}$ However, in the majority of children symptoms are virally induced and transient (so-called transient wheezers). ${ }^{2}$ So, the associated airway symptoms are subjective and not specific for asthma. Moreover, young children are not able to perform lung function tests. Consequently, a diagnosis of asthma at young age has proven to be difficult. ${ }^{1,2}$ Objective measurements of airway inflammation require invasive procedures such as bronchoalveolar lavage, bronchial biopsy and induced sputum and therefore are not routinely used. Effective asthma treatment is available in the form of inhaled corticosteroids (ICS). ICS are less effective in children with airway symptoms not due to asthma. ${ }^{1,3}$ As a result of difficulties in proper asthma diagnosis, true asthmatics are often 'under-treated' whereas children with transient symptoms are often 'over-treated'. ${ }^{4}$ Although international guidelines advocate a trial treatment with ICS for a likely diagnosis of asthma in young children, so far studies addressing response to ICS as a diagnostic tool in children have been scarce. ${ }^{1}$

Exhaled Breath Condensate (EBC) is a non-invasive tool to assess biomarkers of airway inflammation. ${ }^{5}$ Based on the ICS response of inflammation biomarkers in EBC at preschool age, a prediction of asthma at a later age might be possible. Besides, ICS induced changes in Fractional exhaled Nitric Oxide (FeNO), airway resistance and symptoms might contribute to an early asthma diagnosis. Therefore, our study aim was to assess whether an ICS response based on changes in biomarkers in EBC, FeNO, airway resistance and symptoms in preschool aged wheezing children has a predictive value for an asthma diagnosis at the age of six years.

\section{Methods}

\section{Study population}

Participants from the ADEM study (Asthma DEtection and Monitoring study registered at clinicaltrial.gov: NCT 00422747) were included. The ADEM study is a long-term, case-control study that started in 2006 in the Netherlands and aimed to develop a non-invasive instrument for an early asthma diagnosis by using biomarkers of airway inflammation in Exhaled Breath (Condensate) and early lung function measurements (airway resistance). The study protocol has been described previously. ${ }^{6}$ In total, 252 children aged two to four years were included; 202 children with recurrent wheezing symptoms ( $\geq 2$ wheezing episodes until inclusion according to the International Study of Asthma and Allergies in Childhood (ISAAC) questionnaire) and 50 healthy controls 
without wheezing episodes until inclusion. ${ }^{7}$ For the present analysis only the children with recurrent wheezing symptoms were included.

\section{Study design}

The main study objective was to assess whether an ICS response in biomarkers in EBC at preschool age was able to predict an asthma diagnosis at six years of age. Besides, the diagnostic value of the ICS response in FeNO, airway resistance and symptoms for the prediction of asthma at age six years was assessed. For this purpose, an ICS trial was started in preschool children with recurrent wheeze. Airway medication (such as ICS and $\beta_{2}$-agonists) was temporarily stopped prior to measurement. Children who were not able to discontinue ICS from four weeks before the trial were excluded from analyses. In case of clear symptoms of an airway infection, the measurement was postponed for four weeks. During the initial visit EBC was collected, FeNO and airway resistance were assessed and questionnaires were completed (for details see below). Subsequently, recurrent wheezing children received $100 \mu \mathrm{g}$ ICS (Beclomethasone) extra-fine two times a day via the AeroChamber (Trudell Medical International, Ontario, Canada) for eight weeks. Symptom relieve by using salbutamol (Airomir ${ }^{\oplus}$, Teva Pharma NL, Haarlem, the Netherlands) distributed by an AeroChamber was allowed during the trial. At the end of the ICS trial, all measurements were reassessed. Compliance to ICS was assessed by weighting ICS canisters before and after the trial. Children who used a minimum of $80 \%$ of the prescribed medication were considered compliant (used for the per-protocol sub-analysis). Children were followed-up until six years of age. At this age a definite asthma diagnoses was made (see further).

The study protocol was approved by the Dutch Central Committee on Research Involving Human Subjects (CCMO: NL17407.000.07/2007-001817-40, The Hague, the Netherlands). All parents gave written informed consent.

\section{Asthma diagnosis}

At the age of six years, a definite diagnosis (transient wheezer or true asthmatic) was made by two paediatricians in the field of respiratory medicine. An asthma diagnosis was based on symptoms, lung function (reversibility to a $\beta_{2}$-agonist and bronchial hyper-responsiveness) and medication use. Next to this clinical assessment a diagnosis was assessed by a computer calculated algorithm. In this algorithm, asthma was diagnosed in case two out of the following three features were present: (1) positive symptoms (coughing $\geq 1$ night(s) a week, $\geq 2$ episodes of wheezing during the last twelve months, some days wheeze during colds or exercise or night time, two out of the following three items; some days wheeze during colds or during exercise in combination with night time coughing; every day, most days or several days wheeze 
during colds, during exercise or during the night time; cough during the night time), ${ }^{7,8}$ (2) presence of lung function abnormalities (a $20 \%$ fall in forced expiratory volume in one second $\left(\mathrm{FEV}_{1}\right)$ induced by a provocative concentration of histamine $<2 \mathrm{mg} / \mathrm{ml}$, or bronchodilator reversibility $\geq 9 \%$ (see below)), ${ }^{9}$ and (3) ICS use. In case of disagreement between the clinical diagnosis and the computer calculated diagnosis, children were re-assessed by the two paediatricians in the field of respiratory medicine who decided on the final diagnosis.

Bronchial hyper-responsiveness and reversibility measurements were performed according to the ERS guideline. ${ }^{10} \mathrm{FEV}_{1}$ was assessed in each child by means of the Masterscreen Pneumo (Jaeger, Wuerzburg, Germany). The highest FEV ${ }_{1}$ of three technically satisfactory curves was used for analysis. A challenge test was performed by using histamine dissolved in physiologic saline in doubling concentrations from 0.032 to $16 \mathrm{mg} / \mathrm{ml}$. Concentrations were increased until a fall of $\geq 20 \%\left(\mathrm{PC}_{20}\right)$ in $\mathrm{FEV}_{1}$ was measured, or the final dilution was reached. Thereafter, all children directly received $400 \mu \mathrm{g}$ salbutamol and the $\mathrm{FEV}_{1}$ was re-evaluated after fifteen minutes. The change in $\mathrm{FEV}_{1}$ was expressed as a percentage of the predicted value.

\section{Biomarkers of inflammation in Exhaled Breath Condensate}

EBC was collected during ten minutes of tidal breathing into a mask with a two-way non-rebreathing valve connected to a closed glass condenser with recirculation unit developed at our institute. ${ }^{5}$ Directly after EBC collection and $\mathrm{pH}$ measurement (Radiometer, Zoetermeer, the Netherlands), samples were stored at $-80^{\circ} \mathrm{C}$ until further analysis. A selection of pro-inflammatory cytokines ((interleukin (IL)-1 $\alpha$,), T-helper 1 cytokines (interferon- $\gamma$ (IFN- - ) and IL-2), T-helper 2 cytokines (IL-4 and IL-5)), an anti-inflammatory cytokine (IL-10), a chemokine (Eotaxin (CCL-11)) and an adhesion molecule (soluble Intercellular Adhesion Molecule 1 (sICAM1)) were used for analysis. These biomarkers were analysed by using the multiplex immunoassay (Luminex ${ }^{\oplus}$ Corporation, Austin, TX, USA) as described previously. ${ }^{5,11-13}$ Values under the detection limit received a randomly generated value between zero and the detection limit. $^{12}$

\section{Fractional exhaled nitric oxide}

As previously described, FeNO was collected off-line in a $500 \mathrm{ml}$ inert balloon during tidal breathing and measured by using a nitric oxide monitoring system (NIOX Aerocrine, Solna, Sweden). ${ }^{6}$

\section{Airway resistance}

Airway resistance was measured during tidal breathing by means of the MicroRint ${ }^{\bullet}$ (Micro Medical, Rochester Ltd, UK) as described before. ${ }^{6,14}$ The median of at least 
5 technically acceptable airway interruptions during an expiratory peak flow was used for analysis. Measurements were performed before and fifteen minutes after inhalation of $300 \mu \mathrm{g}$ of salbutamol via a spacer (AeroChamber ${ }^{\circ}$ ).

\section{Symptom score}

Parents completed a questionnaire on airway symptoms. ${ }^{8}$ Based on this questionnaire a symptom score was computed by adding six items (cough during daytime, cough at night, wheeze during daytime, wheeze at night, dyspnoea during daytime and dyspnoea at night) on a Likert-scale (every day $=1$, most days $=2$, some days $=3$, a few days $=4$, not at all=5). The minimal score was six and the maximal score was 30 (no day and nighttime symptoms).

\section{Statistical analysis}

Data were analysed by using SPSS 18 (SPSS Inc., Chicago, IL, USA). Due to the skewed distributions, biomarkers in EBC were log-transformed which successfully imparted a normal distribution. Differences in baseline characteristics between transient wheezers and true asthmatics were evaluated by using the chi-square test for categorical variables and the independent t-test for continuous parametric variables. The effect of each individual potential predictor (both before the ICS trial and changes during ICS) on asthma diagnosis at six years of age was tested by separate logistic regression models. Models were adjusted for possible confounders (gender, atopy, eczema, previous ICS use, first degree relative with asthma, smoking exposure and season of measurement). Data were presented for intention-to-treat analysis unless otherwise specified. P-values were corrected for multiple testing by the False Discovery Rate (FDR) for each hypothesis. ${ }^{15}$ Differences were considered statistically significant when the FDR corrected $p$-value was $<0.05$.

\section{Power analysis}

The primary outcome measure is the definite asthma diagnosis at six years of age. In a population of young children with recurrent airway symptoms, the prevalence of asthma at six years of age is $30 \% .{ }^{16}$ In the current study, including 202 children with recurrent wheeze, this will result in at least 50 children with asthma taken into account a drop-out rate of $10 \%$. Based on an earlier study in children with asthma and healthy controls aged 6-16 years, differences in concentrations of IL-1 $\alpha$, IL-2, IL-4, IFN- $\gamma$, CCL-11 and SICAM1 were found of respectively 4.5, 13.2, 2.9, 11.3, 0.9 and 80.0 $\mathrm{pg} / \mathrm{ml}^{17}{ }^{17}$ If we assume comparable differences in for example CCL-11 in the present population between asthmatics and transient wheezers with a power of $90 \%$ and an alpha of $0.05,39$ asthmatics and 78 transient wheezers are needed. 


\section{Results}

\section{Baseline characteristics}

Of the 202 recurrent wheezers included in the ADEM study, 175 parents gave informed consent to participate in the ICS trial. One participant was excluded from analysis as an asthma diagnosis could not be assessed due to missing data. Four children (all true asthmatics) were unable to stop their regular ICS medication and were therefore excluded from further analysis. In total, 170 (65 asthmatics and 105 transient wheezers) children were included in the intention-to-treat analysis and 103 (42 asthmatics and 61 transient wheezers) in the per-protocol analysis (as they used a minimum of $80 \%$ prescribed ICS). Figure 1 presents the study flow chart. Agreement between the clinical and computed diagnosis was reached in $83 \%$ before and $89 \%$ after clinical re-assessment.

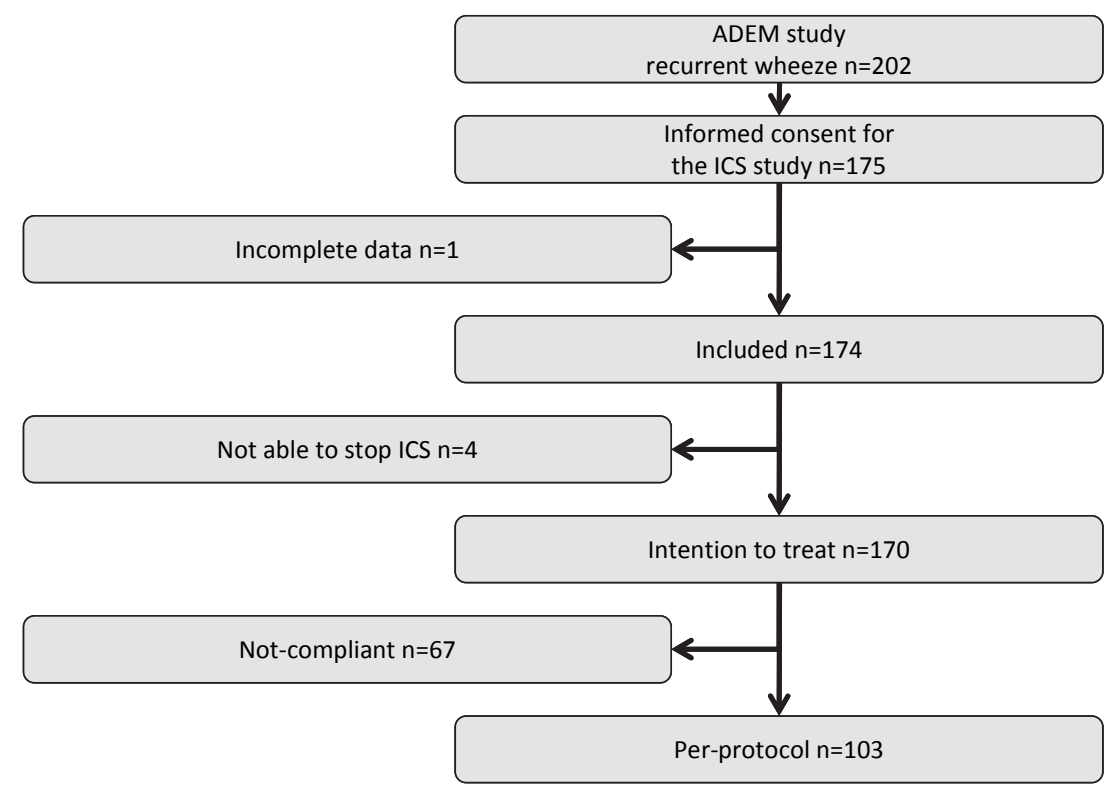

Figure 1 Study flow chart

Baseline characteristics are displayed in Table 1. Preschool children in the asthmatic group used significantly more ICS and short-acting $\beta_{2}$-agonists in the preceding year compared to the transient wheeze group. Besides, atopy at preschool age was significantly more frequent in true asthmatics. At six years of age, ICS and short-acting $\beta_{2}$-agonists were used in $40 / 43 \%$ of the asthmatics and $2 / 6 \%$ of the transient 
wheezers respectively. Atopy was present in $45 \%$ of the asthmatics and $31 \%$ of the transient wheezers at six years of age.

Table 1 Characteristics at baseline for transient wheezers and true asthmatics

\begin{tabular}{lccc}
\hline & Transient wheeze & Asthma & Total \\
& $\mathrm{N}=105$ & $\mathrm{~N}=65$ & $\mathrm{~N}=170$ \\
\hline Mean age (SD) & $3.3(0.6)$ & $3.3(0.6)$ & $3.3(0.6)$ \\
Gender: male/female $(\mathrm{n})$ & $55 / 50$ & $37 / 28$ & $92 / 78$ \\
Atopy,$+ \% *$ & 20 & 35 & 26 \\
Eczema, \% & 36 & 47 & 40 \\
Use of ICS, \% & 12 & 26 & 18 \\
Use of short-acting $\beta_{2}$-agonists, \%* & 31 & 54 & 40 \\
Asthma first degree relatives, \% & 36 & 44 & 39 \\
Smoking exposure, \% & 30 & 31 & 31 \\
\hline
\end{tabular}

* $p<0.05$ between transient wheezers and true asthmatics; + Atopy is defined as a positive ( $\geq 0.35 \mathrm{kU} / \mathrm{I})$; Phadiatop infant test (Phadiatop Infant , Phadia, Uppsala, Sweden); N: Number of children; SD=standard Deviation.

\section{Analysis at baseline}

EBC and FeNO were successfully collected in all children (100\%). With the exception of Eotaxin (89\%), all EBC markers were above the detection limit in more than $98 \%$ of the samples. Pre-bronchodilator and post-bronchodilator airway resistance were successfully assessed in 95 and $97 \%$ of the children respectively. The symptom score was present in all children (100\%). No statistically significant differences in biomarkers of inflammation in EBC, FeNO or airway resistance were observed between the groups at preschool age (Table 2). However, children with an asthma diagnosis at six years of age had significantly more symptoms (lower symptom score) at preschool age compared to transient wheezers (Odds Ratio $=0.85$ 95\% Confidence Interval=0.770.93, $p<0.01$, FDR corrected).

\section{Changes induced by inhaled corticosteroids}

No statistically significant changes between transient wheezers and asthmatics in biomarkers in EBC, FeNO, airway resistance or symptom score were induced by the ICS trial (Table 3). FeNO levels in the total group neither showed significant changes (median ppb (interquartile range) before the ICS trial: 8.4 (4.2-14.3) after the ICS trial: $9.6(4.5-15.4), p=0.45)$.

\section{Sub-analysis per-protocol}

Results of the study did not change when only compliant children were included in the analysis (per-protocol analysis). 
Table 2 Baseline analysis at preschool age

\begin{tabular}{|c|c|c|c|c|}
\hline & $\begin{array}{c}\text { Transient wheeze } \\
\text { Median (IQR) }\end{array}$ & $\begin{array}{c}\text { Asthma } \\
\text { Median (IQR) }\end{array}$ & OR & $95 \% \mathrm{Cl}$ \\
\hline IL-1 $\alpha$, in $\mathrm{pg} / \mathrm{ml}$ & $34.0(15.6-83.7)$ & $44.2(18.3-97.6)$ & 1.10 & $0.84-1.44$ \\
\hline $\mathrm{IL}-2$, in $\mathrm{pg} / \mathrm{ml}$ & 55.5 (35.7-76.8) & $57.0(43.1-81.2)$ & 1.32 & $0.80-2.16$ \\
\hline $\mathrm{IL}-4$, in $\mathrm{pg} / \mathrm{ml}$ & $8.8(4.8-13.9)$ & $9.6(6.0-14.5)$ & 1.15 & $0.70-1.88$ \\
\hline $\mathrm{IL}-5$, in $\mathrm{pg} / \mathrm{ml}$ & $29.8(17.8-58.7)$ & $37.2(19.4-80.6)$ & 1.21 & $0.85-1.73$ \\
\hline IL-10, in $\mathrm{pg} / \mathrm{ml}$ & $4.5(2.8-6.9)$ & $5.2(3.2-8.4)$ & 1.09 & $0.72-1.65$ \\
\hline IFN- - , in $\mathrm{pg} / \mathrm{ml}$ & $28.1(17.5-44.6)$ & $27.1(16.0-44.2)$ & 0.88 & $0.67-1.16$ \\
\hline sICAM1, in $\mathrm{pg} / \mathrm{ml}$ & $190.4(94.8-416.2)$ & 265.5 (104.1-516.4) & 1.08 & $0.79-1.48$ \\
\hline $\mathrm{CCL}-11$, in $\mathrm{pg} / \mathrm{ml}$ & $8.3(5.2-12.5))$ & $8.0(5.3-14.6)$ & 0.90 & $0.71-1.15$ \\
\hline $\mathrm{pH}$ & $6.0(5.7-6.3)$ & $5.8(5.6-6.2)$ & 0.66 & $0.34-1.28$ \\
\hline FeNO, in ppb & $6.7(3.7-13.3)$ & $8.9(5.4-18.1)$ & 1.02 & $0.98-1.05$ \\
\hline Airway resistance before medication ${ }^{\S}$ & $1.4(0.3)$ & $1.5(0.4)$ & 2.15 & $0.83-5.56$ \\
\hline Airway resistance after medication ${ }^{\S}$ & $1.2(0.4)$ & $1.3(0.3)$ & 2.06 & $0.70-6.01$ \\
\hline Bronchodilator response ${ }^{\S}$ & $0.1(0.3)$ & $0.0(0.5)$ & 1.44 & $0.45-4.55$ \\
\hline Total symptom score* & $27(25-29)$ & $25(20-28)$ & 0.85 & $0.77-0.93$ \\
\hline
\end{tabular}

* False Discovery Rate (FDR) corrected $\mathrm{p}<0.01{ }^{\S}$ Mean (standard deviation). IL: interleukin; IFN- $\gamma$ : Interferon- $\gamma$; sICAM1: soluble Intercellular Adhesion Molecule 1; CCL-11: Eotaxin; FeNO: Fractional exhaled Nitric Oxide; OR: Odds Ratio; 95\%Cl: 95\% Confidence Interval. Analysis adjusted for gender atopy, eczema, previous inhaled corticosteroids use, asthma first relative, smoking exposure and season of measurement. The transient wheeze group is the reference group.

Table 3 Changes induced by inhaled corticosteroids related to an asthma diagnosis

\begin{tabular}{lcc}
\hline & OR & $95 \% \mathrm{Cl}$ \\
\hline IL-1 $\alpha$ & 0.96 & $0.78-1.19$ \\
IL-2 & 0.99 & $0.71-1.38$ \\
IL-4 & 0.90 & $0.64-1.28$ \\
IL-5 & 0.97 & $0.76-1.24$ \\
IL-10 & 0.87 & $0.65-1.16$ \\
IFN- $\gamma$ & 0.93 & $0.73-1.20$ \\
SICAM1 & 0.97 & $0.77-1.22$ \\
CCL-11 & 0.94 & $0.75-1.17$ \\
pH & 0.99 & $0.61-1.60$ \\
FeNO & 1.01 & $0.99-1.04$ \\
Airway resistance before medication & 0.80 & $0.33-1.93$ \\
Airway resistance after medication & 1.51 & $0.55-4.16$ \\
Total symptom score decreased & Ref. & \\
Total symptom score equal & 0.74 & $0.27-2.04$ \\
Total symptom score increased & 0.65 & $0.30-1.39$ \\
\hline
\end{tabular}

IL: interleukin; IFN- $\gamma$ : Interferon- $\gamma$; sICAM1: soluble Intercellular Adhesion Molecule 1; CCL-11: Eotaxin; FeNO: Fractional exhaled Nitric Oxide; OR: Odds Ratio; 95\% Cl: 95\% Confidence Interval; Ref.: reference category. Analysis adjusted for gender atopy, eczema, previous inhaled corticosteroids use, asthma first relative, smoking exposure and season of measurement. The transient wheeze group is the reference group. Due to violation of linearity assumption in log transformation, results for total symptom score are split up into three equal categories. 


\section{Discussion}

Presently, no adequate diagnostic tool is available for an early asthma diagnosis in preschool wheezing children. This study addressed the question whether the response to ICS treatment of biomarkers of inflammation in EBC, FeNO, airway resistance and symptoms at preschool age could predict an asthma diagnosis at six years of age. Changes in biomarkers in EBC, FeNO, airway resistance, or symptoms induced by an eight week ICS treatment at preschool age were not related to an asthma diagnosis at six years of age. However, it was demonstrated that children with asthma at six years of age had more respiratory symptoms at preschool age compared to transient wheezers. Also, medication use and atopy at baseline were significantly higher in asthmatics compared to transient wheezers.

Collection of EBC is a non-invasive method in which biomarkers expected to reflect airway inflammation can be assessed and most influence of the systemic metabolism is avoided. Previously our research group has shown differences of biomarkers of inflammation between asthmatics and healthy children. ${ }^{17}$ Moreover, a higher concentration for multiple biomarkers was noted in children with more severe wheeze compared to children without wheeze in the present population. ${ }^{13}$ In adult populations with asthma, it was demonstrated that several biomarkers in EBC significantly changed after ICS treatment. ${ }^{18,19}$ Differences of ICS response based on changes in biomarkers in children have not yet been investigated. In the present study, none of the selected biomarkers in EBC before or changes during the ICS treatment were associated with an asthma diagnosis at six years of age. Besides, FeNO assessed before or a change during ICS treatment at preschool age was not associated with an asthma diagnosis at six years of age. FeNO levels in the total group neither showed significant changes. Data on the effectiveness of predicting an ICS response by FeNO in children are conflicting. ${ }^{20-22}$ Asthma is expected to be predominated by an eosinophilic airway inflammation while transient wheeze is characterised by a neutrophilic inflammation. ${ }^{23-25}$ ICS are believed to mainly have an anti-eosinophilic inflammation effect. ${ }^{1,3,24}$ Therefore, ICS are expected to be more effective in asthmatics compared to transient wheezers. However, increasing evidence points towards overlap between eosinophilic and neutrophilic inflammation in both asthma and transient wheeze. ${ }^{26,27}$ Due to this overlap, changes in inflammation biomarkers induced by ICS treatment might be less pronounced and these changes may not be able to distinguish between transient wheezers and true asthmatics, as was observed in our study. It would be interesting to study differences with healthy children as well. Previously, we did demonstrate differences between baseline measurements of biomarkers in EBC in healthy children and children with recurrent wheeze in the same cohort. ${ }^{12}$ However, due to ethical constraints the healthy children have not been included in the trial. 
Airway resistance in preschool children has been found to be predictive for asthma symptoms at six years of age. ${ }^{28}$ Besides, bronchodilator reversibility was able to predict effectiveness of anti-inflammatory therapy in young children with asthma. ${ }^{20}$ No ICS response for airway resistance or reversibility was demonstrated in the present study. These results should be interpreted with caution as the children participating in our study in general had mild symptoms before and during ICS treatment, thus leaving little room for improvement.

Even though most children had only mild symptoms, symptoms at preschool age were positively associated with an asthma diagnosis at six years of age. This association remained highly significant after multiple testing correction. However, changes in symptoms during ICS treatment were not related to the asthma diagnosis at six years of age. This result can be interpreted twofold. First, as symptoms were mild there was not enough room for improvement during ICS treatment. Second, improvement in symptoms was equal for asthmatics and for transient wheezers. Either way, differentiation of true asthmatics from transient wheezers based on symptom reduction due to ICS treatment was not possible in our study. It will be interesting to address this issue in a population with more severe symptoms.

The major strength of this study is the longitudinal design that enabled the assessment of an ICS response of several biomarkers at preschool age and an asthma diagnosis at six years of age. A second strength of this study is the high follow-up rate. Information to assess an asthma diagnosis was available in all but one child at six years of age. Thirdly, measurements were feasible and non-invasive which made them suitable for young children. Feasibility of assessing biomarkers in EBC was increased by the use of a double-jacketed condenser with heated breath recirculation unit as was developed at our institute. ${ }^{5}$ Due to this efficient condenser system EBC could be collected in a relatively short collection time. Besides, multiple biomarkers could be measured in a small sample by the highly sensitive multiplexed liquid bead arrays with good to excellent reproducibility. ${ }^{11,17}$ Finally, we chose to administer Beclomethasone extra-fine. Previous research demonstrated that the use of small particles in young children are effective and safe and are expected to result in increased and more uniform deposition in the lower respiratory tracts. This minimises the necessary dosage for administration. ${ }^{29,30}$

However, some limitations need to be addressed. Firstly, measurement of biomarkers of inflammation in EBC is a technique that still needs more validation and standardisation. Despite these restrictions, our research group has extensive experience on the use of EBC as a non-invasive technique to assess biomarkers in airway inflammation. ${ }^{5,6,17}$ Secondly, as asthma is heterogeneous by nature, difficulties might arise when assessing an asthma diagnosis. In the present study, both a clinical and a computer algorithm were used for an asthma diagnosis The degree of accordance between the clinical and algorithm diagnosis was high and mismatches were re-evaluated in order to prevent an incorrect diagnoses. Finally, it can be argued 
whether a period of eight weeks ICS is sufficient to assess changes in biomarkers in EBC, FeNO, airway resistance and symptoms at preschool age to predict an asthma diagnosis at six years of age. According to international guidelines, a treatment trial with ICS of at least eight weeks in preschool children can give guidance to the presence of asthma. ${ }^{1}$ Therefore, changes in biomarkers in EBC, airway resistance, FeNO and symptoms are to be expected after eight weeks.

\section{Conclusions}

In conclusion, in this study we demonstrated that, although symptoms at preschool age were predictive for an asthma diagnosis at age six years, changes in biomarkers of inflammation in EBC, FeNO, airway resistance and symptoms induced by ICS at preschool age could not predict an asthma diagnosis at six years of age. In the absence of a proper diagnostic tool for asthma at young age, adequate care and management of children with airway symptoms remains hampered. Although no predictive value of biomarkers in EBC could be demonstrated in the present study, EBC biomarkers might still be of additional value for an asthma diagnosis. In the future, we will determine whether profiles of EBC biomarkers in combination with other parameters such as clinical features, exhaled volatile organic compounds and gene expression can be of value in predicting an asthma diagnosis. 


\section{References}

1. Pedersen SE, Hurd SS, Lemanske RF, Jr., Becker A, Zar HJ, Sly PD, Soto-Quiroz M, Wong G, Bateman ED. Global strategy for the diagnosis and management of asthma in children 5 years and younger. Pediatr Pulmonol 2011:46: 1-17.

2. Savenije OE, Granell R, Caudri D, Koppelman GH, Smit HA, Wijga A, de Jongste JC, Brunekreef B, Sterne JA, Postma DS, Henderson J, Kerkhof M. Comparison of childhood wheezing phenotypes in 2 birth cohorts: ALSPAC and PIAMA. J Allergy Clin Immunol 2011:127:1505-12 e1514.

3. Schokker S, Kooi EM, de Vries TW, Brand PL, Mulder PG, Duiverman EJ, van der Molen T. Inhaled corticosteroids for recurrent respiratory symptoms in preschool children in general practice: randomized controlled trial. Pulm Pharmacol Ther 2008:21:88-97.

4. Caudri D, Wijga AH, Smit HA, Koppelman GH, Kerkhof M, Hoekstra MO, Brunekreef B, de Jongste JC. Asthma symptoms and medication in the PIAMA birth cohort: Evidence for under and overtreatment. Pediatr Allergy Immunol 2011:22:652-9.

5. Rosias PP, Robroeks CM, van de Kant KD, Rijkers GT, Zimmermann LJ, van Schayck CP, Heynens JW, Jöbsis Q, Dompeling E. Feasibility of a new method to collect exhaled breath condensate in pre-school children. Pediatr Allergy Immunol 2010:21:e235-44.

6. van de Kant KD, Klaassen EM, Jöbsis Q, Nijhuis AJ, van Schayck OC, Dompeling E. Early diagnosis of asthma in young children by using non-invasive biomarkers of airway inflammation and early lung function measurements: study protocol of a case-control study. BMC Public Health 2009:9:210.

7. Worldwide variation in prevalence of symptoms of asthma, allergic rhinoconjunctivitis, and atopic eczema: ISAAC. The International Study of Asthma and Allergies in Childhood (ISAAC) Steering Committee. Lancet 1998:351:1225-32.

8. Powell CV, McNamara P, Solis A, Shaw NJ. A parent completed questionnaire to describe the patterns of wheezing and other respiratory symptoms in infants and preschool children. Arch Dis Child 2002: 87:376-9.

9. Pellegrino R, Viegi G, Brusasco V, Crapo RO, Burgos F, Casaburi R, Coates A, van der Grinten CP, Gustafsson P, Hankinson J, Jensen R, Johnson DC, Maclntyre N, McKay R, Miller MR, Navajas D, Pedersen OF, Wanger J. Interpretative strategies for lung function tests. Eur Respir J 2005:26:948-68.

10. Miller MR, Hankinson J, Brusasco V, Burgos F, Casaburi R, Coates A, Crapo R, Enright P, van der Grinten CP, Gustafsson P, Jensen R, Johnson DC, Maclntyre N, McKay R, Navajas D, Pedersen OF, Pellegrino R, Viegi G, Wanger J. Standardisation of spirometry. Eur Respir J 2005:26:319-38.

11. de Jager W, te Velthuis H, Prakken BJ, Kuis W, Rijkers GT. Simultaneous detection of 15 human cytokines in a single sample of stimulated peripheral blood mononuclear cells. Clin Diagn Lab Immunol 2003:10:133-9.

12. van de Kant KD, Koers K, Rijkers GT, Lima Passos V, Klaassen EM, Mommers M, Dagnelie PC, van Schayck CP, Dompeling E, Jöbsis Q. Can exhaled inflammatory markers predict a steroid response in wheezing preschool children? Clin Exp Allergy 2011:41:1076-83.

13. van de Kant KD, Klaassen EM, Jöbsis Q, Koers K, Rijkers GT, van der Grinten CP, van Schayck OC, Passos VL, Dompeling E. Wheezing in preschool children is associated with increased levels of cytokines/chemokines in exhaled breath condensate. J Allergy Clin Immunol 2010:126:669-71.

14. Merkus PJ, Arets HG, Joosten T, Siero A, Brouha M, Mijnsbergen JY, de Jongste JC, van der Ent CK. Measurements of interrupter resistance: reference values for children 3-13 yrs of age. Eur Respir J 2002:20:907-11.

15. Curran-Everett D. Multiple comparisons: philosophies and illustrations. Am J Physiol Regul Integr Comp Physiol 2000:279.

16. Kurukulaaratchy RJ, Fenn MH, Waterhouse LM, Matthews SM, Holgate ST, Arshad SH. Characterization of wheezing phenotypes in the first 10 years of life. Clin Exp Allergy 2003:33:573-8.

17. Robroeks CM, Rijkers GT, Jöbsis Q, Hendriks HJ, Damoiseaux JG, Zimmermann LJ, van Schayck OP, Dompeling E. Increased cytokines, chemokines and soluble adhesion molecules in exhaled breath condensate of asthmatic children. Clin Exp Allergy 2010:40:77-84. 
18. Carpagnano GE, Foschino Barbaro MP, Resta O, Gramiccioni E, Valerio NV, Bracciale P, Valerio G. Exhaled markers in the monitoring of airways inflammation and its response to steroid's treatment in mild persistent asthma. European journal of pharmacology 2005:519:175-81.

19. Matsunaga K, Ichikawa T, Yanagisawa S, Akamatsu K, Koarai A, Hirano T, Sugiura H, Minakata Y, Ichinose M. Clinical Application of Exhaled Breath Condensate Analysis in Asthma: Prediction of FEV(1) Improvement by Steroid Therapy. Respiration 2009:78:393-8.

20. Zielen S, Christmann M, Kloska M, Dogan-Yildiz G, Lieb A, Rosewich M, Schubert R, Rose MA, Schulze J. Predicting short term response to anti-inflammatory therapy in young children with asthma. Curr Med Res Opin 2010:26:483-92.

21. Zacharasiewicz A, Wilson N, Lex C, Erin EM, Li AM, Hansel T, Khan M, Bush A. Clinical use of noninvasive measurements of airway inflammation in steroid reduction in children. Am J Respir Crit Care Med 2005:171:1077-82.

22. Pijnenburg MW, Bakker EM, Hop WC, De Jongste JC. Titrating steroids on exhaled nitric oxide in children with asthma: a randomized controlled trial. Am J Respir Crit Care Med 2005:172: 831-6.

23. Snijders D, Agostini S, Bertuola F, Panizzolo C, Baraldo S, Turato G, Faggian D, Plebani M, Saetta M, Barbato A. Markers of eosinophilic and neutrophilic inflammation in bronchoalveolar lavage of asthmatic and atopic children. Allergy 2010:65:978-85.

24. Cowan DC, Cowan JO, Palmay R, Williamson A, Taylor DR. Effects of steroid therapy on inflammatory cell subtypes in asthma. Thorax 2010:65:384-90.

25. Pitrez PM, Brennan S, Sly PD. Inflammatory profile in nasal secretions of infants hospitalized with acute lower airway tract infections. Respirology 2005:10:365-70.

26. Marguet C, Jouen-Boedes F, Dean TP, Warner JO. Bronchoalveolar cell profiles in children with asthma, infantile wheeze, chronic cough, or cystic fibrosis. Am J Respir Crit Care Med 1999:159: 1533-40.

27. Douwes J, Gibson P, Pekkanen J, Pearce N. Non-eosinophilic asthma: importance and possible mechanisms. Thorax 2002:57:643-8.

28. Caudri D, Wijga AH, Hoekstra MO, Kerkhof M, Koppelman GH, Brunekreef B, Smit HA, de Jongste JC. Prediction of asthma in symptomatic preschool children using exhaled nitric oxide, Rint and specific IgE. Thorax 2010:65:801-7.

29. Davies BR, Carroll WD. The use of inhaled corticosteroids in the wheezy <5-year-old child. Arch Dis Child Educ Pract Ed 2011;96:61-6.

30. Amirav I, Newhouse MT, Minocchieri S, Castro-Rodriguez JA, Schuepp KG. Factors that affect the efficacy of inhaled corticosteroids for infants and young children. J Allergy Clin Immunol 2010:125: 1206-11. 


$$
80
$$




\section{Chapter 8}

\section{Profiling of volatile organic compounds in exhaled}

breath as a strategy to find early predictive

signatures of asthma in children

Smolinska A, Klaassen EMM, Dallinga JW, van de Kant KDG, Jöbsis Q, Moonen EJC, van Schayck CP, Dompeling $E$, van Schooten FJ

Submitted for publication 


\section{Abstract}

One of the most common respiratory symptoms in preschool children is wheeze, which has a very heterogeneous pathophysiology. Currently it is not possible to predict at an early age which part of wheezing children will develop asthma and which part will be transient wheezers. The tests which support the diagnosis of asthma are difficult to use in children, because they are invasive or require active cooperation of a patient. A non-invasive alternative may be found in analysing Volatile Organic Compounds (VOCs) that are excreted in breath resulting from deviant inflammatory processes. The aim of this study is to analyse a total array of exhaled VOCs with GasChromatography time-of-flight Mass Spectrometry and search for a profile of VOCs in breath that can be predictive for asthma at the early age (inclusion at age two-four years). For this purpose 252 children aged two to four years were followed until six years and breath samples were collected. On average, each measured breath-o-gram contained 300-500 VOCs, leading in total to 3256 compounds. Using two sophisticated multivariate methods, Random Forests and dissimilarity Partial Least Squares Discriminant Analysis, we were able to select a set of 17 VOCs enabling the discrimination of preschool asthmatic children from children with transient wheeze with a correct prediction rate equal to $80 \%$ for an independent test set. The origin of discriminating VOCs is related to oxidative stress and consequently lipid peroxidation. We showed that VOCs in exhaled breath might have a new potential use as early predictive signatures of asthma in children. 


\section{Introduction}

During the last few decades, biomarker discovery has become a significant area in biomedical research to deliver tools to accurately assess when a healthy state becomes dysfunctional. This corresponds to the detection of the very early stages of the disease, opening new possibilities for prevention, early diagnosis and monitoring the responses to therapy. Metabolomics is a promising and emerging research field for establishing specific disease biomarkers. ${ }^{1}$ Metabolomic profiling is closely related with the application of spectroscopic techniques and with multivariate statistical analysis. The conjunction of advanced spectroscopy with multivariate analysis allows describing the molecular composition of biofluids, cells and/or tissues. ${ }^{2}$ Multivariate analysis enables extracting the information of interest from numerically large and complex biological data. Exhaled breath is a lesser used biological medium to perform metabolomics in the field of analysing large numbers of volatile metabolites in exhaled breath, referred as breathomics. ${ }^{3,4}$ Similarly to other types of biological samples, exhaled breath can be used to define biomarkers (or breath prints) related to an abnormal health status in humans. The metabolites detected in exhaled breath originate from normal and deviant (for instance inflammatory) metabolic processes occurring in the body. ${ }^{5,6}$ These processes produce volatile products, Volatile Organic Compounds (VOCs), which are first released into the blood and once passing the lungs into exhaled breath. Many degenerative diseases are related to a form of chronic inflammation and/or oxidative stress which lead to the excretion of specific volatile compounds. ${ }^{3,7}$ Therefore several applications of breathomics in monitoring and diagnosing diseases, such as asthma, ${ }^{8,9}$ lung cancer, ${ }^{10}$ chronic obstructive pulmonary disease $^{11-13}$, cystic fibrosis ${ }^{14,15}$, inflammatory bowel disease ${ }^{16}$ and non-alcoholic steatohepatitis ${ }^{17}$ have been demonstrated.

We propose to use breathomics to define early biomarkers of asthma, since this disease involves inflammation processes, making it a suitable target for breathomics. Asthma is the most common chronic illness in childhood and is defined as a chronic condition with symptoms of wheezing, cough and difficulties in breathing. ${ }^{18,19}$ Though worldwide around $30 \%$ of preschool children have at least one asthmatic symptom such as coughing, wheezing and dyspnoea, ${ }^{18}$ only one third will develop asthma at later age, while the remaining children will have transient symptoms, so-called viral wheeze. $^{20,21}$ Nevertheless, in preschool children, wheeze is a respiratory symptom which is often a reason for consulting a medical doctor. The aetiology of preschool wheeze is complex and its development is a combination between genetic predisposition and environmental factors like allergens, passive smoking, pollution and infections. ${ }^{22}$ Due to the heterogeneity of preschool wheezing children, diverse phenotypes of wheeze are defined. They include allergic and non-allergic asthma and transient wheeze in association with viral respiratory tract infections. ${ }^{23}$ 
Diagnosing asthma in preschool children is challenging. Several tests can support the diagnosis of asthma, such as spirometry, bronchoprovocation and sputum induction. ${ }^{24}$ However, these tests are difficult to perform in preschool children due to their invasiveness and to the necessity of active cooperation. ${ }^{25,26}$ Therefore, it is currently difficult to reliably predict who will develop asthma later on. Trustworthy diagnosis of asthma is only possible around the age of six. ${ }^{27}$ Early diagnosis of asthma in preschool children might improve therapies or secondary prevention interventions. ${ }^{28}$ This justifies the increasing interest in the non-invasive assessment of asthma. The application of breathomics seems well indicated here because of its non-invasive nature and the great potential of applications in diseases diagnostic and monitoring. ${ }^{3}$ Thus, the aim of the current study is to investigate whether breath VOCs profiles are capable of discriminating preschool children with asthma from children with transient wheeze at its early stage.

\section{Materials and methods}

\section{Study design and asthma diagnosis}

The study population consists of children from the "Asthma DEtection and Monitoring" (ADEM) study (registered at clinicaltrial.gov: NCT 00422747) that started in the Netherlands (Maastricht). The Ethics Committee of Maastricht University approved the study protocol. All parents gave written informed consent. In the ADEM study, children were included at two to four years old and followed prospectively until the age of six years. In total 252 children were encompassed of which 202 individuals had recurrent wheezing symptoms ( $\geq 2$ wheezing episodes until inclusion according to the International Study of Asthma and Allergies in Childhood (ISAAC) questionnaire) and 50 were healthy controls without wheezing episodes until inclusion. ${ }^{29}$ At the age of six years children were classified as healthy, transient wheezer or true asthmatic by an experienced paediatrician in the field of respiratory medicine and a computeralgorithm based on status at inclusion (healthy control or recurrent wheezer), symptoms, lung function and use of asthma medication. A detailed description of the definitive classification can be found elsewhere. ${ }^{30}$ Note that at the age of six years one child, who was at inclusion selected as healthy, was classified as asthmatic. Moreover, from the set of 202 children, four remained unclassified at the age of six because of loss to follow-up based on personal constraints of the parents (e.g. lack of motivation and time). 


\section{Sampling and measurements}

The subjects involved in the study breathed through a facemask connected to a valve of a resistance-free $1 \mathrm{~L}$ plastic bag (Tedlar bag, SKC Ltd, Dorset, UK). One hour before measurement, eating and exercise were not allowed. The use of inhaled corticosteroids was stopped four weeks before the measurements, except in seven patients at preschool age due to severe asthmatic symptoms. All samples from subjects taken part in this study were collected in the same room in order to prevent background bias. The plastic bags were emptied under pressure over a stainless-steel two-bed sorption tube, filled with carbograph 1TD/Carbopack $X$ (Markes International, Llantrisant, Wales, UK) within $1 \mathrm{~h}$ after collection. The air-tight capped tubes were kept at room temperature until analysis.

The exhaled air samples were measured by means of Gas Chromatography time-offlight Mass Spectrometry (GC-tof-MS). ${ }^{31}$ The volatile compounds are first released from the sorption tubes by thermal desorption using the Markes International UltraUnity automated thermal desorption equipment (Markes International). Next, the mixture of vapour is divided on two parts, namely $90 \%$ of the samples is recollected on an identical sample tube and stored for eventual second analysis and the remaining amount, i.e. $10 \%$ is loaded onto a cold $\left(5^{\circ} \mathrm{C}\right)$ sorption trap, from which it is reloaded for the GC-tof-MS analysis. The temperature of the GC was programmed as follows: first $40^{\circ} \mathrm{C}$ for 5 minutes then an increase of $10^{\circ} \mathrm{C}$ every minute until $270^{\circ} \mathrm{C}$ is reached. This temperature was maintained for 5 minutes. Electron ionization at $70 \mathrm{eV}$ was used with $5 \mathrm{~Hz}$ scanning rate over a range of $\mathrm{m} / \mathrm{z} 35-350$.

\section{Data pre-processing}

The raw original GC-tof-MS spectra are noisy with artefacts and contain background. These distortions have to be removed before proper data analysis is possible. The conceptual flowchart presenting the approach including the data pre-processing and data analysis used in our study is presented in Figure 1. The first step in the approach consists of the pre-processing of raw output data from GC-tof-MS. This phase is particularly important, because it has influence on all subsequent steps. Data preprocessing techniques usually can improve the quality of the data, thereby helping to make the accuracy and efficiency of the subsequent data analysis process better. Data pre-processing usually requires several successive steps. First of all, the beginning and end of each chromatogram (retention index in minutes either $<1.3$ or $>23 \mathrm{~min}$ ) were removed because of noisy mass spectra at the beginning of the chromatograms and column bleeding at the end of each run. The next step consists of noise removal and baseline correction. Denoising was performed by means of wavelets transformation. ${ }^{32}$ In the following step the background was corrected via P-splines. ${ }^{33}$ This algorithm estimates a baseline that contains a smoothed value at each observation and it assumes a piecewise polynomial smooth curve and puts a penalty on the squared 
second derivative. In order to apply multivariate analysis the chromatographic drifting due to column ageing, temperature differences and different sample composition has to be corrected. Retention times (RT) of all samples were corrected by Correlation Optimised Warping. ${ }^{34}$ Chromatograms were progressively aligned using segmental linear compression and/or stretching in order to maximize the correlation to a reference chromatogram. Finally the chromatograms for each sample were merged by combining the corresponding compounds based on retention time and similarities in mass spectra. To make the spectra comparable, the final step of pre-processing involved normalization to the total area. For RF models the data were not scaled, while before d-PLS-DA model rank transformation was applied to the data.

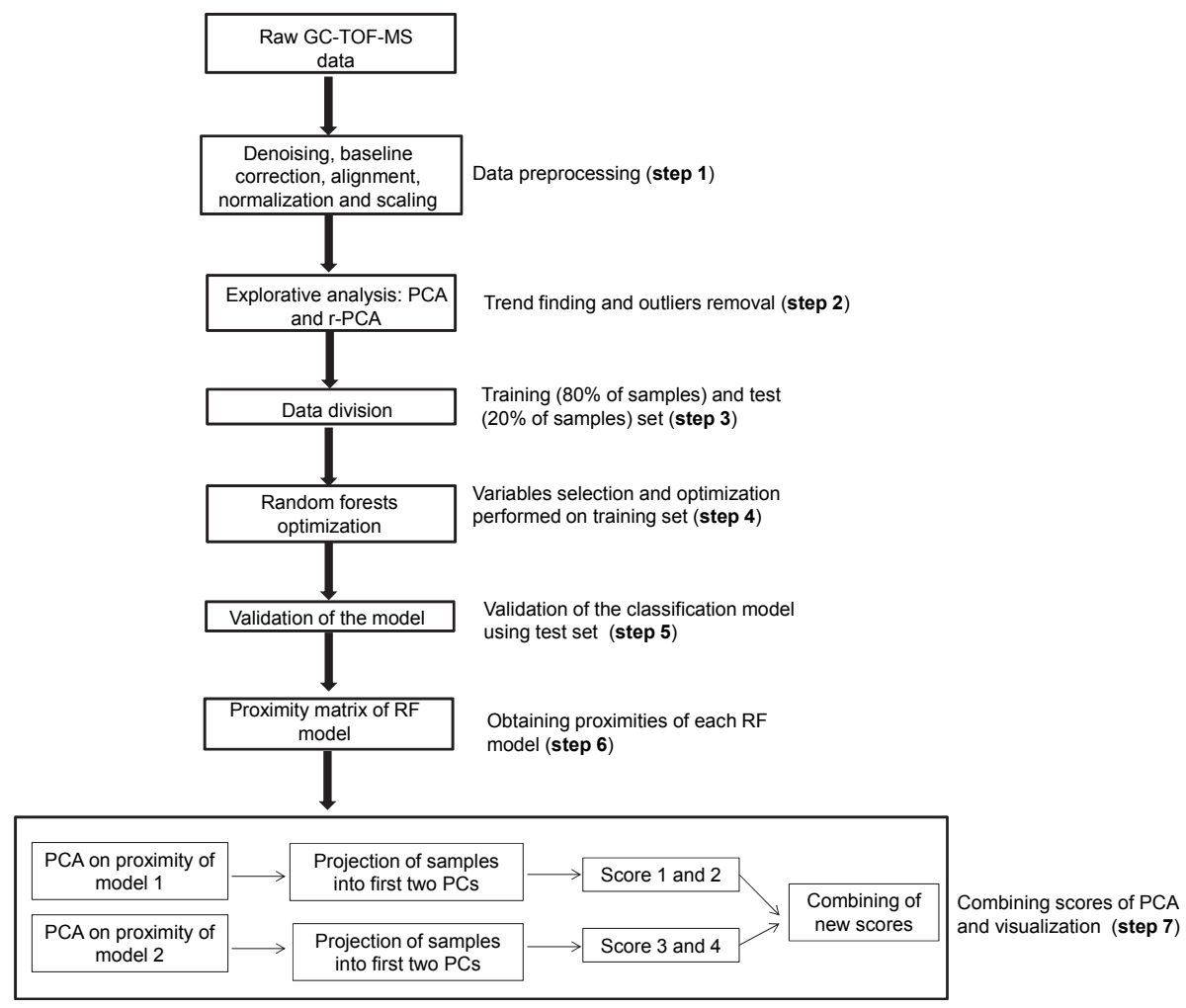

Figure 1 Flowchart of the different steps in data pre-processing and analysis. In step 7 model 1 corresponds to RF analysis of groups healthy and asthma, while model 2 to RF analysis of groups transient wheezers and asthmatics. 


\section{Explorative and supervised analysis}

In step $\mathbf{2}$ of our approach the explorative analysis, by means of robust-Principal Component Analysis (r-PCA) ${ }^{35}$ and PCA, was first used to control the presence of outliers and to find eventual trends and groupings in the data. The strategy for supervised data analysis involved first (step 3) dividing the data into a training set ( $80 \%$ of samples per class) and an independent test set ( $20 \%$ of samples per class) by using the Duplex algorithm. ${ }^{36}$ The Duplex algorithm divides the original data set into training and test sets which both cover the total area in the multidimensional space and moreover have the same statistical properties. This algorithm is based on Euclidian distance and allows selecting representative training and test sets. The training set was used for optimisation steps (i.e. variable selection and selecting model complexity) and for developing a classification model, here $\mathrm{RF}^{37}$ and d-PLSDA. ${ }^{38}$ The test set was subsequently used to validate the constructed model. In case of the RF model an extra validation is employed using the so-called out-of-bag (oob) error. For each RF tree one-third of the training samples were left out and not used in the construction of the classification model. These left-out cases were next used to establish the prediction error.

\section{RF analysis}

The VOCs data of the ADEM study contain three main classes: healthy controls, transient wheezers and asthmatics. In step 4 of our approach, two RF models were constructed, each based on 1000 trees. First the classification algorithm was applied on data containing all samples belonging to healthy controls and asthmatics to find VOCs related to an abnormal status occurring in the lungs. The second model was constructed on data containing all children with transient wheeze and asthma with the purpose to find compounds related solely to asthma. Compound importance is found by permuting the values of each variable in the oob cases and predicting the values of these samples. ${ }^{37}$ By randomly permuting the values in the predictor variable "i", the association with the class vector is lost. When the prediction accuracy for the cases in oob decreases significantly in comparison with non-permuted variables values, it indicates a strong relation of the predictor variable " $i$ " with the response (i.e. classes). The difference in prediction accuracy before and after permuting the values of variable " $\mathrm{i}$ ", averaged over all trees, is a measure of variable importance. The higher the number is the more important the predictor variable " $i$ " is.

Each model was validated in step $\mathbf{5}$ by means of the oob error estimate and separately by the independent test set. It ought to be mentioned that validation is a crucial step of any supervised algorithm. ${ }^{39-41}$ A classification model is considered statistically valid if it shows a good prediction ability in an independent test set. Proper validation ensures the power and reliability of a discriminating model and finding significant compounds. In step 6 proximities for each RF model were obtained. The proximities 
originally formed an $\mathrm{n} \times \mathrm{n}$ matrix (where $\mathrm{n}$ is a number of samples). After each tree was constructed, all data were put down the tree. If two samples ended in the same terminal node, their proximity was increased by one. The final proximity was normalised by dividing by the number of constructed trees. Proximity can be compared to a similarity matrix, thus the higher the number is the more similar the samples are. In other words, it represents similarity scores computed between two samples. Combination of the two classification models (step 7 in Figure 1) allows visualisation of the differences between healthy controls, transient wheezers and asthmatics. For that purpose proximities of both RF models (healthy vs. asthma and transient wheeze vs. asthma) were used and PCA was performed on them. By using loadings obtained from each PCA model it is possible to project the remaining samples (i.e. the ones not used in the RF model) into the PCA score plot (here the first two PCs). In this way, for each sample new scores were obtained. ${ }^{42}$ By combining these new scores, it is possible to visualise relationships between all samples used in the study (step 7 in Figure 1).

\section{d-PLS-DA analysis of children with transient wheeze and asthma at an early age}

The main goal of the paper is to demonstrate the feasibility of VOCs profiling to differentiate the early stage of asthma from transient wheeze in preschool children. Therefore, in order to represent only the differences in VOCs profiles between asthma and transient wheeze at the day of inclusion and to corroborate the results found by $\mathrm{RF}$, d-PLS-DA was constructed using compounds selected by the previous two RF models. d-PLS-DA is a variation of PLS-DA, where the original data are first transformed into dissimilarity measure. In d-PLS-DA a linear model is then constructed according to equation 1 :

$y=D b+r$

where $\mathbf{D}$ is a dissimilarity matrix, $\mathbf{y}$ is a vector of group memberships, $\mathbf{b}$ is a vector of the regression coefficient and $\mathbf{r}$ is a vector of model residuals.

In this study the dissimilarity measure the Euclidean distance was selected. ${ }^{38}$ A crucial step in a PLS model construction is the selection of the optimal number of latent variables (LVs) (so-called model complexity). Usually, this is done by using the crossvalidation (CV) procedure. Here leave-one-out CV was applied. In this approach, during an iterative process, one sample from the training set is left out at each step, while the remaining samples are used to build the d-PLS-DA models by using a different number of LVs. Next, these models are used to predict the object that has been put aside and to assess the resulting prediction error. For each sample that is removed, the average prediction errors are obtained. They express the performance 
of the classification model with respect to the number of LVs. The optimal number of LVs was selected based on the minimal error of the root mean square error of crossvalidation (RMSECV).

\section{Results}

\section{Data}

During the study each child delivered 3-7 breath samples. Table 1 shows the overview of clinical characteristics and number of breath samples and individuals used in the study. Significant differences $(p<0.05)$ in lung function (FEV1/FVC at age six) were only observed between healthy children and children with asthma as well as between healthy children and children with transient wheeze. Eczema was more frequent in children with transient wheeze and asthma compared to healthy children.

In total 1124 GC-MS spectra were measured of which 50 were removed due to poor quality of the recorded spectra. The final 1074 breath-o-grams were pre-processed as described in the materials and methods and the resulting data matrix contained 3256 variables (peaks representing individual VOCs). The data set has a lot of zeros, since not each compound is present in each breath sample (typically 300-500 compounds are measured per breath sample). To reduce the number of zeros present, the following procedure was applied, which will be referred to as the " $20 \%$ rule". A variable is kept if it has a non-zero value in at least $20 \%$ of the samples in at least one of the groups. After the $20 \%$ rule, the final data matrix contained 527 variables.

Table 1 Clinical characteristics of the children involved in the study divided in healthy children, children with transient wheeze and children with asthma at age six.

\begin{tabular}{lccc}
\hline & Healthy & Transient wheeze & Asthma \\
\hline Total number of breath samples & 172 & 545 & 357 \\
Number of individuals at inclusion and age six & 49 & 121 & 76 \\
Age of inclusion (mean \pm std) & $3.3 \pm 0.5$ & $3.3 \pm 0.7$ & $3.1 \pm 0.7$ \\
Male/Female & $24 / 25$ & $62 / 59$ & $45 / 31$ \\
Eczema at inclusion (in \%) & $22 \%$ & $34 \%$ & $46 \%$ \\
MicroRint*** at inclusion (in $\mathrm{kPa} / \mathrm{s} / \mathrm{L}^{-1}$ ) & $1.45 \pm 0.38$ & $1.45 \pm 0.35$ & $1.55 \pm 0.37$ \\
FEV1 ${ }^{*}$ at age six (in ml; mean $\pm \mathrm{SD}$ ) & $1856 \pm 2111$ & $1895 \pm 2164$ & $1720 \pm 1963$ \\
FEV1/FVC** at age six (mean $\pm \mathrm{SD}$ ) & $90.5 \pm 5.8$ & $88.2 \pm 6.9$ & $86.2 \pm 7.3$ \\
\hline
\end{tabular}

* Forced expiratory volume in 1 second in spirometry; ** Tiffeneau index: the proportion of a person's forced vital capacity in the first second of expiration; *** a test to measure airway resistance. 


\section{Explorative and supervised analysis}

After pre-processing, the explorative analysis was performed by means of r-PCA and PCA. Since each individual delivered several breath samples (3-7), inter-individual variation may obscure the information of interest. To diminish the influence of interindividual variation, centring per individual was performed. This allows converting all the relative compound concentrations to fluctuations around zero for each individual instead of around the population mean. In other words, the biological mean for each individual is set to zero. Initially, r-PCA was applied to the mean centred breath-ograms of 1074 samples, to check for outliers. No outliers were detected. As can been seen in the PCA score plot of all breath-o-grams no clear groupings are observed since the samples from all three groups overlap (Figure 2). This indicates that the majority of the variance in the data does not correspond to the available groups. It is important to mention that further PC's did not show groupings either. This observation justifies the use of supervised analysis.

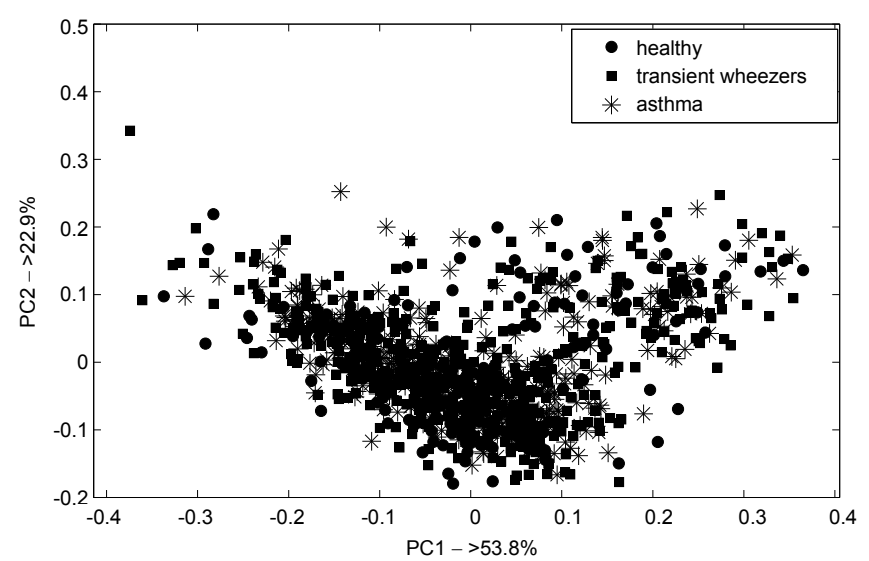

Figure 2 PCA score plot of 1074 breath-o-grams performed on 527 VOCs excreted in breath samples obtained from healthy, transient wheezing and asthmatic children. There is no clear grouping visible.

\section{RF analysis}

In our study we have three groups (healthy, transient wheeze, asthma). Although RF can be used for more than two classes, we decided to split the classification into two separate models. This approach gives an easier interpretation of the outcomes since it focuses on one particular aspect at a time. In the RF model healthy vs. asthma the studied aspect is for instance inflammation in the lungs, which is a common feature of 
asthma and transient wheeze. In the second RF model, i.e. transient wheezers vs. asthma, the features are directly related to either asthma or wheezing.

The comparison between healthy and asthma has been performed in order to find the compounds that represent deviant processes in the lungs. This model leads to a set of 12 compounds that allows differentiating healthy and asthma. The overall prediction for the independent test set was $77.1 \%$ with correct classification rate for healthy and asthma equal to $81.5 \%$ and $74.6 \%$ respectively. In Figure $3 \mathrm{~A}$ the Receiver Operating Characteristic (ROC) curve is shown for the independent test set. This ROC curve and the area under the curve $(85.8 \%)$ indicate that the groups of healthy individuals and asthma are quite well separated and the RF model has a good model performance.

In the second RF model we compared children with asthma and transient wheeze. This model has a relatively good performance with an overall correct classification for the test set of $70.9 \%$. The correct prediction for the test set for transient wheeze and asthma is correspondingly equal to $70.1 \%$ and $71.4 \%$. The ROC curve for the independent test set is shown in Figure 3B. The RF model yields 12 compounds capable to discriminate children with asthma and transient wheeze.
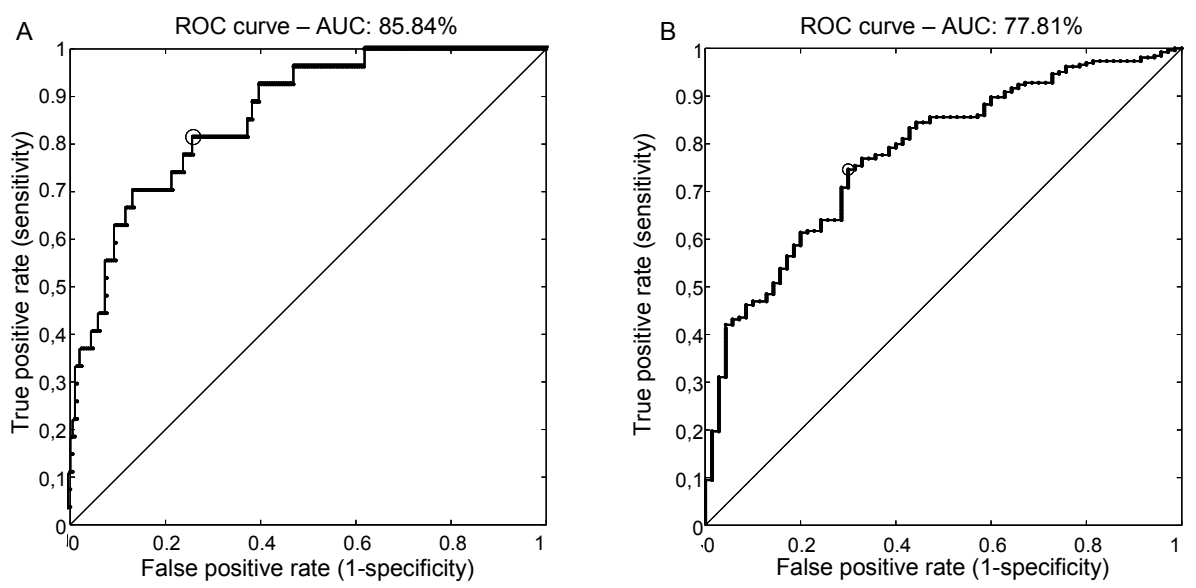

Figure 3 (A) ROC curve for independent test set of the RF model obtained for groups healthy and asthma using 12 VOCs. The area under the curve is $85.8 \%$; (B) ROC curve for independent test set of the RF model obtained for groups transient wheezers and asthma using 12 VOCs. The area under the curve is $77.8 \%$. 


\section{Combining PCA score plots of proximities}

As indicated in the materials and methods section, proximities obtained from RF models give the possibility to study groupings and trends in the data. The higher the proximity between two samples is, the more similar they are. For RF model 1 (healthy vs. asthma) and RF model 2 (transient wheeze vs. asthma) proximities were calculated and next PCA was performed on these proximities matrices. The projection of the remaining samples (i.e. not used in RF model) into PCA plane enables creating for each sample a set of new scores. Since the two first PCs describe the largest amount of variance (here around 50\%), for each sample 4 new scores are created ( 2 scores from each PCA model). Projecting the samples into PCA performed on proximities of RF models for the groups transient wheeze and asthma resulted in score 1 and score 2, while for groups healthy and asthma in score 3 and score 4 . The combination of score 1 , score 2 and score 3 represents the relation between the groups and their separation. The corresponding graph for all 1074 breath samples is shown on Figure $4 \mathrm{~A}$. As can be seen the three studied groups are separated using these three scores. The overlap observed between samples belonging to healthy and transient wheezers as well as between asthma and transient wheezers indicates the partial similarity in VOCs profile of these groups. Interestingly there is a clear separation between samples related to the healthy and the asthma group. It ought to be mentioned that Figure 4A shows all breath samples collected from children at two-four years old and followed prospectively until the age of six years. However, it is possible to focus only on breath samples collected from children at the early age (i.e. inclusion at age twofour years) and at day of definitive diagnosis (i.e. age six years) and to visualise the possible separation and relation between groups. Figure 4B presents only the breath samples collected from children at the early age (i.e. inclusion at age two-four years old). As can be observed the separation between the asthma and transient wheeze groups is achieved. The fractional overlap between the groups of healthy and transient wheeze indicates similarities in VOCs profile at the early age of two-four years. It is worthwhile to point out that the asthmatic and transient wheeze samples are well separated mostly along score 3. In Figure 4C the visualisation of individuals sampled at age six years (day of definitive diagnosis) is demonstrated. Similarly to the previous two figures, the best separation exists between the asthma and healthy group. Nevertheless, the asthma and transient wheeze samples create two separate clouds of points.

\section{d-PLS-DA model of children with asthma and transient wheeze at inclusion}

To further confirm the outcomes obtained from RF models we used d-PLS-DA as a corroborative technique to demonstrate the differences between the asthma and transient wheeze group at inclusion (i.e. at age two-four years). In this model we used 
the significant compounds found by RF model 1 (healthy vs. asthma) and RF model 2 (transient wheeze vs. asthma). In total 17 compounds were used. The optimal complexity of the model found by RMSECV is 2 LVs. The resulting d-PLS-DA score plot is shown in Figure 5. As can be seen the groups are not perfectly separated. Interestingly, the transient wheeze group shows more variation than the asthma group, since the spread of the samples is large. This indicates that the group of children with transient wheeze is more heterogeneous then the asthma group. The $d$ PLS-DA model was validated by using the test set. The overall accuracy of the d-PLSDA model for the test set is $80 \%$. More importantly, this model has good prediction ability for both groups with a correct classification rate of $73.3 \%$ and $86.7 \%$ for children with asthma and transient wheeze. This means that a limited number of compounds in exhaled breath samples at the early age (two-four years old) can predict with a high accuracy whether a recurrent wheezing child is a transient wheezer or will develop asthma at age six.
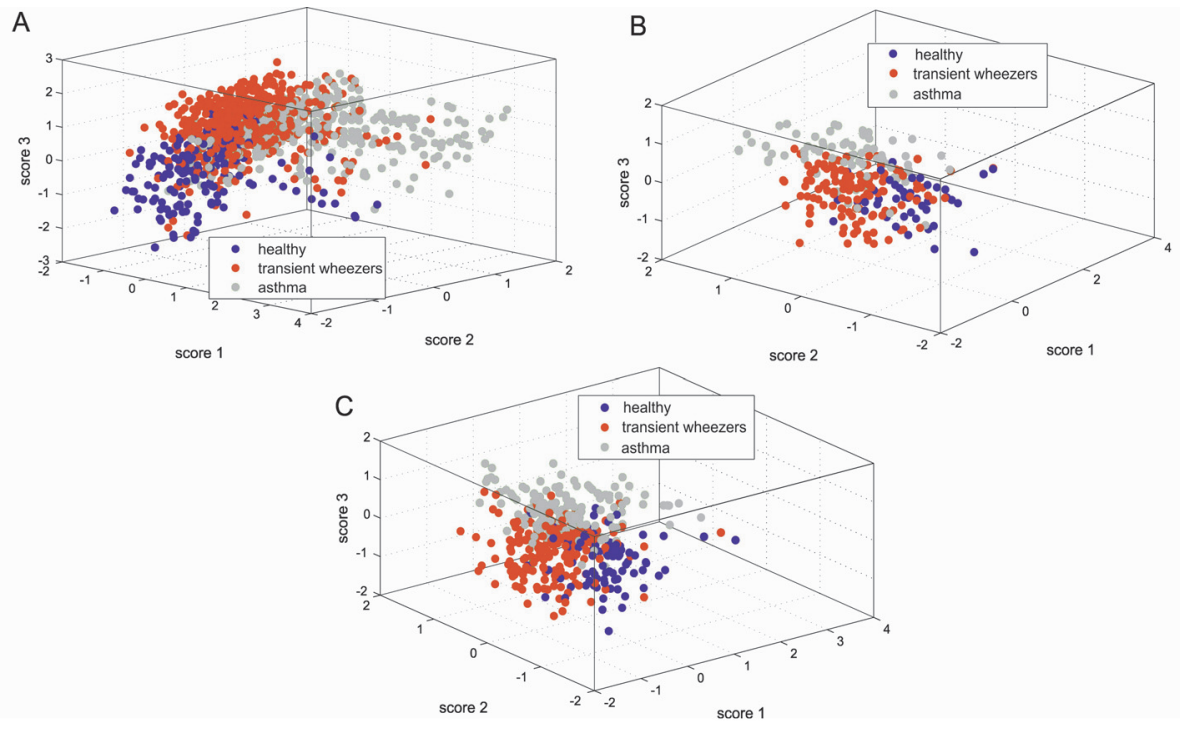

Figure 4 Projection into score 1, score 2 and score 3 delivered from PCA on proximities of RF model 2 (transient wheeze vs. asthma) and model 1 (healthy vs. asthma); (A) of all 1074 breath samples obtained from children collected over time starting at age two and finishing at age six years old; (B) of breath samples collected at the early age (i.e. inclusion at age two-four years); (C) of breath samples obtained at day of the definitive diagnosis (i.e. age six years old). Each breath sample is colour-coded accordingly to group membership: healthy, transient wheeze and asthma. 


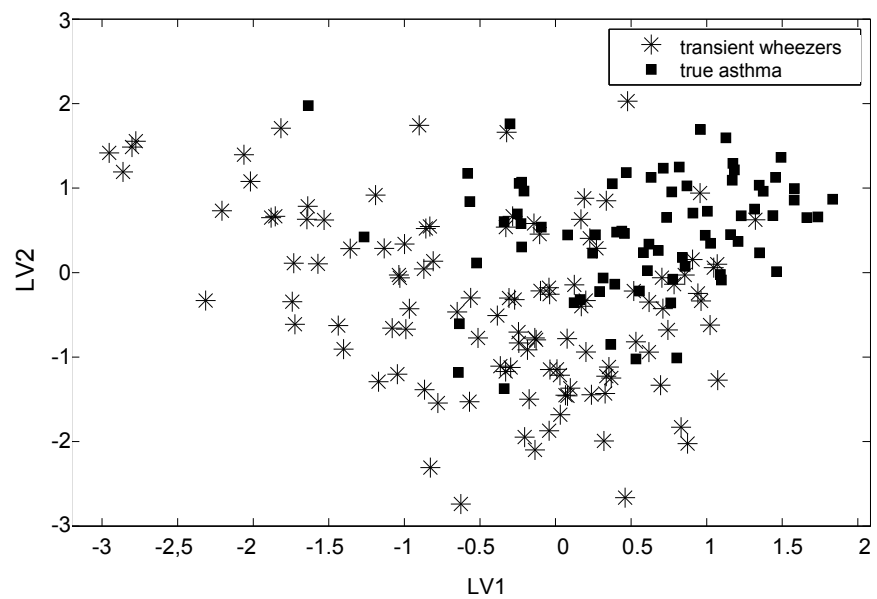

Figure 5 d-PLS-DA score plot, projection of objects into the space of two PLS latent variables of data containing children with transient wheeze and asthma at the early age (inclusion age two-four years old).

\section{Compound identification}

The chemical identification of the 17 VOCs was done by means of spectrum recognition using the National Institute of Standards and Technology library in combination with spectrum interpretation by an experienced mass-spectrometrist and identification based on retention times of compounds. From a set of 17 VOCs it was possible to chemically identify 14 of them. Three compounds could not be identified due to insufficient mass spectrum, overlap in the retention time or absence of mass spectrum in the library. Table 2 shows the list of the 14 identified VOCs and their relative concentration change in breath samples obtained from asthmatic children at day of inclusion. Up- or down-regulation of relative VOC concentration is indicated as (+) or $(-)$, respectively with reference to transient wheeze. As can be observed the discriminatory compounds belong mostly to different alkanes. 
Table 2 List of fourteen chemically identified discriminatory VOCs as measured at early age.

\begin{tabular}{lc}
\hline & $\begin{array}{c}\text { Group } \\
\text { VOCs }\end{array}$ \\
\hline Acetone & - \\
2,4-dimethylpentane & + \\
2,4-dimethylheptane & + \\
2,2,4-trimethylheptane & - \\
1-methyl-4-(1-methylethenyl) Cyclohexen & - \\
2,3,6-trimethyloctane & - \\
2-undecenal & + \\
Biphenyl & - \\
2-ethenylnaphtalene & - \\
2,6,10-trimethyldodecane & - \\
Octane & + \\
2-methylpentane & + \\
2,4-dimethylheptane & + \\
2-methylhexane & + \\
\hline
\end{tabular}

(-) indicates decrease in VOC relative concentration, while + increase in asthmatic children with reference to children with transient wheeze as diagnosed at six years of age.

\section{Discussion}

The analysis of the total array of VOCs in exhaled breath gained popularity over the last few years as a diagnostic and monitoring tool in medical settings. Hundreds of different VOCs are present in human breath and their relative concentration may change due to abnormal physiological processes in the body. VOCs are a various group of carbon-based chemicals that are volatile at ambient temperature and are formed in the body, for instance as a result of lipid peroxidation, protein metabolism or cholesterol biosynthesis. ${ }^{5}$ Due to their low solubility in blood, VOCs are easily excreted into breath after entering the lungs.

In this paper we demonstrated the use of VOCs in exhaled breath analysis, which, in addition to other -omics technologies, constitutes another way of monitoring, diagnosing and studying health status. Similarly to the other -omics methods, exhaled breath VOCs analysis produces huge datasets of biological variables. Therefore we worked out a framework for data pre-processing and analysis of such data, where the first step consists of proper pre-treatment of the data. This step is crucial since improper data pre-processing influences greatly the subsequent data analysis. Since the VOCs data are numerically very complex and contain many irrelevant and redundant features, we applied variable selection to make sure that accurate information extracted from the data can be used in the final classification model. Using only a limited number of compounds, we were able to distinguish healthy, asthmatic and transient wheezing individuals with a good prediction in an 
independent test set. More importantly we were able to distinguish between preschool asthma and transient wheeze, i.e. at inclusion age two-four years old with an overall correct classification rate equal to $80 \%$. Although imperfect, such a result based on the analysis of VOCs in exhaled breath is very attractive for assessing asthma in children at an early age. Collection of breath samples is safe, non-invasive and easy to perform even in infants.

A limited number of 17 VOCs was equipped to classify children with asthma and transient wheeze at the onset of the disease. These compounds were not unique to asthmatic children but were also observed in children with transient wheeze in higher or lower concentration. The set of discriminatory compounds shown in Table 2 are mostly hydrocarbons. In case of asthma, airway inflammation plays a crucial role in the pathophysiology of the disease. Because of the imbalance between oxidants and anti-oxidants, a degradation of polyunsaturated fatty acids, found in cellular membranes takes place during airway inflammation. ${ }^{5,6}$ This imbalance is caused by the continuous production of reactive oxygen species, which is triggered by an influx of leukocytes. During this process hydrocarbons are created by lipid peroxidation of $\omega-3$ and $\omega-6$ polyunsaturated fatty acids. An example of a hydrocarbon with raised levels in exhaled breath that has previously been associated with asthma is pentane. ${ }^{43}$ Yet, pentane has also been associated with other inflammatory diseases, ${ }^{16,44,45}$ suggesting that it is relatively non-specific to asthma. The alkanes found to be discriminatory in our study belong to long-chain alkanes which might be more specific to asthma. Moreover these types of alkanes have also been found as asthma related in other studies. ${ }^{8,9,46-48}$ Taking into account differences in analytical methodologies, breath collection and multivariate analysis, it is not to be expected that we find the same discriminating VOCs profile to previous asthma studies. Despite this fact, the repeated finding of similar compounds (alkanes and methylated alkanes) enhances their importance in asthma. Furthermore, it has been proposed that the group of compounds of $\mathrm{C} 7$ to $\mathrm{C} 12$ alkanes and their methylated derivatives are indicative for lung cancer ${ }^{49}$ but also require further exploration as potential biomarkers for asthma. ${ }^{9}$ Asthma is characterised by an inflammatory process and alkanes are end-compounds of oxidative stress. Consequently, they indicate that the oxidative state is at a higher level in asthmatic conditions. Following this hypothesis, it is expected that the relative amount of alkanes in exhaled breath should be higher in asthmatic children than in transient wheezers. In our study this is true for the majority of discriminatory alkanes (see Table 2). However, three of the discriminatory alkanes (2,2,4-trimethylheptan, 2,3,6-trimethyloctane and 2,6,10-trimethyldodecane) demonstrate an opposing trend. Our findings are in line with previous studies, ${ }^{8,47}$ and may be explained by the complex equilibrium between formation and removal of VOCs in the body. Additionally, a reduced relative concentration of these VOCs might be related to further oxidization into smaller molecules due to enhanced oxidative stress. Besides the oxidative stress assumption, the changes in VOCs relative concentration can be explained by 
differences in gas exchanges over the blood-lung barrier between asthma-affected and transient wheeze-affected lungs. Consequently, this might influence the alterations in relative VOCs level in exhaled breath.

Another compound found as discriminatory between children with asthma and transient wheeze is acetone. Its level was found lower in asthmatic children compared to children with transient wheeze. This endogenous and most abundant VOC in exhaled breath is created in the body by decarboxylation of acetoacetate, which is derived from lipolysis or lipid peroxidation. ${ }^{50}$ Increased acetone level in exhaled breath is related with uncontrolled diabetes mellitus. ${ }^{51,52}$ Recently a decreased relative concentration of acetone in exhaled breath has also been found in asthmatic children in comparison to controls. ${ }^{47} \mathrm{~A}$ change in acetone levels has also been established for patients with lung cancer. ${ }^{53}$ Two other differentiating compounds, i.e. biphenyl and 2-ethenylnaphtalene belong to the family of aromatic hydrocarbons. Both these compounds are present in exhaled air as results of lipid peroxidation. ${ }^{53}$ The relative concentrations of these VOCs were reduced in exhaled breath of asthmatic children with respect to children with transient wheeze. These compounds have not been reported in the literature as asthma related, but similar aromatic compounds have been associated with lung cancer $^{54}$ and asthma. ${ }^{8}$ The two remaining discriminating compounds, cyclohexen,1-methyl-4-(1-methylethenyl) and 2-undecenal belong to cycloalkanes and aldehydes, respectively. The source of these VOCs in exhaled breath is probably also related to lipid peroxidation. However, physiological function of these two compounds remains elusive.

It is important to mention that breath analysis has been used in various studies and several VOCs have been reported as discriminatory for asthma, COPD and CF. ${ }^{8,12}$ However, in most of the studies, due to for instance a limited number of subjects, the outcomes were not completely validated, i.e. only cross-validation was used. On contrary, in our study we used an external test set (so-called independent test set). This is a higher level of validation and therefore gives a stronger certainty to the findings. Nevertheless, another validation in a new cohort is recommendable before the use of the discriminative compounds in the clinics.

\section{Concluding Remarks}

In conclusion, we demonstrated that a VOCs profile in exhaled breath was able to discriminate between healthy children, children with transient wheeze and children with asthma. Moreover, with an $80 \%$ of correct classification, the VOCs profile containing 17 VOCs allowed distinguishing children with transient wheeze from asthma at preschool age. As indicated earlier, asthma is related to oxidative stress and thus to lipid peroxidation. Therefore, this process may play a crucial role in the production of differentiating VOCs in exhaled breath of asthmatic subjects. Nevertheless, the deviant VOCs found in the study may as well come from different 
pathways and therefore other possibilities cannot be excluded. Further research has to be performed to establish the probable pathways of their involvements. Despite the potential use of VOCs in clinical practice, several issues have to be standardised, such as sampling procedure and measurements. The development of international recommendations for a standardised procedure in analysis of VOCs in exhaled breath would improve the inter-laboratory comparisons. 


\section{References}

1. Nicholson JK, Connelly J, Lindon JC, Holmes E. Metabonomics: a platform for studying drug toxicity and gene function. Nat Rev Drug Discov 2002;1:153-61.

2. Smolinska A, Blanchet L, Buydens LM, Wijmenga SS. NMR and pattern recognition methods in metabolomics: from data acquisition to biomarker discovery: a review. Anal Chim Acta 2012;750: 82-97.

3. Boots AW, van Berkel JJ, Dallinga JW, Smolinska A, Wouters EF, van Schooten FJ. The versatile use of exhaled volatile organic compounds in human health and disease. J Breath Res 2012;6:027108.

4. Carraro S, Rezzi S, Reniero F, Héberger K, Giordano G, Zanconato S, Guillou C, Baraldi E. Metabolomics applied to exhaled breath condensate in childhood asthma. Am J Respir Crit Care Med 2007;175: 986-90.

5. Buszewski B, Kesy M, Ligor T, Amann A. Human exhaled air analytics: Biomarkers of diseases. Biomed Chromatogr 2007;21:553-66.

6. Miekisch W, Schubert JK, Noeldge-Schomburg GF. Diagnostic potential of breath analysis - focus on volatile organic compounds. Clin Chim Acta. 2004;347:25-39.

7. Schubert JK, Miekisch W, Geiger K, Nöldge-Schomburg GF. Breath analysis in critically ill patients: potential and limitations. Expert Rev Mol Diagn 2004;4:619-29.

8. Dallinga JW, Robroeks CM, van Berkel JJ, Moonen EJ, Godschalk RW, Jöbsis Q, Dompeling E, Wouters $\mathrm{EF}$, van Schooten FJ. Volatile organic compounds in exhaled breath as a diagnostic tool for asthma in children. Clin Exp Allergy 2010;40:68-76.

9. Ibrahim B, Basanta M, Cadden P, Singh D, Douce D, Woodcock A, Fowler SJ. Non-invasive phenotyping using exhaled volatile organic compounds in asthma. Thorax 2011;66:804-9

10. Dragonieri S, Annema JT, Schot R, van der Schee MP, Spanevello A, Carratú P, Resta O, Rabe KF, Sterk PJ. An electronic nose in the discrimination of patients with non-small cell lung cancer and COPD. Lung Cancer 2009;64:166-70.

11. Cristescu SM, Gietema HA, Blanchet L, Kruitwagen CL, Munnik P, van Klaveren RJ, Lammers JW, Buydens L, Harren FJ, Zanen P. Screening for emphysema via exhaled volatile organic compounds. J Breath Res 2011;5:046009.

12. Fens N, Zwinderman AH, van der Schee MP, de Nijs SB, Dijkers E, Roldaan AC, Cheung D, Bel EH, Sterk PJ. Exhaled Breath Profiling Enables Discrimination of Chronic Obstructive Pulmonary Disease and Asthma. Am J Respir Crit Care Med 2009;180:1076-82.

13. Van Berkel JJ, Dallinga JW, Möller GM, Godschalk RW, Moonen EJ, Wouters EF, Van Schooten FJ. A profile of volatile organic compounds in breath discriminates COPD patients from controls. Respir Med 2010;104:557-63.

14. Robroeks CM, van Berkel JJ, Dallinga JW, Jöbsis Q, Zimmermann LJ, Hendriks HJ, Wouters MF, van der Grinten $\mathrm{CP}$, van de Kant KD, van Schooten FJ, Dompeling E. Metabolomics of Volatile Organic Compounds in Cystic Fibrosis Patients and Controls. Pediatr Res 2010;68:75-80.

15. Romoli R, Papaleo MC, de Pascale D, Tutino ML, Michaud L, LoGiudice A, Fani R, Bartolucci G. Characterization of the volatile profile of Antarctic bacteria by using solid-phase microextraction-gas chromatography-mass spectrometry. J Mass Spectrom 2011;46:1051-9.

16. Kokoszka J, Nelson RL, Swedler WI, Skosey J, Abcarian H. Determination of Inflammatory BowelDisease Activity by Breath Pentane Analysis. Dis Colon Rectum 1993;36:597-601.

17. Verdam FJ, Dallinga JW, Driessen A, de Jonge C, Moonen EJ, van Berkel JB, Luijk J, Bouvy ND, Buurman WA, Rensen SS, Greve JW, van Schooten FJ. Non-alcoholic steatohepatitis: A non-invasive diagnosis by analysis of exhaled breath. J Hepatol 2013;58:543-8.

18. Bisgaard H, Szefler S. Prevalence of asthma-like symptoms in young children. Pediatr Pulmonol 2007;42:723-8.

19. Martinez FD, Wright AL, Taussig LM, Holberg CJ, Halonen M, Morgan WJ. Asthma and wheezing in the first six years of life. The Group Health Medical Associates. N Engl J Med 1995;332:133-8. 
20. Savenije OE, Granell R, Caudri D, Koppelman GH, Smit HA, Wijga A, de Jongste JC, Brunekreef B, Sterne JA, Postma DS, Henderson J, Kerkhof M. Comparison of childhood wheezing phenotypes in 2 birth cohorts: ALSPAC and PIAMA. J Allergy Clin Immunol 2011;127:1505-12.

21. Taussig LM, Wright AL, Holberg CJ, Halonen M, Morgan WJ, Martinez FD. Tucson Children's Respiratory Study: 1980 to present. J Allergy Clin Immunol 2003;111:661-75.

22. Tregoning JS, Schwarze J. Respiratory viral infections in infants: causes, clinical symptoms, virology, and immunology. Clin Microbiol Rev 2010;23:74-98.

23. Henderson J, Granell R, Sterne J. The search for new asthma phenotypes. Arch Dis Child 2009;94: 333-6.

24. Zar HJ, Tannenbaum E, Apolles P, Roux P, Hanslo D, Hussey G. Sputum induction for the diagnosis of pulmonary tuberculosis in infants and young children in an urban setting in South Africa. Arch Dis Child 2000;82:305-8.

25. Crenesse D, Berlioz M, Bourrier T, Albertini M. Spirometry in children aged 3 to 5 years: Reliability of forced expiratory maneuvers. Pediatr Pulmonol 2001;32:56-61.

26. Kanengiser S, Dozor AJ. Forced Expiratory Maneuvers in Children Aged 3 to 5 Years. Pediatr Pulmonol 1994;18:144-149.

27. Caudri D, Wijga $\mathrm{AH}$, Hoekstra MO, et al. Prediction of asthma in symptomatic preschool children using exhaled nitric oxide, Rint and specific IgE. Thorax 2010;65:801-807.

28. Bacharier LB, Guilbert TW. Diagnosis and management of early asthma in preschool-aged children. J Allergy Clin Immunol 2012;130:287-96.

29. Worldwide variation in prevalence of symptoms of asthma, a. r., and atopic eczema: ISAAC. The International Study of Asthma and Allergies in Childhood (ISAAC) Steering Committee. Lancet 1998;351:1225-32.

30. Klaassen $E$, van de Kant K, Jöbsis $Q$ et al. Symptoms, but not a biomarker response to inhaled corticosteroids, predict asthma in preschool children with recurrent wheeze. Mediators of Inflamm 2012;2012:162571.

31. Watson JT, Sparkman OD. Introduction to mass spectrometry: instrumentation, applications and and strategies for data interpretation. West Sussex 2007.

32. Walczak B. Wavelets in Chemistry. Amsterdam, Elsevier Science 2000.

33. Eilers PHC, Marx BD. Flexible Smoothing Using B- Splines and Penalized Likelihood. Statistical Science 1996;11:89-121.

34. Nielsen NP, Carstensen JM, Smedsgaard J. Aligning of single and multiple wavelength chromatographic profiles for chemometric data analysis using correlation optimised warping. Journal of Chromatography A 1998;805;1-2:17-35.

35. Daszykowski M, Serneels S, Kaczmarek K, Van Espen P, Croux C, Walczak B. TOMCAT: A MATLAB toolbox for multivariate calibration techniques. Chemometrics and Intelligent Laboratory Systems 2007;85:269-77.

36. Snee RD. Validation of regression models: Methods and examples. Technometrics 1977;19:415-28.

37. Breiman L. Random forests. Machine Learning 2001;45:5-32.

38. Zerzucha $\mathrm{P}$, Daszykowski $\mathrm{M}$, Walczak B. Dissimilarity partial least squares applied to non-linear modeling problems. Chemometrics and Intelligent Laboratory Systems 2012;110:156-62.

39. Esbensen KH, Geladi P. Principles of Proper Validation: use and abuse of re-sampling for validation. Journal of Chemometrics 2010;24:168-87.

40. Miekisch W, Herbig J, Schubert JK. Data interpretation in breath biomarker research: pitfalls and directions. J Breath Res 2012;6:036007.

41. Westerhuis JA, Hoefsloot HC, Smit S, et al. Assessment of PLSDA cross validation. Metabolomics 2008;4:81-9.

42. Smolinska A, Posma JM, Blanchet L, Ampt KA, Attali A, Tuinstra T, Luider T, Doskocz M, Michiels PJ, Girard FC, Buydens LM, Wijmenga SS. Simultaneous analysis of plasma and CSF by NMR and hierarchical models fusion. Anal Bioanal Chem 2012;403:947-59.

43. Kneepkens CM, Lepage G, Roy CC. The Potential of the Hydrocarbon Breath Test as a Measure of Lipid-Peroxidation. Free Radic Biol Med 1994;17:127-60. 
44. Humad S, Zarling E, Clapper M, Skosey JL. Breath Pentane Excretion as a Marker of Disease-Activity in Rheumatoid-Arthritis. Free Radic Res Commun 1988;5:101-6.

45. Olopade CO, Christon JA, Zakkar M, Hua C, Swedler WI, Scheff PA, Rubinstein I. Exhaled pentane and nitric oxide levels in patients with obstructive sleep apnea. Chest 1997;111:1500-4.

46. Caldeira M, Barros AS, Bilelo MJ, Parada A, Camara JS, Rocha SM. Profiling allergic asthma volatile metabolic patterns using a headspace-solid phase microextraction/gas chromatography based methodology. J Chromatogr A 2011;1218:3771-80.

47. Caldeira M, Perestrelo R, Barros AS, et al. Allergic asthma exhaled breath metabolome: A challenge for comprehensive two-dimensional gas chromatography. J Chromatogr A 2012;1254:87-97.

48. van de Kant KD, van Berkel JJ, Jöbsis Q, Lima Passos V, Klaassen EM, van der Sande L, van Schayck OC, de Jongste JC, van Schooten FJ, Derks E, Dompeling E, Dallinga JW. Exhaled breath profiling in diagnosing wheezy preschool children. Eur Respir J 2013;41:183-8.

49. Phillips $\mathrm{M}$, Altorki N, Austin JH, et al. Prediction of lung cancer using volatile biomarkers in breath. Cancer Biomarkers 2007;3:95-109.

50. Ma W, Liu X, Pawliszyn J. Analysis of human breath with micro extraction techniques and continuous monitoring of carbon dioxide concentration. Anal Bioanal Chem 2006;385:1398-408.

51. Lebovitz HE. Diabetic ketoacidosis. Lancet 1995;345:767-72.

52. Minh Tdo C, Blake DR, Galassetti PR. The clinical potential of exhaled breath analysis for diabetes mellitus. Diabetes Res Clin Pract. 2012;97:195-205.

53. Wang C, Sahay P. Breath analysis using laser spectroscopic techniques: breath biomarkers, spectral fingerprints, and detection limits. Sensors 2009;9:8230-62.

54. Poli D, Carbognani $P$, CorradiM, et al. Exhaled volatile organic compounds in patients with non-small cell lung cancer: cross sectional and nested short-term follow-up study. Respir Res 2005;6:71. 


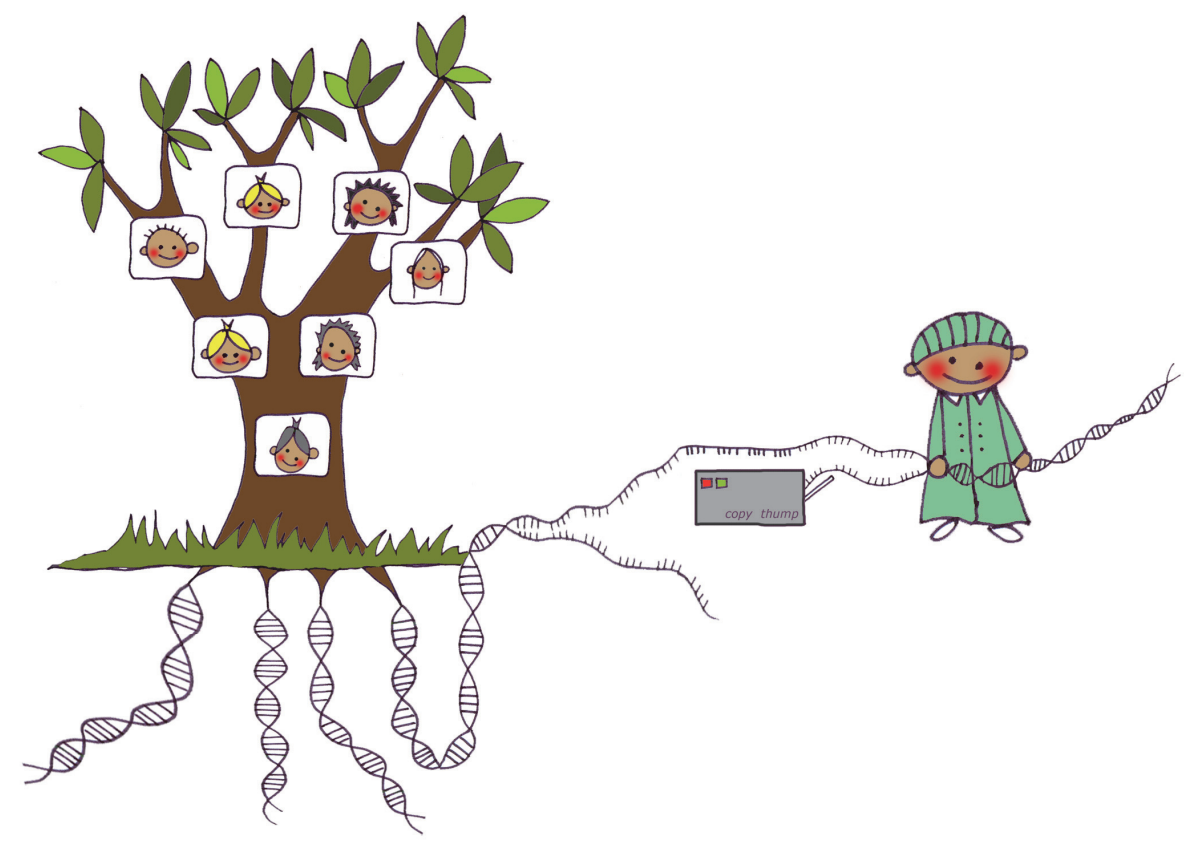




\section{Chapter 9}

\section{Predicting asthma at preschool age by family history and expression of inflammation genes}

Klaassen EMM, van Schayck CP, van de Kant KDG, Jöbsis Q, den Hartog GJM, van Eys $\mathrm{G}$, Dompeling $\mathrm{E}$

Submitted for publication 
Asthma is a major chronic health problem in children. Worldwide, approximately $30 \%$ of young children have at least one episode of asthmatic symptoms. About one in three children will have asthma at the age of six years. The rest is symptom-free and has transient wheeze frequently in association with recurrent viral respiratory tract infections. ${ }^{1}$ Differentiating between these phenotypes at preschool age is currently very difficult. $^{2}$ Information on familial asthma may help to predict asthma as it has consistently been identified as a risk factor for childhood asthma. ${ }^{3}$ Biomarkers, such as expression of inflammation genes, are expected to improve an early asthma diagnosis. ${ }^{3,4}$ However, the additional value of gene expression to easy obtainable clinical variables, such as familial asthma, is not elucidated yet. If an additional value can be demonstrated, implementation of expression of inflammation genes can improve early asthma diagnosis in clinical practice. The aim of the present paper is to assess whether expression of inflammation genes can be complementary to family history alone in diagnosing asthma at preschool age.

For this purpose, 202 recurrently wheezing children ( $\geq 2$ wheezing episodes) ${ }^{5}$ from the Asthma DEtection and Monitoring (ADEM) study were prospectively studied from age two-four years until age six. ${ }^{6}$ At preschool age, clinical patient characteristics were assessed and RNA was extracted from peripheral blood mononuclear cells (Qiagen , Hilden, Germany). In case of symptoms of an airway infection, the measurement was postponed. Inhaled corticosteroids (ICS) were stopped four weeks before the sampling. Quantitative real-time PCR was performed (AROS Applied Biotechnology, Aarhus, Denmark) to assess expression levels of inflammation genes relevant for asthma. Inflammation genes with values in $>90 \%$ of the children were included in the analysis (Interleukin (IL)8, IL10, Tumour-Necrosis-Factor alpha (TNF $\alpha$ ), Intercellular Adhesion Molecule 1, Chemokine (C-C motif) ligands (CCL)2, CCL3, CCL5, toll-like receptor (TLR)2, TLR4, TLR5, TLR9, Catalase (CAT), Cyclo-oxygenase 2, Forkhead box P3, Glutathione S-transferase, NF- $\kappa-B$ inhibitor- $\alpha$, Macrophage migration inhibitory factor, Signal transducer and activator of transcription 6 , Transforming growth factor$\beta)$. Single regression imputation replaced remaining missing values. ${ }^{7}$ At age six, children were classified as asthmatic or transient wheezer by two experienced paediatricians in the field of respiratory medicine and a computer-calculated algorithm based on symptoms, lung function and medication use. ${ }^{8}$

A model with family history (a first-degree relative with asthma) as predictor was built by logistic regression with 'asthma' or 'transient wheeze' as outcome variable. Information on expression of inflammation genes identified by backward logistic regression (threshold $p<0.10$ ) was added to this model. ${ }^{7}$ The model performance was assessed by quantifying discrimination (Receiver Operating Characteristics curve) and calibration (Hosmer-Lemeshow goodness-of-fit test). To assess the additional value of expression of inflammation genes, a chi-square test comparing the Area Under the Curve (AUC) of the model with and without gene expression markers was used. 
Written informed consent was given by all parents and the study was approved by the Dutch National Medical Ethical Committee.

In four children, a diagnosis at six years of age could not be assessed due to personal constraints of the parents, such as lack of time or motivation. Information on gene expression and family history was available in 180 of the remaining children (missing data mostly due to refusal of venous puncture). At age six, 66 children of these were classified as true asthmatic and 114 as transient wheezer. At preschool age, atopy and the use of ICS and/or $\beta_{2}$-agonists were positively associated with an asthma diagnosis at six years of age.

A first-degree relative with asthma at preschool age was not significantly associated with an asthma diagnosis at six years of age $(p=0.08)$. The AUC of the model including family history alone was $0.57(95 \% \mathrm{Cl}: 0.49-0.64$, Figure 1$)$. Three gene expression markers were identified by backward logistic regression (TLR4, CAT and TNF $\alpha$ ). The AUC of the definitive model significantly improved to 0.73 (95\% $\mathrm{Cl}: 0.66-0.81$, Figure 1 ) compared to the model with family history alone $(p=0.0002)$. The calibration of both models was good.

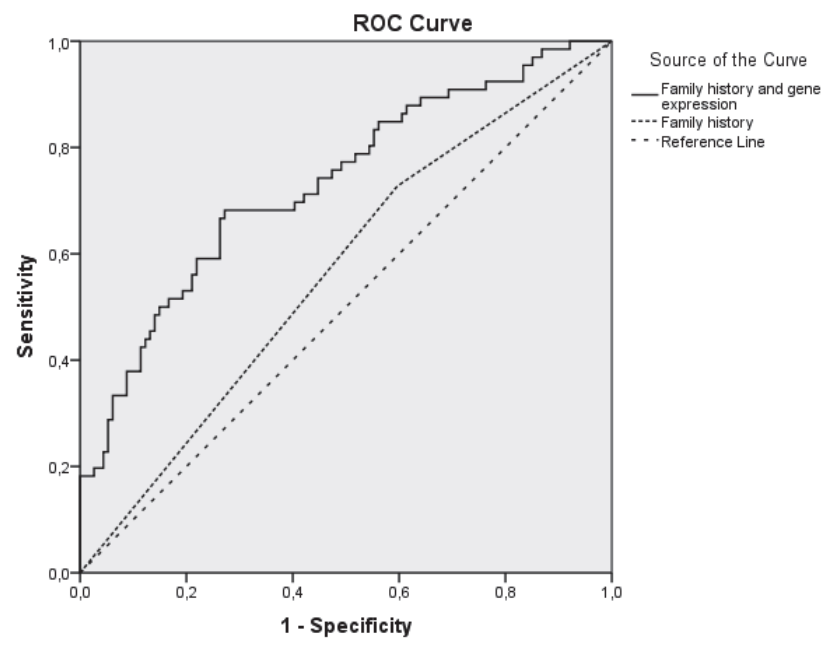

Figure 1 Receiver Operating Characteristics curve for early asthma prediction models.

Gene expression of toll-like receptor 4, catalase and TNF $\alpha$ : Tumour-Necrosis Factor alpha. ROC: Receiver Operating Characteristics curve.

This study provides the first important step for the translation of gene expression into the health care of preschool children at risk for asthma development. ${ }^{9}$ We demonstrated that a better asthma prediction was possible when information on 
gene expression of TLR4, CAT and TNF $\alpha$ was added to a family history of asthma. Our study suggests that preschool phenotyping of transient wheezers and asthmatics can be improved by adding information on gene expression markers involved in asthma pathogenesis. As early differentiation can impact asthma management by preventing 'under-treatment' of true asthmatics and 'over-treatment' of transient wheezers, ${ }^{10}$ which will beneficially influence quality of life of parents and children and health care costs. If confirmed in a replication study, adding information on expression of inflammation genes may improve risk assessment in preschool wheezing children and therefore may be beneficial for quality of care and cost-effective treatment of this large group of preschool children. 


\section{References}

1. Savenije OE, Granell R, Caudri D, et al. Comparison of childhood wheezing phenotypes in 2 birth cohorts: ALSPAC and PIAMA. J Allergy Clin Immunol 2011;127:1505-12 e14.

2. Pedersen SE, Hurd SS, Lemanske RF, Jr., et al. Global strategy for the diagnosis and management of asthma in children 5 years and younger. Pediatr Pulmonol 2011; 46:1-17.

3. Burke W, Fesinmeyer M, Reed K, Hampson L, Carlsten C. Family history as a predictor of asthma risk. Am J Prev Med 2003; 24:160-9.

4. Savenije OE, Kerkhof M, Koppelman GH, Postma DS. Predicting who will have asthma at school age among preschool children. J Allergy Clin Immunol 2012;130:325-31.

5. Worldwide variation in prevalence of symptoms of asthma, allergic rhinoconjunctivitis, and atopic eczema: ISAAC. The International Study of Asthma and Allergies in Childhood (ISAAC) Steering Committee. Lancet 1998;351:1225-32.

6. van de Kant KD, Klaassen EM, Jöbsis Q, Nijhuis AJ, van Schayck OC, Dompeling E. Early diagnosis of asthma in young children by using non-invasive biomarkers of airway inflammation and early lung function measurements: study protocol of a case-control study. BMC public health 2009;9:210.

7. Moons KG, Kengne AP, Woodward M, et al. Risk prediction models: I. Development, internal validation, and assessing the incremental value of a new (bio)marker. Heart 2012;98:683-90.

8. Klaassen EM, van Kant KD, Jöbsis $Q$, et al. Symptoms, but not a biomarker response to inhaled corticosteroids, predict asthma in preschool children with recurrent wheeze. Mediators of Inflamm 2012;2012:162571.

9. Khoury MJ, Gwinn M, Yoon PW, Dowling N, Moore CA, Bradley L. The continuum of translation research in genomic medicine: how can we accelerate the appropriate integration of human genome discoveries into health care and disease prevention? Geneti Med 2007;9:665-74.

10. Caudri D, Wijga AH, Smit HA, et al. Asthma symptoms and medication in the PIAMA birth cohort: evidence for under and overtreatment. Pediatr Allergy Immunol 2011;22:652-9. 

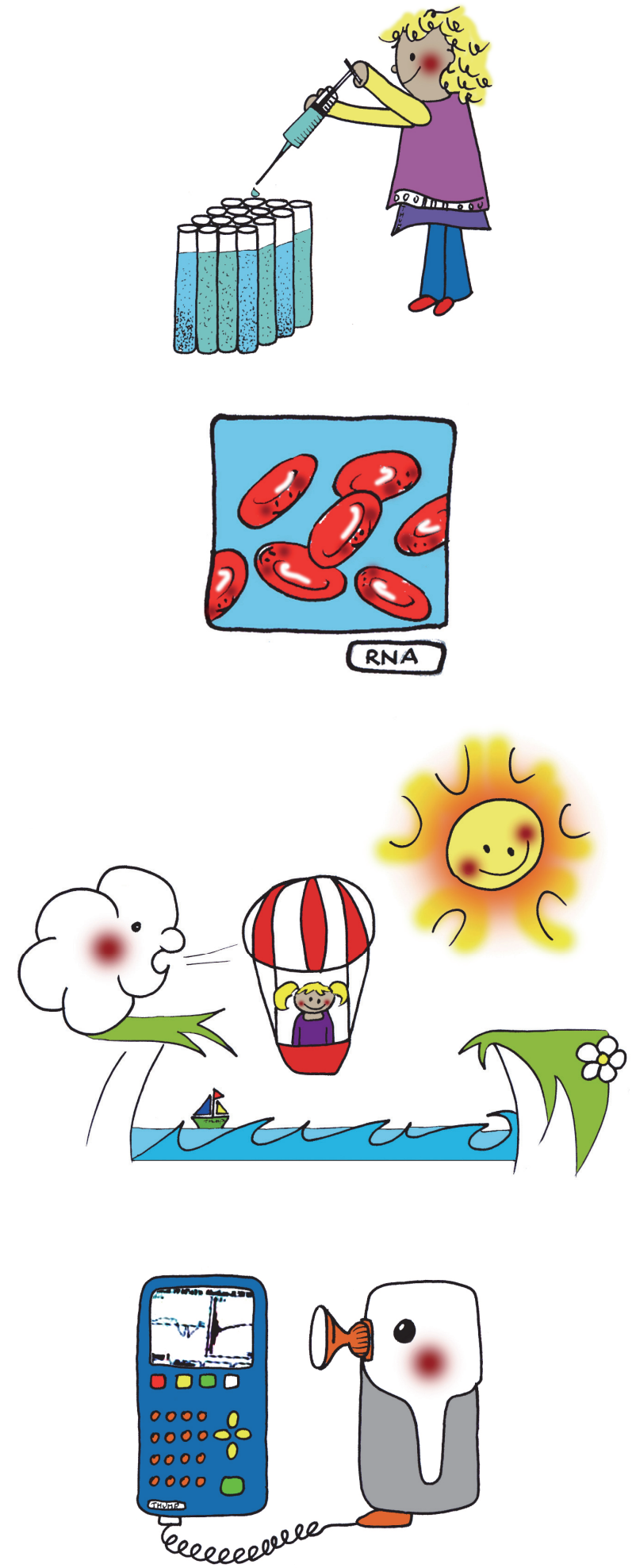


\section{Chapter 10}

\section{Exhaled biomarkers and expression of inflammation}

genes at preschool age improve prediction of

asthma at age six

Klaassen EMM / van de Kant KDG, Jöbsis $Q$, van Schayck CP, Smolinska A, van Schooten FJ, den Hartog GJM, de Jongste JC, Rijkers GT, Dompeling E Submitted for publication 


\section{Background}

A reliable asthma diagnosis is difficult in preschool children with wheezing symptoms. The Asthma Predictive Index (API) has been developed to aid in an early asthma diagnosis. However, this clinical classification index leaves room for improvement.

\section{Objective}

To assess the added value of combining biomarkers in exhaled breath condensate (EBC), exhaled volatile organic compounds (VOCs), expression of inflammation genes and airway resistance with the API, in asthma prediction at preschool age.

\section{Methods}

The Asthma DEtection and Monitoring (ADEM) study is a long-term prospective casecontrol study in which 202 preschool children with recurrent wheeze were included. At the age of six years a definite diagnosis (asthma or transient wheeze) was based on symptoms, lung function and use of asthma medication. The added predictive value in Area Under the Curve (AUC) of the independent predictors to the API at preschool age, in diagnosing asthma at age six, was determined with external validation.

\section{Results}

At age six 198 children were diagnosed (76 asthmatics, 122 transient wheezers). Information on VOCs significantly improved asthma prediction (Area Under the Curve (AUC): $89 \%$ (increase of 28\%, sensitivity/specificity $84 / 82 \%$ ) which persisted in external validation. Information on expression of toll-like receptor 4 , catalase and Tumour Necrosis Factor alpha significantly improved asthma prediction (AUC: $75 \%$ (increase of $17 \%$, sensitivity/specificity $71 / 77 \%$ ). However, this could not be confirmed in the external validation. Biomarkers in EBC and airway resistance (before and after a bronchodilator) did not add to a diagnosis of asthma at six years. The combined model with VOCs, expression of inflammation genes and API had an AUC of 95\% (sensitivity/specificity 89/90\%).

\section{Discussion}

Adding information on exhaled VOCs and expression of inflammation genes to the API can significantly improve an accurate early asthma diagnosis in preschool children. 


\section{Introduction}

Doctors are confronted with the heterogeneous group of wheezing children on a daily basis. In children with 'transient viral wheeze', symptoms cease before the age of six. However, in about one in three children, symptoms persist and these children develop asthma. ${ }^{1}$ At a young age, the distinction between 'true asthmatics' and 'transient wheezers' is currently not possible. ${ }^{2}$ This leads to difficulties in the management of airway symptoms and, consequently, over-treatment of children with transient wheeze and under-treatment of children with true asthma. ${ }^{3}$ Therefore, the development of diagnostics to distinguish between these wheezing phenotypes at a young age will have considerable clinical impact.

Multiple clinical predictive indexes, such as The Asthma Predictive Index (API), the Isle of Wight and the PIAMA (Prevention and Incidence of Asthma and Mite Allergy) indices have been developed to identify young children at high risk for asthma development. ${ }^{4-6}$ Although the accuracy of these indices is reasonable, a more accurate predictive model is warranted. By adding information about underlying pathophysiology, for example inflammation biomarkers, improvement in a reliable asthma diagnosis might be possible. In recent years, non-invasive instruments to analyse airway inflammation have been developed including analysis of inflammation markers in exhaled breath condensate $(\mathrm{EBC}) .^{7-9}$ Another promising tool has been developed in the form of analysis of volatile organic compounds (VOCs) in exhaled breath. ${ }^{10-12}$ VOCs have appeared to be helpful in the diagnosis of lung cancer. ${ }^{11}$ Moreover, analysis of gene expression by up- or down-regulation of inflammation genes is expected to have additional diagnostic potential in identifying wheezing phenotypes. ${ }^{13}$ Furthermore, information on proxy measures of lung function at preschool age, such as airway resistance, might add to the correct classification of wheezing phenotypes at preschool age. ${ }^{14-16}$

In previous publications, we demonstrated that the analysis of EBC, VOCs and measurement of airway resistance is feasible and reproducible in (young) children. ${ }^{8,10,17,18}$ In addition, differences in EBC markers, VOCs profiles and airway resistance levels in children with wheeze, asthma and healthy controls have been observed. ${ }^{8,10,17-20}$ Moreover, gene expression of certain inflammation markers has been shown to be associated with recurrent wheezing and childhood asthma. ${ }^{21,22}$ Until now it has not been investigated whether markers in EBC, VOCs in exhaled breath, expression of inflammation genes and early lung function are of added value to clinical parameters in reliable asthma prediction. The aim of the present study is to assess the added value of these biomarkers to the API in the prediction of asthma at age six in children with preschool wheeze. 


\section{Materials and methods}

\section{Study design}

The Asthma DEtection and Monitoring (ADEM) study is a longitudinal study that started in 2006 at the Maastricht University Medical Centre, the Netherlands. The aim of this study is to develop a non-invasive instrument for an early asthma diagnosis by using biomarkers of airway inflammation in exhaled breath (condensate) and early lung function measurements (airway resistance). In total, 202 wheezing children were prospectively studied from age two-four years until age six years. Wheezing was defined as $\geq 2$ wheezing episodes before inclusion, according to the International Study of Asthma and Allergies in Childhood (ISAAC) questionnaire. ${ }^{23}$ The design of the ADEM study has been published previously. ${ }^{24}$ This study was ethically approved by the Dutch National Medical Ethical Committee (CCMO; NL17407.000.07.2007-001817-40) and is registered at clinicaltrial.gov (NCT 00422747). Written informed consent was given by all parents.

At preschool age, all children were invited for a baseline visit. During this visit, clinical patient characteristics, including airway resistance, were assessed and EBC, VOCs and RNA data were collected (see details below). In case of symptoms of an airway infection, the visit was postponed for four weeks. Inhaled corticosteroids (ICS) were stopped at least four weeks before the visit. Solid foods and exercise were not allowed one hour before the measurements.

\section{Asthma diagnosis}

At the age of six, a diagnosis of transient wheeze or asthma was made by an experienced paediatrician in the field of respiratory medicine. This classification was based on symptoms, lung function (reversibility to a $\beta_{2}$-agonist and bronchial hyperresponsiveness) and medication use. In addition to this clinical diagnosis, the diagnosis was assessed by a computer-calculated algorithm as described previously. ${ }^{25}$ Mismatch of cases between the clinical and the computer diagnosis were re-evaluated by the paediatrician, who was blinded to the previous assessment. There was a high concordance rate of $90 \%$. Bronchial hyper-responsiveness and reversibility measurements were performed according to the European Respiratory Society guideline as described before. ${ }^{25,26}$

\section{Asthma Predictive Index}

The API (based on parental asthma, eczema, allergic rhinitis, wheezing apart from colds and atopy (as a proxy measure of eosinophilia)) was assessed. ${ }^{4}$ Except for atopy, variables were reported by parents by using questionnaires. ${ }^{23,27}$ Atopy was positive in case of a specific IgE concentration against a mixture of inhalant and food allergens of 
$\geq 0.35 \mathrm{kU} / \mathrm{I}$ on the Phadiatop infant test (Phadiatop Infant ${ }^{\circledR}$, Phadia, Uppsala, Sweden). Although eosinophilia is argued to be a better predictor of remission of wheezing by the age of six than total serum levels of $\operatorname{lgE},{ }^{28}$, atopy was selected as this marker is commonly used in clinical practice. Missing values were imputed by means of single regression imputation. ${ }^{29}$

\section{Biomarkers in exhaled breath condensate}

EBC was collected during tidal breathing with a closed glass condenser as has been described previously. ${ }^{7}$ Immediately after EBC collection and acidity assessment (Radiometer, Zoetermeer, the Netherlands), samples were stored at $-80^{\circ} \mathrm{C}$ until further analysis. Interleukin (IL)-1 $\alpha$, IL-2, IL-4, IL-5, IL-8, IL-10, IL-13, Tumour Necrosis Factor alpha (TNF- $\alpha$ ), soluble intercellular adhesion molecule 1 (sICAM1), RANTES (C-C motif ligand (CCL)-5) and Eotaxin (CCL-11) were analysed by using a multiplex immunoassay (Luminex Corporation, Austin, TX, USA). ${ }^{30}$ Values under the detection limit received a randomly generated value between zero and the detection limit. ${ }^{31}$

\section{Volatile organic compounds}

During EBC collection a one-litre polycarbonate bag (Tedlar bag ${ }^{\circledR}$, SKC Ltd., Blandford Forum, UK) was connected to the expiratory port of the valve to collect exhaled breath. A stainless steel two-bed sorption tube, filled with carbograph 1 TD/Carbopack X (Markes International ${ }^{\circledR}$, Llantrisant, UK) enabled rapid adsorption and stabilisation of volatile compounds. Until analysis the tubes were airtight capped and stored at room temperature. VOCs were released from the tube using thermal desorption (Marks Unity desorption unit, Marks International Limited, Llantrisant, UK). The analysis of the chromatograms was described before. ${ }^{32}$

The pre-processing of the raw GC-TOF-MS spectra consisted of noise removal, ${ }^{33}$ baseline correction, ${ }^{34}$ alignment $^{35}$ and peak detection. Thereafter, complementary compounds in different samples were linked, based on similarity of retention times and mass spectra. For each compound, the area under the peak was calculated. To make the spectra comparable, the final step of pre-processing involved normalisation to the total area. The most discriminative VOCs between transient wheezers and true asthmatics were selected for analysis (chapter 8).

\section{Gene expression}

Total RNA was extracted from peripheral blood mononuclear cells (PBMCs) obtained by blood sampling. PBMCs were isolated with the Qiagen PaxGene Blood RNA kit according to the manufacturer's protocol (Qiagen , Hilden, Germany). cDNAs were generated by poly-A and random primed reverse transcription with the accompanying Qiagen kit. cDNAs were stored and used for the productions of cRNA pools. 
Quantitative real-time PCR was performed by using the Fluidigm BioMark system (AROS Applied Biotechnology, Aarhus, Denmark). Expression of the selected genes was assessed (Table 1). A quality control was conducted by the software based on slope and appearance of the amplification curve (AROS Applied Biotechnology, Aarhus, Denmark). An internal standard was obtained by computing the geometric mean of three housekeeping genes (Glyceraldehyde 3-phosphate dehydrogenase, Beta-actin, Cyclophilin A) in each participant. For each selected gene the Cycle threshold (Ct) value was adjusted by subtraction of the geometric mean (Delta $\mathrm{Ct}$ ) according to this internal standard. In cases where only two housekeeping genes passed the quality control, the $\mathrm{Ct}$ value of the missing housekeeping gene was imputed by the mean $\mathrm{Ct}$ value of this gene within the study population. Missing values were imputed by means of single regression imputation. ${ }^{29}$

Table 1 Selected genes for gene expression analysis.

\begin{tabular}{|c|c|c|c|c|}
\hline Gene & Full name & Chr. & NM-number & $\%$ \\
\hline IL4* & Interleukin-4 & 5 & NM_000589.2 & 9 \\
\hline IL5* & Interleukin-5 & 5 & NM_000879.2 & 7 \\
\hline IL8 & Interleukin-8 & 4 & NM_000584.2 & 95 \\
\hline IL10 & Interleukin-10 & 1 & NM_000572.2 & 92 \\
\hline IL12* & Interleukin-12 & 5 & NM_002187+2 & 37 \\
\hline IL13* & Interleukin-13 & 1 & NM_002188.2 & 21 \\
\hline IL17a* & Interleukin-17a & 6 & NM_002190+2 & 35 \\
\hline TNF $\alpha$ & Tumour Necrosis Factor alpha & 6 & NM_000594.2 & 90 \\
\hline ICAM1 & Intercellular Adhesion Molecule 1 & 19 & NM_000201.2 & 95 \\
\hline $\mathrm{CCL} 2$ & Monocyte chemo attractant protein 1 & 17 & NM_002982+3 & 92 \\
\hline CCL3 & Macrophage inflammatory protein 1 alpha & 17 & NM_002983.2 & 95 \\
\hline CCL5 & Regulated and normal T-cell expressed and secreted & 17 & NM_002985.2 & 100 \\
\hline CCL11* & Eotaxin & 17 & NM_001032874.1 & 0 \\
\hline TLR2 & Toll-like receptor 2 & 4 & NM_003264.3 & 95 \\
\hline TLR4 & Toll-like receptor 4 & 9 & NM_138554.3 & 98 \\
\hline TLR5 & Toll-like receptor 5 & 1 & NM_003268.4 & 100 \\
\hline TLR9 & Toll-like receptor 9 & 3 & NM_017442.2 & 100 \\
\hline CAT & Catalase & 11 & NM_001752.3 & 100 \\
\hline $\mathrm{CHIA} *$ & Chitinase acidic & 1 & NM_021797.2 & 25 \\
\hline $\operatorname{cox} 2$ & Cyclo-oxygenase 2 & 1 & NC_012920.1 & 95 \\
\hline FOXP3 & Forkhead box P3 & $x$ & NM_eo1114377.1 & 98 \\
\hline GST & Glutathione S-transferase & 1 & NM_015917 & 100 \\
\hline $\mathrm{IKB} \alpha$ & NF-kappa-B inhibitor alpha & 9 & NM_020529+2 & 99 \\
\hline MIF & Macrophage migration inhibitory factor & 22 & NM_002415.1 & 100 \\
\hline NOS1* & Nitric oxide synthase 1 & 12 & NM_000620.2 & 4 \\
\hline STAT6 & Signal transducer and activator of transcription 6 & 12 & NM_003153.3 & 99 \\
\hline SOD3* & Superoxide dismutase 3 & 4 & NM_003102.2 & 2 \\
\hline TGF $\beta$ & Transforming growth factor beta & 19 & NM_000660.4 & 100 \\
\hline$\beta$-actin ${ }^{\#}$ & Beta-actin & 7 & NM_001101.2 & 96 \\
\hline GAPDH $^{\#}$ & Glyceraldehyde 3-phosphate dehydrogenase & 12 & NM_002046.3 & 100 \\
\hline Cyp1 $1^{\#}$ & Cyclophilin A & 19 & NM_002046.3 & 100 \\
\hline
\end{tabular}

$\%$ : percentage of samples with detected gene expression; Chr.: chromosome. * Low expression in peripheral blood mononuclear cells, \# housekeeping genes. 


\section{Lung function by airway resistance}

Airway resistance was measured during tidal breathing by means of MicroRint (Micro Medical Ltd, Rochester, UK) as described in previous papers. ${ }^{14,24}$ The median value of at least five technically acceptable airway interruptions on expiratory peak flow was used for analysis. Measurements were performed before and fifteen minutes after inhalation of 300 microgram of salbutamol (Airomir, Teva Pharma NL, Haarlem, the Netherlands). Only children with both pre- and post-bronchodilator values were included in the analysis.

\section{Statistical analysis}

IBM SPSS Statistics 20 and SAS 7.30 were used for data analysis. Before analysis, fifteen asthmatic children (about $20 \%$ of total asthmatics) and about half of the children with transient wheeze were set apart for each biomarker model for external validation based on the Duplex algorithm (Table 2). ${ }^{36}$ Consequently, an equal number of children with asthma and transient wheeze in the internal validation sets was obtained. The Duplex algorithm divides the original data set into a training and an external validation set which both cover the total area in the multidimensional space and moreover have the same statistical properties. A logistic regression model with the API score as predictor was built in the internal validation sets with transient wheeze or asthma at six years as outcome. Thereafter, biomarkers in EBC, VOCs, gene expression and airway resistance were separately added to their API models to assess the added value. The model performance was assessed by quantifying discrimination (receiver operating characteristics (ROC) curve). Bootstrapping ( $\mathrm{N}=1000)$ was applied to internally validate the model. ${ }^{29}$ If results could not be computed from jackknife samples, the confidence interval was computed by the percentile method rather than the Bias Corrected accelerated method. To compare the incremental value of the different models to the API model a chi-square test was used. Differences were defined as significant when $p<0.05$. In case where there was a significant increase in the Area Under the Curve (AUC), sensitivity and specificity were addressed. In addition, a model was built combining the factors that significantly improved the AUC. Due to the skewed distributions, EBC markers were log-transformed which successfully imparted a normal distribution. As biomarkers in EBC had a high multicollinearity with the exception of $\mathrm{pH}$, principal component analysis was conducted on these biomarkers resulting in two components that explained $84 \%$ of the variance (Table 3). Backward logistic regression with a threshold of $p<0.10$ was used to select the final VOCs and gene expression markers for model building. ${ }^{29}$ The API score remained in this backward procedure. 
Table 2 Number of individuals in the internal validation and external validation set.

\begin{tabular}{lcccccc}
\hline & \multicolumn{2}{c}{ Total group } & \multicolumn{2}{c}{ Internal validation set } & \multicolumn{2}{c}{ External validation set } \\
& Asthma & TW & Asthma & TW & Asthma & TW \\
\hline Biomarkers in EBC & 76 & 120 & 61 & 61 & 15 & 59 \\
VOCs & 76 & 113 & 61 & 61 & 15 & 52 \\
Gene expression & 67 & 114 & 52 & 52 & 15 & 62 \\
Lung function* & 71 & 110 & 56 & 56 & 15 & 54 \\
VOCs and gene expression & 67 & 107 & 52 & 52 & 15 & 55 \\
\hline
\end{tabular}

EBC: Exhaled Breath Condensate; TW: Transient Wheeze; VOCs: Volatile Organic Compounds. *Lung function was assessed by airway resistance.

Table 3 Factor loadings of the principal components of exhaled breath condensate biomarkers.

\begin{tabular}{lcc}
\hline Biomarker & Component 1 & Component 2 \\
\hline IL-1 $\alpha$ & 0.85 & 0.41 \\
IL-2 & 0.84 & 0.36 \\
IL-4 & 0.48 & 0.79 \\
IL-5 & 0.88 & 0.33 \\
IL-8 & 0.55 & 0.74 \\
IL-10 & 0.78 & 0.47 \\
IL-13 & 0.73 & 0.63 \\
SICAM1 & 0.77 & 0.45 \\
CCL-5 & 0.74 & 0.31 \\
CCL-11 & 0.27 & 0.92 \\
\hline
\end{tabular}

CCL-5: C-C motif ligand 5 (RANTES); CCL-11: Eotaxin; IL: Interleukin; sICAM1=soluble Intercellular Adhesion Molecule 1. Rotation Method = Varimax with Kaiser' normalization.

\section{Power analysis}

In a population of young children with recurrent wheezing symptoms the prevalence of asthma at the age of six years is $30 \%$. In the current study with 202 children with recurrent wheeze at inclusion and taking into account a drop-out rate of $10 \%$, this will result in at least 50 children with asthma. The standard error of sensitivity is $4 \%$, taking into account the chance of a positive test result of 0.8 . The standard error of specificity with 150 children with transient wheeze is $3 \%$, based on the chance of a positive test result of 0.8 . If the positive predictive value of a test is 0.7 and the negative predictive value 0.2 in a population of 200 children, the statistical power between the relation of the test and the definitive diagnosis of asthma is $94 \%$. 


\section{Results}

\section{Baseline characteristics}

In four children, a diagnosis at six years of age could not be assessed as they were lost-to-follow-up because of personal constraints of the parents, leaving 198 children in the analysis. At age six, 122 children were classified as transient wheezers and 76 as true asthmatics. Baseline characteristics at preschool age are displayed in Table 4. At preschool age, wheezing apart from colds, atopy, parental asthma and use of ICS and/or short acting $\beta_{2}$-agonists were positively associated with an asthma diagnosis at six years of age. The calibration of all models was good, confirmed by a non-significant Hosmer-Lemeshow goodness-of-fit test $(p \geq 0.05)$.

Table 4 Baseline characteristics at preschool age.

\begin{tabular}{|c|c|c|}
\hline & $\begin{array}{c}\text { Transient wheeze } \\
n=122\end{array}$ & $\begin{array}{c}\text { Asthma } \\
\mathrm{n}=76\end{array}$ \\
\hline Age (years), mean (SD) & $3.2(0.6)$ & $3.3(0.6)$ \\
\hline Sex: male / female, in $\mathrm{N}$ & $63 / 59$ & $46 / 30$ \\
\hline White European descent $^{+}$ & 95 & 97 \\
\hline Eczema & 34 & 47 \\
\hline Allergic rhinitis* & 2 & 8 \\
\hline Wheezing episodes apart form colds*\# & 8 & 33 \\
\hline Atopy*, ${ }^{* \neq}$ & 17 & 37 \\
\hline Parental asthma* & 29 & 45 \\
\hline Use of inhaled corticosteroids* & 11 & 30 \\
\hline Use of short acting $\beta_{2}$-agonists* & 27 & 53 \\
\hline Day-care attendance & 73 & 71 \\
\hline Exposure to furry pets & 46 & 46 \\
\hline Passive smoking & 30 & 30 \\
\hline
\end{tabular}

Results are displayed as \%, unless stated otherwise. Values before imputation are displayed. $\mathrm{N}$ : number of children; SD: Standard Deviation. * Significantly different between transient wheezers and asthmatics $(p<0.05)$. + White European descent was defined as at least two grandparents from white European descent. ¥ Atopy was defined as presence of a specific IgE concentration against a mixture of inhalant and food allergens of $\geq 0.35 \mathrm{kU} / \mathrm{I}$ with the Phadiatop Infant test ${ }^{\circledR}$ (Pharmacia, Uppsala, Sweden). ${ }^{\#}$ Wheezing episodes apart from colds were assessed during the month previous to measurement.

\section{API}

Due to a different selection of children in the internal validation and external validation sets for biomarkers in EBC, VOCs, gene expression and airway resistance (Table 2), the AUC of the API models ranged from $55 \%$ to $61 \%$ in the internal validation set (Table $5 \mathrm{a}$ ) and from $56 \%$ to $64 \%$ in the external validation set (Table $5 \mathrm{~b}$ ). 
Table 5a AUC of API with and without EBC, VOCs, expression of inflammation genes and Rint: results of the internal validation.

\begin{tabular}{lcccccc}
\hline Model & AUC & $95 \% \mathrm{Cl}$ & Model & AUC & $95 \% \mathrm{Cl}$ & $\mathrm{p}$ \\
\hline API & 60 & $51-68$ & API + EBC & 65 & $55-74$ & 0.15 \\
API & 61 & $52-69$ & API + VOCs & 89 & $83-95$ & $<0.01$ \\
API & 58 & $48-67$ & API + GE & 75 & $66-85$ & $<0.01$ \\
API & 55 & $47-64$ & API + LF & 60 & $50-71$ & 0.23 \\
\hline
\end{tabular}

95\% Cl: 95\% Confidence Interval; API: Asthma Predictive Index; AUC: Area Under the Curve displayed in \%; EBC: Exhaled Breath Condensate; GE: Gene Expression; LF: Lung Function as assessed by airway resistance; p: p-value based on a chi-square test; VOCs: Volatile Organic Compounds.

Table 5b AUC of API with and without EBC, VOCs, expression of inflammation genes and Rint: results of the external validation.

\begin{tabular}{lcccccc}
\hline Model & AUC & $95 \% \mathrm{Cl}$ & Model & AUC & $95 \% \mathrm{Cl}$ & $\mathrm{p}$ \\
\hline API & 57 & $43-71$ & API + EBC & 63 & $47-78$ & 0.41 \\
API & 64 & $52-77$ & API + VOCs & 86 & $76-96$ & $<0.01$ \\
API & 56 & $42-70$ & API + GE & 68 & $53-84$ & 0.13 \\
API & 59 & $45-74$ & API + LF & 61 & $44-77$ & 0.70 \\
\hline
\end{tabular}

95\% Cl: 95\% Confidence Interval; API: Asthma Predictive Index; AUC: Area Under the Curve displayed in \%; EBC: Exhaled Breath Condensate; GE: Gene Expression; LF: Lung Function as assessed by airway resistance; $\mathrm{p}$ : $\mathrm{p}$-value based on a chi-square test; VOCs: Volatile Organic Compounds.

\section{Biomarkers in exhaled breath condensate}

EBC was successfully collected in 196 children with detection of markers in $\geq 98 \%$ of the samples. In the remaining two children $E B C$ could not be collected due to technical difficulties. The mean EBC volume was $501 \mu$ (range: 60-1410 $\mu$ ). The results of the logistic regression analysis are presented in Table 6. Data on EBC did not improve the AUC when added to the API (Table 5a and 5b).

\section{Volatile organic compounds}

Good quality breathograms were present in 189 children in the analysis. Seventeen VOCs have been demonstrated to discriminate between transient wheezers and asthmatics in an earlier analysis (chapter 8). After backward logistic regression, nine of the seventeen discriminative VOCs were included in the model (Table 7). Adding data on these VOCs significantly improved the AUC by $28 \%$ compared with the clinical model only ( $p<0.01$, Table 5 a, Figure 1 ). The sensitivity increased from $66 \%$ to $84 \%$ and the specificity from $56 \%$ to $82 \%$. The significant improvement in AUC persisted in the external validation set (increase in AUC of $22 \%, p<0.01$, Table $5 b$ ). 
Table 6 Logistic regression model of the internal validation set for markers in exhaled breath condensate.

\begin{tabular}{lcccccccc}
\hline & & \multicolumn{3}{c}{ API } & \multicolumn{4}{c}{ API including markers in EBC } \\
& $\mathrm{B}$ & $\mathrm{OR}$ & $\mathrm{BCa} 95 \% \mathrm{Cl}$ & $\mathrm{p}$ & $\mathrm{B}$ & $\mathrm{OR}$ & $\mathrm{BCa} 95 \% \mathrm{Cl}$ & $\mathrm{p}$ \\
\hline Constant & -0.51 & 0.60 & $0.33-1.03$ & 0.07 & 6.33 & 563.49 & $0.07-3.7^{\wedge} 10^{9}$ & 0.21 \\
API & 0.84 & 2.31 & $1.13-5.09$ & 0.02 & 0.81 & 2.26 & $1.03-5.86$ & 0.04 \\
EBC Component 1 & - & - & - & - & -0.04 & 0.96 & $0.66-1.34$ & 0.79 \\
EBC Component 2 & - & - & - & - & -0.13 & 0.87 & $0.57-1.21$ & 0.47 \\
pH & - & - & - & - & -3.79 & 0.02 & $2.4^{\wedge} 10^{-5}-1.57$ & 0.17 \\
\hline
\end{tabular}

API: Asthma Predictive Index; B: regression coefficient; $\mathrm{BCa} 95 \% \mathrm{Cl}$ : Bias Corrected accelerated Confidence Interval; OR: Odds Ratio; p: p-value.

Table 7 Logistic regression model of the internal validation set for volatile organic compounds.

\begin{tabular}{|c|c|c|c|c|c|c|c|c|}
\hline & \multicolumn{4}{|l|}{ API } & \multicolumn{4}{|c|}{ API including VOCs } \\
\hline & $\mathrm{B}$ & OR & $\mathrm{BCa} 95 \% \mathrm{Cl}$ & $\mathrm{p}$ & $\mathrm{B}$ & OR & $\mathrm{BCa} 95 \% \mathrm{Cl}$ & $\mathrm{p}$ \\
\hline Constant & -0.48 & 0.62 & $0.33-1.08$ & 0.87 & -0.14 & 0.87 & $0.22-2.45$ & 0.77 \\
\hline API & 0.88 & 2.40 & $1.11-5.38$ & 0.02 & 1.60 & 4.94 & $1.81-43.25$ & $<0.01$ \\
\hline VOC2 & - & - & - & - & -0.77 & 0.46 & $0.13-0.78$ & $<0.01$ \\
\hline VOC3 & - & - & - & - & 10.69 & $4.3^{\wedge} 10^{4}$ & $2.40-2.2^{\wedge} 10^{11}$ & $<0.01$ \\
\hline VOC5 & - & - & - & - & 13.78 & $9.6^{\wedge} 10^{5}$ & $7.52-1.0^{\wedge} 10^{21}$ & 0.04 \\
\hline VOC6 & - & - & - & - & 4.13 & 62.11 & $0.35-2.7^{\wedge} 10^{8}$ & 0.04 \\
\hline VOC7 & - & - & - & - & -0.19 & 0.83 & $0.56-0.92$ & 0.14 \\
\hline VOC9 & - & - & - & - & -2.34 & 0.10 & $0.004-0.91$ & 0.02 \\
\hline Voc11 & - & - & - & - & 14.48 & $1.9^{\wedge} 10^{6}$ & $4007-1.9^{\wedge} 10^{16}$ & 0.06 \\
\hline Voc15 & - & - & - & - & -25.50 & $<0.01$ & $<0.01-<0.01$ & $<0.01$ \\
\hline Voc16 & - & - & - & - & -24.45 & $<0.01$ & $0.22-2.45$ & $<0.01$ \\
\hline
\end{tabular}

API: Asthma Predictive Index; B: regression coefficient; $\mathrm{BCa} 95 \% \mathrm{Cl}$ : Bias Corrected accelerated $95 \%$ Confidence Interval; OR: Odds Ratio; p: p-value; VOC; Volatile Organic Compound.

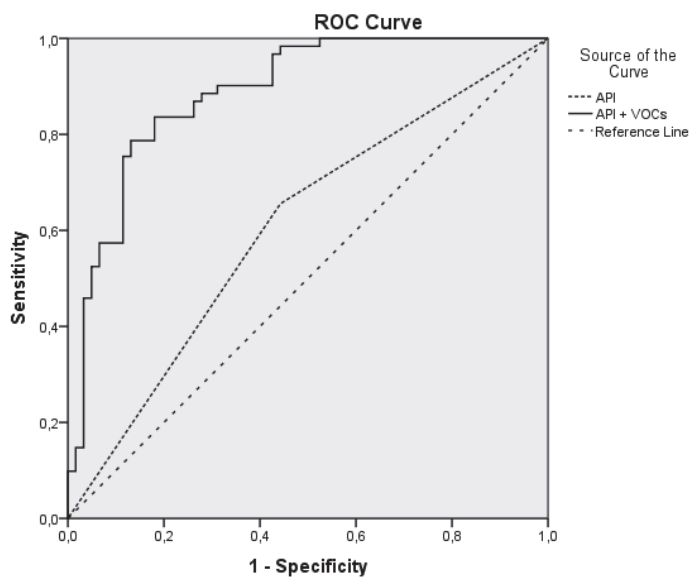

Figure 1 Receiver Operating Characteristics (ROC) curve for Asthma Predictive Index (API) and selected Volatile Organic Compounds (VOCs) in the internal validation set.. 


\section{Gene expression}

Information on gene expression was obtained in 181 children. The main reason for missing data in the remaining seventeen children was refusal of venous puncture. In eight samples, only two housekeeping genes passed the quality control and the third housekeeping gene was imputed. Some markers were excluded from analysis as expression was only detected in a small number of samples (Table 1). Values on the remaining gene expression markers were present in $90-100 \%$ of the children. Backward logistic regression yielded three gene expression markers (toll-like receptor 4 (TLR4), catalase (CAT) and Tumour-Necrosis-Factor alpha (TNF $\alpha)$ ) in association with the diagnosis at six years of age. These three gene expression markers were included in the model (Table 8). The AUC significantly improved by $17 \%$ when data on gene expression were added to the API $(p<0.01$, Table $5 a$, Figure 2$)$. The sensitivity increased from $67 \%$ to $71 \%$ and the specificity from $48 \%$ to $77 \%$. Although improvement was still present in the external validation set (increase of $12 \%$ ), it was not significant $(p=0.13$, Table $5 b)$.

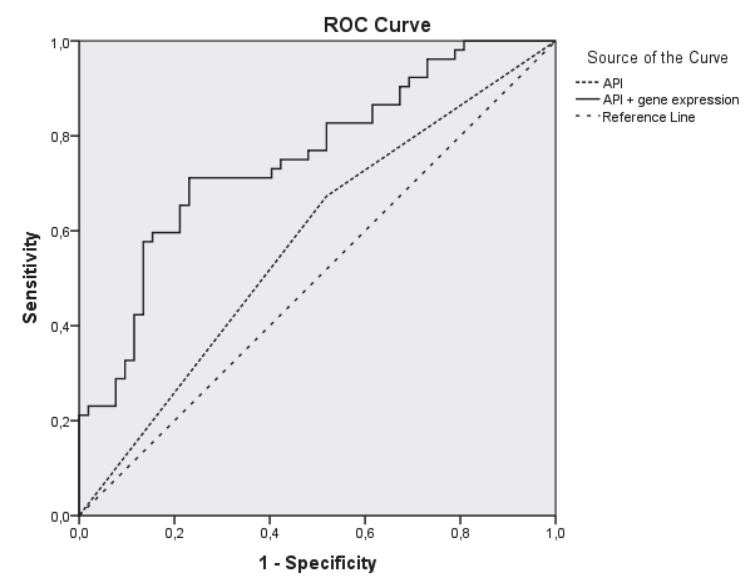

Figure 2 Receiver Operating Characteristics (ROC) curve for Asthma Predictive Index (API) and expression of selected (TLR4, CAT, TNF $\alpha$ ) inflammation genes (GE) in the internal validation set. .

\section{Airway resistance}

Data on pre- and post-bronchodilator airway resistance were available in 181 children. Anxiety during measurements was the main reason for missing values. In Table 9 the results of the logistic regression analysis are displayed. The discrimination of the model did not improve when data on airway resistance were added to the API (Table $5 a$ and $5 b)$. 
Table 8 Logistic regression model of the internal validation set for gene expression markers.

\begin{tabular}{lcccccccc}
\hline & & \multicolumn{3}{c}{ API } & \multicolumn{4}{c}{ API including gene expression } \\
& $\mathrm{B}$ & $\mathrm{OR}$ & $\mathrm{BCa} 95 \% \mathrm{Cl}$ & $\mathrm{p}$ & $\mathrm{B}$ & OR & $\mathrm{BCa} 95 \% \mathrm{Cl}$ & $\mathrm{p}$ \\
\hline Constant & -0.39 & 0.68 & $0.34-1.33$ & 0.23 & -5.35 & 0.01 & $3.1^{\wedge} 10^{-5}-0.34$ & 0.02 \\
API & 0.65 & 1.91 & $0.81-4.31$ & 0.12 & 0.97 & 2.65 & $0.93-8.49$ & 0.04 \\
TLR4 & - & - & - & - & 0.39 & 1.48 & $0.96-2.50$ & 0.02 \\
CAT & - & - & - & - & -0.79 & 0.45 & $0.30-0.60$ & $<0.01$ \\
TNF $\alpha$ & - & - & - & - & 0.39 & 1.47 & $0.96-2.41$ & 0.04 \\
\hline
\end{tabular}

API: Asthma Predictive Index; B: regression coefficient; $\mathrm{BCa} 95 \% \mathrm{Cl}$ : Bias Corrected accelerated $95 \%$ Confidence Interval; CAT: catalase; OR: Odds Ratio; p: p-value; TNF $\alpha$ : Tumour-Necrosis Factor alpha; TLR4: toll-like Receptor 4.

Table 9 Logistic regression model of the internal validation set for airway resistance.

\begin{tabular}{lcccccccc}
\hline & & \multicolumn{3}{c}{ API } & \multicolumn{5}{c}{ API airway resistance } \\
& $\mathrm{B}$ & $\mathrm{OR}$ & $\mathrm{BCa} 95 \% \mathrm{Cl}$ & $\mathrm{p}$ & $\mathrm{B}$ & $\mathrm{OR}$ & $\mathrm{BCa} 95 \% \mathrm{Cl}$ & $\mathrm{p}$ \\
\hline Constant & -0.32 & 0.73 & $0.35-1.49$ & 0.32 & -1.26 & 0.29 & $0.04-1.51$ & 0.15 \\
$\mathrm{API}$ & 0.48 & 1.62 & $0.78-1.22$ & 0.22 & 0.49 & 1.64 & $0.74-3.60$ & 0.23 \\
Airway resistance & - & - & - & - & 0.58 & 1.79 & $0.53-8.01$ & 0.27 \\
$\begin{array}{l}\text { before salbutamol } \\
\begin{array}{l}\text { Airway resistance } \\
\text { after salbutamol }\end{array}\end{array}$ & - & - & - & - & 0.03 & 1.03 & $0.34-3.50$ & 0.96 \\
\hline
\end{tabular}

API: Asthma Predictive Index; B: regression coefficient; $\mathrm{BCa} 95 \% \mathrm{Cl}$ : Bias Corrected accelerated $95 \%$ Confidence Interval; OR: Odds Ratio; p: p-value.

\section{Combined model including volatile organic compounds and gene expression}

Using a combined model, we assessed the value of VOCs, expression of inflammation genes and the API score. The ROC curves are displayed in Figure 3. The total AUC was $95 \%$ (92-99)) with a sensitivity of $89 \%$ and a specificity of $90 \%$ in the internal validation set. In the external validation the AUC was $86 \%$ (77-96)).

\section{Discussion}

We studied the predictive value of (non-invasive) inflammation biomarkers and early lung function measures as additions to the API, in relation to a reliable asthma diagnosis in a large group of children with preschool wheeze. When compared with the API alone, information on exhaled VOCs combined with the API score assessed at preschool age, significantly improved a correct classification of asthma at six years of age. Although information on expression of inflammation genes improved a correct asthma classification when added to the API, this result could not be confirmed by 
external validation. Both, biomarkers in EBC and Rint before or after a bronchodilator, did not add to the prediction of asthma at six years. A combined model with VOCs, gene expression and API had the highest AUC of $95 \%$.

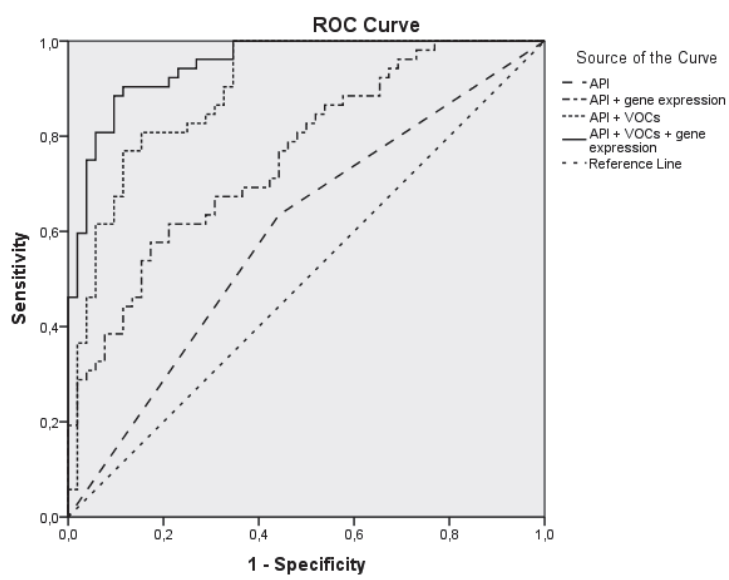

Figure 3 Receiver Operating Characteristics (ROC) curve for Volatile Organic Compounds (VOCs), expression of selected (TLR4, CAT, TNF $\alpha$ ) inflammation genes (GE) and Asthma Predictive Index (API) in a combined model in the internal validation set.

Various prediction models of clinical parameters have been proposed to assist physicians in the diagnostic process. Early diagnostic models that have been externally validated are the API, the cumulative risk score of the Isle of Wight and the PIAMA risk score. ${ }^{4-6}$ These indices are based on easily obtainable clinical variables and, therefore, highly applicable in general clinical practice. However, in general, the sensitivity is low (ranging from 16 to $71 \%$ ) and their clinical value modest. ${ }^{13}$ These prediction rules might be improved by adding information on biomarkers. In the current study we elaborated the diagnostic value of various non-invasive inflammation biomarkers in addition to the API. This index was chosen because it is widely used in several independent studies and increasingly in clinical practice. Moreover, it is approved by the international Global Initiative for Asthma and by the American guidelines. ${ }^{37-39}$ We demonstrated that information on VOCs could improve the diagnostic prediction model. VOCs are believed to be formed during various (patho-) physiological processes in the body such as during airway inflammation. ${ }^{40,41}$ Several studies demonstrated a distinct VOCs profile in children with asthma compared to healthy controls. ${ }^{42-44}$ This distinct profile in asthmatic children indicates that the exhaled VOCs pattern might be altered by the inflammatory status of the airways. Thus VOCs profiling might be a tool to monitor airway inflammation. In a previous analysis we identified several VOCs that, in combination, were able to accurately differentiate between children with asthma and children with transient wheeze (chapter 8). The 
most discriminative VOCs of this model were used in the current study. We demonstrated that when these VOCs were added to the API score, they could significantly improve an accurate asthma diagnosis at preschool age. The discriminative VOCs were mostly hydrocarbons and long-chain alkanes, which have previously been associated with asthma and are plausible markers in childhood asthma due to their role in airway inflammation. ${ }^{11}$

Information on expression of various inflammation genes (TLR4, CAT and TNF $\alpha$ ) was also associated with a more accurate asthma prediction, although this was not confirmed in the external validation set. These genes are generally known to be relevant in childhood asthma and airway inflammation. It was demonstrated that gene expression markers were related to asthma and recurrent wheeze compared to a healthy population. ${ }^{21,22,45}$ Currently, no other studies have assessed the added value of expression of inflammation genes to clinical characteristics. Our findings on gene expression support the hypothesis that the incorporation of markers of underlying pathophysiology can help to improve an early asthma diagnosis in preschool children. In a combined model of VOCs, expression of inflammation genes and to the API score, an even higher accurate asthma diagnosis was reached.

In addition to VOCs and expression of inflammation genes, we analysed various inflammation markers in EBC. Inflammation markers in EBC in addition to the API score were not associated with a better asthma prediction in our study. Yet, in schoolage children, an association has been demonstrated between markers of inflammation in EBC and childhood asthma, implying the potential for an asthma diagnosis through use of this medium. ${ }^{8,46-48}$ Two of these studies focussed on inflammatory profiling by using techniques comparable to those often used in VOCs analysis. $^{47,48}$ In contrast to our findings, the addition of information on $\mathrm{pH}$ of EBC to the API improved asthma prediction in a recent case-control study. ${ }^{49}$ It is possible that with innovative 'omic-like' techniques, new markers in EBC can be found which are helpful for an early asthma diagnosis. So far, however, a combination of several important cytokines and chemokines has not proved helpful for distinguishing between children with asthma and viral wheeze.

In our study, information on airway resistance before and after a bronchodilator did not improve an early asthma diagnosis when added to the API score. In school-age children, airway resistance has been found to be elevated in children with persistent wheeze compared to children who previously had transient wheezing symptoms. ${ }^{15,20}$ However, in a prospective study it was demonstrated that although airway resistance in children aged four years was positively associated with symptoms of wheeze at six years, airway resistance could not improve the prediction of asthma at the age of eight years. ${ }^{19}$ It might be that Rint is too variable or inadequately reflects the airway resistance in the lower airways. This finding underlines our results indicating a limited predictive value of airway resistance in an early asthma diagnosis. 
We were innovative in our approach to assess the added predictive value of various different non-invasive biomarkers in an early asthma diagnosis in a prospective study of wheezing preschool children. The ADEM study was especially designed to answer this research question. We were able to follow a relevant and sufficiently large group of children for the duration of four years and obtained all the necessary information with only four drop-outs. The non-invasiveness and simple obtainable character of the studied biomarkers are another important strengths of our study. Thus, the promising techniques that were revealed in our study are highly feasible to be incorporated in clinical practice in young children. Exhaled VOCs can easily and quickly be obtained in preschool children without disturbing underlying disease processes. Although we assessed gene expression in venous blood, new non-invasive techniques, such as the collection of gene expression material in saliva are currently available. Another strength of our study is the way of diagnosing asthma at six years, which was based on expert opinion and a computer-algorithm with re-assessment of inconclusive cases, legitimating an accurate diagnosis at six years of age. Moreover, the external validation implies the reliability and generalisability of our results.

The limitation of our study may be that, although internal and external validation was provided in this study, research in different populations is needed to confirm our findings and to extend their meaning into daily clinical practice. Furthermore, the use of exhaled breath analysis for assessing the inflammatory status of the airways needs to be further standardised and validated. A list of recommendations on collecting and analysing exhaled VOCs, as was provided for EBC by an international taskforce, will facilitate standardisation. ${ }^{50}$ Future studies should also focus more extensively on the broad range of information available from gene expression.

In our analysis we focussed on improvement of the AUC of the API score. An AUC of $>80 \%$ is suitable for screening options, while an AUC of $>99 \%$ can be used for presymptomatic diagnosis. ${ }^{51}$ Based on our results, VOCs and expression of inflammation genes in combination with the API score are suitable for screening purposes. Inclusion of more markers might further improve the AUC making these tools suitable for diagnostic purposes. Moreover, a clinically optimal threshold has to be determined to assess sensitivity, specificity, negative predictive value and positive predictive value. The question is whether the improvement in total correct classification will outweigh the extra costs, time and effort that will be required when these non-invasive biomarkers begin to be routinely used in clinical practice. Future studies should focus on the implications for clinical practice regarding decision making and clinical outcome effects when non-invasive biomarkers are added.

In conclusion, we demonstrated that information on VOCs and possibly gene expression at preschool age can enhance a correct asthma diagnosis at six years of age. A combined model with VOCs, expression of inflammation genes and API had an optimal prediction of $95 \%$. Whether a reliable asthma diagnosis at preschool age can 
improve the current treatment strategies in preschool wheeze should be further studied. 


\section{References}

1. Savenije OE, Granell R, Caudri D, Koppelman GH, Smit HA, Wijga A, et al. Comparison of childhood wheezing phenotypes in 2 birth cohorts: ALSPAC and PIAMA. J Allergy Clin Immunol 2011;127:150512 e14.

2. Pedersen SE, Hurd SS, Lemanske RF, Jr., Becker A, Zar HJ, Sly PD, et al. Global strategy for the diagnosis and management of asthma in children 5 years and younger. Pediatr Pulmonol 2011;46: 1-17.

3. Caudri D, Wijga AH, Smit HA, Koppelman GH, Kerkhof M, Hoekstra MO, et al. Asthma symptoms and medication in the PIAMA birth cohort: evidence for under and overtreatment. Pediatr Allergy Immunol 2011;22:652-9.

4. Castro-Rodriguez JA, Holberg CJ, Wright AL, Martinez FD. A clinical index to define risk of asthma in young children with recurrent wheezing. Am J Respir Crit Care Med 2000;162:1403-6.

5. Kurukulaaratchy RJ, Matthews S, Holgate ST, Arshad SH. Predicting persistent disease among children who wheeze during early life. Eur Respir J 2003;22:767-71.

6. Caudri D, Wijga A, CM AS, Hoekstra M, Postma DS, Koppelman GH, et al. Predicting the long-term prognosis of children with symptoms suggestive of asthma at preschool age. J Allergy Clin Immunol 2009;124:903-10.

7. Rosias PP, Robroeks CM, van de Kant KD, Rijkers GT, Zimmermann LJ, van Schayck CP, et al. Feasibility of a new method to collect exhaled breath condensate in pre-school children Pediatr Allergy Immunol 2010;21.

8. Robroeks CM, Rijkers GT, Jöbsis Q, Hendriks HJ, Damoiseaux JG, Zimmermann LJ, et al. Increased cytokines, chemokines and soluble adhesion molecules in exhaled breath condensate of asthmatic children. Clin Exp Allergy 2010;40:77-84.

9. Kazani S, Israel E. Exhaled breath condensates in asthma: diagnostic and therapeutic implications. J Breath Res 2010;4:047001

10. Dallinga JW, Robroeks CM, van Berkel JJ, Moonen EJ, Godschalk RW, Jöbsis Q, Dompeling E, Wouters $E F$, van Schooten FJ. Volatile organic compounds in exhaled breath as a diagnostic tool for asthma in children. Clin Exp Allergy 2010;40:68-76.

11. van de Kant KD, van der Sande $L$, Jöbsis Q, van Schayck OC, Dompeling E. Clinical use of exhaled volatile organic compounds in pulmonary diseases: a systematic review. Respir Res 2012;13:117.

12. Popov TA. Human exhaled breath analysis. Ann Allergy Asthma Immunol 2011;106:451-6; quiz 7.

13. Savenije OE, Kerkhof M, Koppelman GH, Postma DS. Predicting who will have asthma at school age among preschool children. J Allergy Clin Immunol 2012;130:325-31.

14. Merkus PJ, Arets HG, Joosten T, Siero A, Brouha M, Mijnsbergen JY, et al. Measurements of interrupter resistance: reference values for children 3-13 yrs of age. Eur Respir J 2002;20:907-11.

15. Brussee JE, Smit HA, Koopman LP, Wijga AH, Kerkhof M, Corver K, et al. Interrupter resistance and wheezing phenotypes at 4 years of age. Am J Respir Crit Care Med 2004;169:209-13.

16. Kooi EM, Schokker S, van der Molen T, Duiverman EJ. Airway resistance measurements in pre-school children with asthmatic symptoms: the interrupter technique. Respir Med 2006;100:955-64.

17. van de Kant KD, van Berkel JJ, Jöbsis Q, Lima Passos V, Klaassen EM, van der Sande L, van Schayck OC, de Jongste JC, van Schooten FJ, Derks E, Dompeling E, Dallinga JW.. Exhaled breath profiling in diagnosing wheezy preschool children. Eur Respir J 2013;41:183-8.

18. van de Kant KD, Klaassen EM, Jöbsis Q, Koers K, Rijkers GT, van der Grinten CP, et al. Wheezing in preschool children is associated with increased levels of cytokines/chemokines in exhaled breath condensate. J Allergy Clin Immunol 2010;126:669-71.

19. Caudri D, Wijga AH, Hoekstra MO, Kerkhof M, Koppelman GH, Brunekreef B, et al. Prediction of asthma in symptomatic preschool children using exhaled nitric oxide, Rint and specific IgE. Thorax 2010;65:801-7.

20. Oostveen E, Dom S, Desager K, Hagendorens M, De Backer W, Weyler J. Lung function and bronchodilator response in 4-year-old children with different wheezing phenotypes. Eur Respir J 2010;35:865-72. 
21. Cai X, Yang YC, Wang JF, Wang Q, Gao J, Fu WL, et al. Transient Receptor Potential Vanilloid 2 (TRPV2), a Potential Novel Biomarker in Childhood Asthma. J Asthma 2013;50:209-14.

22. Jin $R, X u H G$, Yuan WX, Zhuang LL, Liu LF, Jiang $L$, et al. Mechanisms elevating ORMDL3 expression in recurrent wheeze patients: role of Ets-1, p300 and CREB. Int J Biochem Cell Biol 2012;44:1174-83.

23. Worldwide variation in prevalence of symptoms of asthma, allergic rhinoconjunctivitis, and atopic eczema: ISAAC. The International Study of Asthma and Allergies in Childhood (ISAAC) Steering Committee. Lancet 1998;351:1225-32.

24. van de Kant KD, Klaassen EM, Jöbsis Q, Nijhuis AJ, van Schayck OC, Dompeling E. Early diagnosis of asthma in young children by using non-invasive biomarkers of airway inflammation and early lung function measurements: study protocol of a case-control study. BMC Public Health 2009;9:210.

25. Klaassen EM, van Kant KD, Jöbsis Q, Høvig ST, van Schayck CP, Rijkers GT, et al. Symptoms, but not a biomarker response to inhaled corticosteroids, predict asthma in preschool children with recurrent wheeze. Mediators Inflamm 2012;2012:162571.

26. Miller MR, Hankinson J, Brusasco V, Burgos F, Casaburi R, Coates A, et al. Standardisation of spirometry. Eur Respir J 2005;26:319-38.

27. Powell CV, McNamara P, Solis A, Shaw NJ. A parent completed questionnaire to describe the patterns of wheezing and other respiratory symptoms in infants and preschool children. Arch Dis Child 2002;87:376-9

28. Just J, Nicoloyanis N, Chauvin M, Pribil C, Grimfeld A, Duru G. Lack of eosinophilia can predict remission in wheezy infants? Clin Exp Allergy 2008;38:767-73.

29. Moons KG, Kengne AP, Woodward M, Royston P, Vergouwe $Y$, Altman DG, et al. Risk prediction models: I. Development, internal validation, and assessing the incremental value of a new (bio)marker. Heart 2012;98:683-90.

30. de Jager W, te Velthuis H, Prakken BJ, Kuis W, Rijkers GT. Simultaneous detection of 15 human cytokines in a single sample of stimulated peripheral blood mononuclear cells. Clin Diagn Lab Immunol 2003;10:133-9.

31. van de Kant KD, Koers K, Rijkers GT, Lima Passos V, Klaassen EM, Mommers M, et al. Can exhaled inflammatory markers predict a steroid response in wheezing preschool children? Clin Exp Allergy 2011;41:1076-83.

32. Van Berkel JJ, Dallinga JW, Moller GM, Godschalk RW, Moonen E, Wouters EF, et al. Development of accurate classification method based on the analysis of volatile organic compounds from human exhaled air. J Chromatogr B Analyt Technol Biomed Life Sci 2008;861:101-7.

33. Walczak B. Wavelets in Chemistry 2000.

34. Eilers PHC, Marx D. Flexible smoothing using B-splines and penalized likelihood. Statistical Science 1996;11:89-121.

35. Nielsen NPV, Carstensen JM, Smedsgaard J. Aligning of single and multiple wavelength chromatographic profiles for chemometric data analysis using correlation optimised warping. Journal of Chromatography 1998;805:17-35.

36. Snee RD. 1977 Validation of regression models; Methods and examples. Technometrics 1977;19:41528.

37. Castro-Rodriguez JA. The Asthma Predictive Index: a very useful tool for predicting asthma in young children. J Allergy Clin Immunol 2010;126:212-6.

38. From the global strategy for the diagnosis and management of asthma in children 5 years and younger: Global Initiative for Asthma (GINA); 2009. Available from: http://www.ginasthma.org.

39. Guidelines for the diagnosis and management of asthma 2007: Expert Panel Report 3 (EPR3); 2007. Available from: http://www.nhlbi.nih.gov/guidelines/asthma/asthgdln.htm.

40. Buszewski B, Kesy M, Ligor T, Amann A. Human exhaled air analytics: biomarkers of diseases. Biomedical chromatography : BMC 2007;21:553-66.

41. Miekisch W, Schubert JK, Noeldge-Schomburg GF. Diagnostic potential of breath analysis--focus on volatile organic compounds. Clin Chim Acta 2004;347:25-39.

42. Dallinga JW, Robroeks CM, van Berkel JJ, Moonen EJ, Godschalk RW, Jöbsis Q, et al. Volatile organic compounds in exhaled breath as a diagnostic tool for asthma in children. Clin Exp Allergy 2010;40: 68-76. 
43. Caldeira M, Barros AS, Bilelo MJ, Parada A, Camara JS, Rocha SM. Profiling allergic asthma volatile metabolic patterns using a headspace-solid phase microextraction/gas chromatography based methodology. J Chromatogr A 2011;1218:3771-80.

44. Caldeira M, Perestrelo R, Barros AS, Bilelo MJ, Morete A, Camara JS, et al. Allergic asthma exhaled breath metabolome: a challenge for comprehensive two-dimensional gas chromatography. J Chromatogr A 2012;1254:87-97.

45. Kovacic MB, Myers JM, Wang N, Martin L, Lindsey M, Ericksen MB, et al. Identification of KIF3A as a novel candidate gene for childhood asthma using RNA expression and population allelic frequencies differences. PloS One 2011;6:e23714.

46. Brunetti L, Francavilla R, Tesse R, Fiermonte P, Fiore FP, Lore M, et al. Exhaled breath condensate cytokines and $\mathrm{pH}$ in pediatric asthma and atopic dermatitis. Allergy Asthma Proc 2008;29:461-7.

47. Carraro S, Rezzi S, Reniero F, Heberger K, Giordano G, Zanconato S, et al. Metabolomics applied to exhaled breath condensate in childhood asthma. Am J Respir Crit Care Med 2007;175:986-90.

48. Bloemen K, Van Den Heuvel R, Govarts E, Hooyberghs J, Nelen V, Witters E, et al. A new approach to study exhaled proteins as potential biomarkers for asthma. Clin Exp Allergy 2011;41:346-56.

49. von Jagwitz M, Pessler F, Akmatov M, Li J, Range U, Vogelberg C. Reduced breath condensate $\mathrm{pH}$ in asymptomatic children with prior wheezing as a risk factor for asthma. J Allergy Clin Immunol 2011;128:50-5.

50. Horvath I, Hunt J, Barnes PJ, Alving K, Antczak A, Baraldi E, et al. Exhaled breath condensate: methodological recommendations and unresolved questions. Eur Respir J 2005;26:523-48.

51. Koppelman GH, te Meerman GJ, Postma DS. Genetic testing for asthma. Eur Respir J 2008;32:775-82. 

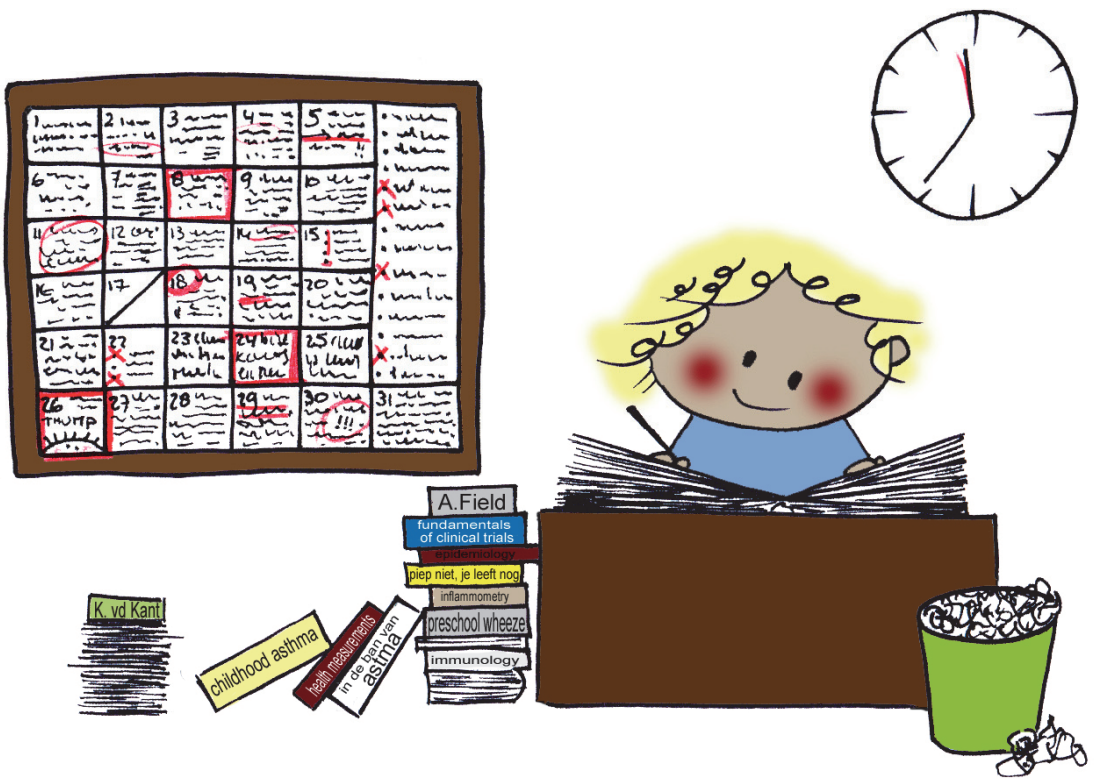


\section{Chapter 11}

General discussion 


\section{Introduction: problems in childhood asthma}

Although asthma is the most common chronic disease in childhood, an asthma diagnosis at preschool age remains difficult. ${ }^{1,2}$ Mostly, preschool children with respiratory symptoms, like wheeze, have symptoms due to viral infections and will not develop asthma at later age, so-called viral or transient wheeze. ${ }^{2}$ Inhaled corticosteroids (ICS) are an effective treatment in children with asthma, although, they are less effective in children with transient symptoms. ${ }^{1,3}$ Airway remodelling starts at a young age. ${ }^{4}$ As a reliable diagnosis of asthma at preschool age is difficult, children with asthma are often under-treated. ${ }^{5}$ If an early asthma diagnosis would be possible, we might be able to influence disease progression and to prevent airway remodelling by proper treatment. However, children with transient wheeze are often over-treated. ${ }^{5}$ The inability to diagnose asthma at an early age leads to a high burden on health care costs. ${ }^{6,7}$ Furthermore, children with asthma and their parents experience a decreased quality of life. ${ }^{7-9}$ Thus, a reliable and early asthma diagnosis may result in more appropriate asthma health care. A reliable tool at preschool age that can differentiate between children that will develop asthma and children with transient symptoms would be of great help. To be clinically useful and implementable, this tool has to be primarily non-invasive and feasible in young children. ${ }^{10}$ Possible diagnostic candidates are the assessment of inflammation markers in Exhaled Breath Condensate (EBC), exhaled Volatile Organic Compounds (VOCs), lung function and information on expression of inflammation genes.

One of the main problems in asthma prevention is our lack of a proper understanding of the underlying pathophysiology. It is generally known that asthma is a complex disease which develops as a consequence of multiple interacting genetic and environmental factors. However, exact mechanisms remain largely obscure. If we would be able to gain more insight in these complex mechanisms, we might be able to identify children with an enhanced asthma risk. The identification of these children can potentially lead to better asthma health care. In future, we might even be able to prevent asthma development by influencing factors involved in asthma development. The studies in this thesis were performed to gain insight into the underlying pathophysiological mechanisms of the early development of asthma and to assess whether (non-invasive) measurements of exhaled inflammation markers and early lung function measurements in children at risk for asthma can diagnose asthma at preschool age. In this chapter our main findings are put into perspective. 


\section{Aetiology of childhood asthma}

\subsection{Genetic predisposition}

The first knowledge on the genetic aetiology of childhood asthma goes back to the seventeenth century. ${ }^{11}$ Since then, many studies have been performed with changeable success. Twin studies have indicated a large genetic contribution in asthma up to $90 \% .{ }^{12,13}$ The relatively recent use of genome wide association studies has enabled us to gain a massive amount of genetic data, increasing our options to find associations. ${ }^{14}$ In total, 30-100 genes have been demonstrated to be involved in childhood asthma, ${ }^{15}$ however, independent replication often fails. Many of the associated genes are involved in airway inflammation, although their exact role in childhood asthma needs further study. Furthermore, the contribution of genetic predisposition on asthma prediction is limited. ${ }^{15}$

Genetic variants can influence gene expression and consequently protein level. ${ }^{16}$ The unique design of the Asthma DEtection and Monitoring (ADEM) study made it possible to study genetic variants, gene expression and protein levels in an integrated way in order to further improve our understanding of asthma development. ${ }^{17}$ For this approach, we selected several important genes involved in airway inflammation (Interleukin (IL)4, IL8, IL10, IL13, Tumour-Necrosis-Factor alpha (TNF $\alpha$ ) and Intercellular Adhesion Molecule 1 (ICAM1)) and analysed genetic variants, gene expression in peripheral blood mononuclear cells and protein levels in EBC in healthy controls, children with transient wheeze and asthmatics (chapter 5). We demonstrated an association of the ICAM1 rs5498 A-allele with childhood asthma. Furthermore, the Aallele was associated with an increased expression of ICAM1 mRNA, and in turn was accompanied by increased levels of soluble (s)ICAM1 in EBC. In addition to increased sICAM1 levels in asthmatic children, increased levels of IL4, IL8, IL10 and IL13 in EBC were found.

The A-allele has been associated with childhood asthma before. ${ }^{18}$ The increased binding capacity of leucocytes in presence of the A-allele, ${ }^{19-22}$ which might be due to a shift in electric charge, influence on protein-protein dimerisation or an increased susceptibility to enzymatic cleavage in presence of the G-allele, ${ }^{20-23}$ is probably responsible for this association. The increased mRNA concentration of ICAM1 in presence of the A-allele is expected to result into a higher expression of ICAM1 on the leukocyte cell membrane which results in an enhanced binding of leukocytes. Due to this enhanced binding, the number of local leukocytes will increase with a higher total production of inflammation markers. Several studies have confirmed a higher level of inflammation markers in EBC. ${ }^{24-26}$ Thus, ICAM1 is probably involved in the development of childhood asthma and increased levels of (s)ICAM1 in EBC can be used as a marker for asthma. 
It has been demonstrated that transient wheeze and asthma are associated with different genes. ${ }^{27}$ Thus, studying differences in genetic background between children with transient wheeze and asthma can give insight into genes involved in disease development. The design of the ADEM study was developed in such a way that we could study genetic variants in asthma candidate genes in children with transient wheeze and asthma at the age of six (chapter 6). We were able to demonstrate that genetic variants in ADAM33 (rs511898 and rs528557), IL4 (rs2070874 and rs2244350) and ORMDL3 (rs7216389) were associated with asthma development. The KOALA (the Child, Parent and Health: Lifestyle and, Genetic Constitution study) birth cohort was used to replicate our findings. ${ }^{28}$ As the children from this cohort originated from the same region in the Netherlands as our cohort, genetic and environmental similarities were expected, increasing the odds to successful replication. Indeed we were able to replicate the negative association of the ADAM33 rs528557 CG/GG-genotype in relationship to childhood asthma. The other observed associations in the ADEM study could not be replicated in the KOALA birth cohort.

As $A D A M 33$ is expected to be involved in airway remodelling, it makes a good asthma candidate gene. Polymorphisms in ADAM33 have been related to childhood asthma and transient early wheeze in some previous studies. ${ }^{29-31}$ In contrast to our results, the ADAM33 rs528557 polymorphism has previously demonstrated a positive association with asthma. ${ }^{30}$ The replication of our association in an independent birth cohort study further confirms the relationship of ADAM33 with childhood asthma in children with recurrent wheeze. As previously stated, replication of genetic associations remains an issue. ${ }^{29}$ We were unable to replicate the associations for the IL4 and ORMDL3 polymorphisms. There are multiple causes for failure of replication, such as small gene effects, populations with unique (unidentified) characteristics, methodological issues, interaction with environmental influences and phenotypic heterogeneity or poor phenotype definition. ${ }^{32-36}$ To minimise environmental influences we corrected for several known confounders (sex, exposure to furry pets and smoking exposure) which did not influence our results. However, differences in asthma classification between the ADEM study and the KOALA birth cohort study are possibly partly responsible for failure of replication in our study. Off course associations can also be based on linkage or chance. Thus, it is important to take these factors into account in data analysis and interpretation of study results. For this purpose it is important to have enough power by the use of large samples of individuals. Large samples can be achieved by for example combining individuals from several studies or through meta-analysis.

\subsection{Genetic predisposition and environmental influences}

Our review describes the role of CD14 and toll-like receptors (TLRs) in the development of asthma in Caucasian children (chapter 3). Based on the available literature, no clear separate role for CD14 and TLRs on the development of childhood asthma could 
be demonstrated. As asthma is not the consequence of an abnormality in a single gene, haplotype spanning within and between genes can give more information on the aetiology of asthma and enable us to reveal possible connections between genes and childhood asthma (chapter 3). ${ }^{37,38}$ However, investigating only the genetic background of childhood asthma gives a limited view on this complex disease. Environmental exposures have been demonstrated to influence the relationship between CD14 and TLRs and childhood asthma, although the number of studies is limited. ${ }^{39-41}$ If these contributing factors remain unknown, they can confound or mediate relationships thereby clouding existing associations. This can explain (part of) the discrepancies between genetic asthma studies. ${ }^{42}$ Therefore, when studying the aetiology of asthma, it is important to study both genetic and environmental factors and their interactions simultaneously.

\subsection{The immune system, bacterial exposure and interactions}

The hygiene hypothesis, which was posed for the first time in 1989 , suggests that infections in early childhood protect against the development of allergic diseases, such as asthma. ${ }^{43}$ Microbes would give protection as they stimulate the maturation towards a balanced immune response. ${ }^{43,44}$ This hypothesis can clarify the recent increase in asthma incidence in western countries, which cannot be explained by changes in genetic predisposition. ${ }^{45-47}$ For many years, the hygiene hypothesis has been supported by indirect evidence from numerous epidemiological studies. However, there are several studies in contradiction with the hygiene hypothesis. ${ }^{48}$ Furthermore, the hygiene hypothesis does not provide an explanation for the development of non-allergic asthma. Other hypotheses have been proposed, such as the 'defective epithelial barrier function'. ${ }^{49-51}$ This hypothesis assumes a defect of the epithelial barrier in genetically susceptible individuals. This allows a greater access of environmental allergens, micro-organisms and toxicants to the airway tissue, ultimately leading to asthma development. ${ }^{51}$ According to the defective epithelial barrier hypothesis, bacterial colonisation or infection may have a negative influence on the development of asthma. Timing as well as persistence of the exposure have been demonstrated to be important in regard to the development of asthma. ${ }^{49,52-54}$ In summary, asthma is expected to develop as a consequence of the interplay between a genetically deprived immune system, exposure to environmental stimuli and timing of exposure.

Microbes are expected to play a role in the origins of asthma. ${ }^{55}$ CD14 and TLRs are important components of the immune system that induce the immune response after interaction with microbes, ${ }^{56,57}$ and are expected to play a role in childhood asthma. ${ }^{58-61}$ Thus, CD14 and TLRs are an attractive target to study the influence of bacteria and the reaction of the immune system based on genetic predisposition in relationship to childhood asthma. In our prospective cohort, we studied the influence 
of genetic variants in CD14 and TLRs (TLR2, TLR4, TLR5 and TLR9) in combination with colonisation of several bacteria (Haemophilus (para)influezae, Streptococcus pneumoniae and Staphylococcus aureus) at preschool age in the development of childhood asthma at the age of six years in healthy children, transient wheezers and asthmatics (chapter 4). We observed significant interactions between genetic variants in CD14 and TLRs and bacterial colonisation at preschool age on early asthma development ( $H$. parainfluenzae and TLR4 rs2737190, $H$. influenzae and CD14 rs2569190, S. pneumoniae and TLR2 rs4696480 and H. parainfluenzae and CD14 rs2569190). These interactions indicated an increased risk of asthma development only in the presence of certain genotypes in combination with bacterial colonisation. We did not find an independent influence of bacterial colonisation and CD14/TLR polymorphisms on the development of asthma. Our findings further stress the importance to take environmental influences in genetic studies into account, which was also confirmed by our systematic review (chapter 3 ). In the literature several interactions between environmental exposures such as endotoxin exposure, farm milk consumption, tobacco smoke and air pollutant levels have been demonstrated as well for CD14 and TLRs in relationship to childhood asthma. ${ }^{39-41}$

In addition, we studied the role of regulatory T-cells ( $T_{\text {reg }}$ cells) at preschool age on the development of childhood asthma (chapter 4). $\mathrm{T}_{\text {reg }}$ cells are part of the adaptive immune response and are involved in the inflammatory response of the airways. ${ }^{62,63}$ We found no independent association between the proportion of $T_{\text {reg }}$ cells at preschool age and the development of asthma at the age of six years. However, we observed significant interactions between the proportion of $T_{\text {reg }}$ cells at preschool age and asthma development in the presence of certain genotypes in TLRS (TLR2 rs4696480 and TLR9 rs187084). For these genotypes a higher proportion of $\mathrm{T}_{\text {reg }}$ cells at preschool age was associated with an increased asthma risk at six years of age. One might expect a lower proportion of $\mathrm{T}_{\text {reg }}$ cells in children with an increased asthma risk due to an inadequate immune response in these children. However, we only measured the proportion and not the functionality of $\mathrm{T}_{\text {reg }}$ cells. In the literature both a quantitative and functional impairment of $\mathrm{T}_{\text {reg }}$ cells have been demonstrated in children with asthma compared to healthy controls, although the number of studies is limited. ${ }^{63,64}$ However, these studies were performed in older children, which might explain differences in results. Moreover, as $\mathrm{T}_{\text {reg }}$ cells exert a coordinating function in the immune system, multiple other (unknown) factors can influence the relationship between $T_{\text {reg }}$ cells and childhood asthma and determine the direction of the association. Furthermore, the increased asthma risk in the presence of a higher proportion of $\mathrm{T}_{\text {reg }}$ cells was only observed in certain genetic variants compared to the wild type alleles. Thus, the association of proportion of $\mathrm{T}_{\text {reg }}$ cells with asthma development is genotype dependent.

We hypothesise that the combination of genetic predisposition and bacterial exposure at preschool age leads to an altered immune response, as demonstrated by $T_{\text {reg }}$ cell 
response, which in turn leads to the development of asthma at six years of age. This conclusion fits the concept of the hypothesis of the defective epithelial barrier function and stresses the importance of studying genetic and environmental stimuli simultaneously. Furthermore, these findings imply that asthma prevention strategies should be more personalised by taking genotype into account to be successful. Indeed, a general preventive measures intervention study did not appear to be very successful at six years of age. ${ }^{65}$

\section{Diagnosing childhood asthma at preschool age}

\subsection{Diagnosis based on symptoms}

At preschool age, a diagnosis of asthma is challenging due to a large overlap in symptoms and the inability of preschool children to perform lung function tests. ${ }^{1,2}$ Currently, the gold standard for an asthma diagnosis is based on symptoms and lung function at the age of six years and over. In (inter)national guidelines on asthma, an ICS trial in young children with asthmatic symptoms is advocated ${ }^{1}$ and the symptom response to this ICS treatment at preschool age is advocated as a diagnostic instrument for asthma. ${ }^{10}$ We were not able to demonstrate differences in response to ICS at preschool age between asthmatics and transient wheezers (chapter 7), although the generally low levels of symptoms may have contributed to this result. Nevertheless, symptoms at baseline (two-four years of age) were significantly higher in asthmatic children compared to children with transient wheeze classified at age six.

Multiple well-known symptomatic risk factors for asthma development have been identified such as eczema, a family history of asthma and allergies. Based on these easily obtainable clinical variables, several clinical prediction models have been developed to aid in an early asthma diagnosis. ${ }^{10}$ Externally validated prediction rules are The Asthma Predictive Index (API), the cumulative risk score of the Isle of Wight birth cohort and the Prevention and Incidence of Asthma and Mite Allergy (PIAMA) risk score. ${ }^{66-71}$ Although these prediction rules have been developed as a diagnostic tool, their prediction is modest due to a low positive predictive value and sensitivity and improvement is warranted. ${ }^{10}$ To improve asthma prediction rules, several adaptations have been proposed; 1 ) a more precise definition of risk factors, 2) the addition of environmental exposures, 3) a more precise phenotyping of asthma, 4) a combination with non-invasive objective measurements and 5) a better characterisation of the genetic risk. ${ }^{10}$ 


\subsection{Diagnosis based on Fractional exhaled Nitric Oxide}

Fractional exhaled Nitric Oxide (FeNO) has been demonstrated to be a marker of allergic status. ${ }^{72}$ As ICS predominantly demonstrate an anti-eosinophilic inflammation effect, ${ }^{1,3,73}$ changes in FeNO based on ICS response are conceivable to have diagnostic value in asthma. We have examined this response for FeNO and found no differences in ICS response based on FeNO between children with transient wheeze and asthma (chapter 7). However, only a limited part of the children in our study has an allergic status. Furthermore, the use of off-line measurements might have influenced our results as well. In the literature the effectiveness of an ICS response by FeNO shows conflicting results. ${ }^{74-76}$ This indicates that changes in FeNO induced by ICS response have a limited diagnostic value for childhood asthma.

\subsection{Diagnosis based on Exhaled Breath Condensate}

A non-invasive objective measurement that might be used in asthma prediction is the assessment of inflammation markers in EBC. As these markers reflect the inflammation in the lungs and airway inflammation is a central feature in asthma, they can be expected to provide additional information for a reliable asthma diagnosis. ${ }^{77,78}$

In our cohort differences in inflammation markers in EBC were present between healthy children and children with wheeze at preschool age. ${ }^{79}$ When these children were followed till the age of six and classified as healthy, transient wheezer or asthma, differences in several interleukins and ICAM1 at preschool age were demonstrated as well, with the highest levels in asthmatics (chapter 5). During our ICS trial of children with recurrent wheeze at preschool age, inflammation markers in EBC were assessed before and after eight weeks of ICS administration (chapter 7). Unfortunately, absolute levels or changes in inflammation markers in EBC based on ICS response at preschool age did not demonstrate differences between asthmatics and children with transient wheeze and therefore was not able to predict a diagnosis at six years.

From a research point of view it is interesting to assess whether a biomarker has a predictive probability for a certain disease. However, from a clinical point of view it is more interesting to assess whether a biomarker has additional value to easy obtainable clinical parameters, as was also a suggested improvement for asthma prediction rules. ${ }^{10}$ Therefore we assessed (chapter 10 ) whether inflammation markers in EBC at preschool age in children with recurrent wheeze were of additional value to the API (eczema, allergic rhinitis, wheezing apart from colds, atopy and parental asthma). ${ }^{67}$ We were unable to demonstrated an increase in Area Under the Curve (AUC) in asthma diagnosis by adding information on inflammation markers in $\mathrm{EBC}$ and $\mathrm{EBC} \mathrm{pH}$ to the API.

In line with our findings, several studies have observed increased levels of exhaled inflammation markers in asthmatics compared to healthy children. ${ }^{25,80-82}$ However, 
children with transient wheeze were not included in these studies. No literature is provided regarding the assessment of differences in inflammation markers in EBC in response to ICS treatment in children with recurrent wheeze. Although the response to ICS by inflammation markers in EBC in children has not proven to be helpful in diagnosing asthma in our study, in adult populations EBC markers have been demonstrated to change by ICS treatment. ${ }^{83,84}$ One study has assessed the addition of information on $\mathrm{pH}$ of EBC to the API. In contradiction with our findings, adding $\mathrm{pH}$ to the API substantially improved asthma prediction, indicating its usefulness in clinical practice. $^{85}$

In conclusion, not enough data are currently available to conclude whether EBC is useful in a reliable asthma diagnosis based on the current measured inflammation markers. Furthermore the data available are conflicting. Before a definitive conclusion can be drawn, it is necessary to improve the collection methods and assays of EBC. ${ }^{86}$ This improvement can enhance the comparability between the studies. Promising techniques are the Nuclear Magnetic Resonance spectroscopy and proteomics of EBC, which may reveal new biomarkers. ${ }^{87,88}$

\subsection{Diagnosis based on Volatile Organic Compounds}

VOCs are formed during several (patho)physiological processes and are increasingly studied to diagnose disease. ${ }^{89-91}$ In our cohort we observed differences in VOCs between healthy children and children with recurrent wheeze at preschool age. ${ }^{92}$ When these children reached the age of six and were divided in healthy children, children with transient wheeze and children with asthma, a limited number of compounds at preschool age presented differences between the groups (chapter 8). Moreover, distinction between children with transient wheeze and asthma at preschool age was possible based on 17 VOCs, with an overall correct classification rate of $80 \%$. The discriminating components included mostly hydrocarbons and longchain alkanes, which are created during oxidative stress in airway inflammation. ${ }^{89,90}$ The next step in assessing the relevance of VOCs in clinical practice was to consider the additional value of VOCs to the API in diagnosing asthma at preschool age (chapter 10). From the 17 identified VOCs in association with distinction between transient wheeze and asthma, a selection of nine VOCs improved a correct classification to the API with $28 \%$ (AUC:0.89, sensitivity/specificity $84 / 82 \%$ ). This improvement in a correct classification was confirmed by the external validation, which implicates the generalisability of our results. Furthermore, combination of the nine selected VOCs, information on expression of inflammation genes (TLR4, catalase (CAT) and TNF $\alpha$ ) and the API score had an AUC of 0.95 (sensitivity/specificity 89/90\%). This indicates that VOCs and expression of inflammation genes have an additional value not only to clinical variables, but also to each other in diagnosing asthma at preschool age. 
Several studies have been successful in demonstrating differences in VOCs between healthy children and children with asthma. ${ }^{93-95}$ Mostly, hydrocarbons and long-chain alkanes have been associated with asthma. ${ }^{93-95=97}$ No studies so far addressed the additional performance of VOCs to the API.

As a result of the positive findings of previous studies and our study, VOCs are a promising technique in asthma diagnosis. This is even further stressed by the safe, non-invasive and easy to perform sampling and the sensitive techniques to detect compounds. $^{91}$ Our study has made an important step to introduce the analysis of VOCs into the clinical practice of childhood asthma by assessing the predictive value of VOCs in addition to clinical variables. However, before implementation is possible, additional studies need to determine the most relevant cut-off value based on the positive-predictive value and the negative-predictive value of VOCs. Furthermore, standardisation of procedures and influences of potential confounders are some issues that deserve further study. ${ }^{91}$

\subsection{Diagnosis based on expression of inflammation genes}

The analysis of gene expression has gained attention during the last few years in asthma research. In the literature gene expression of several genes have displayed association with asthma and also wheeze in comparison to healthy children. ${ }^{98-100}$ These observations make the assessment of gene expression an interesting candidate in asthma diagnostics, although the number of studies is limited. As the positive predictive value of a single gene test for a complex disease, such as asthma, is limited, the combination of several genes is expected to lead to a better prediction. ${ }^{15}$

It is generally known that asthma in the family is a risk factor for the development of childhood asthma. ${ }^{101}$ In addition, biomarkers, such as expression of inflammation genes, are expected to improve asthma prediction. ${ }^{10}$ We examined whether information on expression of inflammation genes at preschool age aids in the prediction of asthma at age six in addition to a family history of asthma (chapter 9). When information on the most predictive measured gene expression markers (TLR4, CAT and TNF $\alpha$ ) was added to a family history, the asthma classification improved (AUC: $0.73,16 \%$ increase compared to the model with family history alone), indicating an additional value of information on the expression of these genes to a family history of asthma. Thus, if confirmed in a replication study, information on expression of inflammation genes may improve an early differentiation between children with transient wheeze and asthma. Early differentiation is beneficially for quality of life of parents and children and health care costs.

Furthermore, we illustrated that information on gene expression of TLR4, CAT and TNF $\alpha$ at preschool age was significantly associated with a more accurate asthma prediction (chapter 10) in addition to the API (AUC:0.75, sensitivity/specificity $71 / 77 \%$, increase of $17 \%$ compared to the model with the API index alone). However, this 
result could not be confirmed in external validation. As previously stated, the combination of VOCs, information on expression of inflammation genes and the API score had additional value in diagnosing asthma at preschool age.

Previously, material for gene expression was mostly collected by venous puncture. However, recently assessment of gene expression in saliva has come in use, making it a non-invasive technique suitable for young children. Moreover, RNA expression arrays make it possible to assess the whole gene expression profile, possible leading to an even more precise asthma prediction at preschool age. Therefore, expression of inflammation genes is a very promising technique in assisting in a reliable asthma diagnosis at preschool age. However, as was the case for VOCs, additional studies need to validate our results and determine the most relevant cut-off value based on the positive-predictive value and the negative-predictive value, especially as this study is the first one of its kind.

\subsection{Diagnosis based on early lung function}

The standard forced expiratory manoeuvres for asthma at preschool age are not possible in preschool children. Several alternatives have been developed to give an impression of the lung status at this young age, such as the interrupter technique (microRint), impulse oscillation and forced oscillation technique which are performed during tidal breathing. ${ }^{102-104}$ The gold standard for an asthma diagnosis is the assessment of symptoms and lung function. Therefore, information on lung function at preschool age is expected to improve an accurate asthma diagnosis.

In our cohort, we demonstrated that Rint values assessed at preschool age were slightly elevated in children with persistent wheeze compared to healthy children and children with transient symptoms at school age. ${ }^{105}$ The response in Rint as a consequence of ICS treatment at preschool age did not demonstrate differences between children with asthma and transient wheeze (chapter 7). We assessed the incremental performance to the API of Rint assessment at preschool age in the asthma prediction at the age of six (chapter 10), but found that airway resistance was not able to improve differentiation in addition to the API.

Some studies have demonstrated increased airway resistance in children with persistent wheezing symptoms compared to children with transient wheeze at school age. ${ }^{106,107}$ Another study demonstrated that Rint assessed at age four was associated with wheezing at age six, however, these differences did not sustain at the age of eight years. ${ }^{108}$ The bronchodilator reversibility was able to predict the effectiveness of anti-inflammatory therapy in young children with asthma in one study. ${ }^{74}$ Furthermore, Rint was of additional value to the API in one study. ${ }^{66}$ In conclusion, although differences in Rint values could be observed between wheezing phenotypes at school age, the predictive power of Rint for a reliable preschool asthma diagnosis is limited. 


\section{Future research perspectives}

During the last few decades much progress has been made in the research field of complex diseases such as asthma. Due to new technical developments that allowed us to retrieve a tremendous amount of data for relative low costs, it was expected that we would gain complete insight into the origin of asthma and asthma prevention within a few years. This induced an explosion of studies on asthma. However, the expected increase in insight was not achieved and large pieces of the puzzle are still missing.

\subsection{Endotyping childhood asthma}

During the last few years, it has become increasingly clear that asthma is not one disease, but a composition of several endotypes with distinct clinical features, different underlying pathological processes and different treatment responses. ${ }^{109-112}$ Thus, studying asthma as one disease does not value its complexity and, more importantly, its heterogeneity. ${ }^{36}$ Furthermore, identification of several endotypes leads to strong associations despite the loss of power due to smaller groups. ${ }^{113}$ Several studies have identified different asthma endotypes. ${ }^{36,113,114}$ For example, the quantitative assessment of recurrent episodes of troublesome lung function in children, which was associated with the genetic risk variant ORMDL3, was superior to the qualitative assessment of doctor-verified wheeze as well as division into children with transient, persistent and late onset symptoms. ${ }^{113}$ In an adult population, gene expression profiling resulted in three distinct transcriptional phenotypes of asthma that related to both clinical and inflammation parameters. ${ }^{114}$ In children, IgE antibody responses demonstrated to reflect several different atopic vulnerabilities which differ in their relation with asthma presence and severity. ${ }^{36}$ In conclusion, the application of endotyping of asthma can beneficially improve our insight into disease pathophysiology and improve treatment strategies.

\subsection{System biology}

To gain further insight into childhood asthma (development) a network-based approach can be used. ${ }^{115}$ This disease network can be used to identify new genes in the network-based vicinity, ${ }^{115-117}$ as has been demonstrated for asthma in a proteinprotein interaction network. ${ }^{118}$ In addition, it is possible to establish links between apparently distinct phenotypes, ${ }^{115,116}$ which increases our understanding why certain groups of diseases arise together. ${ }^{36,37}$ The use of machine learning techniques can identify latent structures within the data that may accurately reflect 'unbiased' endotypes and avoid constraints of investigator-imposed classifications. ${ }^{36}$ Several publications have demonstrated the usefulness of a clustering approach in multidi- 
mensional data to identify different asthma phenotypes. ${ }^{112,}{ }^{119-121}$ In addition, this approach takes full advantage of the data-intensive environment. ${ }^{36}$ Thus, implementation of system biology in asthma research aids in achieving a better insight in the asthma pathophysiology, which might induce new and improve old therapeutic options. $^{115,122}$ 


\section{References}

1. Pedersen SE, Hurd SS, Lemanske RF, Jr., Becker A, Zar HJ, Sly PD, et al. Global strategy for the diagnosis and management of asthma in children 5 years and younger. Pediatr Pulmonol 2011;46: 1-17.

2. Savenije OE, Granell R, Caudri D, Koppelman GH, Smit HA, Wijga A, et al. Comparison of childhood wheezing phenotypes in 2 birth cohorts: ALSPAC and PIAMA. J Allergy Clin Immunol 2011;127:150512 e14.

3. Schokker S, Kooi EM, de Vries TW, Brand PL, Mulder PG, Duiverman EJ, et al. Inhaled corticosteroids for recurrent respiratory symptoms in preschool children in general practice: randomized controlled trial. Pulm Pharmacol Ther 2008;21:88-97.

4. Malmstrom K, Pelkonen AS, Makela MJ. Remodeling, inflammation and airway responsiveness in early childhood asthma. Curr Opin Allergy Clin Immunol 2013;13:203-10.

5. Caudri D, Wijga AH, Smit HA, Koppelman GH, Kerkhof M, Hoekstra MO, et al. Asthma symptoms and medication in the PIAMA birth cohort: evidence for under and overtreatment. Pediatr Allergy Immunol 2011;22:652-9.

6. Stevens CA, Turner D, Kuehni CE, Couriel JM, Silverman M. The economic impact of preschool asthma and wheeze. Eur Respir J 2003;21:1000-6.

7. O'Connell EJ. The burden of atopy and asthma in children. Allergy 2004;59.

8. von Mutius E. The burden of childhood asthma. Arch Dis Child 2000;82.

9. van den Bemt L, Kooijman S, Linssen V, Lucassen P, Muris J, Slabbers G, et al. How does asthma influence the daily life of children? Results of focus group interviews. Health Qual Life Outcomes 2010;8:5.

10. Savenije OE, Kerkhof M, Koppelman GH, Postma DS. Predicting who will have asthma at school age among preschool children. J Allergy Clin Immunol 2012;130:325-31.

11. Wiener AS, Zieve I, Fries JH. The inheritance of allergic disease. Annals of Eugenics 1936;7:141-62.

12. Thomsen SF, van der Sluis S, Kyvik KO, Skytthe A, Skadhauge LR, Backer V. Increase in the heritability of asthma from 1994 to 2003 among adolescent twins. Respir Med 2011;105:1147-52.

13. Pinto LA, Stein RT, Kabesch M. Impact of genetics in childhood asthma. J Pediatr (Rio J) 2008;84: S68-75.

14. Hirschhorn JN. Genomewide association studies--illuminating biologic pathways. N Engl J Med 2009; 360:1699-701.

15. Koppelman GH, te Meerman GJ, Postma DS. Genetic testing for asthma. Eur Respir J 2008;32:775-82.

16. Rosenwasser LJ, Borish L. Genetics of atopy and asthma: the rationale behind promoter-based candidate gene studies (IL-4 and IL-10). Am J Respir Crit Care Med 1997;156:S152-5.

17. Koppelman GH, Nawijn MC. Recent advances in the epigenetics and genomics of asthma. Curr Opin Allergy Clin Immunol 2011;11:414-9.

18. Li YF, Tsao YH, Gauderman WJ, Conti DV, Avol E, Dubeau L, et al. Intercellular adhesion molecule-1 and childhood asthma. Hum Genet 2005;117:476-84.

19. Tang ML, Fiscus LC. Important roles for L-selectin and ICAM-1 in the development of allergic airway inflammation in asthma. Pulm Pharmacol Ther 2001;14:203-10.

20. Robledo O, Papaioannou A, Ochietti B, Beauchemin C, Legault D, Cantin A, et al. ICAM-1 isoforms: specific activity and sensitivity to cleavage by leukocyte elastase and cathepsin G. Eur J Immunol 2003;33:1351-60.

21. Iwao M, Morisaki H, Morisaki T. Single-nucleotide polymorphism g.1548G > A (E469K) in human ICAM-1 gene affects mRNA splicing pattern and TPA-induced apoptosis. Biochem Biophys Res Commun 2004;317:729-35.

22. Casasnovas JM, Stehle T, Liu JH, Wang JH, Springer TA. A dimeric crystal structure for the N-terminal two domains of intercellular adhesion molecule-1. Proc Natl Acad Sci U S A 1998;95:4134-9.

23. Bella J, Kolatkar PR, Marlor CW, Greve JM, Rossmann MG. The structure of the two amino-terminal domains of human ICAM-1 suggests how it functions as a rhinovirus receptor and as an LFA-1 integrin ligand. Proc Natl Acad Sci USA 1998;95:4140-5. 
24. Tang RB, Chen SJ, Soong WJ, Chung RL. Circulating adhesion molecules in sera of asthmatic children. Pediatr Pulmonol 2002;33:249-54.

25. Robroeks CM, Rijkers GT, Jöbsis Q, Hendriks HJ, Damoiseaux JG, Zimmermann LJ, et al. Increased cytokines, chemokines and soluble adhesion molecules in exhaled breath condensate of asthmatic children. Clin Exp Allergy 2010;40:77-84.

26. Rosias PP, Robroeks CM, van de Kant KD, Rijkers GT, Zimmermann LJ, van Schayck CP, et al. Feasibility of a new method to collect exhaled breath condensate in pre-school children. Pediatr Allergy Immunol 2010;21:e235-44.

27. Pinto LA, Stein RT, Ribeiro JD. Genetic associations with asthma and virus-induced wheezing: a systematic review. J Bras Pneumol 2009;35:1220-6.

28. Kummeling I, Thijs C, Penders J, Snijders BE, Stelma F, Reimerink J, et al. Etiology of atopy in infancy: the KOALA Birth Cohort Study. Pediatr Allergy Immunol 2005;16:679-84.

29. Simpson A, Maniatis N, Jury F, Cakebread JA, Lowe LA, Holgate ST, et al. Polymorphisms in a disintegrin and metalloprotease 33 (ADAM33) predict impaired early-life lung function. Am J Respir Crit Care Med 2005;172:55-60.

30. Van Eerdewegh P, Little RD, Dupuis J, Del Mastro RG, Falls K, Simon J, et al. Association of the ADAM33 gene with asthma and bronchial hyperresponsiveness. Nature 2002;418:426-30.

31. Reijmerink NE, Kerkhof M, Koppelman GH, Gerritsen J, de Jongste JC, Smit HA, et al. Smoke exposure interacts with ADAM33 polymorphisms in the development of lung function and hyperresponsiveness. Allergy 2009;64:898-904.

32. Raby BA, Silverman EK, Kwiatkowski DJ, Lange C, Lazarus R, Weiss ST. ADAM33 polymorphisms and phenotype associations in childhood asthma. J Allergy Clin Immunol 2004;113:1071-8.

33. Postma DS, Howard T. ADAM33 gene: confirming a gene without linkage. Clin Exp Allergy 2004;34: 1-3.

34. Murk W, Walsh K, Hsu LI, Zhao L, Bracken MB, Dewan AT. Attempted replication of 50 reported asthma risk genes identifies a SNP in RAD50 as associated with childhood atopic asthma. Hum Hered 2011;71:97-105.

35. Vercelli D. Gene-environment interactions: the road less traveled by in asthma genetics. J Allergy Clin Immunol 2009;123:26-7.

36. Simpson A, Tan VY, Winn J, Svensen M, Bishop CM, Heckerman DE, et al. Beyond atopy: multiple patterns of sensitization in relation to asthma in a birth cohort study. Am J Respir Crit Care Med 2010; 181:1200-6.

37. Puthothu B, Heinzmann A. Is toll-like receptor 6 or toll-like receptor 10 involved in asthma genetics-or both? Allergy 2006;61:649-50.

38. Heinzmann A, Brugger M, Bierbaum S, Mailaparambil B, Kopp MV, Strauch K. Joint influences of Acidic-Mammalian-Chitinase with Interleukin-4 and Toll-like receptor-10 with Interleukin-13 in the genetics of asthma. Pediatr Allergy Immunol 2010;21:e679-86.

39. Bieli C, Eder W, Frei R, Braun-Fahrlander C, Klimecki W, Waser M, et al. A polymorphism in CD14 modifies the effect of farm milk consumption on allergic diseases and CD14 gene expression. J Allergy Clin Immunol 2007;120:1308-15.

40. Choudhry S, Avila PC, Nazario S, Ung N, Kho J, Rodriguez-Santana JR, et al. CD14 tobacco geneenvironment interaction modifies asthma severity and immunoglobulin $E$ levels in Latinos with asthma. Am J Respir Crit Care Med 2005;172:173-82.

41. Simpson A, John SL, Jury F, Niven R, Woodcock A, Ollier WE, et al. Endotoxin exposure, CD14, and allergic disease: an interaction between genes and the environment. Am J Respir Crit Care Med 2006; 174:386-92.

42. Rigoli L, Briuglia S, Caimmi S, Ferrau V, Gallizzi R, Leonardi S, et al. Gene-environment interaction in childhood asthma. Int J Immunopathol Pharmacol 2011;24:41-7.

43. Strachan DP. Hay fever, hygiene, and household size. BMJ 1989;299:1259-60.

44. Schaub B, Lauener R, von Mutius E. The many faces of the hygiene hypothesis. J Allergy Clin Immunol 2006;117:969-77.

45. Manning PJ, Goodman P, O'Sullivan A, Clancy L. Rising prevalence of asthma but declining wheeze in teenagers (1995-2003): ISAAC protocol. Ir Med J 2007;100:614-5. 
46. Beasley R, Crane J, Lai CK, Pearce N. Prevalence and etiology of asthma. J Allergy Clin Immunol 2000; 105:S466-72.

47. Britton J. Parasites, allergy, and asthma. Am J Respir Crit Care Med 2003;168:266-7.

48. Bjorksten B. The hygiene hypothesis: do we still believe in it? Nestle Nutr Workshop Ser Pediatr Program 2009;64:11-8; discussion 8-22, 251-7.

49. Bisgaard H, Hermansen MN, Buchvald F, Loland L, Halkjaer LB, Bonnelykke K, et al. Childhood asthma after bacterial colonization of the airway in neonates. N Engl J Med 2007;357:1487-95.

50. Hauk PJ, Krawiec M, Murphy J, Boguniewicz J, Schiltz A, Goleva E, et al. Neutrophilic airway inflammation and association with bacterial lipopolysaccharide in children with asthma and wheezing. Pediatr Pulmonol 2008;43:916-23.

51. Holgate ST. The sentinel role of the airway epithelium in asthma pathogenesis. Immunol Rev 2011; 242:205-19.

52. Schroder NW, Crother TR, Naiki Y, Chen S, Wong MH, Yilmaz A, et al. Innate immune responses during respiratory tract infection with a bacterial pathogen induce allergic airway sensitization. J Allergy Clin Immunol 2008;122:595-602 e5.

53. Sordillo JE, Hoffman EB, Celedon JC, Litonjua AA, Milton DK, Gold DR. Multiple microbial exposures in the home may protect against asthma or allergy in childhood. Clin Exp Allergy 2010;40:902-10.

54. von Mutius E. Of attraction and rejection--asthma and the microbial world. N Engl J Med 2007; 357:1545-7.

55. Brar T, Nagaraj S, Mohapatra S. Microbes and asthma: the missing cellular and molecular links. Curr Opin Pulm Med 2012;18:14-22.

56. Cook DN, Pisetsky DS, Schwartz DA. Toll-like receptors in the pathogenesis of human disease. Nat Immunol 2004;5:975-9.

57. Imler JL, Hoffmann JA. Toll receptors in innate immunity. Trends Cell Biol 2001;11:304-11.

58. Martin AC, Laing IA, Khoo SK, Zhang G, Rueter K, Teoh L, et al. Acute asthma in children: Relationships among CD14 and CC16 genotypes, plasma levels, and severity. Am J Respir Crit Care Med 2006; 173:617-22.

59. Tremblay K, Daley D, Chamberland A, Lemire M, Montpetit A, Laviolette $M$, et al. Genetic variation in immune signaling genes differentially expressed in asthmatic lung tissues. J Allergy Clin Immunol 2008;122:529-36 e17.

60. Moller-Larsen S, Nyegaard M, Haagerup A, Vestbo J, Kruse TA, Borglum AD. Association analysis identifies TLR7 and TLR8 as novel risk genes in asthma and related disorders. Thorax 2008;63:1064-9.

61. Kormann MS, Depner M, Hartl D, Klopp N, Illig T, Adamski J, et al. Toll-like receptor heterodimer variants protect from childhood asthma. J Allergy Clin Immunol 2008;122:86-92.

62. Strickland DH, Holt PG. T regulatory cells in childhood asthma. Trends Immunol 2011;32:420-7.

63. Hartl D, Koller B, Mehlhorn AT, Reinhardt D, Nicolai T, Schendel DJ, et al. Quantitative and functional impairment of pulmonary CD4+CD25hi regulatory $\mathrm{T}$ cells in pediatric asthma. J Allergy Clin Immunol 2007;119:1258-66.

64. Yamamoto Y, Negoro T, Hoshi A, Wakagi A, Shimizu S, Banham AH, et al. Impaired Ca(2)(+) regulation of $\mathrm{CD} 4(+) C D 25(+)$ regulatory $T$ cells from pediatric asthma. Int Arch Allergy Immunol 2011;156: 148-58.

65. Maas T, Dompeling E, Muris JW, Wesseling G, Knottnerus JA, van Schayck OC. Prevention of asthma in genetically susceptible children: a multifaceted intervention trial focussed on feasibility in general practice. Pediatr Allergy Immunol 2011;22:794-802.

66. Caudri D, Wijga A, CM AS, Hoekstra M, Postma DS, Koppelman GH, et al. Predicting the long-term prognosis of children with symptoms suggestive of asthma at preschool age. J Allergy Clin Immunol 2009;124:903-10.

67. Castro-Rodriguez JA, Holberg CJ, Wright AL, Martinez FD. A clinical index to define risk of asthma in young children with recurrent wheezing. Am J Respir Crit Care Med 2000;162:1403-6.

68. Kurukulaaratchy RJ, Matthews S, Holgate ST, Arshad SH. Predicting persistent disease among children who wheeze during early life. Eur Respir J 2003;22:767-71. 
69. Leonardi NA, Spycher BD, Strippoli MP, Frey U, Silverman M, Kuehni CE. Validation of the Asthma Predictive Index and comparison with simpler clinical prediction rules. J Allergy Clin Immunol 2011; 127:1466-72.

70. Matricardi PM, Illi S, Keil T, Wagner P, Wahn U, Lau S. Predicting persistence of wheezing: one algorithm does not fit all. Eur Respir J 2010;35:701-3.

71. Rodriguez-Martinez CE, Sossa-Briceno MP, Castro-Rodriguez JA. Discriminative properties of two predictive indices for asthma diagnosis in a sample of preschoolers with recurrent wheezing. Pediatr Pulmonol 2011;46:1175-81.

72. Scott M, Raza A, Karmaus W, Mitchell F, Grundy J, Kurukulaaratchy RJ, et al. Influence of atopy and asthma on exhaled nitric oxide in an unselected birth cohort study. Thorax 2010;65:258-62.

73. Cowan DC, Cowan JO, Palmay R, Williamson A, Taylor DR. Effects of steroid therapy on inflammatory cell subtypes in asthma. Thorax 2010;65:384-90.

74. Zielen S, Christmann M, Kloska M, Dogan-Yildiz G, Lieb A, Rosewich M, et al. Predicting short term response to anti-inflammatory therapy in young children with asthma. Curr Med Res Opin 2010; 26:483-92.

75. Zacharasiewicz A, Wilson N, Lex C, Erin EM, Li AM, Hansel T, et al. Clinical use of noninvasive measurements of airway inflammation in steroid reduction in children. Am J Respir Crit Care Med 2005;171:1077-82.

76. Pijnenburg MW, Bakker EM, Hop WC, De Jongste JC. Titrating steroids on exhaled nitric oxide in children with asthma: a randomized controlled trial. Am J Respir Crit Care Med 2005;172:831-6.

77. Hunt J. Exhaled breath condensate: an evolving tool for noninvasive evaluation of lung disease. J Allergy Clin Immunol 2002;110:28-34.

78. Effros RM, Hoagland KW, Bosbous M, Castillo D, Foss B, Dunning $M$, et al. Dilution of respiratory solutes in exhaled condensates. Am J Respir Crit Care Med 2002;165:663-9.

79. van de Kant KD, Klaassen EM, Jöbsis Q, Koers K, Rijkers GT, van der Grinten CP, et al. Wheezing in preschool children is associated with increased levels of cytokines/chemokines in exhaled breath condensate. J Allergy Clin Immunol 2010;126:669-71.

80. Brunetti L, Francavilla R, Tesse R, Fiermonte P, Fiore FP, Lore M, et al. Exhaled breath condensate cytokines and $\mathrm{pH}$ in pediatric asthma and atopic dermatitis. Allergy Asthma Proc 2008;29:461-7.

81. Carraro S, Rezzi S, Reniero F, Heberger K, Giordano G, Zanconato S, et al. Metabolomics applied to exhaled breath condensate in childhood asthma. Am J Respir Crit Care Med 2007;175:986-90.

82. Bloemen K, Van Den Heuvel R, Govarts E, Hooyberghs J, Nelen V, Witters E, et al. A new approach to study exhaled proteins as potential biomarkers for asthma. Clin Exp Allergy 2011;41:346-56.

83. Carpagnano GE, Foschino Barbaro MP, Resta O, Gramiccioni E, Valerio NV, Bracciale P, et al. Exhaled markers in the monitoring of airways inflammation and its response to steroid's treatment in mild persistent asthma. Eur J Pharmacol 2005;519:175-81.

84. Matsunaga K, Ichikawa T, Yanagisawa S, Akamatsu K, Koarai A, Hirano T, et al. Clinical application of exhaled breath condensate analysis in asthma: prediction of FEV1 improvement by steroid therapy. Respiration 2009;78:393-8.

85. von Jagwitz M, Pessler F, Akmatov M, Li J, Range U, Vogelberg C. Reduced breath condensate $\mathrm{pH}$ in asymptomatic children with prior wheezing as a risk factor for asthma. J Allergy Clin Immunol 2011; 128:50-5.

86. Horvath I, Hunt J, Barnes PJ, Alving K, Antczak A, Baraldi E, et al. Exhaled breath condensate: methodological recommendations and unresolved questions. Eur Respir J 2005;26:523-48.

87. Lin JL, Bonnichsen MH, Nogeh EU, Raftery MJ, Thomas PS. Proteomics in detection and monitoring of asthma and smoking-related lung diseases. Expert Rev Proteomics 2010;7:361-72.

88. Sofia M, Maniscalco M, de Laurentiis G, Paris D, Melck D, Motta A. Exploring airway diseases by NMRbased metabonomics: a review of application to exhaled breath condensate. J Biomed Biotechnol 2011;2011:403260.

89. Buszewski B, Kesy M, Ligor T, Amann A. Human exhaled air analytics: biomarkers of diseases. Biomed Chromatogr 2007;21:553-66.

90. Miekisch W, Schubert JK, Noeldge-Schomburg GF. Diagnostic potential of breath analysis--focus on volatile organic compounds. Clin Chim Acta 2004;347:25-39. 
91. van de Kant KD, van der Sande $L$, Jöbsis Q, van Schayck OC, Dompeling E. Clinical use of exhaled volatile organic compounds in pulmonary diseases: a systematic review. Respir Res 2012;13:117.

92. van de Kant KD, van Berkel JJ, Jöbsis Q, Lima Passos V, Klaassen EM, van der Sande L, et al. Exhaled breath profiling in diagnosing wheezy preschool children. Eur Respir J 2013;41:183-8.

93. Dallinga JW, Robroeks CM, van Berkel JJ, Moonen EJ, Godschalk RW, Jöbsis Q, et al. Volatile organic compounds in exhaled breath as a diagnostic tool for asthma in children. Clin Exp Allergy 2010;40: 68-76.

94. Caldeira M, Barros AS, Bilelo MJ, Parada A, Camara JS, Rocha SM. Profiling allergic asthma volatile metabolic patterns using a headspace-solid phase microextraction/gas chromatography based methodology. J Chromatogr A 2011;1218:3771-80.

95. Caldeira M, Perestrelo R, Barros AS, Bilelo MJ, Morete A, Camara JS, et al. Allergic asthma exhaled breath metabolome: a challenge for comprehensive two-dimensional gas chromatography. J Chromatogr A 2012;1254:87-97.

96. Kneepkens CM, Lepage G, Roy CC. The potential of the hydrocarbon breath test as a measure of lipid peroxidation. Free Radic Biol Med 1994;17:127-60.

97. Ibrahim B, Basanta M, Cadden P, Singh D, Douce D, Woodcock A, et al. Non-invasive phenotyping using exhaled volatile organic compounds in asthma. Thorax 2011;66:804-9.

98. Cai X, Yang YC, Wang JF, Wang Q, Gao J, Fu WL, et al. Transient Receptor Potential Vanilloid 2 (TRPV2), a Potential Novel Biomarker in Childhood Asthma. J Asthma 2013;50:209-14.

99. Jin R, Xu HG, Yuan WX, Zhuang LL, Liu LF, Jiang L, et al. Mechanisms elevating ORMDL3 expression in recurrent wheeze patients: role of Ets-1, p300 and CREB. Int J Biochem Cell Biol 2012;44:1174-83.

100. Kovacic MB, Myers JM, Wang N, Martin LJ, Lindsey M, Ericksen MB, et al. Identification of KIF3A as a novel candidate gene for childhood asthma using RNA expression and population allelic frequencies differences. PLoS One 2011;6.

101. Burke W, Fesinmeyer M, Reed K, Hampson L, Carlsten C. Family history as a predictor of asthma risk. Am J Prev Med 2003;24:160-9.

102. Merkus PJ, Arets HG, Joosten T, Siero A, Brouha M, Mijnsbergen JY, et al. Measurements of interrupter resistance: reference values for children 3-13 yrs of age. Eur Respir J 2002;20:907-11.

103. Nielsen KG, Bisgaard $H$. Discriminative capacity of bronchodilator response measured with three different lung function techniques in asthmatic and healthy children aged 2 to 5 years. Am J Respir Crit Care Med 2001;164:554-9.

104. Bridge PD, Ranganathan S, McKenzie SA. Measurement of airway resistance using the interrupter technique in preschool children in the ambulatory setting. Eur Respir J 1999;13:792-6.

105. van de Kant KD, Jansen MA, Klaassen EM, van der Grinten CP, Rijkers GT, Muris JW, et al. Elevated inflammatory markers at preschool age precede persistent wheezing at school age. Pediatr Allergy Immunol 2012;23:259-64.

106. Brussee JE, Smit HA, Koopman LP, Wijga AH, Kerkhof M, Corver K, et al. Interrupter resistance and wheezing phenotypes at 4 years of age. Am J Respir Crit Care Med 2004;169:209-13.

107. Oostveen E, Dom S, Desager K, Hagendorens M, De Backer W, Weyler J. Lung function and bronchodilator response in 4-year-old children with different wheezing phenotypes. Eur Respir J 2010;35:865-72.

108. Caudri D, Wijga AH, Hoekstra MO, Kerkhof M, Koppelman GH, Brunekreef B, et al. Prediction of asthma in symptomatic preschool children using exhaled nitric oxide, Rint and specific IgE. Thorax 2010;65:801-7.

109. Anderson GP. Endotyping asthma: new insights into key pathogenic mechanisms in a complex, heterogeneous disease. Lancet 2008;372:1107-19.

110. Schultz A, Brand PL. Phenotype-directed treatment of pre-school-aged children with recurrent wheeze. J Paediatr Child Health 2012;48:E73-8.

111. Wenzel SE. Asthma: defining of the persistent adult phenotypes. Lancet 2006;368:804-13.

112. Smith JA, Drake R, Simpson A, Woodcock A, Pickles A, Custovic A. Dimensions of respiratory symptoms in preschool children: population-based birth cohort study. Am J Respir Crit Care Med 2008;177:1358-63. 
113. Bisgaard H, Pipper CB, Bonnelykke K. Endotyping early childhood asthma by quantitative symptom assessment. J Allergy Clin Immunol 2011;127:1155-64 e2.

114. Baines KJ, Simpson JL, Wood LG, Scott RJ, Gibson PG. Transcriptional phenotypes of asthma defined by gene expression profiling of induced sputum samples. J Allergy Clin Immunol 2011;127:153-60, 60 e1-9.

115. Barabasi AL, Gulbahce N, Loscalzo J. Network medicine: a network-based approach to human disease. Nat Rev Genet 2011;12:56-68.

116. Goh KI, Cusick ME, Valle D, Childs B, Vidal M, Barabasi AL. The human disease network. Proc Natl Acad Sci U S A 2007;104:8685-90.

117. Oti M, Snel B, Huynen MA, Brunner HG. Predicting disease genes using protein-protein interactions. J Med Genet 2006;43:691-8.

118. Hwang S, Son SW, Kim SC, Kim YJ, Jeong H, Lee D. A protein interaction network associated with asthma. The Journal of Theoretical Biology 2008;252:722-31.

119. Haldar P, Pavord ID, Shaw DE, Berry MA, Thomas M, Brightling CE, et al. Cluster analysis and clinical asthma phenotypes. Am J Respir Crit Care Med 2008;178:218-24.

120. Henderson J, Granell R, Heron J, Sherriff A, Simpson A, Woodcock A, et al. Associations of wheezing phenotypes in the first 6 years of life with atopy, lung function and airway responsiveness in midchildhood. Thorax 2008;63:974-80.

121. Moore WC, Meyers DA, Wenzel SE, Teague WG, Li H, Li X, et al. Identification of asthma phenotypes using cluster analysis in the Severe Asthma Research Program. Am J Respir Crit Care Med 2010; 181:315-23.

122. Zanzoni A, Soler-Lopez M, Aloy P. A network medicine approach to human disease. FEBS Lett 2009; 583:1759-65. 


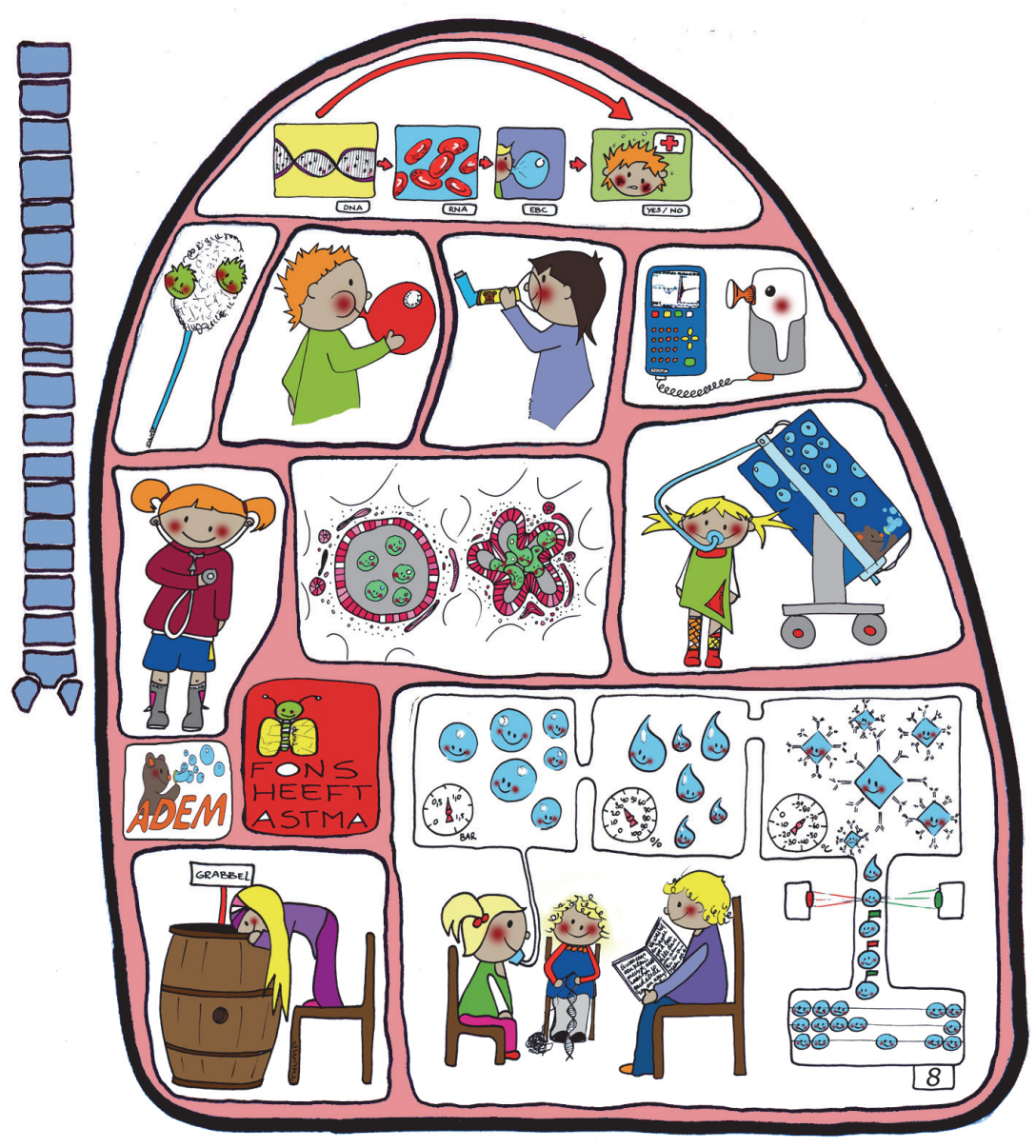


Summary 


\section{Summary}

In this dissertation the genetic background, influences of bacterial colonisation and regulatory $T\left(T_{\text {reg }}\right)$ cells in the aetiology of childhood asthma in preschool children was evaluated. Furthermore, the value of exhaled inflammatory markers, expression of inflammation genes, early lung function measurements and response to treatment in the diagnosis of asthma in preschool children was evaluated.

In chapter 1 the clinical challenges in childhood asthma were introduced. Although asthma is the most common chronic disease in childhood, an asthma diagnosis at preschool age remains difficult. Consequently, physicians face a daily dilemma how to manage preschool children with respiratory symptoms. There is a need for a reliable diagnostic tool that can differentiate between children that will develop asthma and children with transient symptoms at preschool age. Possible diagnostic candidates are the assessment of (exhaled) inflammation markers and lung function. In addition to the diagnostic problems, the underlying pathophysiology of childhood asthma is still largely unknown. Insight into the pathophysiology of childhood asthma might identify children with an enhanced risk. The pathophysiology of childhood asthma can be studied by addressing genetic predisposition and environmental influences. If children with an enhanced risk are identified, preventive measures might be applied to avoid asthma development.

The research described in this dissertation is conducted within the context of the Asthma DEtection and Monitoring (ADEM) study. In chapter 2 the study protocol of the ADEM study is discussed. The ADEM study is a prospective study that started in 2006 in Maastricht, the Netherlands. In this study, 202 children with recurrent wheezing symptoms and 50 control subjects with no wheezing symptoms were included at the age of two to four years and were studied prospectively until six years of age. The primary objective of the ADEM study is to early diagnose asthma by using biomarkers of airway inflammation and oxidative stress in exhaled breath (condensate) and early lung function measurements. Moreover, possible aetiological factors (such as gene polymorphisms, bacterial colonisation in the airways and $T_{\text {reg }}$ cells at preschool age) are studied in relation to the early development of asthma.

Although it is commonly accepted that interaction between genetic predisposition and environmental exposures are important for the development of childhood asthma, exact mechanisms are mainly unclear. To gain more insight into this complex process, the role of CD14 and Toll-like receptors (TLRs) in the development of asthma in Caucasian children is systematically reviewed in chapter 3. In conclusion, no clear role for CD14 and TLRs on childhood asthma could be determined. However, this does not necessary imply that CD14 and TLRs do not play a role. Unknown underlying 
confounding or mediating environmental factors can cloud existing associations as has been demonstrated in some studies. Furthermore, the dissimilarity between the used study methods might be an obstacle to rightfully interpret the data. This might be resolved by a guideline for reporting genetic association studies that is increasingly used. Finally, the contribution based on individual genetic variants is small and, therefore, difficult to observe. Haplotype spanning has an increased power to detect associations compared to analysis of individual genetic variants. Consequently, the application of haplotype spanning can enable us to reveal possible associations of genes in relationship to childhood asthma.

In chapter 4 we studied the influence of genetic variants in CD14 and TLRS (TLR2, TLR4, TLR5, and TLR9) in combination with bacterial colonisation and $\mathrm{T}_{\text {reg }}$ cells in relation to the development of childhood asthma. We were unable to demonstrate a direct association between genetic variants in CD14 and TLRs and the development of childhood asthma. Neither was such an association observed for several typical (Haemophilus (para)influenzae, Streptococcus pneumoniae, and Staphylococcus aureus) and atypical (Mycoplasma pneumoniae and Chlamydia pneumoniae) bacteria or for the percentage of $\mathrm{T}_{\text {reg }}$ cells at preschool age. However, we did observe a significant interaction between genetic variants in CD14 and TLRs and bacterial colonisation at preschool age on early asthma development. This interaction indicated an increased risk of asthma development in the presence of certain genotypes in combination with bacterial colonisation. Furthermore significant interactions were also observed between certain genotypes in TLRs and proportion of $T_{\text {reg }}$ cells at preschool age. The interactions pointed to an association of a higher proportion of $\mathrm{T}_{\text {reg }}$ cells at preschool age with an increased asthma risk at six years of age in the presence of certain genotypes. In conclusion, we suggest that the combination of genetic predisposition and bacterial exposure at preschool age leads to an altered immune response, as demonstrated by $T_{\text {reg }}$ response, which in turn increases the risk of asthma development at six years of age.

To further study the role of airway inflammation in relationship to the development of asthma, several inflammation markers (interleukin (IL)4, IL8, IL10, IL13, Tumor Necrosis Factor alpha (TNF $\alpha$ ) and Intercellular Adhesion Molecule 1 (ICAM1)) were studied in an integrative genomic analysis in chapter $\mathbf{5}$. In this analysis genetic variants, gene expression in white blood cells and protein levels in exhaled breath condensate (EBC) were considered. We demonstrated an association of the ICAM1 rs5498 A-allele with asthma development. The A-allele was also associated with an increased expression of ICAM1 mRNA, and in turn increased levels of soluble (s)ICAM1 in EBC. Furthermore, increased SICAM1 levels and increased levels of IL4, IL8, IL10 and IL13 in EBC were associated with the development of asthma. The mechanism by which the rs5498 polymorphism in ICAM1 is involved in the development of asthma 
and airway inflammation is expected to depend on an increased binding capacity of leucocytes in presence of the A-allele. Consequently an increased number of local leukocytes is present leading to an increased total production of inflammation markers. In conclusion, our study points to the significance of ICAM1 as a marker of and might indicate involvement of ICAM1 in asthma development.

It has been demonstrated that transient wheeze and asthma are associated with different genes. Therefore, in chapter 6 we studied several genetic variants in genes associated with childhood asthma in children with transient wheeze and asthma at the age of six. We attempted to replicate our findings in an independent birth cohort named the Kind, Ouders en gezondheid: Aandacht voor Leefstijl en Aanleg (KOALA) study. We were able to demonstrate that genetic variants in ADAM33 (rs511898 and rs528557), IL4 (rs2070874 and rs2244350) and ORMDL3 (rs7216389) were associated with asthma development in the ADEM study. The found negative association of the CG/GG-genotype of ADAM33 in relationship to childhood asthma was replicated in the KOALA birth cohort. Thus, our study confirms the relationship of ADAM33 with childhood asthma in children with recurrent wheeze

As it is known that inhaled corticosteroids (ICS) are effective in asthmatic children and less effective in children with transient symptoms, the response to ICS treatment at preschool age might be used as a diagnostic instrument for asthma. In chapter 7 we have examined this response in inflammation markers in EBC, Fractional exhaled Nitric Oxide (FeNO), airway resistance, and symptoms. None of these predictors demonstrated differences in response to ICS at preschool age between asthmatics and transient wheezers. Nevertheless, symptoms were significantly higher at baseline in asthmatic children compared to transient wheezers classified at age six.

Volatile Organic Compounds (VOCs) are increasingly studied to diagnose respiratory and non-respiratoty diseases. In chapter $\mathbf{8}$ we examined whether differences in VOCs were present at preschool age between healthy children, transient wheezers and asthmatics at age six. Moreover, we studied whether distinction between transient wheezers and asthma at preschool age was possible. Differences between the three groups were present based on a limited number of compounds. Furthermore, 17 VOCs measured at preschool age were able to differentiate between children with transient wheeze and asthma with an overall correct classification rate of $80 \%$. The discriminating components included mostly hydrocarbons and long-chain alkanes. Thus, the origin of discriminating VOCs is related to oxidative stress and consequently lipid peroxidation. Our study indicates that VOCs in exhaled breath may have a potential use as early predictive signatures of asthma in children. 
Information on familial asthma may help to predict asthma as it has consistently been identified as a risk factor for childhood asthma. Expression of inflammation genes is expected to improve an early asthma diagnosis. In chapter 9 we evaluate the additional value of gene expression to a family history at preschool age in the prediction of asthma at six years of age. In our cohort we demonstrated that gene expression of TLR4, catalase (CAT) and TNF $\alpha$ in addition to a family history of asthma improved preschool differentiation between children with transient wheeze and asthma. If confirmed in a replication study, adding information on expression of inflammation genes may improve risk assessment in preschool wheezing children, and therefore may be beneficial for quality of care and cost-effective treatment of preschool children with wheezing symptoms.

Several clinical prediction models based on easily obtainable clinical variables exist to aid in an early asthma diagnosis such as the Asthma Prediction Index (API). As the prediction is modest, improvement is warranted which might be achieved by adding information on biomarkers. In chapter $\mathbf{1 0}$ we assessed the incremental performance to the API (eczema, allergic rhinitis, wheezing apart from colds, atopy and parental asthma) of markers in EBC, VOCs, expression of inflammation genes, and early lung function in the asthma prediction at the age of six in preschool wheezing children. We illustrated that a selection of nine of the identified VOCs from chapter 8 were associated with a better discrimination between children with transient wheeze and asthma in addition to the API, which was confirmed in external validation. Furthermore, information on gene expression of TLR4, CAT and TNF $\alpha$ at preschool age was associated with a more accurate asthma prediction in addition to the API. However, this result could not be confirmed by external validation. Information on markers in EBC and airway resistance was not able to improve differentiation in addition to clinical parameters. Our findings imply that information on VOCs and possibly expression of inflammation genes are of value alongside clinical characteristics in diagnosing asthma at preschool age. Therefore, our study is the first important step for the introduction of breath analysis and gene expression in the clinical practice of preschool children with childhood asthma.

Chapter 11 encompassed the general discussion of this dissertation. In this chapter we discussed what genetic variants of inflammation genes, bacterial colonisation and $\mathrm{T}_{\text {reg }}$ cells can add to our pathophysiolocial knowledge of asthma. Furthermore, we discussed the value of response to ICS, inflammation markers in EBC, VOCs, expression of inflammation markers and early lung function in asthma prediction at preschool age. When considering our findings and those of others, we can draw the conclusion that it is important to study both genetic and environmental influences to gain insight into the pathophysiology of asthma. Furthermore, information on VOCs and expression of inflammation genes can aid us in a reliable asthma diagnosis at 
preschool age in addition to clinical characteristics. Before implementation into clinical practice is possible however, additional studies need to be completed to confirm our findings and indicate clinically relevant thresholds on sensitivity and specificity. Moreover, future studies can benefit by using multiple asthma endotypes and by the application of system biology. 


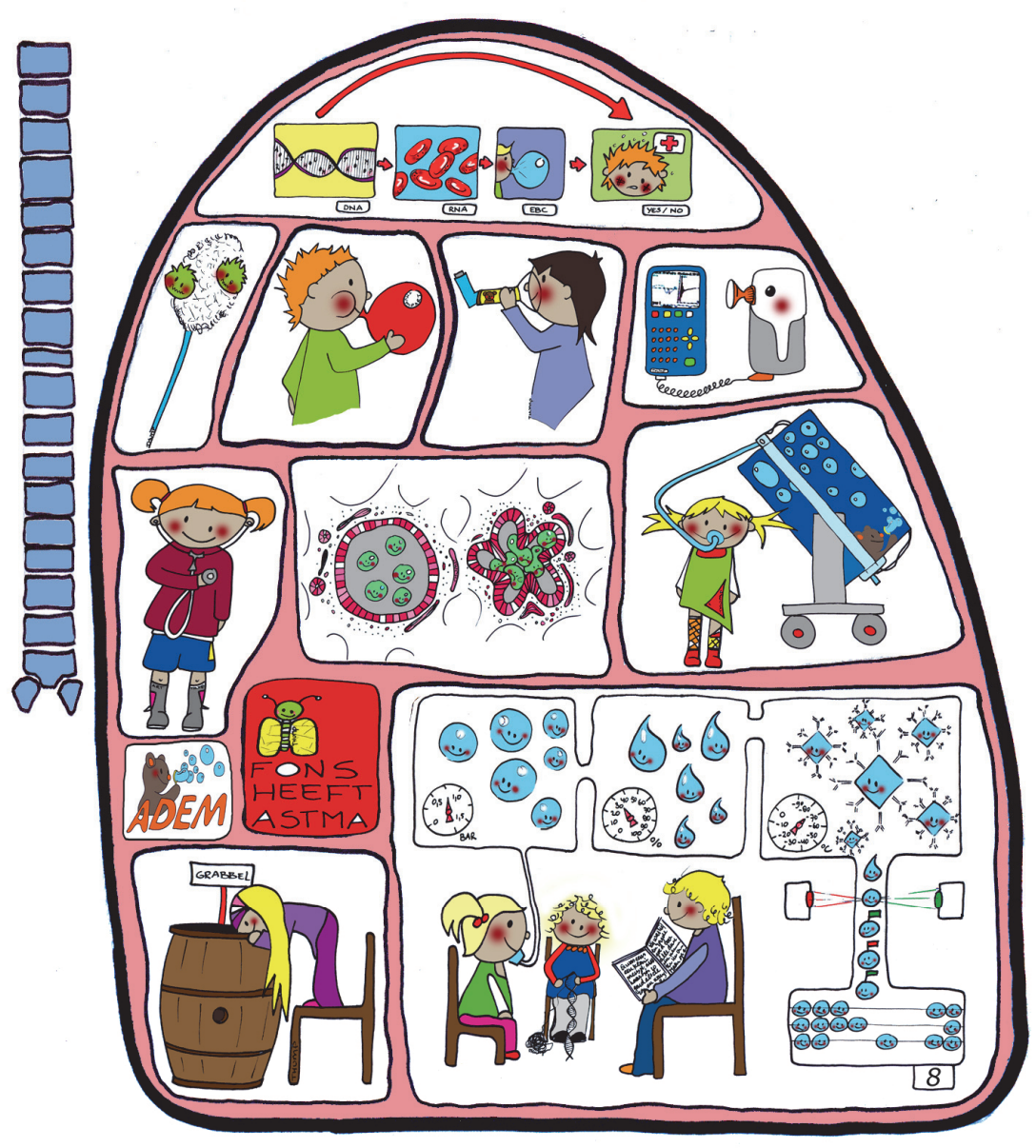


Samenvatting 


\section{Samenvatting}

In dit proefschrift wordt de genetische achtergrond, invloed van bacteriële kolonisatie en regulatoire $T$-cellen ( $T_{\text {reg }}$ cellen) in de etiologie van astma bij kinderen op peuterleeftijd geëvalueerd. Daarnaast wordt de waarde van uitgeademde ontstekingsmarkers, expressie van ontstekingsgenen, vroege longfunctiemetingen en reactie op behandeling voor het vaststellen van astma op de peuterleeftijd onderzocht. Dit proefschrift beschrijft de resultaten van de ADEM studie (in het Engels: Asthma DEtection and Monitoring study).

In hoofdstuk 1 worden de klinische uitdagingen van astma bij kinderen geïntroduceerd. Ondanks het feit, dat astma de meest voorkomende chronische ziekte op kinderleeftijd is, blijft het vaststellen van een astmadiagnose op peuterleeftijd moeilijk. Daardoor hebben artsen een dagelijks dilemma hoe om te gaan met kinderen met luchtwegklachten. Een betrouwbaar diagnostisch instrument dat op peuterleeftijd kan differentiëren tussen kinderen die astma zullen ontwikkelen en kinderen met voorbijgaande klachten, is dus noodzakelijk. Mogelijke niet-invasieve diagnostische middelen zijn de beoordeling van (uitgeademde) ontstekingsmarkers en vroege longfunctiemetingen. Naast het diagnostisch probleem is het onderliggende mechanisme van astma bij kinderen nog steeds grotendeels onbekend. Inzicht in dit mechanisme zou kunnen leiden tot identificatie van kinderen met een verhoogd risico. Het onderliggende mechanisme van astma bij kinderen kan worden bestudeerd door genetische aanleg en invloed van omgevingsfactoren te bestuderen. Als kinderen met een verhoogd risico kunnen worden geïdentificeerd, zouden eventueel preventieve maatregelen kunnen worden toegepast, die mogelijk de ontwikkeling van astma voorkomen.

In hoofdstuk 2 wordt het protocol van de ADEM studie beschreven. De ADEM studie is een prospectieve studie, die in 2006 op de afdeling kinderlongziekten van het Maastricht Universitair Medisch Centrum (MUMC+) is gestart. In totaal zijn er 202 kinderen op twee tot vierjarige leeftijd met recidiverende episodes van piepen/zagen op de borst en 50 kinderen zonder piepen/zagen op de borst geïncludeerd. Vervolgens zijn deze kinderen tot zesjarige leeftijd gevolgd. Het primaire doel van de ADEM studie is om een vroege astmadiagnose te stellen door gebruik te maken van ontstekingsstoffen en vroege longfunctiemetingen. Daarnaast zijn mogelijke etiologische factoren onderzocht in relatie tot de vroege ontwikkeling van astma zoals genetische polymorfismen, bacteriële kolonisatie in de luchtwegen en $T_{\text {reg }}$ cellen op peuterleeftijd.

Ondanks het feit dat het algemeen geaccepteerd is, dat interactie tussen genetische aanleg en omgevingsinvloeden belangrijk is voor de ontwikkeling van astma bij 
kinderen, zijn de exacte mechanismen nog grotendeels onbekend. Om meer inzicht in dit complexe proces te verkrijgen, wordt in hoofdstuk 3 de rol van CD14 en toll-like receptoren (TLRs) in relatie tot de ontwikkeling van astma bij blanke kinderen systematisch onderzocht. Er wordt geen duidelijk rol voor CD14 en TLRs in relatie tot astma bij kinderen vastgesteld. Echter dit betekent niet per se dat er geen rol is. Onbekende onderliggende omgevingsfactoren, die de relatie tussen CD14 en/of TLRs en bij kinderen met astma beïnvloeden, kunnen bestaande associaties vertroebelen. Dit effect is in een aantal studies aangetoond. Daarnaast beperken de verschillen in studieopzet een juiste interpretatie van de data. Dit probleem kan mogelijk worden opgelost door gebruik te maken van een richtlijn voor het rapporteren van genetische associatiestudies, die momenteel steeds vaker wordt gebruikt. Tenslotte is de bijdrage gebaseerd op individuele genetische varianten klein en daardoor moeilijk vast te stellen. Het gebruik van haplotypering (het effect van meerdere genetische varianten in combinatie bestuderen) geeft ons meer mogelijkheden om relaties met astma bij kinderen vast te stellen.

In hoofdstuk 4 bestuderen we de invloed van genetische varianten in CD14 en TLRs (TLR2, TLR4, TLR5 en TLR9) in combinatie met bacteriële kolonisatie en $\mathrm{T}_{\text {reg }}$ cellen in relatie tot de ontwikkeling van astma bij kinderen. We kunnen geen directe associatie vaststellen tussen genetische varianten in CD14 en TLRs en de ontwikkeling van astma bij kinderen. Ook wordt geen relatie gevonden tussen positieve kweken voor verschillende typische (Haemophilus (para)influenzae, Streptococcus pneumoniae en Staphylococcus aureus) en atypische (Mycoplasma pneumoniae and Chlamydia pneumoniae) bacteriën of voor het percentage $T_{\text {reg }}$ cellen op peuterleeftijd en de ontwikkeling van astma. We tonen wel een significante interactie aan tussen genetische varianten in CD14 en TLRs en bacteriële kolonisatie op peuterleeftijd in relatie tot de vroege ontwikkeling van astma bij kinderen. Deze interactie wijst op een verhoogd risico op de ontwikkeling van astma in aanwezigheid van bepaalde genotypes in combinatie met bacteriële kolonisatie. Daarnaast worden significante interacties gevonden tussen bepaalde genotypes in TLRs en het percentage van $T_{\text {reg }}$ cellen op peuterleeftijd. De interacties wijzen in de richting van een associatie tussen een hoger percentage van $T_{\text {reg }}$ cellen op peuterleeftijd, gepaard gaande met een verhoogd risico op astma in aanwezigheid van bepaalde genotypen. Op basis van deze gegevens denken wij dat de combinatie tussen genetische aanleg en bacteriële blootstelling op peuterleeftijd leidt tot een veranderde immuunreactie, hetgeen gedemonstreerd wordt door de reactie van $\mathrm{T}_{\text {reg }}$ cellen, wat vervolgens het risico op astma op zesjarige leeftijd verhoogt.

Om de rol van luchtwegontsteking in relatie tot de ontwikkeling van astma verder te bestuderen, werden verschillende ontstekingsmarkers (interleukine (IL)4, IL8, IL10, IL13, Tumour-Necrosis-Factor alfa (TNF $\alpha$ ) en Intercellulair Adhesie Molecuul 1 
(ICAM1)) onderzocht in een integrale genetische analyse in hoofdstuk 5. In deze analyse werden genetische varianten, genexpressie in witte bloedcellen en eiwitniveau in uitademingslucht bekeken. Een associatie van ICAM1 rs5498 A-allel met de ontwikkeling van astma werd vastgesteld. Het A-allel is ook geassocieerd met een verhoogde expressie van ICAM1 mRNA hetgeen vervolgens geassocieerd is met een verhoogde niveau van oplosbaar (s)ICAM1 in uitademingsluchtcondensaat. Daarnaast worden verhoogde sICAM1 en IL4, IL8, IL10 and IL13 niveaus in condensaat geassocieerd met de ontwikkeling van astma. Het onderliggende mechanisme tussen de associatie van het rs5498 polymorfisme in ICAM1 met de ontwikkeling van astma bij kinderen, is waarschijnlijk gebaseerd op een verhoogde bindingscapaciteit van witte bloedcellen in aanwezigheid van het A-allel. Dit leidt tot een verhoogde hoeveelheid lokale witte bloedcellen, die een verhoogde totale productie van ontstekingsmarkers tot gevolg heeft. Concluderend wijst onze studie naar het belang van ICAM1 als een marker van en mogelijk de betrokkenheid van ICAM1 in de ontwikkeling van astma.

Vastgesteld is, dat voorbijgaande luchtwegklachten en astma geassocieerd zijn met verschillende genen. In hoofdstuk 6 bestuderen we daarom meerdere genetische varianten in astmagenen bij kinderen met voorbijgaande klachten en kinderen met astma op zesjarige leeftijd. De gevonden associaties in de ADEM studie hebben we geprobeerd te herhalen in een onafhankelijk geboortecohort, genaamd de KOALA studie (Kind, Ouders en gezondheid: Aandacht voor Leefstijl en Aanleg). We hebben kunnen vaststellen in de ADEM studie dat genetische varianten in ADAM33 (rs511898 en rs528557), IL4 (rs2070874 en rs2244350) en ORMDL3 (rs7216389) geassocieerd zijn met de ontwikkeling van astma. De gevonden negatieve associatie voor het CG/GG-genotype van ADAM33 in relatie tot astma bij kinderen werd door ons ook aangetoond in het KOALA geboortecohort. Concluderend bevestigt onze studie de relatie van $A D A M 33$ met astma bij kinderen bij kinderen met recidiverend piepen/zagen op de borst.

Het is bekend dat inhalatiecorticosteroïden (ICS) effectief zijn bij kinderen met astma en minder effectief bij kinderen met voorbijgaande luchtwegklachten. De reactie op de behandeling met ICS op peuterleeftijd kan daarom mogelijk worden gebruikt als middel om astma vast te stellen. In hoofdstuk $\mathbf{7}$ hebben we deze reactie op ontstekingsmarkers in condensaat, stikstofmonoxide, luchtwegweerstand en symptomen bekeken. Geen van deze parameters demonstreert verschillen in reactie op ICS op peuterleeftijd tussen kinderen met astma en kinderen met voorbijgaande klachten vastgesteld op zesjarige leeftijd. Echter kinderen met astma hebben wel significant meer klachten op peuterleeftijd vergeleken met kinderen met voorbijgaande klachten. 
Vluchtige Organische Componenten (VOCs) worden toenemend bestudeerd om ziekten van de luchtwegen en andere ziekten te diagnosticeren. In hoofdstuk 8 hebben we bekeken of er verschillen zijn tussen VOCs in uitademingslucht op peuterleeftijd bij gezonde kinderen, kinderen met voorbijgaande klachten en kinderen met astma vastgesteld op zesjarige leeftijd. Daarnaast hebben we bekeken of onderscheid mogelijk te vinden is tussen kinderen met voorbijgaande klachten en kinderen met astma op de peuterleeftijd. Verschillen tussen deze twee groepen en gezonde kinderen zijn aanwezig en gebaseerd op een beperkt aantal componenten. Daarnaast waren 17 VOCs op peuterleeftijd onderscheidend tussen kinderen met voorbijgaande klachten en kinderen met astma waarbij er een algehele correcte classificatie was van $80 \%$. De onderscheidende componenten waren over het algemeen hydrocarbonen en lange keten alkanen. De onderscheidende VOCs zijn dus gerelateerd aan oxidatieve stress en de daaropvolgend vetperoxidatie. De ADEM studie duidt erop dat VOCs in uitademinglucht mogelijk kunnen worden gebruikt om astma op vroege leeftijd te voorspellen.

Informatie over astma in de familie zou helpen bij de voorspelling voor de ontwikkeling van astma, aangezien astma in de familie consequent als risicofactor voor astma bij kinderen wordt aangewezen. Daarnaast verbetert -naar verwachtingexpressie van ontstekingsgenen de voorspelling van een vroege astma diagnose. In hoofdstuk 9 evalueren we op peuterleeftijd de toegevoegde waarde van genexpressie naast het familiair voorkomen van astma in de voorspelling van astma op zesjarige leeftijd. In deze studie laten we zien dat genexpressie van TLR4, catalase (CAT) en TNF $\alpha$, naast gegevens van het familiair voorkomen van astma, differentiatie op peuterleeftijd tussen kinderen met voorbijgaande klachten en kinderen met astma verbeteren. Als deze bevinding wordt bevestigd in een nieuwe studie, kunnen we concluderen dat informatie over expressie van ontstekingsgenen de risicoinschatting van kinderen met piepen/zagen op de borst op peuterleeftijd kan verbeteren. Dit zal resulteren in een betere kwaliteit van zorg en meer kosteneffectieve behandeling van deze kinderen.

Er zijn verschillende klinische voorspellingsmodellen gebaseerd op gemakkelijk verkrijgbare klinische variabelen, om te helpen bij het vroeg vaststellen van astma zoals de Astma Predictie Index (API). De voorspellende kracht van deze klinische modellen is echter beperkt. Verbetering is daarom noodzakelijk en dit kan mogelijk worden bereikt door het toevoegen van informatie over biomarkers. In hoofdstuk $\mathbf{1 0}$ bekijken we de waarde van markers in condensaat, VOCs, expressie van ontstekingsgenen en vroege longfunctiemetingen, toegevoegd op de API (gebaseerd op eczeem, hooikoorts, piepen/zagen op de borst zonder verkoudheid, atopie en astma bij ouders) op peuterleeftijd wat betreft de voorspelling van astma op zesjarige leeftijd bij kinderen met piepen/zagen op de borst. Een selectie van negen VOCs uit hoofdstuk 
8 toegevoegd aan de API is geassocieerd met een betere discriminatie tussen kinderen met voorbijgaande klachten en kinderen met astma op zesjarige leeftijd. Dit resultaat werd bevestigd door middel van externe validatie. Daarnaast is informatie over genexpressie van TLR4, CAT en TNF $\alpha$ op peuterleeftijd toegevoegd aan de API geassocieerd met een betere voorspelling voor de ontwikkeling van astma. Dit resultaat kon niet worden bevestigd door middel van externe validatie. Informatie over ontstekingsmarkers in condensaat en luchtwegweerstand op peuterleeftijd konden het onderscheid toegevoegd aan de API niet verbeteren. Onze bevindingen impliceren dat informatie over VOCs en mogelijk expressie van ontstekingsgenen naast klinische variabelen een toegevoegde waarde hebben in het diagnosticeren van astma op peuterleeftijd. Onze studie is de eerste belangrijke stap voor de introductie van ademanalyse en genexpressie in de kliniek van kinderen met astma op peuterleeftijd.

Hoofdstuk 11 omvat de algemene discussie van het proefschrift. In dit hoofdstuk bespreken we wat een aantal genetische varianten in ontstekingsgenen, bacteriële kolonisatie en $\mathrm{T}_{\text {reg }}$ cellen toevoegen aan onze onderliggende kennis over het ontstaan van astma. Daarnaast bespreken we de waarde van de reactie op ICS, ontstekingsmarkers in condensaat, VOCs, expressie van ontstekingsgenen en vroege longfunctiemetingen bij de voorspelling van de ontwikkeling van astma op peuter-leeftijd. Als we onze bevindingen en die van anderen vergelijken, kunnen we de conclusie trekken dat het, om inzicht te krijgen in de onderliggende mechanismen van astma, belangrijk is zowel genetische als omgevingsinvloeden te bestuderen. Daarnaast kan, naast klinische variabelen, informatie over VOCs en expressie van ontstekingsgenen ons helpen bij een betrouwbare astmadiagnose op de peuterleeftijd. Alvorens implementatie in de kliniek mogelijk is, zijn aanvullende studies nodig om onze bevindingen te bevestigen en richting te geven aan klinische relevante drempels omtrent sensitiviteit en specificiteit. Daarnaast kunnen toekomstige studies profiteren van het indelen van astma in verschillende endotypen en het toepassen van systeembiologie. 
Samenvatting 


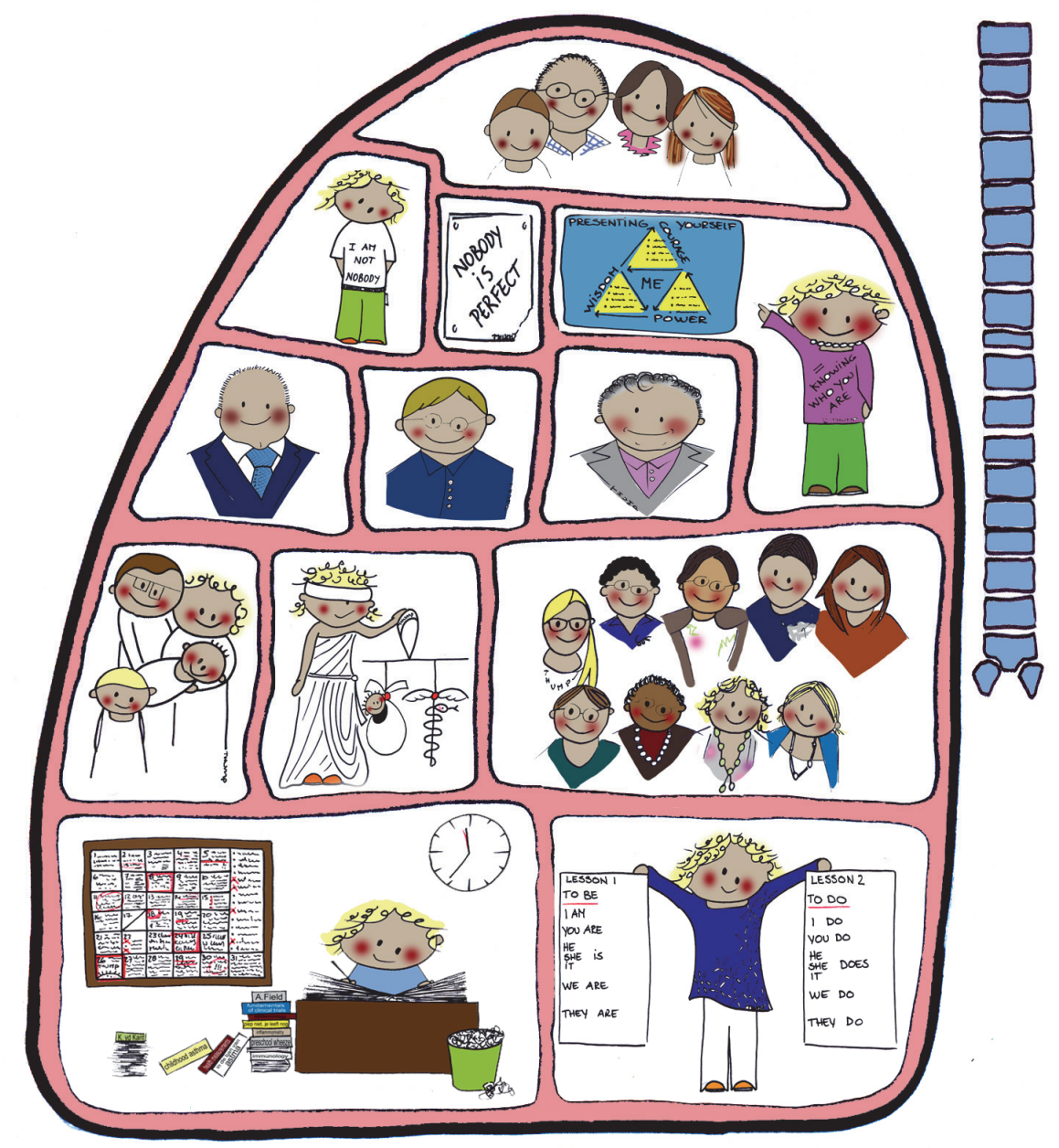


Dankwoord 


\section{Dankwoord}

De essentie van kennis is, als je haar hebt, ze ook te gebruiken. Zonder hulp van velen, had ik de kennis die ik nu heb niet kunnen opdoen. "Bedankt" zeggen is een beetje afscheid nemen. Afscheid nemen van een turbulente tijd in mijn leven waar ik gelukkig veel steun heb gehad van de mensen om mij heen.

Zonder deelnemers, geen studie. Allereerst wil ik dan ook alle kinderen en hun ouders, die aan de ADEM studie hebben deelgenomen hartelijk bedanken. Met veel plezier heb ik jullie jaarlijks terug gezien en met spijt heb ik afscheid van jullie genomen bij de afsluiting van de studie. Hartelijk dank jullie voor jullie medewerking, enthousiasme, interesse en inspanning.

Grote dank gaat uit naar mijn promotieteam: Prof. dr. Edward Dompeling, prof. dr. Onno van Schayck en dr. Quirijn Jöbsis. Edward, je bent optimistisch en opportunistisch ingesteld. Af en toe was het voor mij moeilijk om hierin met je mee te gaan. Echter, deze manier van aanpak heeft ervoor gezorgd dat alle mogelijkheden optimaal werden benut. Onno, je helikoptervisie en de daarbij behorende sturing van het traject heb ik als prettig ervaren. Rijn, voor mij ben jij een echte mensenmanager. Je had altijd oog voor de planning en voor mij als persoon. Jullie gezamenlijke inzet in mijn begeleiding heeft geresulteerd in een mooi resultaat.

Graag wil ik alle leden van de beoordelingscommissie bedanken voor hun vakkundige beoordeling van dit proefschrift: Prof. dr. Geertjan Wesseling, prof. dr. Cathrien Bruggeman, prof. dr. Connie Stumpel, prof. dr. Dirkje Postma en prof. dr. Luc Zimmermann

Mijn directe collega's: Kim, Sasha, Bob, Cynthia, Maartje, Inge, Marlou, Dillys en Marieke. Ik dank jullie voor alle interesse en gezelligheid, maar vooral ook voor alle steun. Kim, als mede onderzoeker op de ADEM studie, hebben wij vanaf het begin tot het eind van mijn promotietraject intensief met elkaar samengewerkt. We zijn een goed team en ik ben je dankbaar voor alle hulp en inzet. Het is erg bijzonder dat we deze periode nu samen kunnen afsluiten met jou als mijn paranimf. Sasha, met jou kan ik alles delen. Ik ben blij met jou als vriendin en zal onze koffiepauzes missen. Bob, je opgewektheid en je humor hebben veel verlichting geboden.

Vele studenten hebben een positieve bijdrage geleverd aan de studie: Esther, Brenda, Emily, Kiki, Imke en Nedim, jullie hulp bij de metingen en administratieve werkzaamheden was meer dan welkom. Linda en Maran, samen met Kim heb ik jullie met veel plezier begeleid tijdens jullie vrijwillige stage bij ons hetgeen heeft 
geresulteerd in mooie publicaties. Marijn, je wetenschapsstage was een groot succes door je grondige aanpak en je kritische houding.

Een studie als de ADEM studie kan nooit groot worden zonder degelijke ondersteuning. Peggy en Tamara, voor alle administratieve, contractuele en planningsvraagstukken kon ik bij jullie terecht; Jacqueline en Paula, onze 'poetsdames' die met ongelooflijk veel nauwkeurigheid onze data hebben gecontroleerd; Erie en Harrie, dank voor jullie vakkundige behering van het studiebudget; Frank en Yordi, bij elke materiaalcrisis boden jullie direct hulp (IDEE, MUMC+); Stephan, voor elk probleem had jij een oplossing (Instrumentele dienst, MUMC+); Marie-José, de planning was vaak lastig, maar je wist me altijd tegemoet te komen (longfunctie, MUMC+); Manon, Judith en Kirsten, jullie enthousiaste benadering van de deelnemende kinderen heeft de metingen tot een succes gemaakt; en verder dank ik Jos Boesten en alle deelnemende huisartsen van het RNH netwerk.

Ook ben ik dankbaar voor de fijne samenwerking met alle medewerkers van de laboratoria. Zonder jullie zou de ADEM studie niet zijn geslaagd: dr. Ger Rijkers (Medische microbiologie, Nieuwegein); dr. Jan Damoiseaux (Klinische immunologie, MUMC+); Loe Donselaar en prof. dr. Paul Menheere (Klinische chemie, MUMC+); prof. dr. Frederik-Jan van Schooten, dr. Jan Dallinga, Edwin Moonen, dr. Marieke Quaak en dr. Agnieszka Smolinska (Toxicologie, MUMC+); prof. dr. Ellen Stobberingh, dr. Foekje Stelma en Christel Driessen (Medische Microbiologie, MUMC+); en dr. Gertjan den Hartog (Toxicologie, MUMC+);

Mijn mentoren, Connie en Guillaume, jullie hebben mij kostbare inzichten gegeven waar ik nog lang op kan bouwen. Connie, regelmatig mocht ik met je van gedachten wisselen over toekomstige stappen in mijn carrière. De gesprekken verliepen vaak anders dan ik gedacht had, maar juist dat gaf ze veel waarde. Guillaume, tijdens mijn promotie gaf jij mij moed en positieve energie en wist je zaken in perspectief te plaatsen met je nuchtere blik op de wereld. Ik voel me bevoorrecht met je te hebben mogen samenwerken.

Graag wil ik alle co-auteurs, die nog niet eerder genoemd zijn in dit dankwoord, bedanken: drs. Steven Hövig, dr. Johan de Jongste, prof. dr. Gerard Koppelman, dr. Monique Mommers, dr. Jean Muris, drs. Annedien Nijhuis, dr. John Penders en dr. Carel Thijs.

Speciale dank gaat uit naar Tatiana voor het ontwerpen van de omslag en de illustraties. Daarnaast mijn dank aan Tiny voor de mooie lay-out van dit proefschrift. Het resultaat is prachtig! 
Vrienden zijn de familie die je zelf uitkiest. Kris \& Arnold, bij jullie voel ik me thuis. Mirjam, heerlijk om met jou te discussiëren en de tijd te vergeten. Gaby \& Youri, altijd goed op de hoogte en oprecht geïnteresseerd. Victor, altijd beschikbaar voor praktische (Excel) problemen, maar ook voor dieper gaande discussies. Sherinda \& Michiel, bedankt voor al jullie steun en interesse. Alvin \& Marlies, Annelies \& Tim, Annemarie \& Ruben, Carla \& Arjen, Chantalle, Charlotte \& Erwin, Dominique \& Hugo, Esther \& Roderick, Eward \& Ela, Guido \& Fiona, Helen, Jennifer, Kirsten \& Leonard, Loes, Naima, Patricia \& Rob, Paul, Sylvia \& Marc, Tatiana en Tom; ik prijs me gelukkig met zo veel mooie mensen om mij heen.

Lieve Marij en Joop, bedankt voor jullie aanhoudende interesse in mijn promotietraject. Bij elke mijlpaal kreeg ik succeswensen vooraf en bij behaald succes een bloemetje met complimenten. Jullie hebben me een warm welkom gegeven vanaf het moment dat Chris me voor het eerst mee naar jullie heeft genomen samen met Roy \& Jill en Nicolle \& Robby.

Lieve Marlie en Frank, jullie betrokkenheid bij mij als peetouders zorgt ervoor dat jullie een speciale plaats in mijn hart hebben.

Lieve Monique en Tjeu, sinds mijn geboorte hebben jullie mij alle mogelijkheden gegeven om mezelf te ontwikkelen en mij met veel liefde en vertrouwen gesteund. Jullie aanhoudende enthousiasme, maar ook jullie kritische noten zijn goud waard. Het heeft mij gemaakt tot wie ik nu ben. Ik wens iedereen zulke betrokken ouders toe en hoop dat zelf ook te zijn voor mijn kinderen.

Lieve Myrte en Sanne, als zussen denken we soms niet minder op elkaar te kunnen lijken. Maar ondanks onze grote verschillen kan ik altijd bij jullie terecht. Lieve Myrte, vaak heb jij me de afgelopen jaren laten weten hoe trots je op me bent. Graag wil ik je nu laten weten hoe trots ik ben dat jij mijn zus bent. Lieve Sanne, onze gesprekken zijn voor mij erg waardevol en je staat altijd voor me klaar. Je bent een super zus. Ook wil ik Ad bedanken voor alle gezelligheid en interesse. En natuurlijk ben ik dankbaar voor mijn mooie nichtje Emma.

Lieve Chris, dank is moeilijk in woorden uit te drukken, maar ik zal toch een poging doen. Al jarenlang kan ik rekenen op je steun, je liefde en je vertrouwen. Tijdens mijn promotietraject heb je onvermoeid urenlang geluisterd naar alle ontwikkelingen, alle analyses, alle theorieën en alles wat verder bij het traject kwam kijken. Elke keer als ik een nieuw plan had, zoals bijvoorbeeld het volgen van een extra studie, heb jij me alle ruimte gegeven om dat uit te voeren. Menigmaal heb je zonder commentaar geaccepteerd, dat ik vermoeid of chagrijnig was. Bij jou ben ik thuis. 
Lieve Kian, jij hebt mij laten inzien wat daadwerkelijk belangrijk is in het leven. Door jou ervaar ik hoe mooi en eenvoudig het leven kan zijn en leer ik te genieten van simpele dingen. Lieve Remi, we kennen elkaar nog maar kort, maar ik hou nu al onvoorwaardelijk van je. Ik kijk ernaar uit om samen met jullie en Chris onze bijzondere reis te vervolgen. 


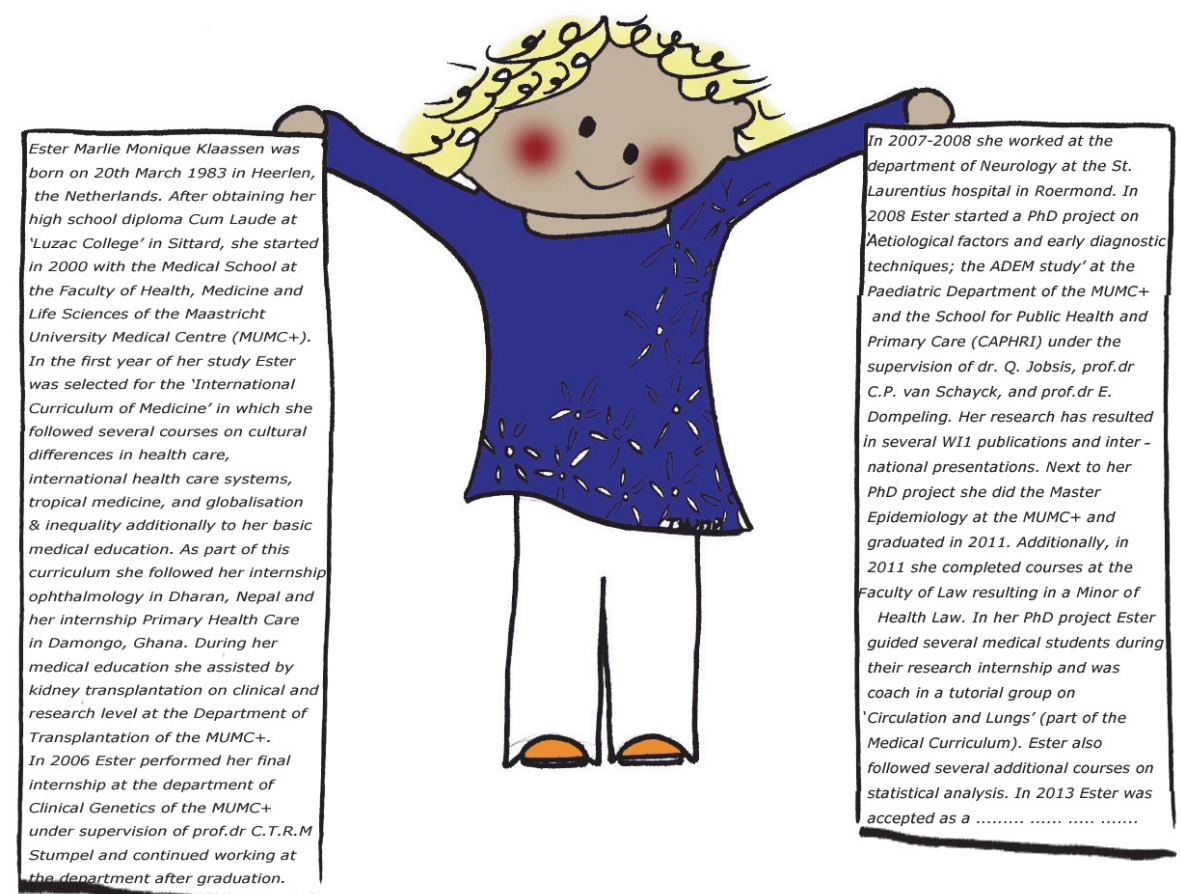


Curriculum Vitae 


\section{Curriculum Vitae}

Ester Marlie Monique Klaassen was born on $20^{\text {th }}$ March 1983 in Heerlen, the Netherlands. After obtaining her high school diploma Cum Laude at 'Luzac College' in Sittard, she started in 2010 with the Medical School at the Faculty of Health, Medicine and Life Sciences of the Maastricht University Medical Centre (MUMC+). In the first year of her study Ester was selected for the 'International Curriculum of Medicine' in which she followed several courses on cultural differences in health care, international health care systems, tropical medicine, and globalisation \& inequality additionally to her basic medical education. As part of this curriculum

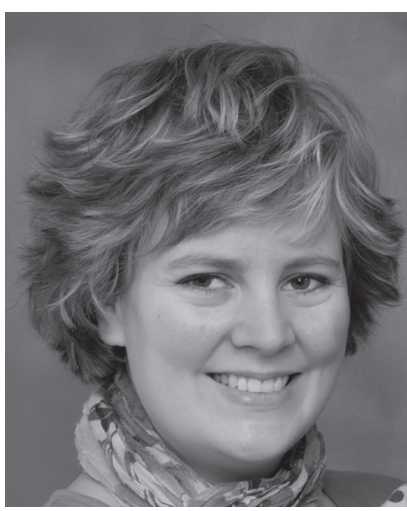
she followed her internship ophthalmology in Dharan, Nepal and her internship Primary Health Care in Damongo, Ghana. During her medical education she assisted by kidney transplantation on clinical and research level at the Department of Transplantation of the MUMC+. In 2006 Ester performed her final internship at the department of Clinical Genetics of the MUMC+ under supervision of prof. dr. C.T.R.M Stumpel and continued working at the department after graduation. In 2007-2008 she worked at the department of Neurology at the St. Laurentius hospital in Roermond. In 2008 Ester started a PhD project on 'Aetiological factors and early diagnostic techniques; the ADEM study' at the Paediatric Department of the MUMC+ and the School for Public Health and Primary Care (CAPHRI) under the supervision of prof. dr. E. Dompeling, prof. dr. C.P. van Schayck and dr. Q. Jobsis. Her research has resulted in several WI1 publications and international presentations. Next to her PhD project she did the Master Epidemiology at the MUMC+ and graduated in 2011. Additionally, in 2011 she completed courses at the Faculty of Law resulting in a Minor of Health Law. In her PhD project Ester guided several medical students during their research internship and was coach in a tutorial group on 'Circulation and Lungs' (part of the Medical Curriculum). Ester also followed several additional courses on statistical analysis. Ester plans to proceed her career in family medicine. 


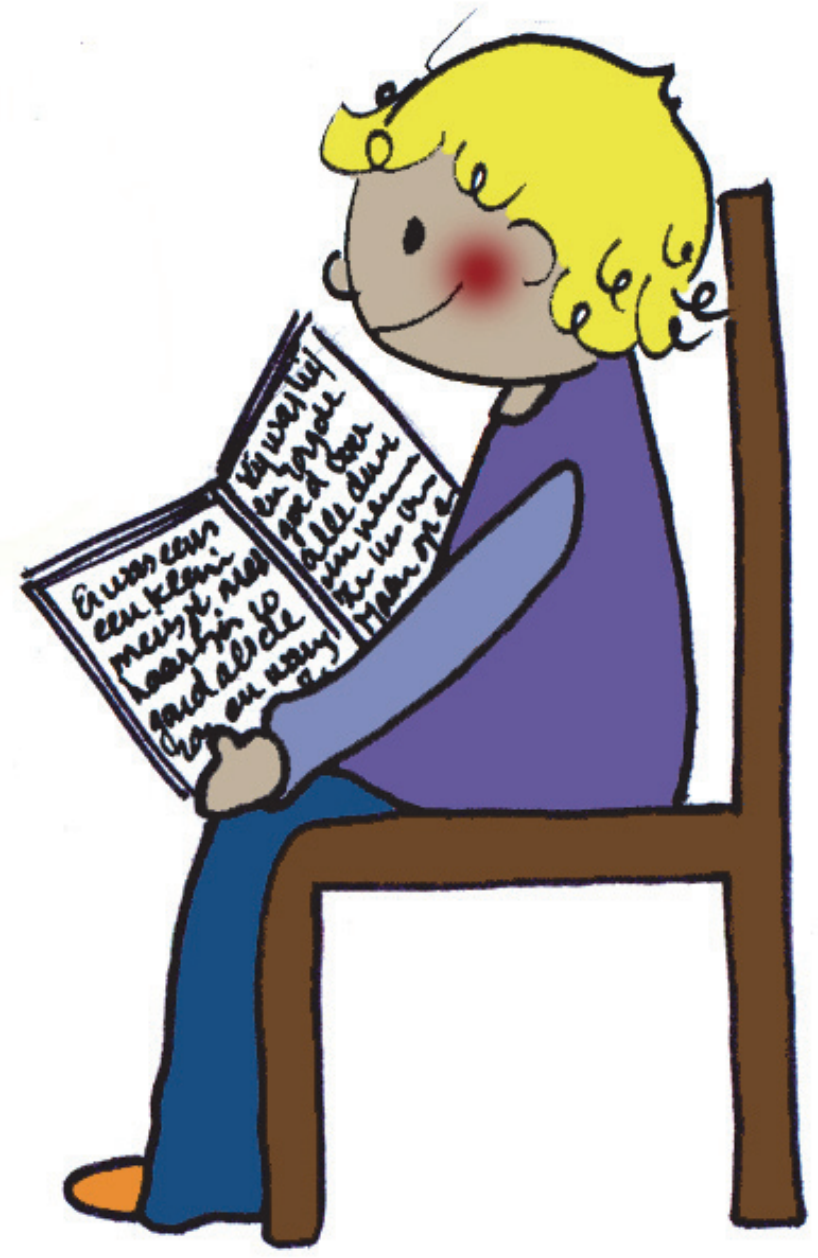


List of publications 


\section{List of publications}

\section{International peer-reviewed publications}

Klaassen EMM, Thönissen BEJT, van Eys G, Dompeling E, Jöbsis Q. A systematic review of CD14 and toll-like receptors in relation to asthma in Caucasian children. Allergy Asthma Clin Immunol. 2013;9:10.

Klaassen EMM, van de Kant KDG, Jöbsis Q, Høvig STP, van Schayck CP, Rijkers, GT, Dompeling E. Symptoms, but not a biomarker response to inhaled corticosteroids, predict asthma in preschool children with recurrent wheeze. Mediators Inflamm. 2012:162571.

van de Kant KDG, Klaassen EMM, van Aerde KJ, Damoiseaux J, Bruggeman CA, Stelma FF, Stobberingh EE, Muris JWM, Jöbsis Q, van Schayck CP, Dompeling E. Impact of bacterial colonisation on exhaled inflammatory markers in wheezing preschool children. J Breath Res. 2012;6:046001.

van de Kant KDG, van Berkel JBN, Jöbsis Q, Lima Passos V, Klaassen EMM, van der Sande L, van Schayck CP, de Jongste JC, van Schooten FJ, Derks E, Dompeling E, Dallinga JW. Exhaled breath profiling in the diagnosis of wheezy preschool children: a proof of principle study. Eur Resp J. 2012;41:183-8.

van de Kant KDG, Jansen M, Klaassen EMM, van der Grinten CP, Rijkers GT, Muris JWM, van Schayck CP, Jöbsis $Q$, Dompeling E. Elevated inflammatory markers at preschool age precede persistent wheezing at school age. Pediatr Allergy Immunol 2012:23:259-64.

van de Kant KDG, Koers K, Rijkers GT, Lima Passos V, Klaassen EMM, Mommers M, Dagnelie PC, van Schayck CP, Dompeling E, Jöbsis Q. Can exhaled inflammatory markers predict a steroid response in wheezing preschool children? Clin Exp Allergy. 2011;41:1076-83.

van de Kant KDG, Klaassen EMM, Jöbsis Q, Koers K, Rijkers GT, van der Grinten CP, van Schayck $C P$, Lima Passos $V$, Dompeling $E$. Wheezing in preschool children is associated with increased levels of cytokines / chemokines in exhaled breath condensate. J Allergy Clin Immunol. 2010;126:669-71. 
van de Kant KDG, Klaassen EMM, Jöbsis Q, Nijhuis AJ, van Schayck CP, Dompeling E. Early diagnosis of asthma in young children by using non-invasive biomarkers of airway inflammation and early lung function measurements: study protocol of a casecontrol study. BMC Public Health 2009;9:210.

\section{Submitted manuscripts}

Klaassen EMM, van de Kant KDG, Soeteman M, Damoiseaux J, van Eys G, Stobberingh $E E$, Stelma FF, Quaak M, van Schayck CP, Jöbsis Q, Dompeling E. CD14 and TLR polymorphisms interact with bacteria and regulatory T-cells in childhood asthma development.

Klaassen EMM, van de Kant KDG, Jöbsis Q, Penders J, van Schooten FJ, Quaak M, den Hartog GJ, Koppelman GH, van Schayck CP, van Eys G, Dompeling E. Integrative genomic analysis identifies a role for ICAM1 in childhood asthma.

Klaassen EMM, Penders J, Jöbsis Q, van de Kant KDG, Thijs C, Mommers M, van Schayck CP, van Eys G, Koppelman GH, Dompeling E. Genetic variants in ADAM33 are associated with asthma at six years of age.

Smolinska A, Klaassen EMM, Dallinga JW, van de Kant KDG, Jöbsis Q, Moonen EJC, van Schayck CP, Dompeling E, van Schooten FJ. Profiling of volatile organic compounds in exhaled breath as a strategy to find early predictive signatures of asthma in children.

Klaassen EMM, van Schayck CP, van de Kant KDG, Jöbsis Q, den Hartog GJ, van Eys G, Dompeling E. Predicting asthma at preschool age by family history and expression of inflammation genes.

Klaassen EMM/van de Kant KDG, Jöbsis Q, van Schayck CP, Smolinksa A van Schooten FJ, den Hartog GJM, de Jongste JC, Rijkers GT, Dompeling E. Exhaled biomarkers and expression of inflammation genes at preschool age improve prediction of asthma at age six. 
